\title{
THE AMPHIBIA OF THE \\ INDO-AUSTRALIAN ARCHIPELAGO
}

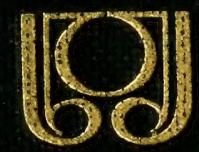


FOR THE PEOPLE FOR EDVCATION FOR SCIENCE

\section{LIBRARY}

OF

THE AMERICAN MUSEUM of

NATURAL HISTORY 


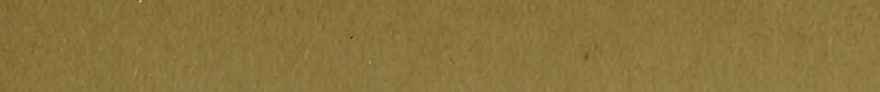

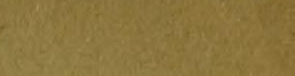

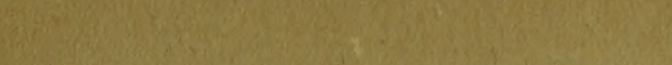

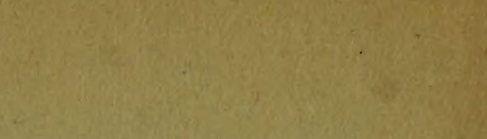

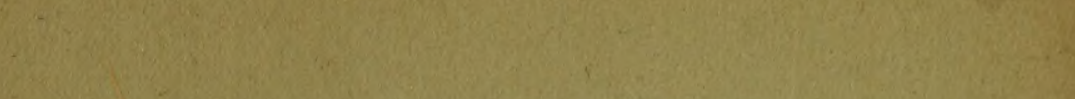

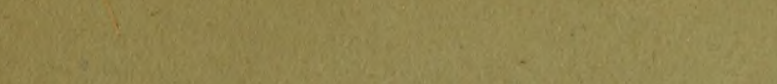

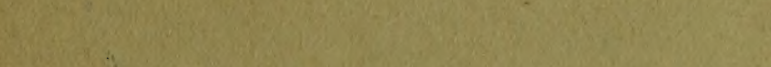

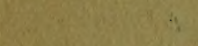

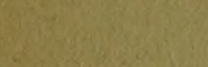

(2)

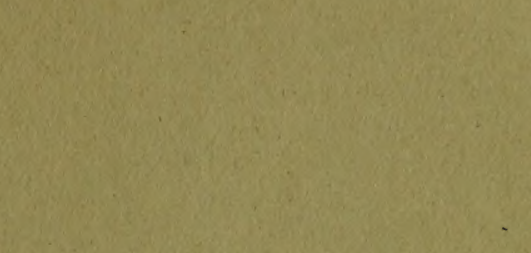

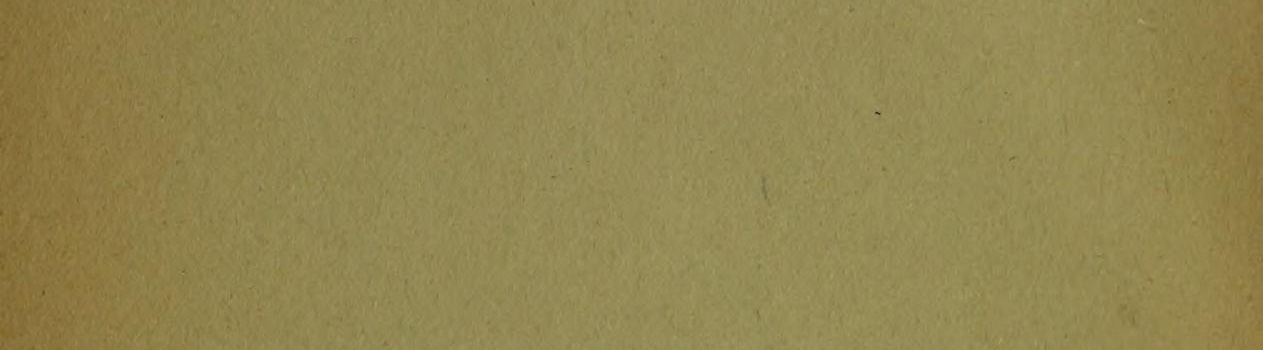

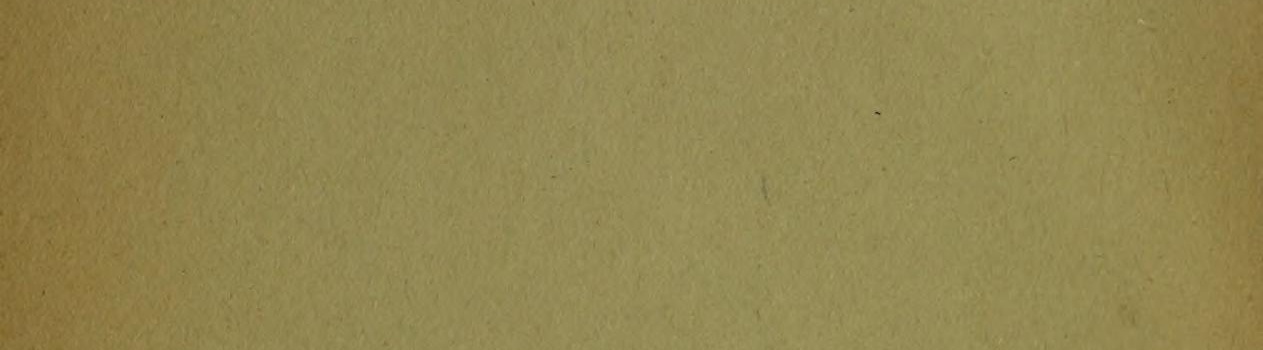
3.

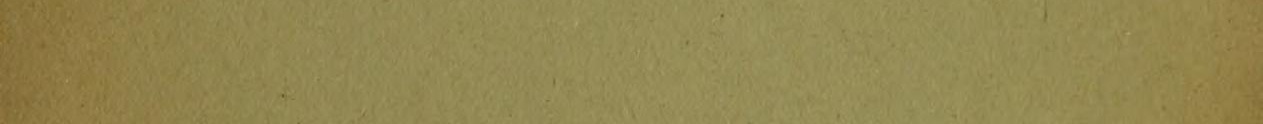
18: 
THE AMPHIBIA

OF THE

INDO-AUSTRALIAN ARCHIPELAGO. 



\title{
THE AMPHIBIA
}

\author{
OF THE
}

\section{INDO-AUSTRALIAN ARCHIPELAGO}

with 29 illustrations

BY

\section{Dr. P. N. VAN KAMPEN}

Professor at the University, Leiden.

LEIDEN - 1923.

E. J. B R I L L Ltd. 
PRINTED BY E. J. BRILL LTD., LEIDEN (HOLLAND).

$$
23-93201-\text { nov. } 1
$$




\section{PREFACE.}

In the preface to the two volumes of this series, describing the Reptiles of the indo-australian Archipelago, I have given a short history about the work on the Vertebrates of Dutch East-India.

It began with the publication of a work on the fishes of the Archipelago of which four volumes have already appeared.

With the valuable cooperation of Dr. J. C. KonINGSBERGER, while director of 's Lands Plantentuin at Buitenzorg, Java, and later on with that of his successor Dr. W. M. DOCTERS VAN LEEUWEN, the original plan got successively a wider scope and the preparation of a series of handbooks of the vertebrate fauna of the Archipelago was recommended.

In I9I 2 the aid of the government was gained for the publication of the two quoted volumes about the Reptiles, which were issued in I9I5 and I9I7.

It was then allowed to presume, that the governmental aid would also be bestowed upon a volume describing the indoaustralian Amphibia, which was under preparation by Prof. P. N. VAN KAMPEN. However, in I92 I, when the manuscript of his work was finished, the economical situation was so totally changed, that there was no chance to get the financial support from the government, necessary for issuing the volume.

This financial dilemna was solved by the "Zoologisch Insulindefonds", by the "Gresshoff-Rumphius-fonds" and by the "Leidsch Universiteitsfonds", who were ready to support the finances.

All those who are interested in the fauna of this region are therefore indebted to the councils of these institutions, and it is a pleasing duty of thanking them for their valuable help so cordially given.

The Amphibia of the indo-australian Archipelago described in the present volume enumerate 254 species.

In 1907 Prof. VAN KAMPEN published a list of the Amphibia of the same region which contained 194 species. The greatest 
advance, since the publication of that list, in our knowledge of indo-australian Amphibia, is due to the intensive scientific exploration of the western or dutch part of New Guinea by several dutch (between 1907 and 1921) and two british expeditions (I9IO, I9I2). The greatest part of the collected Amphibia were described by VAN KAMPEN in different papers.

In no less degree our knowledge about the distribution of Amphibia through the Archipelago was furthered since 1907 by scientific exploration of various islands by individual collectors and by scientific expeditions, dutch and otherwise.

Accordingly Prof. VAN KAMPEN had the advantage to profite of recently published results of other investigators and to dispose of extensive material collected in Sumatra by L. PH. DE Bussy, Edw. JaCobson and Jhr. F. C. van HEurn; on the island Simalur by EDW. JACOBSON; on the island Nias by J. P. KLeiweg DE ZwaAN; on Celebes by W. KaUdern; on Ceram by L. F. DE Beaufort and L. RutTen; on Buru by L. J. Toxopeus; on Waigeu by L. F. DE Beaufort. These collectors deserve our thanks for contributing materially to the study of indian Amphibia.

We are under particular obligations to Dr. K. W. Dammerman, Director of the Zoological Museum at Buitenzorg, for sending for study the Amphibia in the institution under his control; as also to Prof. E. D. VAN OORT, Director and of Dr. TH. W. VAN LIDTH DE JEUdE, Curator of the Museum at Leiden, for the facilities given for studying the Amphibia under their charge.

In bringing this volume before the public, those who are interested in the vertebrate fauna of the Dutch East Indies are to be congratulated, that Prof. VAN KAMPEN presented them with an able guide to the study of the Amphibia of the Archipelago. The discussion, at the end of the volume, of the distribution of the species on the various islands of the Archipelago and on the neighbouring continents of Asia and Australia, will be of much interest to students of zoogeography.

It is also a pleasure to acknowledge the interest of the publisher, the firma E. J. BRILL, Ltd. of Leiden, while this volume went through the press.

Prof. Max Weber,

Late Director of the Zoological Museum of the University of Amsterdam. 


\section{INTRODUCTION.}

The great increase of the number of species of Amphibians known from the Dutch East Indies, which has taken place especially since the beginning of this century, seems to make a critical compilation of the very dispersed literature on this subject not superfluous. In the present work $I$ have given descriptions with synoptic tables of all Amphibians and tadpoles known from that region.

In confining its boundaries I followed the authors of the works on Fishes and Reptiles of this same series in extending them a little beyond the Dutch Archipelago. So I included the whole of Borneo, Timor and New Guinea and also the island Pelawan, the fauna of which is closely related to that of Borneo, and the Bismarck archipelago, Solomon islands and a few other islands, which show the same affinity to New Guinea. A ! behind the name of a locality means that I have seen one or more specimens from that locality.

For each species I cited only the more important literature, f. i. those papers in which further ones are quoted and those which contain synonymes or figures. Papers issued before $\mathbf{I} 882$, the year of publication of the well-known Catalogue of Boulenger, as a rule are not mentioned, except those which contain original descriptions.

I must add here a short explication of the manner used by me in taking the measures. In the description of the adult animals with length I mean, if not otherwise stated, the distance from the tip of the snout to the posterior end of the body. The measures given are the largest ones which are known. In measuring the length of the head I take the distance from the tip of the snout to the posterior border of the skull in the median line; its width is measured at the point, where the head is broadest, i. e. usually at its posterior end. The length of the snout is taken from its tip to the anterior border 
of the upper cyelid, its depth is the vertical distance between canthus rostralis and mouth, measured at the anterior border of the upper eyelid. The width of the interorbital space is the smallest distance between the upper eyclids. The sise of the tympanum is measured along its greatest diameter.

In the tadpoles the vidth of the body is taken in its broadest part; with length of the body' is meant the distance from the tip of the snout to the point of origin of the hind limbs; the length of the tail is measured from this point to its tip, its depth is taken at its highest point, both crests included. The number of series of horny teeth is indicated by a formula, f. i. $3^{1} 3 / /^{1} 2^{1}$ signifies: four series in the upper, three in the lower lip, the three lower (inner) ones of upper lip and the upper (inner) one of lower lip each being divided into two portions by a median interruption.

I wish to direct the attention of collectors on the fact, that only very few tadpoles of Indo-Australian Anura are known at present. In collecting tadpoles, however, it is necessary (when it is impossible to rear them) to collect material of young and full-grown frogs at the same locality; otherwise the tadpoles usually cannot be determined. The best preservation fluid for tadpoles is formol.

I have to express my thanks to Prof. Max Weber for his valuable assistance in many points. I am much indebted also to : Mr. Th. Barbour, Dr. G. A. Boulenger, Prof. L. Dollo, Mr. C. Boden Kloss, Prof. L. Roule, Dr. J. Roux, Mr. Malc. Smith, Dr. Th. Vogt, Prof. F. Werner for useful informations and the sending of specimens for examination.

Leiden, July 1923.

P. N. VAN KAMPEN. 


\section{SYSTEMATIC INDEX.}

\section{AMPHIBIA.}

Page

Family Caecilinde ..... I

I. Ichthyophis Fitz..... 2

I. glutinosus (L.).... 2

2. monochrous (Blkr.) .. 3

II. Order Anura ..... 4

Arcifera ........ 5

I. Family Pelobatidae ... 5

I. Nesobia nom, nov. ... 6

I. natunae (Gthr.) . . . 6

2. Megalophrys Kuhl\&rv.Hass. 7

1. ligayae Taylor..... 8

2. montana Kuhl\&v.Hass. 8

3. nasuta (Schlg.) .... I0

4. hasselti (S. Müll.) . . I3

5. gracilis (Gthr.) ... I 5

6. baluensis (Blgr.) ... I 6

3. Batrachopsis Blgr. ... I6

I. melanopyga (Doria). . I 7

2. Family Cystignathidae . I 8

I. Phanerotis Blgr...... I 8

I. Aletcheri Blgr..... I8

2. Ranaster Macl. ..... I9

r. convexiusculus Macl. . I9

3. Crinia Tschudi .....2 I

I. signifera Girard . . . 2 I

3. Family Hylidae ..... 22

I. Nyctimantis Blgr. . . 22

I. papua Blgr. ..... 22

2. granti Blgr...... 23

2. Hyla Laur. . . . . . 24
Page

I. rhacophorus v. Kamp. 28

2. amboinensis Horst. . 29

3. papuensis Wern. .. 30

4. graminea Blgr.... 30

5. bernsteini Horst. . . 3 I

6. eucnemis Lünnb. . . $3^{2}$

7. obsoleta Lönnb. . . 32

8. montana Ptrs. \& Dor. 33

- spec.? ........ 34

9. rueppelli Bttgr.... 35

г. fallax Blgr..... 35

II. brachypus (Wern.) . 37

I2. ouzuensi Barb. . . . 37

I3. atropunctata nom. nov. 37

I 4. longicrus (Blgr.). . 38

I5. albolabris Wand. . . 39

I6. arfakiana Ptrs. \& Dor. 39

I 7. wolterstorffi (Wern.). 40

I8. pratti Blgr. ..... 4 I

I9. wollastoni Blgr.... 42

20. chloronota (Blgr.). . 42

2 r. jeudei Wern. ... 43

22. bicolor (Gray).... 44

23. impura Ptrs. \& Dor. 45

24. macgregori Dgl.-Og. . 46

25. genimaculata Horst. . 47

26. macrops Blgr..... 48

27. thesaurensis Ptrs... 49

28. lutea Blgr...... $5^{\circ}$

29. solomonis Vogt.....50

30. everetti Blgr..... 5 I

3I. infrafrenata Gthr. . 5 $\mathrm{I}$

32. spengeli Blgr..... 54

33. militaria (Ramsay). . 55

34. humeralis Blgr.... $5^{6}$

35. aruensis Horst. . . 56

36. sanguinolenta v. Kamp. 57 
37. caerulea (White) .. $5^{8}$ 38. angiana Blgr..... 59 39. congenita Ptrs. \& Dor.60 40. rubella Gray ..... 62 4I. ohtusirostris (Meyer). 63 42. vagabunda Ptrs. \& Dor. 63 43. nasuta (Gray).... 64 44. (?) dorsalis (Macl.) . . 65

4. Family Bufonidae.... 65

r. Nectophryne Buchh.\&Ptrs. 66

I. misera Mocq......66 66

2. hosii Blgr....... 67

3. everetti Blgr. ... 68

4. guentheri Blgr. ... 68

5. macrotis Blgr..... 69

6. signata Blgr. .... 70

7. borbonica (Boie)... 70

8. maculata Mocq. ... 7 I

9. picturata Smith. . . 72

2. Bufo Laur.. . . . . . 72

I. leptopus Gthr. . . 75

2. penangensis (Stol.) . 75

3. jerboa Blgr..... 76

4. fuligineus Mocq... 77

5. cmentatus 'Tschudi. . 78

6. sumatranus Ptrs... 78

7. valhallae M.-Waldo . 79

8. spinulifer Mocq. . . 79

9. melanostictus Schneid. 80

ro. gymnauchen Blkr. . . 8 I

I1. asper Gravh. ..... 82

I2. celebensis Schlg. . . . 82

13. philippinicus Blgr. 86

14. claviger Ptrs. ... 86

15. quadriporcatus Blgr. 87

16. divergens Ptrs. ... 88

17. parvus Blgr..... 88

I8. cavator Barb. ... 89

19. biporcatus Gravh. . 90

20. chlorogaster Daud. - 92

3. Pseudobufo T'schudi . . 92

I. subasper Tschudi . . 92

2. werneri (v. Kamp.). 94
Firmisternia

5. Family Brevicipitidae . 95

I. Dyscophinae..... 95

r. Dyscophina v. Kamp. . 95

I. volz $i$ v. Kamp. ... 96

2. Colpoglossus Blgr.... 97

I. brooksi Blgr..... 97

3. Calliglutus Barb. \& Noble 98

I. smithi Barb. \& Noble 98

2. Brevicipitinae ... 98

I. Liophryne Blgr...... I00

I. rhododactyla Blgr. . I00

2. brevipes Blgr..... Ior

3. kampeni Blgr..... Iо I

2. Calophrynus Tschudi. . IO2

I. pleurostigma(S. Müll.) roz

2. heterochirus Blgr. .. 104

3. punctatus Ptrs. ... 104

3. Sphenophryne Ptrs.\&Dor. 104

I. cormuta Ptrs. \& Dor. 105

2. klossi Blgr....... 107

3. Macrorhyncha (v.K.) 107

4. polysticta (v. Méh.) . 108

5. fusca (Mocq.) .... Iо9

6. beyeri (Taylor).... I Io

4. Oreophryne Bttgr. ... I ro

I. variabilis (Blgr.) . . II 2

2. celebensis (F. Müll.). I 12

3. monticola (Blgr.) . . II 3

4. verrucosa (Blgr.) . . I I 3

5. ateles (Blgr.).... I I 5

6. senckenbergiana Bttgr. I I 5

7. crucifera (v. Kamp.) I 6

8. anthonyi (Blgr.) . . I I I 7

9. loriae (Blgr.).... I I 7

Iо. biroi (v. Méh.) ... II8

I I. albopunctata (v. K.). I 9

I2. mertoni (Roux) . . I 20

5. Nicrobatrachus Roux. . I I I

I. pusillus Roux .... I 2 I

6. Oxydactyla v. Kamp. . 122

I. brevicrus v. Kamp. . I22

7. Callulops Blgr..... 123 
I. doriae Blgr. ..... I 23

S. Gastrophryne Fitz. . . I 24 I. borneënsis (Blgr.) . . I24

9. Phrynella Blgr...... I 24

I. pulchra Blgr. ... I 25

2. pollicaris Blgr. ... 125

I0. XenobatrachusPtrs\&Dor. 126

I. rostratus (v. Méh.) . I27

2. ocellatus (v. Kamp.) I 28

3. macrops (v. Kamp.) $\mathrm{I}_{2} S$

4. bidens (v. Kamp.). I 29

5. giganteus (v. Kamp.) I30

6. ophiodon Ptrs. \& Dor. I 3 I

I I. Xenorhina Ptrs. . . . I I I

I. oxycephala (Schlg.) . 132

I2. Asterophrys 'Tschudi . . I33

I. turpicula (S. Müll.). I33

13. Copiula v. Méh..... I34

I. oxyrhina (Blgr.) ... $\mathbf{1} 35$

2. (?) rostellifera Wand. I 35

14. Choerophryne v. Kamp. I36 I. proboscidea v. Kamp. I36

I5. Hylophorbus Macl. . . I I 37

I. biroi (v. Méh.) ... I 38

2. variegatus nova spec, 138

3. montanus (Bttgr.) . I I39

4. bocttgeri (v. Méh.). . I 40

5. rufescens Macl. .. I 40

6. ocellatus (v. Méh.). . I4I

7. dubius (Bttgr.)... 143

8. robustus (Blgr.) ... I 43

9. microtis (Wern.). . I 144

Iо. (?) neuhaussi (Vogt) 144

16. Aphantophryne Fry . I45

I. pansa Fry .... I 45

17. Cophixalus Bttgr.... 146

1. geislerorum Bttgr. . 146

I8. Pomatops Barb. .... I47

I. valiifera Barb. . 147

19. Kaloula Gray...... I47

I. baleata (S. Müll.). . I48

2. pulchra Gray. ... I50

3. (?) sundana Ptrs... I I I

20. Microhyla Tschudi . I $5^{2}$
I. inornata Blgr. .... 153

2. bungurana (Gthr.). 154

3. achatina Boie ... I54

4. leucostigma Blgr. . . I 56

5. annectens Blgr.... I 56

6. palmipes Blgr. ... I 57

7. berdmorii (Blyth) . I58

3. Genyophrynina ... I 59

I. Genyophryne ..... I 59

I. thomsoni Blgr... 559

6. Family RanidaE..... I60 I. Rana L......... I $6 \mathrm{I}$ Subg. a. Rana L...... 167

I. limnocharis Boie. . 167

2. cancritiora Gravh. . I70

3. vermuculosa Roux . I72

4. grunniens Daud... 172

5. macrodon Kuhl... I 74

6. modesta Blgr..... I 76

7. kuhli Schlg. .... I 78

8. microdisca Bttgr... I 80

9. hascheana (Stol.). . I8I

Iо. palavanensis Blgr. . I82

Subg. b. Discodeles Blgr. . I83

I I. guppyi Blgr. .... $\mathbf{r}_{3}$

12. bufoniformis Blgr.. I84

I3. opisthodon Blgr. . . I85

14. ventricosa Vogt. . . I86

Subg. c. Platymántis Gthr. 187

I 5. boulengeri (Bttgr.) . I 87

I6. moszkoweskii (Vogt) I88

I 7. beauforti (v. Kamp). I 89

I8. rugata nomen nov. I90

I $8 a$. rugata var. rubri-

striata (Barb.) . I9I

I9. solomonis (Blgr.) . . I9I

20. punctata (Ptrs.\&Dor.) 192

Subg. d. Hylarana Tschudi 193

21. macrops Blgr. ... 193

22. glandulosa Blgr. . . 194

23. baramica Bttgr. . I 195

24. luctuosa (Ptrs.) . . I 196

25. debussyi v. Kamp.. 197 
26. laterimaculata B.\&N. Page

27. arfaki Meyer ... 199 28. elberti Roux..... 200 29. papua Less. .... $20 \mathrm{I}$ 30. celebensis (Schlg.) . 204 31. daemeli (Steind.). . 205 32. kreffit Blgr. . . . 206 33. grisea v. Kamp... 207 34. jerboa (Gthr.). .. 208 35. whiteheadi Blgr. . 2 2 то 36. cavitympanum Blgr. 2 I I 37. kampeni Blgr. ...2 $2 \mathrm{I} 2$ 38. crassiovis Blgr. . . 213 39. everetti Blgr. .... 2 I 4 40. hosii Blgr. .....2 $2 \mathrm{r} 5$ 4I. chalconota (Schlg.). 217 42. labialis Blgr.... 220 43. erythraea (Schlg.) . 222 44. persimilis nova spec. 223 45. nicobariensis (Stol.) 224 46. signata (Gthr.). . 226

2. Ceratobatrachus Blgr. . 228

I. guentheri Blgr. . . 228

3. Oreobatrachus Blgr. . 229

I. baluensis Blgr. . . 229

4. Oxyglossus Tschudi. . 230

I. laevis Gthr.....230

2. lima (Kuhl)....232

5. Staurois Cope.....234

I. larutensis (Blgr.). 234

2. guttatus (Gthr.) . 235

3. mubilus Mocq... 236

4. tuberilinguis Blgr. . 237

6. Simomantis Blgr.... 237

I. latopalmata (Blgr.). 238

7. Cornufer Tschudi ...238

I. vitiensis (Girard). . 239

2. guppyi Blgr. ... 240

3. unicolor Tschudi. . 240

4. baluensis Blgr...2 $24 \mathrm{I}$

8. Batrachylodes Blgr. . 24I

I. vertebralis Blgr. . 242
9. Rhacophorus $\mathrm{K}$ Page

I. leprosus (S. Müll.). 244

2. otilophus Blgr.... 245

3. leucomystax (Kuhl). 246 $3 a$. lencomystax var. sex.

virgata (Reinw.) 249

4. colletti Blgr. ... 250

5. macrotis Blgr. .. 25 I

6. everetti Blgr....25 25

7. macroscelis Blgr. . 252

8. hosii Blgr. .... 253

9. georgii Roux.... 253

10. javanus Bttgr. ... 254

I I. appendiculatus(Gthr.) 255

12. poecilonotus Blgr.. . 256

13. bifasciatus nova spec. 257

14. dulitensis Blgr. . . 258

I5. modestus Blgr. . . 259

16. edentulus F. Müll. . 259

I 7. acutirostris Mocq. . 260

18. monticola Blgr. . . 26I

19. shelfordi Blgr. : . . 262

20. fasciatus Blgr.... 262

21. pardalis Gthr. ... 263

22. reinwardti (Boie). . 264

23. nigropalmatus Blgr. 266

Iо. Philautus Gistel. . . . 268

I. bimaculatus (Ptrs.). 269

2. pictus (Ptrs.) ... 269

3. flavosignatus (Bttg.) 270

4. anodon (v. Kamp.). 27 I

5. longicrus (Blgr.).. . 272

6. jacobsoni (v. Kamp.) 272

7. similis nova spec. 273

8. pallidipes (Barb.). . 273

9. cornutus (Blgr.). . 274

I o. vittiger (Blgr.) . . 275

Ir. petersi (Blgr.). . . . 275

12. aurifasciatus(Schlg.) 276

I I. Nyctixalus Blgr. . . 277

I. Margaritifer Blgr. 277

2. robinsoni Annand. 278 


\section{AMPHIBIA.}

\section{(Batrachia).}

Paired limbs originally adapted for terrestrial life, rarely reduced. Skin glandular. Skull with a large parasphenoid and two condyli occipitales, formed by the exoccipitalia; palatoquadratum coossified with the skull. Usually breathing by gills during the young stages, afterwards by lungs. Heart with one ventricle and two atria. No amnion or allantois. Development with, rarely without metamorphosis.

Synopsis of the Orders.

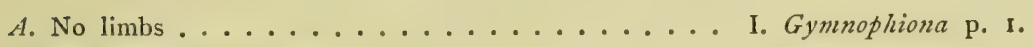

B. Well-developed limbs; no tail ........... II. Anura p. 4 .

\section{Order GYMNOPHIONA.}

(Apoda).

Body worm-shaped; no limbs; tail rudimentary or absent. Usually small osseous scales, hidden in the skin. Eyes rudimentary, sometimes covered by cranial bones. Between eye and nostril a retractile tentacle. Tympanum absent. Male with an unpaired copulatory organ (see fig. I).

Terrestrial, burrowing. Ovi- or viviparous, with or without an aquatic larval stage. Embryo usually with external gills.

Fam. Caecilitdae.

Characters of the Order.

Distribution: tropical parts of America, Africa and Asia. INDO-AUSTRALIAN AMPHIBIA. 


\section{Ichthyophis Fitz.}

(Fitzinger, Neue Classif. Rept., Wien, I826, p. 36).

Epicrium Wagler, Isis, 1828, p. 742.

Scales present. Eyes externally distinguishable. Tentacle conical, near the lip. Two series of teeth in the upper, and usually also in the lower jaw. A short, pointed tail present. Paraquadratum (squamosum) in contact with the parietal bone.

Oviparous.

Distribution: from India to the western part of the Indo-Australian Archipelago.

$$
\text { Synopsis of the Species. }
$$

$A$. Snout as long as the distance between the eyes. A

yellow lateral band ................ I. glutinosus p. 2.

$B$. Snout shorter than the distance between the eyes.

No lateral band ................. 2. I. monochrous p. 3 .

\section{Ichthyophis glutinosus (L.).}

Caccilia glutinosa Linné, Syst. Nat., ed. 10, 1758, p. 229.

Cacilia hypocyanea (v. Hasselt), Schlegel, Abbild. neuer oder unvollst. bek. Amph., Düsseldurf, 1837-44, p. I19, pl. XXXIX, fig. I (larva).

Ichthyophis ghutinosus Boulenger, Cat. Batr. Grad. Brit. Mus., 1882, p. 89, pl. 1V, figs. 2, $2 a-\ell$.

Ichthyophis glutinosus Sarasin, Erg. naturw. Forschungen auf Ceylon, II, I887-9o, pls. I-XXIV.

Ichthyophis glutinosus Boulenger, Vert. Fauna Malay Penins., Rept. and Batr., London, I912, p. 285, fig. 79 (after Sarasin).

Ichthyopluis glutinosus Nieden, Gymnophiona, in „Das Tierreich", Berlin, pt. 37, 1913, p. 6, figs. 12 and 13 .

Body cylindrical, with $240-400$ circular folds, some of them bifurcating. Both series of teeth in lower jaw well developed. Snout rounded, as long as the distance between the eyes, which are easily distinguishable; tentacle small, in front of and below the eye, close to the lip, and usually much nearer the eye than the nostril.

Dark brown or bluish black; along each side of the body a bright lemon-yellow, sharply defined band, varying much in width; tentacles white; eyes black, with a very narrow pale brown ring round them. Length $380 \mathrm{~mm}$.

Lives in moist places, in te mud near the water. The food consists of earth-worms and small burrowing snakes. The very 
large eggs $( \pm 9 \times 6 \mathrm{~mm}$.) are provided with yellow yolk and connected by a gelatinous string. They are deposited by the female in a burrow, which she digs near the water, and she protects them by coiling herself round them. The embryo has three pairs of external gills. The larva, which possesses a pair of spiracula but no gills, a newt-like head with well-developed

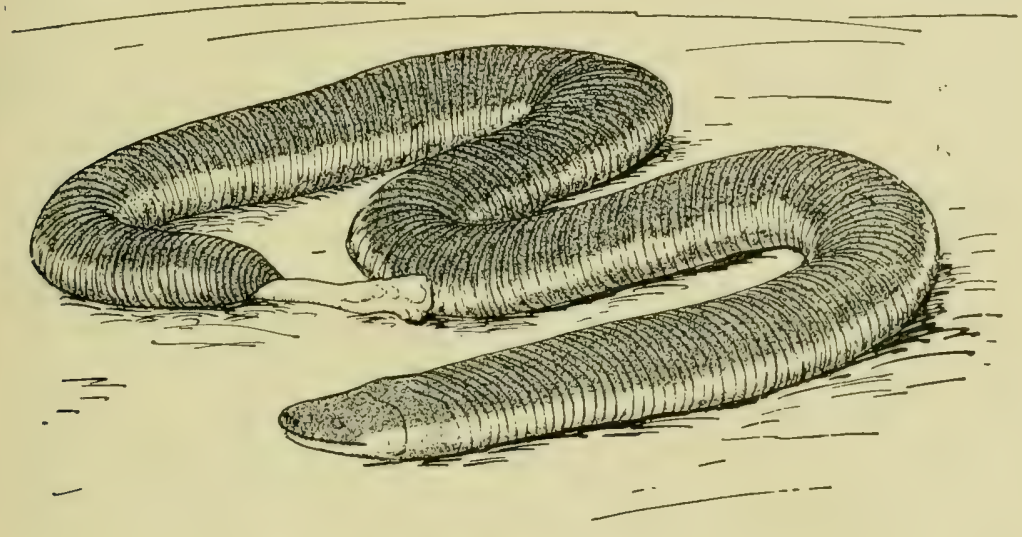

Fig. 1. Ichthyophis glutinosus (L.), $\times 5 / 6$.

eyes and a laterally compressed tail with an upper and a lower dermal fold, lives in the water.

Habitat: Nias!; Mentawei islands (Sipora); Sumatra (Upper and Lower Langkat; Batak mts., \pm 300 and $\pm 1000 \mathrm{~m} . !$; foot of Mt. Simbolon; Tanang Talu, Ophir distr., Ioos m.!; Fort de Kock; Indragiri; Rawas riv. in Palembang!); Borneo (Menternan riv., near Bungol, Brit. N.-Borneo; Serawak; Matan); Java (Sudimanik in Bantam). - Southern India, Ceylon, the eastern Himalayas to the Malay Peninsula.

\section{Ichthyophis monochrous (Blkr.).}

Epicrium monochrous Bleeker, Nat. Tijdschr. Ned.-Indië, XVI, I858/59, p. 188. Ichthyophis monochrous Boulenger, Cat. Batr. Grad. Brit. Mus., 1882, p. 91, pl. IV, figs. I-I $c$ (larva).

Ichthyophis monochrous Boulenger, Vert. Fauna Malay Penins., Rept. and Batr., London, 1912, p. 286.

Ichthyophis monochrous Nieden, Gymnophiona, in "Das Tierreich", Berlin, pt. 37, 1913, p. 7 .

?Ihthyophis weberi Taylor, Philipp. Jrn. of Sc., XVI, I920, p. 227.

1 The inner series of teeth in the lower jaw composed of a few teeth only. Snout shorter than the distance between the eyes. 
Uniform purplish black; tentacles white; anal region and tip of tail pale pinkish. Length $500 \mathrm{~mm}$.

Other characters as in I. glutinosus.

Habitat: Sumatra (Indrapura; Palembang); Borneo (Mt. Dulit; Singkawang); Java. - India to Malay Peninsula (up to I 200 m.) and Singapore; Philippines '), incl. Pelawan ? ${ }^{2}$ ).

\section{Order ANURA. \\ (Ecaudata, Salientia).}

Four well-developed limbs; no tail. Skin naked. Eyes normally developed. No tentacles. No copulatory organ.

Terrestrial or aquatic. Oviparous ${ }^{3}$ ); the eggs are usually deposited in the water, rarely on the land, in moist surroundings. They are enveloped and usually united in clumps or strings by a gelatinous mass. When they are rich of yolk the young are sometimes hatched in the perfect lung-breathing stage; usually however there is an aquatic larval stage. The larvae (tadpoles) are tailed and breath by external, afterwards internal gills; they live in fresh, rarely in brackish water.

Synopsis of the Families and Subfamilies.

$A$. Epicoracoid cartilages overlapping each other (Arcifera).

I. Upper jaw toothed (in the Indo-Australian genera).

I. Terminal phalanges of digits not claw-shaped.

a. Diapophyses of sacral vertebra strongly dilated ................ Pelobatidae p. 5 .

b. Diapophyses of sacral vertebra not or slightly dilated............. 2. Cystignathidae p. 18 .

2. Terminal phalanges of digits claw-shaped.

Diapophyses of sacral vertebra dilated. . 3. Hylidae p. 22.

II. Both jaws toothless. Diapophyses of sacral vertebra dilated ............. 4. Bufonidae p. 65.

$B$. Epicoracoid cartilages firmly united in the median line (Firmisternia).

I) According to De Elera, Catàlogo Sist. de toda la Fauna de Filipinas, I, 1895, p. 457.

2) "l. weberi sp. nov.", Taylor.

3) With very few exceptions. 
I. Diapophyses of sacral vertebra distinctly dilated. 5. Brevicipitidae p. 95.

1. Upper jaw toothed, lower toothless. .... subf. Dyscophinae p. 95.

2. Both jaws toothless. . . . . . . . . subf. Brevicipitinae p. 98 .

3. Lower jaw toothed, upper toothless... subf. Genyophryninae p. I59.

II. Diapophyses of sacral vertebra not or very

slightly dilated ............6. Ranidae p. 160.

Synopsis of the Tadpoles.

$A$. Lips with transverse series of horny teeth.

I. No sucking disk behind the mouth.

I. Series of papillae narrowly interrupted in the middle of the upper lip. Eyes superior. Teeth $6 / 5$ or $6 / 6 \ldots . . . .$. Megalophrys hasselti p. I3.

2. Series of papillae as in $\mathbf{I}$, or papillae absent. Eyes usually lateral. Teeth 2/3. . Hyla p. 24:"

3. Papillae present, but absent along the upper border of the upper lip.

a. Vent median. Eyes superior ...... Bufo p. 72 .

b. Vent dextral, opening at some distance above the lower edge of the subcaudal crest, Eyes usually lateral. ....... Rhacophorizs p. 242.

c. Vent dextral, close to the lower edge of the subcaudal crest. Eyes usually superior. . . . . . . . . Rana part. p. Í̄í.

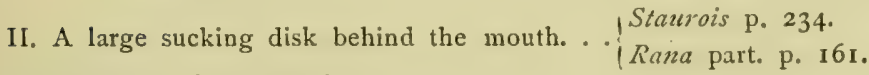
$B$. Lips without horny teeth.

I. Spiraculum sinistral.

I. Lips large . . . . . . . . . Megalophry's montana p. 8 .

2. Lips small ............... Oxyglossus p. 230.

II. Spiraculum median. . . . . . .

\section{Arcifer a.}

Epicoracoid cartilages overlapping each other.

\section{Fam. Pelobatidae.}

Upper jaw toothed, lower toothless. Diapophyses of the sacral vertebra strongly dilated. Terminal phalanges of fingers and toes simple.

Omosternum usually present, but small and cartilaginous, 
rarely calcified; sternum without or with a bony style. Vertebrae procoelous or opisthocoelous. No ribs. Os coccygis fused with the sacral vertebra or articulating with it by one or two condyles.

Distribution: America; Europe; southern Asia to western part of Indo-Australian Archipelago; New Guinea and Aru islands.

Synopsis of the Genera.

A. Pupil horizontal. . . . . . . . . . . I. Nesobia p. 6 .

B. Pupil erect.

I. Sternum with a bony style.......... 2. Megalophrys p. 7 .

II. Sternum cartilaginous .............. Batrachopsis p. I6.

I. Nesobia nomen novum.

Pupil horizontal. Tongue oval, free behind. No vomerine teeth. Tympanum visible. Fingers and toes free, the tips not dilated.

Omosternum present; sternum with a bony style.

Distribution: Natuna islands.

\section{Nesobia natunae (Gthr.).}

Leptobrachium natunae, Günther, Novit. Zool., II, I895, p. 50 I.

Tongue long and narrow. Snout rounded, about as long as the eye; canthus rostralis indistinct; nostril nearly in the middle between eye and tip of snout; interorbital space broader than the upper eyelid; tympanum indistinct, less than half the area of the eye. Tips of fingers and toes blunt; first finger very little shorter than second; toes free; subarticular tubercles indistinct; a flat, elongate inner, no outer metatarsal tubercle; the heel reaches the tip of the snout, or beyond.

Back with very small, flat, indistinct granulations; lower parts quite smooth.

Brownish olive above, uniform or marbled with brown; upper lip black, with some white spots; a black band from the eye over the tympanum to the shoulder; sides of body with larger or smaller black spots; hind limbs with brownish cross-bars. Length $19 \mathrm{~mm}$.

Habitat: Natuna islands (Bunguran). 


\section{Mega 10 phrys Kuhl \& v. Hass.}

(KUHL en v. Hasselt, Alg. Konst- en Letter-bode, 1822, p. 102 ["Mogophry's"] und Isis, IS22, p. 475 [nMegophrys"']).

Lcptobrachium, Megalophrys and Xenophry's Boulenger, Cat. Batr. Sal. Brit. Mus., 1882 , p. $440-442$.

Megalophry's Botlenger, Proc. Zool. Soc. London, I908, p. 407.

Pupil erect. Tongue circular or pyriform, entire or nicked, free behind. Vomerine teeth in two small groups or absent. Tympanum more or less distinct, or hidden. Fingers free, toes free or shortly webbed, the tips without regular disks. Outer metatarsals united or partly separated by web.

Omosternum cartilaginous, sometimes calcified; sternum with a bony style. Os coccygis fused with the sacral vertebra or articulating with it by one condyle. Vertebrae opisthocoelous or procoelous.

Tadpoles. - Eyes superior. Spiraculum sinistral. Vent median or dextral. Upper crest of tail not extending on to the body. Mouth normal, with numerous series of teeth, and almost entirely surrounded with papillae, or funnel-shaped, with scattered papillae and without teeth.

Distribution: S.-E.-Asia, including western part of the Indo-Australian Archipelago.

\section{Synopsis of the Species.}

A. Snout projecting beyond the lower jaw.

I. End of snout without or with a rudimentary dermal appendage.

I. Male with vocal sacs .......... I. M. ligayae p. 8 .

2. Male without vocal sacs. ........... 2. M. montana p. 8 .

II. End of snout with a distinct dermal appendage . 3. M. nasuta p. 10.

$B$. Snout not projecting beyond the lower jaw.

I. No vomerine teeth.

I. Heel reaching the shoulder .......... 4. M. hasselti p. I3.

2. Heel reaching tip of snout .........5. M. gracilis p. 15 .

II. Vomerine teeth present ............6. M. baluensis p. I6.

Synopsis of the Tadpoles.

A. Lips without teeth ............... M. montana p. 8.

$B$. Lips with teeth in regular series .......... 4. M. hasselti p. I3. 


\section{Megalophrys ligayae Taylor.}

Megalophrys ligayae Taylor, Philipp. Jrn. of Sc., XVI, 1920, p. 350, pl. X, figs. 2, 2 a.

Tongue distinctly nicked behind; vomerine teeth in two rounded groups between the posterior part of the choanae. Head much broader than long; snout rather distinctly pointed, longer than the eye, projecting beyond the lower jaw; nostril in the middle between eye and tip of snout, or slightly nearer the latter; interorbital space $1 \%$ times the width of the upper eyelid (exclusive of spine); tympanum moderately distinct, about $2 / 3$ the diameter of the eye, from which it is separated by a distance nearly $\mathrm{I} \frac{1}{2}$ times its greatest length. Tips of fingers and toes slightly swollen; first finger about as long as second, extending beyond fourth; third toe extending distinctly beyond fifth; toes free; no subarticular tubercles; inner metatarsal tubercle large, as long as first toe; the heel reaches the anterior border of the tympanum. Tibia 0,3 length from snout to vent.

Skin of head coossified with the skull. Skin with minute spicules, and with larger tubercles on back; sides and limbs; a prominent tubercle above the insertion of the arm, on the shoulder and in the middle of the back; a distinct fold from the eye to above the arm and another on each side of the back, from the occipital region to half the length of the body; upper eyelid and angle of mouth each with a short dermal spine; belly smooth, with two prominent tubercles on the breast.

Above olive gray (in life), with numerous dark spots; a backward curved line across the head limits the dark occipital area, which continues backwards between the dorsolateral folds to the end of the body; a narrow black line along the outer side of the dorsolateral folds; outer edge of upper eyelid and spine black; a black stripe on the loreal region and a narrow, black, yellow-edged line below the eye, ending in a black spot behind the eye; lips with elongate, yellow-edged spots; limbs with cross-bars; lower parts yellow, with black and brownish spots. From snout to vent $60 \mathrm{~mm}$.

Male with vocal sacs.

Habitat: Pelawan.

2. Megalophrys montana Kuhl \& v. Hass.

Mogophry's montana and Megophry's monticola Kuhl en v. Hasselt, Alg. Ǩonsten Letter-bode, I822, p. 102, 104. 
Megophrys monticola Kuhl und v. Hasselt, Isis, 1822, 'p. 475.

Ceratophrys montana Schlegel, Abbild. neuer oder unvollst. bek. Amph., Diisseldorf, $1837-44$, p. 29, pl. X, fig. 3 .

Megalophrys montana Boulenger, Cat. Batr. Sal. Brit. Mus., I882, p. 442.

Megalophrys montana Weber, Ann. Jardin Bot. Buitenzorg, Suppl. II, I 898 , p. 5, figs. I-5 (tadpole).

Megalophrys montana Boulenger, Vert. Fauna Malay Penins., Rept. and Batr., London, I9I2, p. 277 (with tadpole).

Megalophrys montanc Parbour, Mem. Mus. Comp. Zoöl. Harvard Coll., XLIV, I, I 912 , p. 77, pl. VII, fig. 30.

Megalophrys montana Annandale, Mem. Asiat. Soc. Bengal, VI, 1917, p. 154, pl. VI, fig. ro (tadpole).

Megalophry's montana, Smith, Jrn. Nat. Hist. Soc. Siam, II, I9I7, p. 27 I (tadpole).

Tongue entire or feebly nicked behind; vomerine teeth usually present, in two widely separated small groups just behind the level of the choanae. Head large, once and a half to once and three fourths as broad as long; snout truncate or obtusely pointed, projecting beyond the lower jaw, as long as or a little shorter than the eye; canthus rostralis angular, straight; loreal region vertical or a little oblique, concave; nostril equally distant from eye and end of snout; interorbital space in the adult once and a half to twice the width of the upper eyelid; tympanum usually feebly distinct, rarely hidden, its diameter $1 / 2$ to $2 / 3$ that of eye, from which it is separated by a distance equal to the diameter of the latter. Tips of fingers and toes obtuse or feebly swollen; first finger as long as or a little longer than second, which is equal to fourth; third toe extending distinctly beyond fifth; toes at most $1 / 4$ webbed; no subarticular tubercles; a flat, very indistinct inner, no outer metatarsal tubercle; heel reaching between shoulder and temple; tibia $3 / 8$ to $1 / 2$ length from snout to vent; foot as long as or shorter than the tibia.

Skin of upper parts smooth, or with scattered conical warts, in old specimens more or less calcified on the head and the anterior part of the back; a strong glandular fold from eye to shoulder, usually another on each side of the back; the head usually defined behind by a more or less distinct transverse fold; upper eyelid with a sharp, raised edge, which is produced into a triangular process, not measuring more than $2 / 3$ diameter of eye; an indication of a similar appendage on the tip of the snout rarely present; limbs usually with oblique transverse glandular ridges; belly with small tubercles. 
Olive-brown to violet above, uniform or variously marked with darker or lighter; a more or less distinct large triangular dark spot between the eyes, the base forwards, and a dark oblique bar below the eye; limbs with more or less distinct dark cross-bars; lower parts almost white to black, spotted or marbled with darker; a white tubercle on each side of the breast. Length $100 \mathrm{~mm}$.

Male without vocal sac.

According to Barbour "the specimens vary in color individually, and by frequent changing they always show tints which harmonize wonderfully with dead leaves, in which they lie hidden during the daytime."

Tadpole. - Length of body about twice its width; tail more than twice as long as body, about 5 times as long as deep, the total depth not much greater than the depth of its muscular portion at the base. Nostril close to the eye; eye superior, much nearer tip of snout than spiraculum; spiraculum sinistral, equally distant from tip of snout and root of tail; vent median. Tail pointed; crests low, of nearly equal depth, the upper one extending as a low ridge to the root of the tail. Mouth subterminal; the lips form a funnel, which is broader than long, without papillae, but with numerous, scattered, small tubercles; jaws colourless.

Dark-brown, sometimes lighter below; sides with pale markings; tail with dark-brown spots in its posterior part. Length $54 \mathrm{~mm}$.

The tadpoles live in pools or in shallow, swiftly running water. The funnel-shaped, muscular lips enable it to float on the surface.

Habitat: Sumatra (Deli!; Fort de Kock; Batang Singgalang!); Borneo (Serawak); Java (Mt. Salak; Gadok; Mt. Pangeranggo, \pm 1400 m.; Mt. Gedeh, 900-2000 m.!; Mt. Puntjak!; Sukabumi!; Tjiandjur; Djampang!; Mt. Malabar, I 500 m.!; Mt. Papandajan, I 500 m.; Mt. Ungaran, I600 m.!; Nongkodjadjar, I 200 m.! ; Tosari, I 800 m.!). - Siam; Malay Peninsula, 300-600 m.; Philippines?

\section{Megalophrys nasuta (Schlg.).}

Ceratophryne nasuta Schlegel, Handl. Dierk., Breda, 1858, II, p. 57, pl. 1V, fig. 72. Megalophry's chysii Edeling, Nat. Tijdschr. Nęd.-Indië, XXVII, 1864, p. 265, with plate, 
Megalophrys nasuta Boulenger, Cat. Batr. Sal. Brit. Mus, I882, p. 443.

Pelobatrachus nasutus Beddard, Proc. Zool. Soc. London, 1907, p. 909. Megalophry's nasuta. Boulenger, Proc. Zool. Soc. London, 1908, p. 4I3, pl. XXII. Mcgalophry's nasuta Boulenger, Vert. Fauna Malay Penins., Rept. and Batr., London, 1912, p. 279, fig. 77 .

Tongue entire or more or less distinctly nicked behind; vomcrine teeth in two widely separated small groups on a level with, or a little behind the posterior borders of the choanae. Head large, once and a half to twice as broad as long; snout truncate, projecting, as long as or a little shorter than the upper eyelid, and longer than deep; canthus rostralis strongly angular, curved; loreal region vertical or feebly oblique, concave; nostril about equidistant from eye and end of snout; interorbital space in the adult once and a half to twice the width of the upper eyelid; tympanum often hidden, if distinct $1 / 2$ to $2 / 3$ the width of the eye, from which it is widely separated. Fingers and toes obtuse, or with feebly swollen tips; first finger as long as or longer than second, which extends as far as or a little beyond fourth; third toe distinctly longer than fifth; toes feebly, at most $1 / 4$, webbed; no subarticular tubercles; a flat, very indistinct inner, no outer metatarsal tubercle; heel reaching the shoulder or the commissure of the jaws; the tarso-metatarsal articulation reaches the eye; tibia $1 / 3$ to $2 / 5$ the length from snout to vent; foot a little shorter than the tibia.

Skin of upper parts smooth or with a few scattered warts; adult with calcareous deposits on the head and anterior part of the back, which may completely fuse with the skull, and form a shield on the praesacral part of the body; a narrow ridge from eye to shoulder, sometimes continued on the side of the body; usually a similar ridge along each side of the back, from behind the head to the sacral region; in young specimens two ridges, forming a $\mathrm{V}$, on the head, the tips of the $\mathrm{V}$ being placed on the extremities of the upper eyelid; head usually defined behind by a more or less distinct transverse groove; often one to three subconical tubercles on the scapular region, one or two other ones in the middle of the sacral region, and sometimes a few ones on the head and the sides of the body; upper eyelid produced into a long triangular process, which may be as long as the eye in the adult, but is often shorter; a similar, but shorter appendage on the 
end of the snout and a still smaller one at the angle of the jaws; limbs with or without oblique transverse ridges; lower parts smooth, or belly with small tubercles.

Brown or bronze in various shades above, uniform or vari-

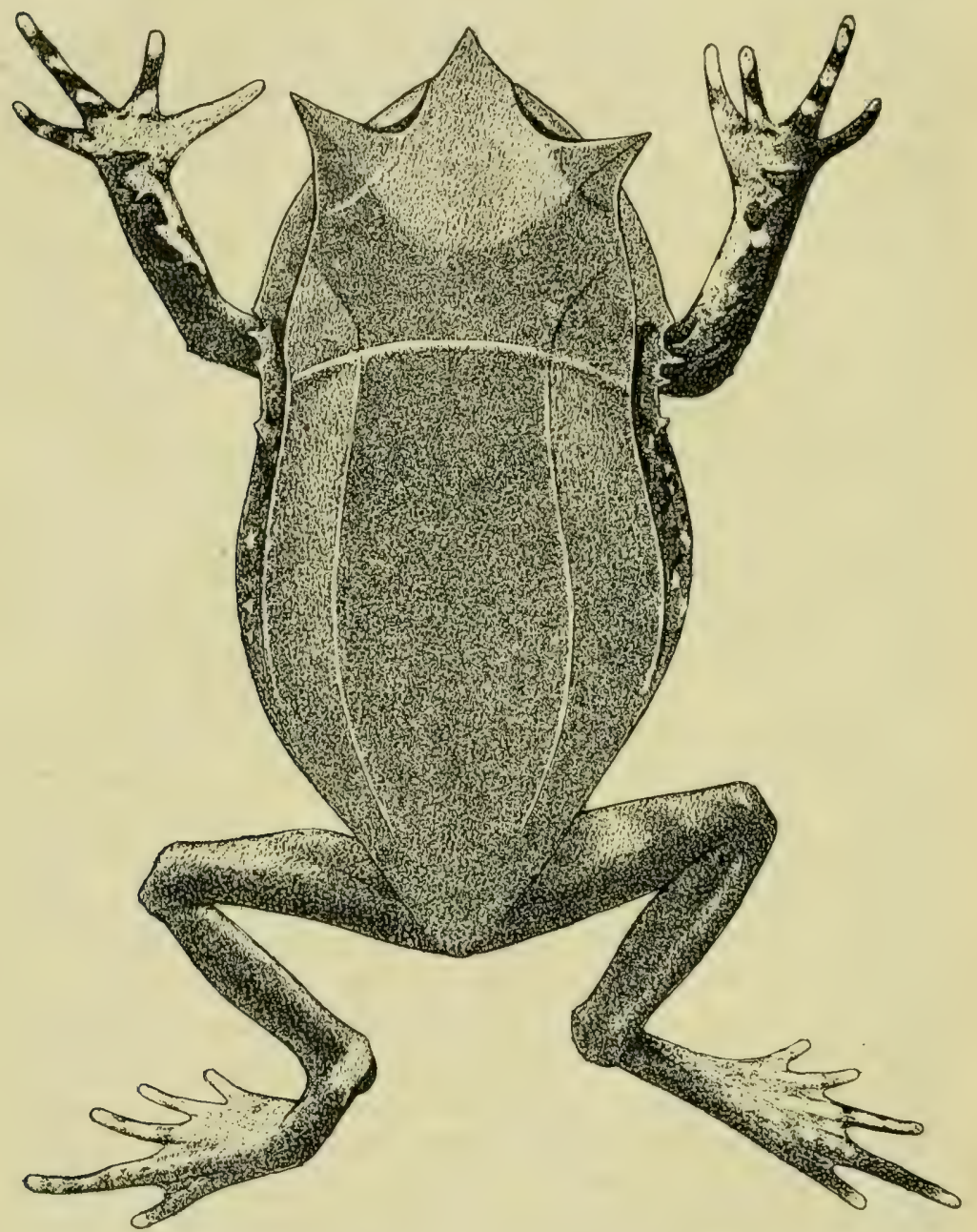

Fig. 2, Megalophrys nasuta (Schlg.), $\times 3 / 4$.

ously marbled with darker and lighter; a more or less distinct Y-shaped dark marking between the eyes and on the occiput may be present; a dark oblique bar below the eye, continued to below the canthus rostralis; lower parts dark brown, or 
spotted or marbled with dark brown. From snout to vent: 万ᄀ 82 , क $127 \mathrm{~mm}$.

Male with an internal vocal sac.

Closely related to $M$. montana; distinguished by the appendage on the end of the snout and the usually greater length of the palpebral appendage.

According to Flower the colour is very variable in the same individual, but always resembling that of dead leaves. In copula the male embraces the female round the lumbar region.

Habitat: Sumatra (Langkat!; Deli !; Serdang!; Karo Highland, I 400 m.!; Batak mts., - 300 and $800-1000$ m.!; Mt. Simbolon; Mt. Ophir, 400 m. !; Batang Singgalang; Batu Sangkar, between 450 and 900 m.; XIII-Koto; Balun! and Muarolabuh! in the Padang Highlands; Rimbo Pengadang in Lebong!; Hari leko riv.!, Penanggungan and Benakat in Palembang); Natuna islands; Borneo (Mt. Kina Balu, 640 m.; Koung; Kiou; Serawak; Mt. Dulit; Matan; Kahajan!; Pramassan-Alai mts.). - Sian; Malay Peninsula; Singapore.

\section{Megalophrys hasselti (S. Müll.).}

Leptobrachium Hasseltii (Müll.) Tschudi, Mém. Soc. Sc. nat. Neuchâtel, II, 1839, p. 8 r.

Rana Hasseltii Schlegel, Handl. Dierk., Breda, I858, II, p. 56, pl. IV, fig. $7 \mathbf{1}$. Leptobrachium hasseltii Boulenger, Cat. Batr. Sal. Brit. Mus., 1882, p. 441.

Leptobrachium montanum Fischer, Arch. f. Naturgesch., LI, I, 1885, p. 44.

Lepiobrachizm hasseltii Boulenger, Proc. Zool. Soc. London, 189o, p. 37 (with tadpole).

Leptobrachium hasseltii v. Kampen, Weber's Zool. Ergebn., Leiden, IV, I907. p. 408 (with tadpole).

Megalophrys hasseltii Boulenger, Proc. Zool. Soc. London, 1908, p. 425, pl. XXV, fig. 3 .

Megalophrys Hasselti v. Kampen, Nat. Tijdschr. Ned.-Indië, LXIX, r9o9, p. 27, pl.'II, fig. I (tadpole).

Megalophrys hasseltii Boulenger, Vert. Fauna Malay Penins, Rept. and Batr., London, 1912, p. $2 S_{2}$.

Megalophrys hasscltii Annandale, Mem. Asiat. Soc. Bengal, VI, I917, p. I53, pl. VI, fig. 9 (tadpole).

Megalophrys hasselti Taylor, Philipp. Jrn. of Sc., XVI, 1920, p. 355, pl. VIII, figs. $4,4 a$.

Tongue nicked behiad; no vomerine teeth. Head large, about once and a fourth as broad as long; snout rounded, not projecting, about as long as the upper eyelid, hardly longer than deep; canthus rostralis distinct, curved; loreal region very 
oblique; nostril a little nearer the end of the snout than the eye; interorbital space broader than the upper eyelid; tympanum hidden or feebly distinct, $1 / 2$ to $3 / 4$ diameter of the eye. Fingers and toes obtuse; first and second finger equal or first the longer, second and fourth of nearly equal length; third toe slightly longer than fifth; toes webbed at the base in females, $1 / 4$ to $1 / 2$ webbed in males; subarticular tubercles sometimes distinct; a small, oval, feebly prominent, inner, no outer metatarsal tubercle; the heel reaches the shoulder, the tarso-metatarsal articulation the posterior border of the eye; tibia $1 / 3$ to $2 / 5$ the length from snout to vent.

Skin smooth or with small tubercles above, granular on the belly; a glandular fold above the tympanum.

Brown, grey, or pale olive above, with small or large dark brown spots or marblings, which may be irregular or form a symmetrical pattern; a more or less distinct dark canthal and temporal streak; sides of snout with dark vertical bars; limbs with dark cross-bars; throat and belly dirty white, or brown, speckled with white. From snout to vent: $0^{7} 47,974 \mathrm{~mm}$.

Male with an internal vocal sac.

Tadpole. - Length of body once and a half its width; tail about once and a half to once and three fourths as long as the body, somewhat more than 3 times as long as deep, and once and a half as high as its muscular part at the base. Nostril nearer the eye than the tip of the snout; eyes superior, as far from tip of snout as from spiraculum; the distance between them twice that between the nostrils; spiraculum sinistral, directed upwards and backwards, visible from above and from below, as far from the tip of the snout as from the base of the tail; anal opening very large, dextral, close to the lower margin of the crest of the tail. Tip of tail rounded; upper crest higher than the lower, with convex margin and not extending to the base of the tail.

Mouth ventral; its entire border, with the exception of a small portion in the centre of the upper margin, with papillae, which along the upper margin are arranged in one, along the sides and the lower margin in two series; jaws almost entirely black, with serrated borders; series of teeth : $5^{1} 5 / 4^{1} 4$ or $5^{1} 5 / 5^{1} 5$; in the upper lip the uppermost series is very short, the second the longest, the other ones gradually becoming shorter, in the lower lip the outer series is short, the next one narrowly 
interrupted, the other ones distinctly divided, with some separated pieces at each side.

Blackish grey, darker above than below; or upper parts brown, with dark spots and marblings. Length $79 \mathrm{~mm}$.

In pools and clear, swiftly running water.

Habitat: Sumatra (Deli; Panjinggahan!; Tandjong Laut in Palembang); Borneo (Mt. Kappa in Brit. N.-Borneo; Pramassan-Alai mts.); Java (Tjibodas; Pasirdatar, $900 \mathrm{~m}$. !; Tjiandjur; Djampang Kulon!; Pengalengan; Mt. Malabar, I 500 m.!; Mt. Sesuru!; Dirk-de-Vries bay!; Nusa Kambangan!; Tengger mts., 1200 m.). - Burma; Siam; Malay Peninsula; Singapore; Philippines, incl. Pelawan.

\section{Megalophrys gracilis (Gthr.).}

Leptobrachium gracile Günther, Proc. Zool. Soc. London, IS72, p. 598. Leptobrachium gracile Boulenger, Cat. Batr. Sal. Brit. Mus., 1882, p. 440.

Megalophrys gracilis Boulenger, Proc. Zool. Soc. London, 1008, p. 421, pl. $\mathrm{XXV}$, fig. $\mathbf{1}$.

Megalophrys gracilis Boulenger, Vert. Fauna Malay Penins., Rept. and Batr., London, I9I2, p. 281 .

Tongue nicked behind; no vomerine teeth. Head moderate, as long as broad or slightly broader than long; snout rounded, not projecting; canthus rostralis distinct; loreal region not very oblique, concave; interorbital space a little narrower than the upper eyelid; tympanum distinct, half the diameter of the eye. Tips of fingers slightly swollen, of toes slightly swollen or blunt; first and second finger equal; toes with a very short web at the base; no subarticular tubercles; a feebly prominent, elliptical inner metatarsal tubercle; heel reaching the tip of the snout; tibia a little more than half the length from snout to vent; foot shorter than the tibia, but longer than the head.

Skin smooth; a curved fold above the tympanum.

Greyish olive to dark brown above, with more or less distinct darker spots or symmetrical markings on the head and body and cross-bars on the limbs; a whitish spot below the eye and another on the arm and elbow sometimes present; lower parts dirty white, with or without irregular brown spots. Length $44 \mathrm{~mm}$.

Habitat: Borneo (Mt. Kina Balu; Matan). - Malay Peninsula ( $1600 \mathrm{~m}$. .). 


\section{Megalophrys baluensis (Blgr.).}

Leplobrachium baluense Boulenger, Ann. Mag. Nat. Hist., (7) IV, 1899, p. 453. Leptobrachium baluense Hanitsch, Jrn. Straits Br. Asiat. Soc., No. 34, 1900, p. 74, pl. II, figs. I, I $a$.

Megalophry's balucnsis Boulenger, Proc. Zool. Soc. London, 1908, p. 429.

Tongue entire; vomerine teeth in two widely separated small groups just behind the level of the choanae. Head moderately large, much depressed, nearly twice as broad as long; snout rounded, not projecting, much shorter than the orbit; canthus rostralis strong; loreal region vertical, concave; nostril equally distant from eye and end of snout; interorbital space slightly concave, nearly twice as broad as the upper eyelid; tympanum feebly distinct, $3 / 5$, the diameter of the eye, about half its distance from the eye. Fingers and toes blunt; first finger a little longer than second; toes with a mere rudiment of web; no subarticular tubercles, but a feeble median ridge or keel under the toes; a very indistinct oval inner metatarsal tubercle; heel reaching the shoulder; tibia $2 / 5$ the length from snout to vent; foot much longer than the head.

Skin adherent to the rugose skull, perfectly smooth; a very small conical tubercle near the border of the upper eyelid.

Back and upper surface of snout dark grey; posterior half of upper surface and sides of head blackish brown; a curved light streak, the concavity turned forwards, across the upper eyelids and the interorbital region, followed by a Y-shaped blackish marking; two light spots on the upper lip, below the eye; large blackish-brown, partly confluent spots on the back; sides dark brown, light-edged above; limbs dark brown, with rather indistinct darker cross-bars; throat brown, belly brownish white. From snout to vent $65 \mathrm{~mm}$.

Habitat: Borneo (Mt. Kina Balu, I 300 m.).

\section{Batrachopsis Blgr.}

(Boulenger, Cat. Batr. Sal. Brit. Mus., I882, p.439; nec Batrachopsis Fitzinger, Syst. Rept., Vindobonae, fasc. I, I 843 , p. 34 : nomen nudum). Lechriodus Boulenger, Cat. Batr. Grad. Brit. Mus., I882, p. II6.

Pupil erect. Tongue subcircular, slightly nicked and free behind. Vomerine teeth in two long transverse series behind the choanae. Tympanum more or less distinct. Fingers free, blunt, toes webbed at the base, the tips feebly swollen. Outer metatarsals slightly separated. 
Omosternum and sternum cartilaginous. Two condyles for articulation with the os coccygis. Vertebrae procoelous.

This genus connects the Pelobatidae with the Cystignathidae. The strongly dilated sacral diapophyses make it necessary to unite it with the Pelobatidae, though in other respects it is more resembling some of the Cystignathidae (Limnodynastes, Ranaster, Phanerotis).

Distribution: Aru islands; New Guinea.

\section{Batrachopsis melanopyga (Doria).}

Asterophry's melanopyga Doria, Ann. Mus. Genova, VI, r874, p. 355, pl. XII, fig. k. Batrachopsis melanopyga Boulenger, Cat. Batr. Sal. Brit. Mus., 1882, p. 439.

Lechrivdus melanopyga Fry, Proc. Roy. Soc. Queensland, XXVII, 19I5, p. 72, pl. I, figs. I, $\mathbf{I} a$, and textfig. $2 c$.

Vomerine teeth in two long, transverse, straight or slightly arched, narrowly separated series behind the choanae, not extending outwards beyond the latter. Head large, much broader than long; snout rounded, not projecting, as long as the upper eyelid, about as long as deep; canthus rostralis angular, straight; loreal region very oblique, concave; interorbital space as broad as, or a little narrower than the upper eyelid; tympanum more or less distinct, vertically oval, its vertical diameter $3 / 4$ to nearly equal to the width of the eye. Tips of fingers blunt, of toes slightly swollen; first finger as long as second, which is slightly longer than fourth; fifth toe slightly longer than third; toes webbed at the base; subarticular tubercles prominent; a small, elliptic inner, no outer metatarsal tubercle; the heel reaches beyond the tip of the snout; tibia $2 / 3$ length of head and body.

Upper parts finely granular; a narrow dermal ridge from the eye to the side of the body, and a few other longitudinal, symmetrical ridges along the back; a transverse fold between the upper eyelids; lower parts smooth.

Brown above, indistinctly spotted with darker; usually a black streak on the canthus rostralis and below the outer glandular fold, and another across the interorbital space; limbs with more or less distinct blackish cross-bars; anal region, border of lower lip and sometimes a series of spots parallel with it on the throat, black; beneath yellowish or brownish. Male with an internal subgular vocal sac; during the breeding- 
season the inner side of the first two fingers and of the strong metacarpal tubercle covered with black spines. In the female the two inner fingers are lobate. Length $80 \mathrm{~mm}$.

Habitat: Aru islands; New Guinea (Mansiman!; Hatam, Arfak mts.!; Mamberamo riv.!; near Idenburg riv., \pm I 800 m. !; Tor riv.!; Fife bay; Vikaiku, St.-Joseph riv.).

\section{Fam. Cystignathidae.}

Upper jaw usually toothed, lower nearly always toothless. Diapophyses of the sacral vertebra not or slightly dilated. Terminal phalanges of fingers and toes simple or T-shaped, not claw-shaped.

Omosternum cartilaginous, sometimes rudimentary; sternum usually cartilaginous; it may be more or less calcified and has rarely a bony style. Vertebrae generally procoelous. No ribs. Os coccygis articulating by two condyles.

Distribution: S.-, Central- and southern N.-America; southern Africa; Australia; New-Guinea.

\section{Synopsis of the Genera.}

A. Vomerine teeth in two long transverse series behind

the choanae.

I. Toes slightly webbed. Tympanum perfectly distinct. I. Phancrotis p. IS.

II. Toes free. Tympanum feebly distinct ........ 2. Ranuster p. I9. B. Vomerine teeth very slightly developed, or absent...3. Crinia p. 2 I.

\section{Phanerotis Blgr.}

(Boulenger, Proc. Linn. Soc. N.-S.-Wales, (2) V, r891, p. 593).

Pupil horizontal. Tongue entire and free behind. Upper jaw toothed, lower toothless; vomerine teeth in two long transverse series behind the choanae. Tympanum perfectly distinct. Fingers free, toes with a very slight rudiment of web, the tips slightly swollen. Outer metatarsals united.

Omosternum and sternum cartilaginous. Diapophyses of sacral vertebra slightly dilated. Terminal phalanges simple.

Distribution: New Guinea; Australia.

\section{Phanerotis fletcheri Blgr.}

Phancrotis Fletcheri Boulenger, Proc. Linn. Soc. N.-S.-Wales, (2) V, I S9r, p. 593. 
Phanerotis fletcheri Andersson, Jahrb. Nass. Ver. Naturk., LXVI, I9I3, p. 75. Phanerotis fletcheri Andersson, Svenska Vet. Akad. Handl., LII, Nº.9, 1916, p. Io, pl. I, figs. $3 a-c$.

Habit ranoid. Head as long as broad; snout obtuse; canthus rostralis sharp; loreal region oblique, slightly concave; nostril nearer the end of the snout than the eye; interorbital space as broad as the upper eyelid; tympanum $3 / 4$ the diameter of the eye. Tips of fingers and toes slightly swollen; first finger as long as second; subarticular tubercles strong; a small, blunt inner metatarsal tubercle; the heel reaches the tip of the snout or a little beyond; tibia as long as the vertebral column, foot a little shorter.

Upper parts finely granulate; upper eyelids warty; a small $\wedge$-shaped glandular fold between the shoulders, and an oblique fold from the eye to the middle of the side, passing above the tympanum; lower parts smooth.

Pale brown above, with very small darker spots; hinder side of thighs blackish-brown; a black band borders the postocular fold inferiorly, its lower border sinuous and involving the upper part of the tympanum; a cross-bar between the eyes and the interscapular chevron-fold blackish; limbs with dark cross-bands; lower parts whitish, with the exception of the brown tibia. Length $37 \mathrm{~mm}$.

Habitat: New Guinea (Bogadjim at Stephansort). Australia.

\section{Ranaster Macl.}

(Macleay, Proc. Linn. Soc. N.-S.-Wales, II, I878, p. I35).

Pupil horizontal. Tongue entire and free behind. Upper jaw toothed, lower toothless; vomerine teeth in two long transverse series behind the choanae. Tympanum feebly distinct. Fingers and toes free, the tips not dilated. Outer metatarsals united.

Omosternum cartilaginous; sternum cartilaginous, calcified in the centre. Clavicles present. Diapophyses of sacral vertebra slightly dilated. Terminal phalanges simple, obtuse.

Distribution: New Guinea.

\section{Ranaster convexiusculus Macl.}

Ranaster convexiusculus Macleay, Proc. Linn. Soc. N.-S.-Wales, II, I878, p. I36. Ranaster contexiusculus Boulenger, Cat. Batr. Sal. Brit. Mus., I882, p. 444. 
Phanerotis novac-guineac v. Kampen, Nova Guinea, IX, pt. I, rgog, p. 36, pl. II, figs. $4,4 \alpha$.

Ranaster convexiusculus Fry, Mem. Queensland Mus., II, I9I3, p. 47.

Habit stout. Tongue nearly circular; vomerine teeth in two slightly separated series. Snout rounded, as long as the upper eyelid; canthus rostralis indistinct, rounded; loreal region very oblique, concave; nostril as far from the tip of the snout as from the eye; interorbital space as broad as or a little broader than the upper eyelid; tympanum feebly distinct, half the diameter of the eye, or a little larger. Tips of fingers and toes blunt; first and second finger equal in length, or the first

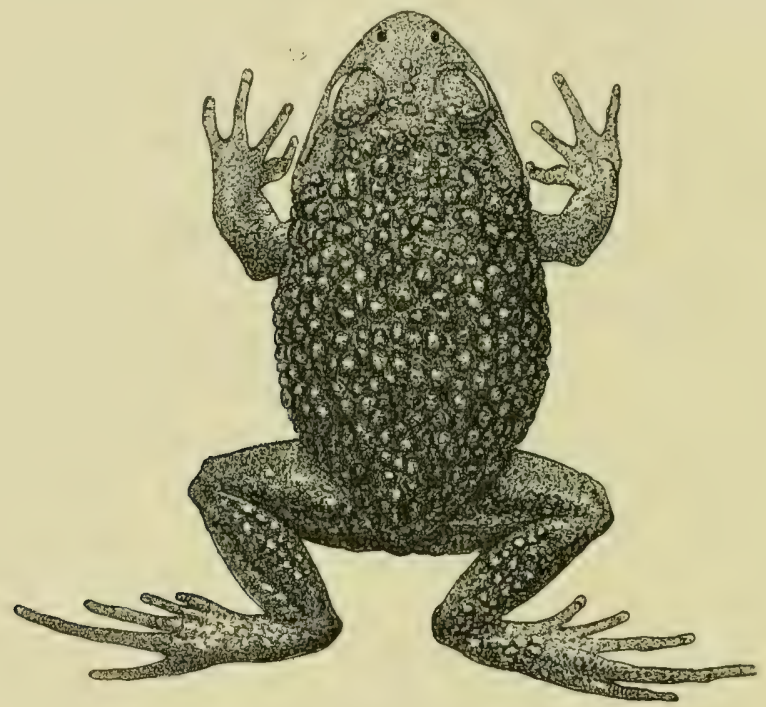

Fig. 3. Ranaster convexinsculus Macl., $X \mathbf{I}$.

slightly shorter; subarticular tubercles small, but very prominent; a strong, oblong inner, no outer metatarsal tubercle; heel reaching the tympanum or the eye; tibia $2 / 5$ the length of head and body.

Back and sides with more or less distinct, smooth, round and oblong warts of different sizes; smaller warts on the upper surface of head and limbs; throat and belly smooth; lower surface of thighs smooth or feebly granular; a longitudinal ridge below the eye and the tympanum.

Brownish black above, or brown with darker spots on head, back and limbs; light brown beneath, usually spotted 
or marbled with darker on throat, breast and limbs; lips with light, vertical streaks. Length $42 \mathrm{mn}$.

Male with a subgular vocal sac.

Habitat: New Guinea (Katow ; Merauke!); Frederik Hendrik isl.!

\section{Crinia Tschudi.}

(Tschudi, Mém. Soc. Sc. nat. Neuchâtel, II, I839, p. 78).

Pupil horizontal. Tongue entire and free behind. Upper jaw toothed, lower toothless; vomerine teeth very slightly developed or absent. Tympanum slightly distinct or hidden, or absent. Fingers and toes free, the tips not dilated. Outer metatarsals united.

Omosternum and sternum cartilaginous. Diapophyses of sacral vertebra slightly dilated. Terminal phalanges simple.

Distribution: New Guinea; Australia.

\section{Crinia signifera Girard.}

Crinia (Ranidella) signifera Girard, Proc. Acad. Philadelphia, VI (1852, I853), 1854 , p. 422 .

Crinia signifera Boulenger, Cat. Batr. Sal. Brit. Mus., I882, p. 265.

Crinia signifera Andersson, Svenska Vet. Akad. Handl., LII, N.4, I9I3, p. I2, pl. I, figs, $1 a-b$.

Crinia signifera Werner, Amphilia, in: Fauna Suidwest-Australiens, herausg. v. Michaelsen und Hartmeyer, IV, Lfg. IO, Jena, I9I4, p. 4 II.

Crinia signifera Roux, Revue Suisse Zool., XXVIII, I920, p. I16.

No vomerine teeth. Snout rounded, as long as the orbit; no canthus rostralis; loreal region oblique, a little concave; nostril as far from the tip of the snout as from the eye; interorbital space as broad as, or broader than the upper eyelid; tympanum hidden. First finger shorter than second; toes fringed; subarticular tubercles distinct; a small, elliptic, inner and a rounded outer metatarsal tubercle; a slight tarsal fold; the heel reaches the shoulder or the temple.

Upper surfaces more or less warty, the warts often confluent into longitudinal lines on the back; lower surfaces granulate.

Dark grey above; two blackish, light bordered spots in the loins; anal region blackish; lips with dark vertical bars; beneath grey, more or less marbled with brown; throat of male blackish; limbs with more or less distinct dark cross-bars. Length $28 \mathrm{~mm}$.

Male with a subgular vocal sac.

Habitat: New Guinea (Merauke). - Australia. 
3. Fam. Hylidae.

Upper jaw toothed, lower usually toothless. Diapophyses of the sacral vertebra dilated. Terminal phalanges of fingers and toes claw-shaped.

Omosternum cartilaginous (rarely ossified); sternum cartilaginous. Vertebrae procoelous. No ribs. Os coccygis articulating by two condyles.

Distribution: cosmopolitan, except the Ethiopian and greatest part of the Indian region. They are abundant in Australia and tropical America, whereas but a few species occur in the Palaearctic and Indian regions; in the western part of the Indo-Australian Archipelago they are absent.

$$
\text { Synopsis of the Genera. }
$$

A. Pupil vertical. ................ Nyctimantis p. 22. B. Pupil horizontal ............... 2. Hyla p. 24 .

\section{Nyctimantis Blgr.}

(Boulenger, Cat. Batr. Sal. Brit. Mus., 1882, p. 421).

Nyctimystes, Stejneger, Proc. Biol. Soc. Washington, XXIX, I916, p. 85.

Pupil vertical. Tongue subcircular, entire, scarcely free behind. Lower jaw toothless; vomerine teeth present. Tympanum distinct. Fingers free, toes webbed, the tips with large disks. Outer metatarsals united.

Omosternum and sternum cartilaginous. Diapophyses of sacral vertebra moderately dilated.

Distribution: S.-America; New Guinea.

$$
\text { Synopsis of the Species. }
$$

A. Tympanum distinct. Fingers webbed at the base.... I. $\Lambda^{\top}$. papua p. 22.

B. Tympanum indistinct. Outer fingers $1 / 3$ webbed..... 2. N. granti p. 23.

\section{Nyctimantis papua Blgr.}

Nyctimantis papua Boulenger, Ann. Mag. Nat. Hist., (6) XIX, I897, p. I2, pl. I, fig. 5 .

Tongue circular, nicked and slightly free behind; vomerine teeth in two short, transverse or slightly oblique series between the large choanae. Head moderate; snout rounded, shorter 
than the orbit; canthus rostralis strong; loreal region concave; interorbital space as broad as the upper eyelid; tympanum distinct, $1 / 3$ to $2 / 5$ the diameter of the eye. Disks of fingers larger than the tympanum; fingers webbed at the base; toes webbed to the disks of the third and fifth and to the penultimate phalanx of the fourth; subarticular tubercles moderate; a very small inner metatarsal tubercle; the heel reaches the tip of the snout or a little beyond.

Skin free from the skull, smooth, or with small warts above, granular beneath; a strong curved fold above the tympanum; heel sometimes with a small conical tubercle.

Grey, olive, or reddish brown above, uniform or marbled with darker, or with large insuliform spots; a light line may run along the canthus rostralis and supraciliary edge; dirty white or brown beneath. From snout to vent $66 \mathrm{~mm}$.

Male with an external subgular vocal sac.

Habitat: New Guinea (Mt. Victoria, Owen Stanley Range; Moroka, $700 \mathrm{~m}$.$) .$

\section{Nyctimantis granti Blgr.}

Nyctimantis Granti Boulenger, Transact. Zool. Soc. London, XX, pt. 5, 19I4, p. 249 , pl. XXVII, fig. 2 .

Tongue circular, nicked and slightly free behind; vomerine teeth in two transverse series between the large choanae. Head moderate, much broader than long; snout rounded, shorter than the orbit; canthus rostralis obtuse; loreal region very oblique, slightly concave; interorbital space as broad as the upper eyelid; tympanum very indistinct, about $1 / 3$ the diameter of the eye. Disks of fingers $2 / 3$ the diameter of the eye; outer fingers $1 / 3$ webbed; toes webbed to the disks of the third and fifth and to the penultimate phalanx of the fourth; subarticular tubercles moderate; a very small inner metatarsal tubercle; the heel reaches the tip of the snout.

Skin free from the skull, smooth above, granular on the belly and under the thighs; a strong curved fold above the tympanum.

Purplish grey above, vermiculate with black; flanks and sides of thighs lilac; lower parts whitish. From snout to vent $100 \mathrm{~mm}$.

Habitat:. New Guinea (Utakwa riv., $900 \mathrm{~m}$.$) .$ 


\section{H y 1 a Laur.}

(Laurenti, Synopsis Rept., Viennae, 1768, p. 32).

Pupil horizontal. Tongue entire or slightly nicked, not or little free behind. Lower jaw toothless; vomerine teeth usually present. Tympanum distinct or hidden. Fingers free or webbed, toes webbed, with disks. Outer metatarsals united or slightly separated.

Omosternum and sternum cartilaginous $\left.{ }^{1}\right)$. Diapophyses of sacral vertebra dilated.

Tadpoles. - Eyes lateral or superior. Spiraculum sinistral. Vent median or dextral. Upper crest of tail usually extending on to the body. Mouth normal, sometimes much enlarged; series of papillae narrowly interrupted in the middle of the upper lip, rarely absent; series of teeth $2 / 3$.

Distribution: the same as the family.

$$
\text { Synopsis of the Species. }
$$

$A$. Fingers webbed.

I. The web reaches the disks of the second and fourth fingers.

I. The heel reaches beyond the tip of the snout.

$a$. No outer metatarsal tubercle.......

b. Outer metatarsal tubercle present....

I. H. rhacophoms p. 28 .

2. H. amboinensis p. 29.

2. The heel does not reach beyond the tip of the snout. Vomerine teeth between the choanae (or absent).

a. Interorbital space twice the width of the upper eyelid, Limbs cross-barred....

b. Interorbital space twice the width of the upper eyelid. Limbs not cross-barred .

c. Interorbital space as broad as the upper eyelid. Limbs not cross-barred .... 5. H. bernstcini p. $3 \mathrm{r}$.

3. The heel does not reach the tip of the snout.

Vomerine teeth behind the level of the

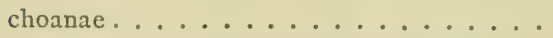

II. The web does not reach the disks of the fingers.

I. No tympanum ............ 7. H. obsoleta p. 32 .

2. Tympanum present, its diameter less than half that of eye.

3. H. papucnsis p. 30 .

4. H. graminea p. 30 .

6. H. cucnemis p. 32 .

I) The omosternum is ossified in the males of $H$. infrafrenata and militaria. 
a. Outer fingers at least $1 / 3$ webbed. Vomerine teeth present.

\%. A dermal ridge along the outer side of the fore-arm...........

p. No dermal ridge along the fore-arm.

Skin smooth above.

t. Outer fingers about $1 / 2$ to $3 / 4$ webbed............. 9. H. rucppelli p. 35 .

††. Outer fingers nearly half webbed. Io. $H$. fallax p. 35.

††. Outer fingers $1 / 3$ webbed.... 38. $H$ angiana p. 59.

$\gamma$. No dermal ridge along the fore-arm.

Upper parts with scattered warts.. 34. H. humeralis p. 56.

b. Outer fingers at least $1 / 3$ webbed. No vomerine teeth.

๔. The heel reaches the tympanum. . II. H. brachypus p. 37 .

f. The heel reaches at least the eye.

†. Tympanum about $1 / 5$ diameter of eye. Toes $3 / 4$ webbed ....... †. Tympanum $1 / 4$ to $1 / 2$ diameter of eye. Toes about $2 / 3$ webbed ... I3. H. atropunctata p. 37.

††. Tympanum not quite $1 / 2$ diameter of eye. Toes ncarly entirely webbed. Canthus rostralis distinct.... I4. H. longicrus p. 38 .

†††. Tympanum $1 / 3$ to $1 / 2$ diameter of eye. Toes nearly entirely webbed. Canthus rostralis rounded..... (10, H. fallax p. 35).

$c$. Outer fingers webbed at the base.

a. Toes narrowly webbed...... I5. H. albolabris p. 39 .

$\beta$. Toes $2 / 3$ webbed. Heel reaching beyond tip of snout.......... 16. H. arfakiana p. 39 .

$\gamma$. Toes $3 / 4$ webbed. Heel reaching tip of snout. ............ I8. H: pratti p. 4 I.

$\delta$. Toes extensively webbed (the web reaching the disks of third and fifth).

Heel reaching beyond tip of snout. 19. H. wollastoni p. 42.

3. Tympanum present, its diameter at least about half that of eye.

a. No vomerine teeth. Outer fingers $1 / 3$ to nearly $1 / 2$ webbed.

«. Coarsely granular above....... (13. H. atropunctata p. 37).

$\beta$. Smooth above.

†. Canthus rostralis distinct.... 20. H. chloronota p. 42.

††. Canthus rostralis rounded..... Io. H. fallax p. 35 . 
b. Vomerine teeth between the choanae, rarely absent. Fingers webbed at the base.

a. $\Lambda$ dark cross-bar between the eyes, 2I. H. juadci p. 43 .

$\beta$. Two white longitudinal streaks pre. sent, at least on the head..... 22. H. bicolor p. 44.

$\gamma$. Three white streaks along the back. 27. II. thesaurensis p. 49.

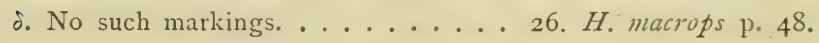

c. Vomerine teeth between the choanae.

Fingers $1 / 3$ to $1 / 2$ webbed.

c. Disks of fingers larger than tympanum, 28. H. lutca p. 50.

. Disks of fingers as large as tympanum. 29. H. solomonis p. 50.

$\gamma$. Disks of fingers smaller than tympanum ............. 30. H. cveretti p. 5 I.

d. Vomerine teeth between the choanae, or absent. Fingers more than $1 / 2$ webbed. (5, H. bernsteini p. $3 \mathrm{I}$ ).

$c$. Vomerine teeth between the posterior borders of the choanae.

«. Upper surface in preserved specimens brown or grey, with or without white markings.

$\uparrow$. Outer fingers webbed at the base. Canthus rostralis angular... 23. H. impura p. 45 .

$\dagger$. Outer fingers webbed at the base.

Canthus rostralis rounded... 24. H. macgregori p. 46.

††. Outer fingers nearly half webbed.

Canthus rostralis rounded.... (IO. H. fallax p. 35).

$\dagger \dagger \dagger$. Outer fingers half webbed. Canthus

rostralis distinct ...... 25. II. genimaculata p. 47 .

$\beta$. Upper surface in preserved specimens

blue or violet (green in life). A white or yellow, below dark-edged streak. along lower jaw.

†. No projecting rudiment of pollex.

Tympanum $3 / 5$ to $4 / 5$ the width

of the eye ........ 3I. H. infrafrenata p. $5 \mathrm{I}$.

††. No projecting rudiment of pollex.

Tympanum as large as the eye 32. $H$. spengeli p. 54.

††. A strong projecting rudiment of pollex........... 33. H. militaria p. 55 .

$\gamma$. Upper surface in preserved specimens

blue or violet. No white streak along

lower jaw.

†. The heel reaches beyond the tip 
of the snout. Outer fingers $2 / 3$

webbed .......... 35. II. aruensis p. 56 .

††. The heel reaches the tip of the snout, or beyond. Fingers $1 / 3$ to $1 / 2$ webbed.......... 36, H. sanguinolenta p. 57 .

$\dagger \uparrow$. The heel reaches the temple or the eye. Fingers $1 / 4$ to $1 / 2$ webbed. $37 . H$. cacrulea p. 58 .

$f$. Vomerine teeth behind the level of the choanae.

«. Fingers $1 / 3$ to $1 / 2$ webbed..... 39. H. congenita p. 60 .

$\beta$. Fingers with a slight rudiment of web (or free)........... 40. H. mublla p. 62 .

$B$. No web between the fingers.

I. Diameter of tympanum less than half that of eye.

i. Vomerine teeth present. Heel reaches beyond tip of snout ............... (16. H. arfakiana p. 39).

2. Vomerine teeth absent. Heel reaches the eye. 17. H. woltcrstorffi p. 40.

11. Diameter of tympanum at least about half that of eye.

I. Snout rounded. Back without longitudinal ridges.

a. Vomerine teeth behind the level of the choanae.

\&. Toes $2 / 3$ or $3 / 4$ webbed....... (40. H. mbella p. 62).

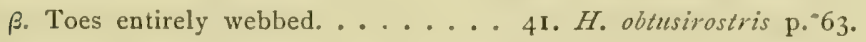

b. Vomerine teeth between the choanae. Toes half webbed ......... 42, H. vagabunda p. 63 .

2. Snout pointed. Back with longitudinal ridges.

Disks very small. .......... 43. H. nasuta p. 64 .

Incertae sedis: 44 . Hyla (i) dorsalis p. 65.

\section{Synopsis of the Tadpoles.}

$A$. Eyes lateral, Mouth of normal size. Lips with papillae.

1. Vent distinctly above the free border of the subcaudal crest.

I. All series of lower labial teeth nearly equal in length. Tail with dark vertical streaks. 22. ? H. bicolor p. 44.

2. Outer series of lower labial teeth shorter than the two other ones. Tail without vertical streaks ............... 3I. H. infrafrenata p. 5 I. 
II. Vent close to the free border of the subcaudal

crest ........................ congenila p. 60.

B. Eyes superior.

I. Nouth of normal size........... 40. H. rubella p. 62 .

II. Mouth very large.

I. Lips without papillae ......... 8. H. montana p. 33 .

2. Papillae present .......... Hy I I spec.? p. 34 .

Incompletely known: 33. $H$. militaria p. 55 .

\section{Hyla rhacophorus v. Kamp.}

Hyla rhacophorus v. Kampen, Nova Guinea, IX, pt. I, I909, p. 32, pl. II, fig. I.

Tongue broadly heart-shaped, free behind; vomerine teeth in two short, oblique series between the posterior borders of the choanae. Head a little broader than long, its width equal to $1 / 3$ the length of head and body; snout rounded, scarcely projecting, as long as the upper eyelid; canthus rostralis angular, curved; loreal region oblique, strongly concave; nostril nearly twice nearer the tip of the snout than the eye; interorbital space as broad as the upper eyelid; tympanum distinct, $2 / 3$ the diameter of the eye. Disks large, smaller than the tympanum, those of toes a little smaller than those of fingers; first finger shorter than second, which is shorter than fourth; fingers strongly webbed, the web reaching the disks at the outer side of the seconr and the inner side of the fourth, nearly reaching the disk at the outer side of the third finger; at the first finger and the inner side of the second and third the penultimate phalanges are free from the web; third and fifth toe of equal length; toes nearly entirely webbed, the web reaching all disks; subarticular tubercles well-developed, the distal one of the fourth finger double; a small, oblong inner, no outer metatarsal tubercle; the heel reaches somewhat beyond the tip of the snout; tibia nearly $2 / 3$ length of head and body.

Upper parts finely granulate, with some scattered small warts; throat, belly and lower surfaces of thighs coarsely granular; some larger warts below the vent (partly arranged in a transverse series) and on the heel; a denticulated ridge along the border of the lower jaw, a more distinct dermal fold along the outer edge of forearm and outer finger and another one along that of tarsus and fifth toe; on the arm and tarsus it is undulated; heel with a triangular dermal appendage; a fold above the tympanum. 
Upper surface bluish violet, yellowish beneath; upper arm and thigh yellowish white, except a small streak along the upper surface; of the same colour are the three inner fingers, the tarsus and the foot, the tympanum and the border of the lips. Length $66 \mathrm{~mm}$.

Habitat: New Guinea (Etna bay!; Setekwa riv.).

\section{Hyla amboinensis Horst.}

Hy'la amboinensis Horst, Notes Leyden Mus., V, r883, p. 239.

Hyla anboinensis Boettger, Ber. Offenb. Ver. f. Naturk, I 892 , p. 156.

Hyla Kampeni Barbour, Bull. Mus. Comp. Zoöl. Harvard Coll., LI, 1908, p. 324. Hyla Kampeni Barbour, Mem. Mus. Comp. Zoöl. Harvard Coll., XLIV, Nº I, I 912 , p. 76 , pl. V, fig. 13.

Tongue slightly nicked and free behind; vomerine teeth in two small groups in the middle between the choanae. Head slightly broader than long; snout rounded, as long as, or a little shorter than the upper eyelid, longer than deep; canthus rostralis indistinct; loreal region oblique, hardly concave; nostril nearer the tip of the snout than the eye; interorbital space as broad as, or broader than the upper eyelid; tympanum distinct, about $1 / 2$ to $2 / 3$ the diameter of the eye. Disks of three outer fingers about as large as or a little smaller than the tympanum, of toes a little smaller; first finger shorter than second, which is shorter than fourth; fingers extensively webbed, the web reaching the disks at the outer side of the second and third, and at the inner side of the fourth finger; first finger included to the disk, or nearly so; third and fifth toe about equal in length; all toes webbed to the disks; subarticular and inner metatarsal tubercles moderate, a small, circular outer metatarsal tubercle; a distinct tarsal fold; the heel reaches beyond the tip of the snout.

Smooth above, with scattered, small tubercles on the back and below the vent; belly and lower surfaces of thighs granular; a fold across the breast; a strong fold above the tympanum; a ridge along outer edge of fore-arm and outer finger, and of tarsus and outer toe; on tarsus and fore-arm it is more or less distinctly broken up into oblong warts.

A bove greyish or brownish, variegated with dark; lower surface yellowish, the throat dotted with dark brown. Length $57 \mathrm{~mm}$.

Male with a subgular vocal sac.

Type specimens in the Leyden Museum examined. The 
specimen of Misool has the tympanum larger and the back more tubercular than those of Ambon.

Habitat: Misoöl!; Ceram!; Ambon!

\section{Hyla papuensis Wern.}

Hyla papucnsis Werner, Zool. Anz., XXIV, 1901, p. 99, IоI.

Tongue elliptical, distinctly nicked and free behind; vomerine teeth in two round groups between the choanae. Head a little broader than long; snout rounded, about once and a half the length of the eye; canthus rostralis curved, rounded; loreal region oblique, concave; nostril twice nearer the tip of the snout than the eye; interorbital space twice as broad as the upper eyelid; tympanum very distinct, its diameter a little larger than half that of eye. Disks of fingers nearly as large as the tympanum; fingers webbed; the web reaches the disks, except at the third finger and the inner side of the second, which is half free; toes entirely webbed; subarticular tubercles well developed; a small inner metatarsal tubercle; the heel reaches the tip of the snout.

Occiput and back indistinctly granular, with small round warts, which on the back are arranged in indistinct longitudinal rows; a denticulated dermal ridge along the outer side of the fore-arm, and a smooth one along that of the fourth finger; a less developed ridge along the outer border of tarsus and fifth toe; a strong fold above the tympanum; throat, belly, lower surface of thighs and surroundings of vent granulate; heel with a small dermal appendage.

Light grey, with a darker, irregular design above; sides whitish, marbled with dark; throat'whitish, with small dark spots; limbs with indistinct, broad transverse bars; webs darkcoloured. Length $58 \mathrm{~mm}$.

Male with a large subgular vocal sac and a brown nuptial excrescence on the first finger.

Habitat: New Guinea (Torricelli mts.).

\section{Hyla graminea Blgr.}

Hyla graminea Boulenger, Ann. Mag. Nat. Hist., (7) XVI, 1905, p. I83.

Tongue heart-shaped, free behind; vomerine teeth in two widely separated, short transverse groups between the very large choanae. Head rather large, much depressed, a little 
broader than long; snout rounded, as long as the orbit; canthus rostralis indistinct; loreal region very oblique, slightly concave; nostril near the end of the snout; interorbital space twice the width of the upper eyelid; tympanum very distinct, $3 / 4$ the diameter of the eye. Disks nearly as large as the tympanum; fingers nearly entirely, toes entirely webbed; subarticular tubercles feeble; heel reaching the tip of the snout.

Skin smooth, finely granulate on the head, coarsely on the belly and under the thighs; deep wrinkles form an areolation on each side of the anterior part of the body; an outer tarsal fold.

Bright green above, yellowish white beneath; hand and arm, tarsus and foot, and upper eyelid with a white edge; arm and thigh colourless, the latter with a narrow green band in the middle. From snout to vent $52 \mathrm{~mm}$.

Habitat: Northern British New Guinea, $275 \mathrm{~m}$.

\section{Hyla bernsteini Horst.}

Hyla bernsteini Horst, Notes Leyden Mus., V, 1883, p. 241.

Hyla mystax v. Kampen, Nova Guinea, V, pt. 1, 1906, p. 173, pl. VI, fig. 6 (head).

Tongue oblong, nicked and little free behind; vomerine teeth in two short series or circular groups between the choanae, or absent. Head as long as broad; snout rounded, vertically truncate, shorter than the upper eyelid, longer than deep; cantheis rostralis distinct, obtuse; loreal region oblique, slightly concave; nostril close to the tip of the snout; interorbital space as broad as the upper eyelid; tympanum distinct, $1 / 2$ the diameter of the eye. Disks of outer fingers nearly as large, or as large as the tympanum, of toes smaller; first finger shorter than second, which is shorter than fourth; fingers broadly webbed, the web usually reaching the second and fourth, and nearly the outer border of third disk, first finger nearly free; third and fifth toe of equal length; toes nearly entirely webbed, the web reaching second, third and fifth disk and nearly fourth; subarticular and inner metatarsal tubercles moderate, no outer metatarsal tubercle; the heel reaches the nostril or the tip of the snout.

Skin smooth or feebly granulate above; belly and lower surface of thighs strongly granulate; a feeble ridge along the outer edge of fore-arm, hand and fourth finger, and another along that of tarsus and fifth toe; no fold across the chest; an 
indistinct fold above the tympanum; sometimes a transverse dermal ridge below the vent.

Colour (in spirit) blue or bluish above, immaculate or dotted with dark blue; posterior surface of thigh and inner surface of tibia blackish; a white streak along the upper jaw from below the eye to the angle of the mouth or the shoulder; the dermal ridges white; yellowish beneath. Length $37 \mathrm{~mm}$.

Type specimen (from Gebe isl.) in the Leiden Museum examined.

Habitat: Gebe isl.!; Salawati; New Guinea (Moaif riv.!).

\section{Hyla eucnemis Lönnb.}

Hylu eucnemis Lönnberg, Ann. Mag. Nat. Hist., (7) VI, I900, p. 579.

Tongue broadly heart-shaped, nicked and free behind; vomerine teeth in two large and confluent groups, behind the level of the choanae. Head large, about as broad as long; snout subtriangular, truncate, longer than the orbit; canthus rostralis very distinct, curved; loreal region concave; interorbital space broader than the upper eyelid; tympanum distinct, about $2 / 3$ the diameter of the eye. Disks of fingers about as large as the tympanum; the three outer fingers extensively webbed, the web reaching the disks of the second and fourth; toes entirely webbed; subarticular tubercles well developed; the heel reaches just beyond the eye.

Upper surfaces very minutely, belly and lower surfaces of thighs coarsely granulate; throat covered with scattered warts; a series of similar warts along the margin of the lower jaw; a glandular fold above the tympanum; a well-developed denticulated fringe along the outer side of the fore-arm and the outer finger; a similar fringe along the outer side of the tarsus and the outer toe; heel with a triangular dermal appendage; some smaller dermal flaps near the vent.

Colour (in spirit) dark plum above, uniform, with the exception of some very indistinct cross-bands on the hind legs; light below. From snout to vent $67 \mathrm{~mm}$.

Habitat: New Guinea (Sattelberg, $\pm 800 \mathrm{~m}$. .).

\section{Hyla obsoleta Lönnb.}

Hyla obsolcta Lönnberg, Ann. Mag. Nat. Hist., (7) VI, I900, p. jSo.

Tongue nicked and free behind; vomerine teeth in two small groups between the choanae. Snout subtriangular, trun- 
cate, longer than the diameter of the eye; canthus rostralis distinct; loreal region concave; interorbital space broader than the upper eyelid; no tympanum. Disks about half the diameter of the eye; fingers webbed at the base, toes nearly entirely webbed; the heel reaches beyond the tip of the snout.

Minutely granulate above; a fold from the eye to the axilla, another across the throat; belly and lower side of thighs granulate; a slight dermal fold with a row of tubercles along the outer side of the fore-arm; a less pronounced series of tubercles along the outer side of the tarsus; heel with a short dermal appendage. From snout to vent $34 \mathrm{~mm}$.

Dark brown above, light below.

Perhaps the young of $H$. montana.

Habitat: New Guinea (Simbang, $50 \mathrm{~m}$.).

\section{Hyla montana Ptrs. \& Dor.}

Hyla (Litoria) montana Peters e Doria, Ann. Mus. Genova, XIII, 1878, p. 423, pl. VII, fig. I.

Hyla montana Boulenger, Cat. Batr. Sal. Brit. Mus, 1882, p. 385.

Hyla papua v. Kampen, Nova Guinea, IX, pt. I, Igog, p. 33, pl. II, fig. 2.

? Hyla pulchra Wandolleck, Abh. Zool. Mus. Dresden, XIII, N0. 6, I9II, p. 12, figs. $50-59$.

Hyla papua v. Kampen, Nova Guinea, IX, pt. 3, I9I3, p. 455, pl. XI, fig. I (tadpole).

Tongue subcircular, nicked and slightly free behind; vomerine teeth in two short transverse series between the large choanae. Head broader than long; snout rounded, vertically truncate, as long as the upper eyelid, longer than deep; canthus rostralis angular, curved; loreal region very oblique, concave; nostril close to the tip of the snout; interorbital space broader than the upper eyelid (as broad as the upper eyelid in the young); tympanum distinct, about $2 / 5$ diameter of eye. Disks of fingers and toes moderate, of second to fourth finger larger, of first finger smaller than tympanum, of toes smaller than those of fingers; first finger shorter than second, which is shorter than fourth; web between the first and second finger only at the base, the other fingers $1 / 3$ to $1 / 2$ webbed; third and fifth toes of equal length; toes webbed to the disks, the two distal phalanges of the fourth toe being included only by a narrow fold; subarticular tubercles of fingers and toes well developed, the distal ones heart-shaped; an oblong inner, and INDO-AUSTRALIAN AMPHIBIA. 
a very small, roundish outer metatarsal tubercle; the heel reaches beyond tip of snout; tibia $2 / 3$ length of head and body.

Skin smooth above, granular on the head; a fold above the tympanum; belly and lower surface of thighs granulate; a dermal ridge along the outer side of the fore-arm and the fourth finger, and along that of the tarsus and the fifth toe; some large granules below the vent; a small triangular dermal appendage at the hecl sometimes present.

Olive-brown (in life yellowish green) above; yellow beneath, sometimes dotted with brown; the inner fingers and the inner toes orange yellow; the dermal ridges whitish; limbs with indistinct dark cross-bars. Length $75 \mathrm{~mm}$.

Male with an internal vocal sac.

Tadpole. - Length of body nearly once and a half its width; tail but little longer than the body, about twice and a half as long as deep, and but little deeper than its muscular portion at the base. Nostril about twice nearer the eye than the tip of the snout; eyes superior, nearer the spiraculum than the tip of the snout; distance between them a little greater than that between the nostrils; spiraculum sinistral, directed upwards and backwards, visible from above and from below, much nearer the vent than the tip of the snout; vent median. Tail with rounded tip; the crests not extending on to the body.

Mouth ventral, very large, nearly as broad and almost half as long as the body; lips without papillae; upper jaw with two short black streaks, lower with a single one; series of teeth $2 / 3$, all series about equal in length; in the lower lip they are placed close to the mouth, the largest part of the lip being toothless.

Brown above, colourless below; tail brown, with three colourless, dark-bordered cross-bars, the posterior one including the tip of the tail. Length $29 \mathrm{~mm}$.

Habitat: New Guinea (Hatam, Arfak mts.; Pomora riv., $\pm 760 \mathrm{~m}$. !; Torricelli mts.?; Gerekanumu; Astrolabe Range; Sattelberg; Lorentz riv.!; Van der Sande riv.!; Went mts., I050 m.!; Utakwa riv.; Setekwa riv.).

Hyla spec.?

Hyla sp., v. Kampen, Zool. Jahrb., Syst., XXXVII, 1914, p. 370.

Tadpole. - Differing from that of H. montana in the following points: 
Tail somewhat longer. Mouth a little shorter, bordered by a series of short papillae; an other series of very short and broad papillae on each lip around the series of teeth; both jaws with two black streaks. Tail without light cross-bars.

Habitat: New Guinea (Bougainville mts., $\pm 500 \mathrm{~m}$. !).

\section{Hyla rueppelli Bttg.}

Hyla rucppelli Boettger, Zool. Anz., XVIII, 1895, p. I37.

Hyla rueppolli Boettger, Abh. Senckenb. Naturf. Ges., XXV, I90r, p. 373, pl.

XVI, figs. $12-12 c$.

Tongue oval, slightly nicked and little free behind; vomerine teeth in two small, roundish groups on a level with the posterior borders of the choanae. Snout rounded, truncate, as long as the orbit; canthus rostralis rounded; loreal region oblique, slightly concave; nostril close to the tip of the snout; interorbital space much broader than the upper eyelid; tympanum distinct, about $1 / 3$ the diameter of the eye. Disks of fingers and toes as large as or somewhat larger than the tympanum; three outer fingers about $1 / 2$ to $3 / 4$ webbed; web between the two inner fingers only at the base; toes nearly entirely webbed; subarticular tubercles feeble; the heel reaches the tip of the snout or a little beyond.

Skin smooth above; a strong fold from the eye to the shoulder; belly and lower surface of thighs strongly granulate; heel often with an indistinct light-coloured roundish tubercle.

Upper parts in life yellow above, sometimes powdered with blackish; in spirit yellowish, greyish or blackish brown, uniform or spotted and marbled with lighter, sometimes light grey with two indistinct, darker, rhombic spots on head and back; usually an indistinct lighter spot on the upper lip, or the whole upper lip yellowish, powdered and spotted with blackish; greyish white beneath. Length $48 \mathrm{~mm}$.

Male with an internal subgular vocal sac and during the breading season a copulatory excrescence on the outer side of the first finger.

Habitat: Halmahera.

IO. Hyla fallax Blgr.

? Hyperolines pygmaeus Meyer, Monatsber. Akad. Berlin, I874, p. I32.

Hylclla boulengeri v. Méhely, Termész. Füzetek, XX, I897, p. 4I4, pl.X, fig. S

(non: Scytopis boulengeri Cope). 
IIyla fallax Boulenger, Proc. Zool, Soc. London, 1898, p. 482, pl. XXXIX, fig. 4. IHyla boulengeri v. Kampen, Nova Guinea, V, pt. I, I906, p. I75.

Hyla boulengeri v. Kampen, Zool. Jahrb., Syst., XXXVII, I9I4, p. 367.

Iylla fallax Boulenger, Transact. Zool. Soc. London, XX, pt. 5, 1914, p. 248.

Tongue subcircular, entire or slightly nicked and little free behind; vomerine teeth in two small, nearly circular groups on a level with the posterior borders of the choanae, absent in the young. Head broader than long; snout rounded, vertically truncate, as long as the eye, longer than deep; canthus rostralis rounded; loreal region very oblique, concave; nostril

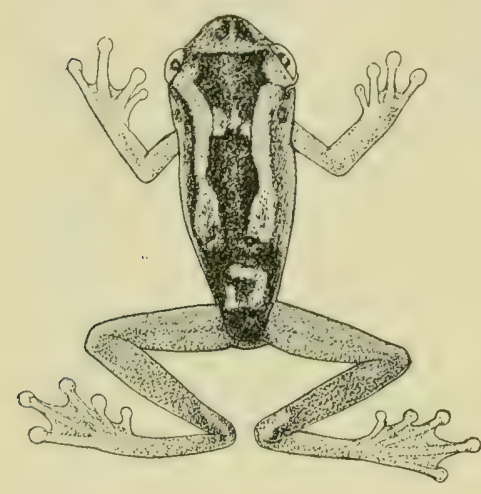

Fig. 4. Hy'la fallax Blgr., X $\mathbf{I}$. nearer tip of snout than eye; interorbital space broader than the upper eyelid; tympanum distinct, $1 / 3$ to $1 / 2$ the diameter of the eye. Disks of second to fourth finger about as large as the tympanum, of first finger and of toes a little smaller; first finger shorter than second, which is shorter than fourth; outer fingers almost half webbed, the web reaching the penultimate subarticular tubercles; third and fifth toe equal in length; toes nearly entirely webbed, the web reaching the disks of third and fifth one; subarticular tubercles and inner metatarsal tubercle feeble, no outer metatarsal tubercle; the heel reaches between the eye and the tip of the snout or to the tip of the snout; tibia half length of head and body, or a little more.

Skin smooth above and on the throat, granular on the belly.

Yellowish-brown above, whitish beneath, lower surface of thighs lemon yellow. Young specimens are purplish-brown above, with large white spots on the head and an often more or less discontinuous, white band on each side of the back; lower surfaces white or yeilowish brown; limbs brownish, with white dots or transverse bars. Length $36 \mathrm{~mm}$.

Male with a subgular vocal sac.

Perhaps identical with $H$. rueppelli.

Habitat: New Guinea (Jamur lake!; Mamberamo riv.!; Van Rees mts.!; Humboldt bay!; Timena riv.!; Friedrich Wilhelmshafen ; Katow ; Digul riv.!; Lorentz riv. !; Setekwa riv.); Jobi isl.? 


\section{I. Hyla brachypus (Wern.).}

Hylella brachypus Werner, Zool. Anz, XXI, 1898, p. 554.

Hylella brachypus Vogt, Sitzungsb. Ges. naturf. Fr., Berlin, 1911, 1. 427.

Tongue oblong, entire; no vomerine teeth. Snout as long as the orbit; canthus rostralis rounded, but distinct; lorea! region nearly vertical; nostril close to the tip of the snout; interorbital space once and a half to almost twice the width of the upper eyelid; tympanum not very distinct, $1 / 3$ the diameter of the eye. Disks larger than the tympanum; fingers $1 / 3$, toes $2 / 3$ webbed; the heel reaches the posterior border of the tympanum.

Smooth, only the belly granulate.

Brown above; grey or white below, the throat sometimes finely mottled; in life the upper parts are blackish brown or olive green, the lower parts greenish yellow. Length $22 \mathrm{~mm}$. Habitat: New Guinea (Sattelberg); Bismarck arch.

\section{I2. Hyla ouwensi Barb.}

Hyla ouwensii Barbour, Bull. Mus. Comp. Zoöl. Harvard Coll., LI, 1908, p. 325. Hyla ouzerzsii Barbour, Mem. Mus. Comp. Zoöl. Harvard Coll., XLIV, I912, p. $77, \mathrm{pl}$. VII, fig. 25 .

No vomerine teeth. Head short; loreal region rather concave; tympanum about $1 / 5$ the diameter of the eye. Fingers $3 / 3$, toes $3 / 4$ webbed; the heel reaches far beyond the tip of the snout.

Skin of back rough; belly with very many small tubercles, largest and most abundant about the anal region.

Upper parts greyish, vermiculated and blotched with blue (green in life); throat white, belly and lower surface of hind limbs yellowish. Length $\pm 38 \mathrm{~mm}$.

Probably based on young individuals, and hardly distinguishable from $H$. atropunctata.

Habitat: Jobi isl.

\section{Hyla atropunctata nomen novum ${ }^{1}$ ).}

Hyperolius nigropunctatzs Meyer, Monatsber. Akad. Berlin, 1874 , p. I39. Hylella nigropunctata Boulenger, Cat. Batr. Sal. Brit. Mus., I882, p. 42 I.

? Hylella solomonis Sternfeld, Abh. Senckenb. Naturf. Ges., XXXVI, 19I8, p. 436, pl. XXXI, fig. Io.

I) Hyla nigropunctata is preoccupied (Boulenger, Cat. Batr. Sal. Brit. Mus., I882, p. 366). 
Tongue slightly notched behind; no vomerine teeth. Head as long as broad; snout rounded, as long as the upper eyelid, not much longer than deep; canthus rostralis obtuse, but distinct; loreal region slightly oblique, concave; nostril a little nearer tip of snout than eye; interorbital space broader than the upper eyelid; tympanum distinct, $1 / 4$ to $1 / 2$ the diameter of the eye. Disks of three outer fingers as large as the tympanum, those of first finger and of toes smaller; first finger shorter than second, which is shorter than fourth; outer fingers almost half webbed, first finger nearly free; third and fifth toe equal in length; toes about $2 / 3$ webbed, two phalanges of fourth and one phalanx of third and fifth toe being free; subarticular tubercles distinct, single; no outer metatarsal tubercle; the heel reaches the tip of the snout or beyond; tibia more than half the length of head and body.

Coarsely granular above; an indistinct fold above the tympanum; belly and lower surface of thighs granulate.

Bluish violet, dotted with blackish, above; upper arm and inner fingers and toes colourless; hind limbs with black crossbars or transverse series of blackish dots; colourless beneath, sides of throat sometimes blackish. Length $27 \mathrm{~mm}$.

The specimens from New Guinea and Jobi may be young individuals of $H$. infrafrenata, those from the Solomon islands perhaps of $H$. militaria.

Habitat: New Guinea (Sattelberg?; Van der Sande riv.!); Jobi; Solomon islands?

\section{I4. Hyla longicrus (Blgr.).}

Hy'lella longicrus Boulenger, Ann. Mag. Nat. Hist., (8) VIII, I9I I, p. 56.

Tongue subcircular, slightly nicked; no vomerine teeth. Head as broad as long; snout rounded, scarcely prominent, shorter than the orbit; canthus rostralis distinct; loreal region oblique, concave; interorbital space broader than the upper eyelid; tympanum distinct, not quite half the diameter of the eye. Disks of the fingers as large as the tympanum; outer fingers half, toes nearly entirely webbed; subarticular tubercles very feeble; the heel reaches far beyond the tip of the snout; tibia $3 / 5$ the length of head and body.

Smooth or finely areolate above; belly and base of lower surface of thighs granulate; throat smooth; no fold across the chest. 
Green above; sides, upper surface of thighs, and hands and feet colourless, with green dots or reticulation; a white band from below the eye to the angle of the mouth; throat and belly white. From snout to vent $33 \mathrm{~mm}$.

Hardly distinguishable from $H$. atropunctata.

Habitat: New Guinea (Wendesi; Fakfak).

\section{I5. Hyla albolabris Wand.}

Hyla albolabris Wandolleck, Abh. Zool. Mus. Dresden, XIII, No. 6, I9II, p. I2, figs. $60-82$.

Vomerine teeth in two roundish groups between the choanae. Snout somewhat produced; the distance from the eye to the nostril a little smaller than the diameter of the eye; canthus rostralis rounded; loreal region concave; nostril nearer tip of snout than eye; interorbital space as broad as the diameter of the eye; tympanum distinct, $1 / 3$ the width of the eye. Fingers and toes with disks; fingers webbed at the base, toes narrowly webbed; limbs very long.

Belly and part of the lower surface of the hind limbs granular; a fold above the tympanum.

Dark blue above, marbled with lighter; beneath light yellowish, with brownish spots; young individuals uniform dark blue above, yellowish white below; upper lip and edge of the mouth yellowish white. Length $4 \mathrm{~cm}$.

Insufficiently described

Habitat: New Guinea (Eitape).

\section{Hyla arfakiana Ptrs. \& Dor.}

Hyla arfakiana Peters e Doria, Ann. Mus. Genova, XIII, 1878, p. 42I, pl. VI, fig. 2. Hyla arfakiana Boulenger, Cat. Batr. Sal. Brit. Mus., I882, p. 4 Io. Hyla arfakiana v. Kampen, Nova Guinea, JX, pt. 3, I913, p. 456.

Tongue suboval, nicked and free behind; vomerine teeth in two short oblique series between the choanae. Head as long as broad or a little broader; snout rounded, vertically truncate, or scarcely prominent, as long as, or longer than the upper eyelid and longer than deep; canthus rostralis angular, straight; loreal region feebly oblique, concave; nostril as far from tip of snout as from the eye, or nearer the first; interorbital space as broad as or broader than the upper eyelid; tympanum little distinct, $1 / 4$ to $1 / 3$ the diameter of the eye. Disks of 
second to fourth finger large, of third finger at least half the diameter of the eye, of first finger smaller; disks of toes a little smaller than those of fingers; first finger shorter than second, which is shorter than fourth; fingers free, or the two or three outer ones webbed at the base; third and fifth toe of equal length; toes $2 / 3$ webbed, the first one nearly entirely free; subarticular tubercles small, single, or the distal ones of the three outer fingers double; an oblong inner and sometimes a very feeble outer metatarsal tubercle; the heel reaches beyond the tip of the snout; tibia $2 / 3$ length of head and body, or a little shorter.

Skin smooth, or finely granulate or with a few scattered warts above; belly and lower surface of thighs, sometimes throat and breast also, granulate; a few warts below the vent; heel with or without a short triangular dermal appendage; usually a dermal ridge or a row of small tubercles along the outer side of the fore-arm and the fourth finger, and along that of foot and fifth toe; a fold above the tympanum.

Colour very variable; upper parts blue, reddish brown or blackish, often with small whitish or rufous dots or a few dark spots or a large dark hourglass-shaped spot on the back, commencing between the eyes; upper surface of snout sometimes light-coloured; upper lip sometimes with a white border; loreal region, and sometimes the side of the body, dark, or a blackish streak beneath canthus rostralis and along temporal region; posterior surface of thighs usually purplish brown; the ridges along the outer sides of the extremities light-coloured; beneath brownish or yellowish, mottled with greyish or dark. Length $70 \mathrm{~mm}$.

Male with a subgular vocal sac.

Habitat: New Guinea (Hatam, Arfak mts., \pm I900 m.!; near Idenburg riv., \pm 1450 m.!; Pomora riv., IO0O-I400 m.!; Torricelli mts.; Fife bay; Moroka, $700 \mathrm{~m}$.; Snow mts., I000-2500 m.!).

\section{I7. Hyla wolterstorffi (Wern.).}

Hylella wolterstorffi Werner, Verh. zool.-bot. Ges. Wien, LI, I90I, p. 6I3.

Tongue oblong, feebly nicked behind; no vomerine teeth. Snout rounded, somewhat longer than the eye; canthus rostralis distinct, straight; loreal region rather steep, flat; nostril 
near the tip of the snout; interorbital space twice the width of the upper eyelid; tympanum not very distinct, about $1 / 5$ the diameter of the eye. Disks of fingers larger than the diameter of the tympanum, of toes a little smaller than those of fingers; first finger shorter than second; fingers free, toes about ${ }^{3} / 4$ webbed; the heel reaches the posterior border of the eye.

Skin of upper parts smooth; throat, belly and lower surface of thighs granulate.

Brownish white above; a dark brown streak from the eye to above the tympanum; anterior part of head to between the eyes light-coloured, occiput dark brown; limbs indistinctly spotted with brown; lower parts white, marbled with light brown. Length $23 \mathrm{~mm}$.

Perhaps the young of $H$. arfakiana.

Ha bitat: N.E.-New Guinea.

\section{I8. Hyla pratti Blgr.}

Hyla pratti Boulenger, Ann. Mag. Nat. Hist., (8) VIII, I9II, p. 55.

Tongue subcircular, nicked behind; vomerine teeth in two small groups or oblique series between the choanae. Head as long as broad; snout rounded, scarcely prominent, hardly as long as the upper eyelid, longer than deep; canthus rostralis distinct; loreal region oblique, concave; nostril equally distant from the eye and the tip of the snout; interorbital space as broad as the upper eyelid; tympanum distinct, not quite half the diameter of the eye. Disks of second to fourth finger as large as or larger than the tympanum, of first finger and of toes smaller than those of outer fingers; first finger shorter than second, which is shorter than fourth; three outer fingers distinctly webbed at the base, first free; third toe as long as fifth; toes $3 / 4$ webbed; subarticular tubercles small, single; an oblong inner, no outer metatarsal tubercle; no tarsal fold; the heel reaches the tip of the snout; tibia a little more than half the length of head and body.

Smooth or with more or less distinct small flat warts above, belly and lower surface of thighs granulate; a series of small tubercles along outer border of fore-arm and fifth finger may be present; a fold above the tympanum.

Bluish grey above in spirit (green in life?), uniform or with small irregular black spots, or with a large, dark, hourglassshaped spot, commencing between the eyes; whitish beneath, 
throat sometimes speckled with greyish. From snout to vent $50 \mathrm{~mm}$.

Male with an external vocal sac and brown nuptial rugosities on the inner finger.

I doubt if this species may be separated from H.arfakiana.

Habitat: New Guinea (Hatam!; Arfak mts., 2400 m.; Wendesi).

\section{Hyla wollastoni Blgr.}

Hyla Wollastoni Boulenger, Transact. Zool. Soc. London, XX, pt. 5, I914 p. 248 , pl. XXVII, fig. I.

Tongue oval, free and feebly notched behind; vomerine teeth in two oblique groups between the choanae. Head slightly broader than long; snout rounded, as long as the eye; canthus rostralis sharp; loreal region not very oblique, concave; nostril nearer the tip of the snout than the eye; interorbital space nearly as broad as the upper eyelid; tympanum distinct, $2 / 5$ the diameter of the eye. Disks of fingers as large as the tympanum, of toes a little smaller; fingers with a rudiment of web; toes extensively webbed, the web reaching the disks of third and fifth, two phalanges of fourth toe free; no tarsal fold; heel reaching beyond the tip of the snout; tibia as long as the distance from occiput to vent.

Smooth above, granular on the sides and beneath; a strong, straight glandular fold from behind the eye to above the shoulder; a subconical tubercle on the upper eyelid and others around the vent; a spur-like tubercle on the heel.

Green above, with black spots forming an hourglass-shaped marking from between the eyes to the sacrum; a fine whitish streak, edged with black beneath, from the tip of the snout along the canthus rostralis to the eye and along the fold behind the eye; lower parts yellowish white, with scattered small brown spots. From snout to vent $46 \mathrm{~mm}$.

Male with an external gular vocal sac.

Nearly related to, if not identical with $H$. arfakiana.

Habitat: New Guinea (Utakwa riv., $640 \mathrm{~m}$.).

\section{Hyla chloronota (Blgr.).}

Hylella chloronota Boulenger, Ann. Mag. Nat. Hist., (8) VIII, I9II, p. 55.

Tongue oval, slightly nicked; no vomerine teeth. Head as broad as long; snout rounded, scarcely prominent, as long as 
the orbit; canthus rostralis distinct; loreal region nearly vertical; interorbital space broader than the upper eyelid; tympanum distinct, about half the diameter of the eye. Disks of fingers as large as the tympanum; outer fingers $1 / 3$ webbed; toes nearly entirely webbed; subarticular tubercles moderate; the heel reaches the tip of the snout; tibia not quite half the length of head and body.

Skin smooth above; throat, belly and base of lower surface of thighs very coarsely granulate; no fold across the chest.

Green above, white beneath, the green colour forming a narrow stripe along the upper surface of the thighs. From snout to vent $27 \mathrm{~mm}$.

Male with an internal vocal sac and brown nuptial rugosities on the inner finger.

Habitat: New Guinea (Arfak mts., 2400 m.; Utakwa riv., $760 \mathrm{~m}$.$) .$

\section{I. Hyla jeudei Wern.}

Hyla Geudii Werner, Zool. Anz., XXIV, I90I, p. 99.

Tongue feebly nicked behind; vomerine teeth in two round groups close to each other between the choanae. Head a little broader than long; snout rounded, once and a half as long as the diameter of the eye; canthus rostralis rounded; loreal region oblique, concave; nostril nearer the tip of the snout than the eye; interorbital space twice the width of the upper eyelid; tympanum distinct, $2 / 3$ the diameter of the eye. Disks of fingers half the diameter of the tympanum; first finger shorter than second; fingers webbed at the base; toes webbed, the two distal phalanges and part of the preceding phalanx of the fourth toe are free, of the other toes only the terminal and part of the penultimate phalanx free from web; subarticular tubercles distinct; a small, elliptic, inner and a still smaller, indistinct outer metatarsal tubercle; the heel reaches the centre of the eye.

Skin indistinctly warty above; belly granulate; a strong - transverse fold across the breast.

Greyish violet above, indistinctly dark spotted and marbled; a dark cross-bar between the eyes and a pair of longitudinal spots in the scapular region; thighs whitish, dark marbled; dirty white beneath. Length $33 \mathrm{~mm}$.

Habitat: N.E.-New Guinea. 


\section{Hyla bicolor (Gray).}

Eucnemis bicolor Gray, Zool. miscell., London, $183 \mathbf{1}$, p. 5 .

Hylomantis fallax Peters, Monatsber. Akad. Berlin, 18So, p. 224, fig. 4.

Hylella bicolor Boulenger, Cat. Batr. Sal. Brit. Mus., 1882, p. $42 \mathbf{1}$.

Hyla bicolor v. Kampen, Nova Guinea, V, pt. I, I906, p. I73, pl. VI, fig 7 (tadpole).

Tongue suboval, slightly nicked; vomerine teeth in two small groups between the choanae, or absent. Head as long as broad; snout projecting, as long as the upper eyelid, much longer than deep; canthus rostralis strong; loreal region nearly vertical, concave; nostril nearer the tip of the snout than the eye; interorbital space broader than the upper eyelid; tympanum distinct, about half the diameter of the eye. Disks of fingers and toes smaller than tympanum; first finger shorter than second, which is shorter than fourth; fingers webbed at the base, toes nearly entirely webbed; subarticular tubercles moderate; inner metatarsal tubercle elliptic, the outer circular, very small or absent; the heel reaches the tip of the snout, or not quite so far; tibia $3 / 5$ length of head and body.

Skin smooth, belly and lower surface of thighs granulate; a more or less distinct fold across the chest.

Bluish above, immaculate or dotted with blackish; a blackish streak on canthus rostralis and temporal region; a white streak from below the eye to the shoulder, sometimes continued along the side of the body; beneath whitish, immaculate. Young individuals probably purplish brown, with a white longitudinal streak at each side from the nostril along the upper eyelid to the sacral region. Length $33 \mathrm{~mm}$.

Male with an external subgular vocal sac, and in the breeding season with a triangular, brown copulatory excrescence on the first finger.

Tadpole. - The following tadpoles probably belong to this species:

Length of body about once and a half its width; tail more than once and a half as long as body, twice as long as deep. Nostril nearer the tip of the snout than the eye; eyes lateral, in the middle between tip of snout and spiraculum, or nearer the former; the distance between them $2 \frac{1}{2}$ to 3 times that between the nostrils and twice the width of the mouth; spiraculum sinistral, not visible from above, nearer the origin of the hind limbs than the tip of the snout; vent dextral, above the lower border of the subcaudal crest of the tail. Tail 
acutely pointed, crests high, convex, equally deep, the upper one extending to above the spiraculum.

Mouth ventral; lips bordered with papillae, which are absent in the middle of the upper lip; jaws narrowly edged with black; series of teeth $\mathrm{I}^{1} \mathrm{I} / 3$, those of lower lip about equal in length.

Greyish white; back, throat and base of tail darkly marbled; tail further yellowish, with a few (usually 4 or 5 ) broad, black vertical streaks; a dark streak, bordered above and below by a white one, from eye to tip of snout. Length $34 \mathrm{~mm}$.

It is not certain, if these tadpoles, found in a small swamp near the lake Sentani, really belong to $H$. bicolor.

Habitat: Aru islands; New Guinea (Idenburg riv.!; Moaif riv.!; Humboldt bay?!; Sentani lake!; Merauke!). - Australia.

\section{Hyla impura Ptrs. \& Dor.}

Hyla impura Peters e Doria, Ann. Mus. Genova, XIII, 1878, p. 426, pl. VII, fig. 2. Hyla impura Boulenger, Cat. Batr. Sal. Brit. Mus., 1882, p. 409.

Hyla impura v, Méhely, Termész. Füzetek, XXI, I898, p. I76.

Hyla impura v. Kampen, Zool. Jahrb., Syst., XXXVII, I9I4, p. 368.

Tongue suboval or subcircular, nicked and free behind; vomerine teeth in two transverse or slightly oblique groups between the posterior borders of the choanae. Head as long as broad; snout rounded, or somewhat pointed, as long as the upper eyelid, longer than deep; canthus rostralis angular; loreal region very oblique, concave; nostril nearer the end of the snout than the eye; interorbital space as broad as, or hardly broader than the upper eyelid; tympanum distinct, $1 / 2$ to $3 / 5$ the diameter of the eye. Disks of three outer fingers half to nearly as large as the tympanum, of first finger much smaller; disks of toes smaller than or as large as those of fingers; first finger as long as second, or a little shorter; second finger shorter than fourth; fingers webbed at the base, only a slight rudiment of web between first and second ones; third and fifth toe equal in length; toes nearly entirely webbed, the web reaching the disks of the third and fifth one, or nearly so; two phalanges of fourth toe free; subarticular tubercles and the oval inner metatarsal tubercle feebly developed, a very feeble outer metatarsal tubercle; the heel reaches between eye and tip of snout, or a little beyond; tibia half the length of head and body, or a little longer. 
Skin smooth above; a feeble fold above the tympanum; a series of tubercles along the outer border of the fore-arm, continued as a feeble ridge along the outer finger, and a feeble ridge along the outer border of foot and fifth toe; belly and lower surface of thighs granulate; often a fold across the chest.

Olive-green, grey, brown or yellow (in spirit brown or grey) above, usually marbled with darker; posterior surface of thighs often dark brown or dark grey, usually white-punctate; tubercles along fore.arm white; around the vent sometimes a black spot, edged with a white line above; white or yellowish beneath. Young specimens with white (in life probably yellow) markings, viz. three longitudinal bands on the back, a streak from below the eye to the shoulder; fine dots on the fore-arm, in addition to the series of white granules along its outer border; a transverse streak beneath the vent and some fine dots on the thighs. Length $55 \mathrm{~mm}$.

Male with an internal vocal sac and in the breeding season with a longish black rugosity on the inner side of the first finger and sometimes some black longitudinal streaks and spots on the back.

Habitat: New Guinea (Mamberamo riv.!; Idenburg riv.!; Sermowai riv.!; Tor riv.!; Moaif riv.!; Humboldt bay! '); Kaiserin Augusta riv.!; Erima, Astrolabe bay; Sattelberg; between Sissano and Sera; Nikura; Merauke?!); Yule isl.

\section{Hyla macgregori Dgl.-Og.}

Hy'la macgresori Douglas Ogilby, Rec. Australian Mus. Sydney, I, IS9o, p. 100. Hyla thesaurcnsis v. Méhely, Termész. Füzetek, XX, I897, p. 4I4, pl. X, fig. 7. Hyla thesaurensis (partim), v. Kampen, Zool. Jahrb., Syst., XXXVII, 1914, p. 368. Hyla macgregori Fry, Proc. Roy. Soc. Queensland, XXVII, I9I5, p. 76, pl. II and textfig. 3 .

Tongue oval or subcircular, entire or slightly nicked and little free behind; vomerine teeth in two slightly oblique groups between the posterior borders of the choanae. Head as long as broad; snout rounded, about as long as the orbit; canthus rostralis rounded; loreal region oblique, concave; nostril nearer the tip of the snout than the eye; interorbital space a little broader than the upper eyelid; tympanum very distinct, about half the diameter of the eye. Disks of three outer

I) Specimen mentioned by me (19I4) as H. thesaurensis. 
fingers as large as the tympanum or smaller, of toes nearly as large as those of fingers; first finger a little shorter than second, which is shorter than fourth; outer fingers webbed at the base, first finger free; third and fifth toe equal in length; toes broadly webbed, the web reaching the disks of third and fifth, or nearly so far; two phalanges of fourth toe free; subarticular tubercles and an oval inner metatarsal tubercle rather distinct; no outer metatarsal tubercle; the heel reaches between eye and tip of snout; tibia a little more than half length of head and body.

Skin smooth above; a feeble fold above the tympanum, and usually another across the chest; belly and lower surfaces of thighs granular.

Upper surface dark purplish brown, with white (in life yellow) spots and streaks, or lighter brown, with the spots and streaks pale brown or dirty white; there are three broad longitudinal streaks on the back, one median, beginning between the eyes or at the tip of the snout, and two lateral ones, beginning on the canthus rostralis or the upper eyelid; small spots on the head and sometimes on the sides; a more or less discontinuous streak at each side of the median one may be present; sometimes a cross-bar on the rump, or another between the eyes; upper surface of limbs pale brown with light dots; yellowish white beneath. Length $27 \mathrm{~mm}$.

In young specimens the vomerine teeth are absent, the lateral and sometimes the median dorsal streaks are broken up into large spots and the light spots are sometimes more numerous.

This species is probably based on young specimens of H. impura.

Habitat: New Guinea (Mamberamo riv.!; Sermowai riv., \pm 70 m.!; Tami riv.!; Friedrich Wilhelmshafen; Stephansort; St. Joseph river district; Lorentz riv.!; Setekwa riv.); Ferguson isl. $\left.{ }^{1}\right)$.

\section{Hyla genimaculata Horst.}

Hyla genimaculata Horst, Notes Leyden Mus, V, 1883, p. 240.

Tongue oblong, very slightly nicked behind; vomerine teeth in two oblique series on a level with the posterior borders of

ז) Perhaps H. thesourensis? 
the choanae. Head nearly as broad as long; snout rounded, vertically truncate, as long as the upper eyelid, longer than deep; canthus rostralis distinct, straight; loreal region very oblique, slightly concave; nostril close to tip of snout; interorbital space a little broader than the upper eyelid; tympanum distinct, $2 / 3$ the width of the eye. Disks of three outer fingers about as large at the tympanum, of toes a little smaller than those of fingers; first finger shorter than second, which is shorter than fourth; fingers half webbed, except the first, which is nearly free; toes extensively webbed, the web reaching the disk at the outer side of the second and third and at the inner side of the fifth toe; penultimate phalanx of first and fourth toe free; subarticular tubercles and the oval inner metatarsal tubercle feebly developed, a very feeble outer metatarsal tubercle; the heel reaches beyond the tip of the snout.

Smooth, with a few scattered, small warts above; larger warts below the vent; a series of oblong tubercles along the outer border of fore-arm and tarsus, continued as a feeble ridge along fourth finger and fifth toe; belly and lower surface of thighs granular; a feeble fold across the breast; an indistinct fold above the tympanum.

Colour (in spirit): greyish brown above, yellowish below; broad transverse bands across the limbs and dark dots along the borders of the mouth; a light cross-bar between the eyes; a white triangular spot from the lower margin of the eye to the angle of the mouth. Length $44 \mathrm{~mm}$.

Type specimen in the Leiden Museum examined ${ }^{1}$ ).

Nearly related to $H$. impura, but distinguished by a more developed web between the fingers.

Habitat: Gebe or Gag isl.!

\section{Hyla macrops Blgr.}

Hyla macrops Boulenger, Ann. Mag. Nat. Hist., (5) XII, I883, p. I64. Hyla macrops Boulenger, Transact. Zool. Soc. London, XII, I89o, p. 59; pl. XI, fig. 3.

Tonguc oval, slightly nicked and slightly free behind; vomerine teeth in two short transverse groups in the middle between the large choanae. Head large, a little broader than long; snout rounded, not projecting, as long as the orbit;

I) The colouration of this specimen has obviously much faded since the original description has been written. 
canthus rostralis distinct, curved; loreal region very oblique, concave; nostril nearer the tip of the snout than the orbit; interorbital space as broad as the upper eyelid; eye very large; tympanum very distinct, half the diameter of the eye, or slightly more; disks of fingers smaller than the tympanum, a little larger than those of toes; first finger shorter than second, which is as long as fourth; no distinct rudiment of pollex; fingers webbed at the base; toes $3 / 4$ webbed; subarticular tubercles small; a small, elliptic inner, and a still smaller, sometimes quite indistinct outer metatarsal tubercle; no tarsal fold; the heel reaches the tip of the snout or nearly so far.

Skin smooth above, belly and lower surface of thighs granulate.

Uniform green above, white beneath; hinder side of thighs brown. From snout to vent $54 \mathrm{~mm}$.

Male with an internal subgular vocal sac and brown rugosities on the inner side of the first finger.

The bones of this species are green.

$\mathrm{Habitat}$ : Solomon islands.

\section{Hyla thesaurensis Ptrs.}

Hyla thesaurensis Peters, Monatsber. Akad. Berlin, 1877, p. $42 \mathrm{r}$.

Hyla thesaurensis Boulenger, Cat. Batr. Sal. Brit. Mus., 1882, p. 409.

Hyla thesaurensis Boulenger, Trans. Zool. Soc. London, XII, pt. 2, 1886, p. бо, pl. XI, fig. 4 .

Hyla thesaurensis Barbour, Proc. New England Zoöl. Club, VII, 1921, p. 93.

Tongue nicked behind; vomerine teeth in two small transverse groups in the middle between the choanae. Snout rounded, as long as the eye; canthus rostralis rounded; loreal region concave; tympanum half the diameter of the eye. Fingers webbed at the base; toes more than half webbed.

Belly and lower surface of thighs granulate.

Blackish brown above, with white (in life yellow?) streaks, viz. three longitudinal streaks along the back, the median one from the tip of the snout to the vent, the lateral ones beginning from the upper eyelids; a cross-bar between the eyes and a streak from the loreal region to the angle of the mouth or to below the tympanum; lower surfaces white. From snout to vent $31 \mathrm{~mm}$.

$H$. thesaurensis is strongly resembling $H$. macgregori, with which it has been confounded, and which it seems to represent on the Solomon islands. Boulenger supposes, that it is a INDO-AUSTRALIAN AMPHIBIA. 
colour-variety of $H$. macrops; I suggest, that it is based on the young of this species.

Habitat: Solomon islands.

\section{Hyla lutea Blgr.}

Iylla lutea Boulenger, Proc. Zool. Soc. London, r887, p. 337, pl. XXVIII, fig. 4. Hyla lutea Vogt, Sitzungsber. Ges. naturf. Fr., Berlin, I912, p. Io.

Hyla thcsaurensis part., Barbour, Proc. New England Zoöl. Club, VII, I92I, p. 93.

Tongue oval, very slightly nicked and slightly free behind; vomerine teeth in two strong transverse groups between the choanae. Head as broad as or slightly broader than long; snout rounded, longer than the eye; canthus rostralis very indistinct; loreal region concave; nostril nearer the tip of the snout than the eye; interorbital space broader than the upper eyelid; tympanum very distinct, about $2 /{ }^{1}$ ) the diameter of the eye. Disks of fingers larger than, of toes as large as the tympanum; no projecting rudiment of pollex; fingers half webbed, the web reaching nearly the disks of the second and third fingers; toes $3 / 4$ webbed; subarticular tubercles small, flat; a small, flat, inner metatarsal tubercle; no tarsal fold; the heel reaches the tip of the snout or a little beyond.

Skin smooth; belly and lower surface of thighs with large, flat granules.

Uniform lemon-yellow above, white inferiorly; a white line along the outer side of fore-arm and fourth finger and of tarsus and fifth toe. From snout to vent $67 \mathrm{~mm}$.

Male with an internal subgular vocal sac and black nuptial excrescences on the inner finger.

Perhaps Barbour is right in regarding this species as identical with Hyla thesaurensis.

Habitat: Solomon islands.

\section{Hyla solomonis Vogt.}

Hyla solomonis Vogt, Sitzungsber. Ges. naturf. Fr., Berlin, I912, p. Io.

Tongue oval, very feebly nicked behind; vomerine teeth in two round groups between the choanae. Snout rounded; canthus rostralis obtuse, but distinct, straight; loreal region oblique; nostril close to the tip of the snout; interorbital space twice the width of the upper eyelid; tympanum half the

i) According to Vogt $1 / 3$, 
diameter of the eye. Disks of fingers as large as the tympanum, those of toes smaller; first finger a little shorter than second; fingers $1 / 3$, toes entirely webbed; an oblong, prominent inner and a small, round outer metatarsal tubercle; the heel reaches the tip of the snout.

Smooth above, granular on belly and posterior surface of thighs; a fold above the tympanum; heel with a dermal flap; a series of tubercles along the outer edge of the fore-arm.

Grey-brown above, white below; a white longitudinal streak from beneath the eye to the shoulder or to the vent; a pair of white dots or a white cross-bar above the vent; tubercles along fore-arm white. Length $48 \mathrm{~mm}$.

Perhaps the young of $H$. luter.

Habitat: Solomon islands.

\section{Hyla everetti Blgr.}

Hyla everetti Boulenger, Ann. Mag. Nat. Hist., (6) XIX, I897, p. 509.

Hyla everetti v. Kampen, Weber's Zool. Ergebn., Leiden, IV, 1907, p. 407.

Tongue circular or shortly oval, free and slightly nicked behind; vomerine teeth in two small groups in the middle between the choanae. Head as long as broad; snout rounded, nearly as long as the upper eyelid; canthus rostralis indistinct; loreal region very oblique; nostril nearer the tip of the snout than the eye; interorbital space as broad as or broader than the upper eyelid; tympanum very distinct, $1 / 2$ to $2 / 3$ the diameter of the eye. Disks of fingers and toes smaller than the tympanum; first finger shorter than second, which is shorter than fourth; fingers $1 / 3$ to $1 / 2$ webbed; third and fifth toe equal in length; toes webbed to the disks, or the penultimate phalanx of fourth toe free from the web; a tarsal fold; the heel reaches between the eye and the tip of the snout, or to the latter.

Skin smooth or with very small warts above; throat, belly, and lower surfaces of thighs granulate.

Grey or brown above, uniform or with darker spots or marblings; back of thighs bright yellow, with brown or black spots or marblings; lower parts white. From snout to vent $48 \mathrm{~mm}$.

Male with an internal vocal sac.

Habitat: Ombai isl.; Sumba; Savu!; Timor.

\section{Hyla infrafrenata Gthr.}

Hy'la cyanea Schlegel (nec Daud.), Abbild. neuer oder unvollst. bek. Amphi, Duisseldorf, $1837-44$, p. 26, pl. IX, fig. 2 。 
Hyla infrafrenata Giinther, Ann. Mag. Nat. Hist., (3) XX, June 1867, p. 56 . Calanita dolichopsis Cope, Jrn. Acad. Nat. Sc. Philadelphia, (2) VI, Sept. I867, p. 204.

Litoria guttata Macleay, Proc. Linn. Soc. N.-S.-Wales, II, 1878, p. 137.

Hyla dolichopsis and $H$. infrafirenata Boulenger, Cat. Batr. Sal. Brit. Mus., 1882, p. 384,385 , pl. XXVI, fig. I.

Hyla dolichopsis var. tenuigranulata Boettger, Zool. Anz., XVIII, 1895, p. I36. Hyla dolichopsis Lönnberg, Ann. Mag. Nat. Hist., (7) VI, I900, p. 580.

Hyla dolichopsis v. Kampen, Nova Guinea, V, pt. I, I 906, p. I 7I (with tadpole). Hyla dolichopsis Roux, Abh. Senckenb. naturf. Ges., XXXIII, I9Io, p. 229.

Hyla dolichopsis Barbour, Mem. Mus. Comp. Zoöl. Harvard Coll., XLIV, Nº I, I $912, \mathrm{p} .76$.

Hyla infrafrenata Boulenger, Zool. Jahrb., Suppl. XV, I, I9I2, p. 21 I.

Tongue slightly notched and free behind; vomerine teeth in two transverse or slightly oblique series on a level with the posterior borders of the choanae. Head nearly as long as broad; snout rounded, as long as or slightly longer than the upper eyelid and longer than deep; its front line in vertical direction strongly convex; canthus rostralis obtuse, but distinct; loreal region very oblique, concave; nostril much nearer the tip of the snout than the eye; interorbital space broader than the upper eyelid; tympanum very distinct, $3 / 5$ to $4 / 5$ the diameter of the eye. Disks of $2^{\text {d }}$ to $4^{\text {th }}$ finger smaller to considerably larger than the tympanum, disk of first finger much smaller than the other ones; disks of toes smaller than those of fingers; first finger shorter than second, which is shorter than fourth; fingers about half webbed, the web between the two outer ones reaching the last subarticular tubercle; third and fifth toe equal in length; toes nearly entirely webbed, the web reaching all disks except the fourth; subarticular tubercles strong, single; an elliptic inner, no outer metatarsal tubercle; a tarsal fold; the heel reaches beyond the eye, often the tip of the snout or beyond; tibia more than half the length of head and body.

Skin smooth or granulate on the back, that of head and scapular region not, or very slightly thickened, without large pores; a fold above the tympanum; sides areolated; belly and lower surface of thighs coarsely granulate.

Bluish violet (in life grass-green), sometimes more or less distinctly spotted with black, above; inner fingers and toes colourless; lower lip bordered with a white or yellow, below dark-edged streak, extending to the shoulders; a white streak along the outer side of fore-arm and tarsus, and often a white 
or yellow, continuous or interrupted streak along the inner edge of the tibia; white beneath, part of the throat sometimes of the same colour as the back. From snout to vent $135 \mathrm{~mm}$.

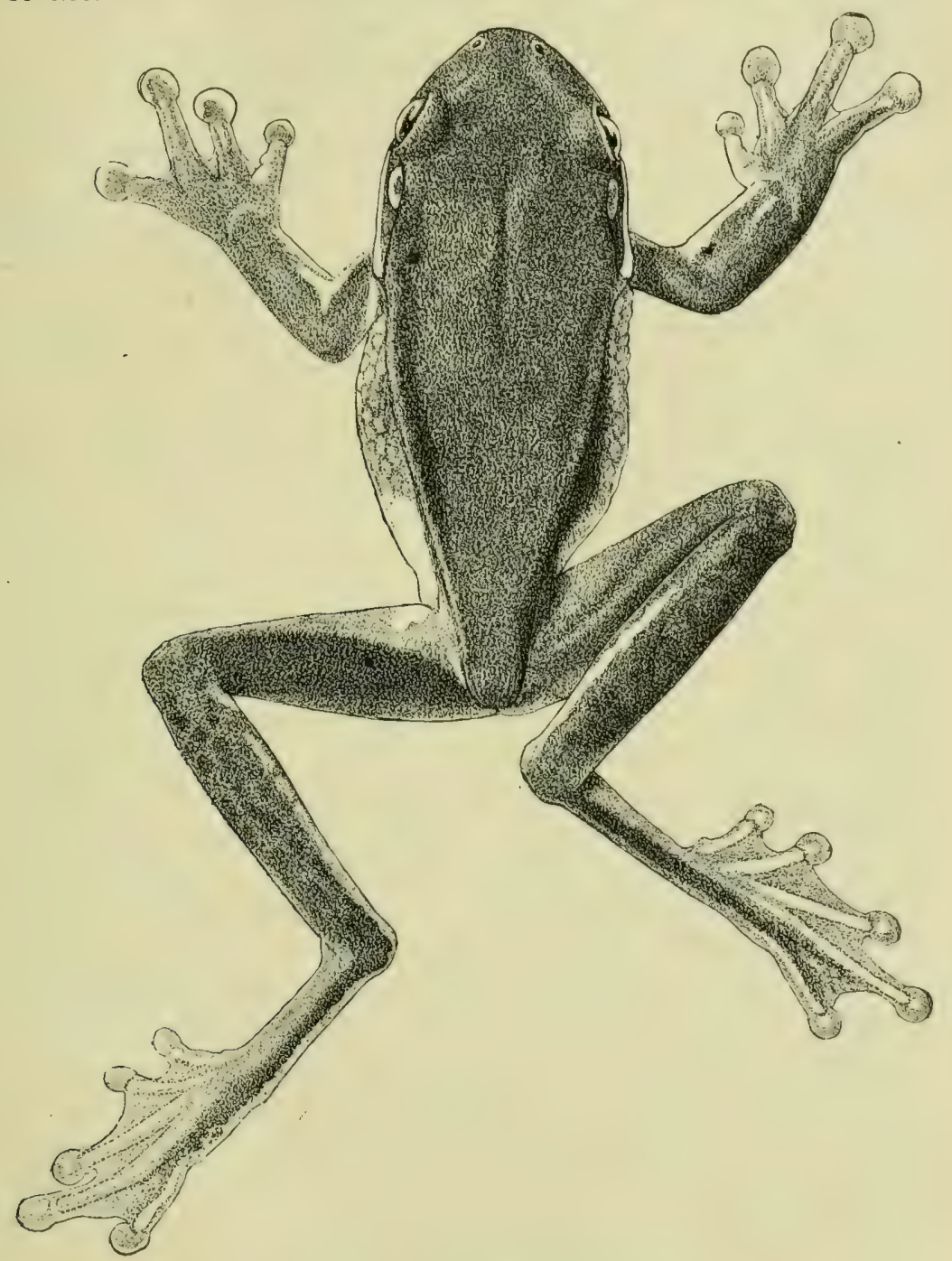

Fig. 5. Hyla infrafrenata Gthr., $\times 4 / 5$.

Male with an external vocal sac, an ossified omosternum and during the breeding-season two, often confluent, groups of black rugosities on the inner side of the first finger.

In young specimens the vomerine teeth are absent. 
Tadpole. - Length of body twice its width; tail somewhat more than once and a half the length of the body, about twice and a half as long as deep. Nostril nearer the tip of the snout than the eye; eyes lateral, as far from the tip of the snout as from the spiraculum; the distance between them about twice and a half that between the nostrils, which equals the width of the mouth; spiraculum without tube; it is a transverse slit on the left side, near the medioventral line, equally distant from tip of snout and base of tail, or nearer the latter; vent dextral, above the lower border of the subcaudal crest. Tail acutely pointed, the crests high, with convex border, the lower distinctly higher than the upper, which reaches forward to above the spiraculum.

Lips bordered with papillae, which are absent only in the middle part of the upper lip; jaws, especially the lower one, broadly edged with black; series of teeth $I^{1} I_{1} / I^{2} I_{\text {or }} I^{1} I / 3$, the outer one of lower lip short.

Grey above, lighter beneath, with a median and a pair of lateral light longitudinal dorsal streaks. Length $62 \mathrm{~mm}$.

Habitat: Timor!; Talaut islands!; Halmahera; Ternate; Batjan; Misoöl; Buru, up to $750 \mathrm{~m}$. !; Ceram!; Ambon!; Nusa Laut!; Timorlaut islands; Kei islands!; Aru islands!; Waigeu!; Salawati; New Guinea (Sorong; Dore; Manokwari!; Andai!; Mansiman; Arfak mts.; Rubi, Geelvink bay; Mamberamo riv.!; Idenburg riv.!; Waipopa riv. !; Humboldt bay!; Sekå!; Sentani lake!; Eitape; Seleo isl.; Kaiserin Augusta riv.!; Friedrich Wilhelmshafen; Erima; Stephansort; Bongu; Sattelberg, \pm 800 m.; Clyde riv.; Dinawa, Owen Stanley range; Oro bay; Maopa; Hula; Yule; Nikura; St. Joseph river clistrict; Bara Bara; Haveri; Moroka, 700 m.; Inawi; Kamali; Katow; Merauke!; Digul riv !; Lorentz riv.!; Van der Sande riv.!; Utakwa riv.; Setekwa riv.; Mimika riv.); Frederik Hendrik isl.!; Jobi isl.; Meisor isl. - Ferguson isl.; d' Entrecasteaux islands; Trobriand islands; But; Valise; Duke of York isl.; islands of Torres strait; Queensland.

\section{Hyla spengeli Blgr.}

Hy'la Spengeli Boulenger, Zool. Jahrb., Suppl. XV, I, r9r2, p. 215.

Head as in H.infrafrenata; snout twice as long as the diameter of the eye; tympanum as large as the eye.

Disk of third finger almost as large as the eye; no pro- 
jecting rudiment of pollex; outer fingers half webbed; the heel reaches the eye; tibia not half the length of head and body.

Skin smooth above, strongly corrugated on the sides; granular on the belly and under the thighs.

Bluish lilac above (in spirit); a white streak, edged with dark purple, borders the lower jaw; and extends to above the shoulder; a whitish streak along the outer side of the forearm and outer finger and of the tarsus and outer toe, prolonged a short way up the inner side of the tibia. From snout to vent II $5 \mathrm{~mm}$.

Other characters as in $H$. infrafrenata.

Habitat: New Guinea (Dinawa, Owen Stanley range).

\section{Hyla militaria (Ramsay).}

Pelodryas militarizes Ramsay, Proc. Linn. Soc. N.-S.-Wales, II, I878, p. 28 . Hyla dolichopsis var. pollicaris Werner, Zool. Anz., XXI, 1898, p. 554.

Hy'la dolichopsis var. pollicaris Werner, Mitt. Mus. f. Naturk. Berlin, I, r9oo,

p. II9 (with description of tadpole and figures of hand, sternal apparatus and tadpole).

Hyla militaria Boulenger, Zuol. Jahrb., Suppl. XV, I, I9I2, p. 214.

Tongue notched and free behind; vomerine teeth in two slightly oblique series between the posterior borders of the choanae. Head as broad as or broader than long; snout rounded, twice the length of the eye; canthus rostralis rounded, indistinct; loreal region concave; interorbital space twice the width of the upper eyelid; tympanum distinct, half to nearly equal to the diameter of the eye. Disks of fingers larger than the tympanum, those of toes somewhat smaller; a strong projecting rudiment of pollex; fingers $1 / 2$ to $2 / 3$ webbed, toes almost entirely webbed, the web reaching all disks, except the fourth; subarticular tubercles well developed; a small inner metatarsal tubercle; a tarsal fold; the heel reaches the anterior border of the eye, the tip of the snout or beyond.

Finely granulate above; breast smooth, otherwise granulate beneath.

Blue or violet (in life green) above; lower lip bordered with a white streak, which is edged with brown below; a white streak along the outer edge of fore-arm and tarsus; fingers and disks often spotted with red; white beneath, only the throat of the same colour as the back. Length $124 \mathrm{~mm}$.

Male with an external vocal sac, an ossified omosternum and a group of black rugosities on the first finger. 
Tadpole. - Length of body nearly twice its width; tail about once and a half the length of the body; eyes lateral; spiraculum sinistral, near the medioventral line; vent dextral.

Grey, with a median and a pair of lateral dark longitudinal dorsal streaks. Length $50 \mathrm{~mm}$.

The projecting rudiment of pollex seems to be the only character distinguishing this species from $H$. infrafrenata.

Habitat: Bismarck arch.

\section{Hyla humeralis Blgr.}

Hyla humeralis Boulenger, Zool. Jahrb., Suppl. XV, I, I912, p. 216.

Head more depressed than in $H$. caerulea and $H$. infrafrenata; snout but little longer than the eye; tympanum $2 / 5$ the diameter of the eye. Disk of third finger nearly as large as the tympanum; no projecting rudiment of pollex; outer fingers nearly half webbed; heel reaching a little beyond the tip of the snout; tibia more than half length of head and body.

Upper parts with scattered, small, granular warts, some of which are capped with deciduous, conical, black, horny tubercles; sides, belly, and lower surface of thighs granulate.

Colour (in spirit) purple above, more pinkish round the eyes, on the arms, sides of thighs, and hands and feet; white beneath; no light border to the lower jaw; upper part of the lower eyelid veined with purple. From snout to vent $100 \mathrm{~mm}$.

Male with a moderately developed external subgular vocal sac, a curved, acutely pointed, spine-like process on the front side of the proximal part of the shaft of the humerus and two deciduous black horny plates, studded with spines, on the inner side of the inner finger.

Closely allied with $H$. infrafrenata (Boulenger).

Habitat: New Guinea (Madew, St. Joseph riv., between 600 and $900 \mathrm{~m}$.$) .$

\section{Hyla aruensis Horst.}

Hyla aruensis Horst, Notes Leyden Mus., V, $\mathbf{I} 88_{3}$, p. 242.

Hyla infrafrenata part., Boulenger, Zool. Jahrb., Suppl. XV, I, Ig̀r2, p. 214.

Tongue oval, slightly nicked behind; vomerine teeth in two short, oblique series between the posterior borders of the choanae. Head broader than long; snout rounded, verticaily truncate, as long as or a little shorter than the upper eyelid, 
longer than deep; canthus rostralis strong, straight; loreal region oblique, feebly concave; nostril much nearer tip of snout than eye; interorbital space once and a half to twice the width of the upper eyelid; tympanum rather distinct, $1 / 2$ the width of the eye. Disks of three outer fingers as large as the tympanum, of toes a little smaller than those of fingers; outer-fingers $2 / 3$ webbed, first finger nearly free; toes nearly entirely webbed, the web reaching all disks, except fourth; subarticular tubercles moderate; a feeble inner, no outer metatarsal tubercle; the heel reaches beyond the tip of the snout.

Smooth above; belly, sides and lower surface of thighs granulate; a fold above the tympanum.

Upper surfaces blue; upper arm, thigh (except a narrow longitudinal blue streak, which however may be absent), fingers and the four inner toes colourless; upper lip very narrowly edged with white; beneath colourless. Length $43 \mathrm{~mm}$.

Male with a subgular vocal sac.

Type specimens in the Leiden Museum examined.

Distinguished from $H$. infrafrenata by the absence of the light border along the lower lip, from the same species and $H$. sanguinolenta by the more extensively webbed fingers.

Habitat: Misoöl!; Aru islands!.

\section{Hyla sanguinolenta v. Kamp.}

Hyla sanguinolenta v. Kampen, Nova Guinea, IX, pt. I, I909, p. 33, pl. II, fig. 3 . Hyla infrafrenate part., Boulenger, Zool. Jahrb., Suppl. XV, I, I9I2, p. 2 I4. Hyla sanguinolenta v. Kampen, Zool. Jahrb., Syst., XXXVII, I9I4, p. 366.

Tongue nicked and free behind; vomerine teeth in two short transverse or oblique series between the posterior borders of the choanae. Head a little broader than long; snout rounded, vertically truncate, as long as the upper eyelid and longer than deep; canthus rostralis distinct; obtuse; loreal region very oblique; concave; nostril about twice nearer to the tip of the snout than to the eye; interorbital space broader than the upper eyelid; tympanum very distinct, $2 / 3$ the diameter of the eye. Disks of three outer fingers a little, of first finger much smaller than the tympanum, of toes smaller than those of fingers; first finger shorter than second, which is shorter than fourth; fingers $1 / 3$ to $1 / 2$ webbed; third and fifth toe equal in length; toes $2 / 3$ to nearly entirely webbed, the web reaching all disks, except fourth; subarticular tubercles strong, the 
distal one of third and fourth finger bilobate or double; an elliptic inner, no outer metatarsal tubercle; a tarsal fold; the heel reaches the tip of the snout or beyond; tibia more than half the length of head and body.

Skin granulate above; a fold above the tympanum; belly and lower surface of thighs coarsely granulate; sides sometimes areolated; a feeble dermal ridge along the outer side of fore-arm, tarsus and fifth toe.

Blue above (in spirit); upper arm, thigh (except a narrow band along the upper surface), inner fingers and toes, the webs and the tympanum colourless; upper lip and upper eyelid narrowly edged with white; a series of small white spots along the inner border of the upper surface of the tibia may be present; white beneath. In life the white parts may be spotted with red. Length $62 \mathrm{~mm}$.

Male with an external vocal sac.

Closely allied with $H$. infrafrenata, from which it is distinguished by the absence of a white streak along the lower lip and by the shape of the snout.

Habitat: New Guinea (Mamberamo riv.!; Idenburg riv.!; Humboldt bay!; Lorentz riv.!; Van der Sande riv.!).

\section{Hyla caerulea (White).}

Rana caerulea White, Journal of a Voyage to New South Wales, London, I790, p. 248, with plate 1).

I'elodryas caeruleus Günther, Cat. Batr. Sal. Brit. Mus., I858, p. I 19, pl. IX, fig. B. Hyla caerulea Boulenger, Cat. Batr. Sal. Brit. Mus, 1882, p. $38_{3}$.

Hyla caerulea v. Kampen, Nova Guinea, IX, pt. I, I909, p. 34.

Hyla caerulea Boulenger, Zool. Jahrb., Suppl. XV, I, I9I2, p. 2 II.

Tongue circular, slightly notched behind; vomerine teeth in two slightly oblique series on a level with the posterior borders of the choanae. Head a little broader than long; snout rounded, about as long as or a little longer than the orbit and longer than deep; canthus rostralis obtuse, but distinct; loreal region oblique, slightly concave; nostril nearer tip of snout than eye; interorbital space as broad as or broader than the upper eyelid; tympanum very distinct, about $2 / 3$ the diameter of the eye. Disks of second to fourth finger very

I) The description of White is very insufficient and the figures are very bad; it is doubtful, if they really represent a Hyla, as is supposed by all the subsequent authors. 
variable in size: from smaller than tympanum (especially in young specimens) to nearly as large as the eye; disks of first finger much smaller than the other ones; disks of toes usually a little smaller than those of fingers; first finger shorter than second, which is shorter than fourth; fingers $1 / 4$ to $1 / 2$ webbed; third and fifth toe equal in length; toes nearly entirely webbed; subarticular tubercles well developed, single; an oblong inner, and a very feeble circular outer metatarsal tubercle; a slight tarsal fold; the heel reaches the temple or the eye; tibia a little less than half the length of head and body.

Skin smooth or granulate above, much thickened and studded with large pores on the hind part of the head and on the scapular region; this glandular region delimited outwards by a strong curved fold above the tympanum; throat, belly, sides of body and lower surface of thighs granulate.

Blue or violet (in life green to brownish olive) above; a white streak along the outer side of the fore-arm and the tarsus may be present; inner fingers and toes white; whitish beneath. From snout to vent $100 \mathrm{~mm}$.

Male with an external subgular vocal sac, and during the breeding-season brown rugosities on the inner side of the first finger.

Habitat: New Guinea (Dinawa, Owen Stanley range; Merauke!). - Islands of Torres strait; Australia.

\section{Hyla angiana Blgr.}

Hy'la angiana Boulenger, Ann. Mag. Nat. Hist., (8) XVI, 19I5, p. 402, pl. XVIII.

Tongue circular, slightly notched behind; vomerine teeth in two oblique series between the choanae or on a level with their posterior borders. Head rather strongly depressed, as broad as long or a little broader; snout rounded, as long as the eye or a little longer; canthus rostralis distinct; loreal region feebly concave; interorbital space broader than the upper eyelid; tympanum very distinct, $1 / 3$ to $2 / 5$ the diameter of the eye. Fingers and toes with large disks; no projecting rudiment of pollex; fingers $1 / 3$ webbed, toes webbed to the disks; subarticular tubercles well developed; heel reaching the eye or the tip of the snout; tibia about half the length from snout to vent.

Smooth above, granular beneath, areolate on the sides; a strong fold above the tympanum. 
Slate blue above (in spirit), the sides of the body and the outer side of head, foot and tarsus sometimes crimson, with white spots or marblings; a white streak on the upper lip, at least from below the eye; a white streak, or white spots, on the lower lip; a white streak above the vent, another along the inner side of the leg and the outer side of the tarsus; throat blue or purple, belly white. From snout to vent $85 \mathrm{~mm}$.

Male without ossified omosternum, with an external gular vocal sac, and a patch of dark brown rugosities on the inner side of the basal part of the first finger.

Closely allied with $H$. caemulea, but differing in the smaller tympanum.

Habitat: New Guinea (Arfak mts., I800-2400 m.).

\section{Hyla congenita Ptrs. \& Dor.}

Hyla (Litoria) congenita Peters e Doria, Ann. Mus. Genova, XIII, I878, p. 427, pl. VI, figs. 4,5 .

Hyla congenita Boulenger, Cat. Batr. Sal. Brit. Mus., 1882, p. 406.

Hyla congenita Roux, Abh. Senckenb. naturf. Ges., XXXIII, I9ro, p. 230 (with tadpole).

Tongue rounded and little free behind; vomerine teeth in two small groups, close together behind the level of the choanae. Head about as long as broad; snout rounded, about as long as, or a little longer than the upper eyelid, a little longer than deep; canthus rostralis indistinct, rounded; loreal region nearly vertical, concave; nostril nearer tip of snout than eye; interorbital space $\mathrm{I}^{1 / 4}$ to $\mathrm{I}^{1} / 2$ the width of the upper eyelid; tympanum very distinct, a little more than half the width of the eye. Disks of fingers smaller than, or as large as tympanum, a little larger than those of toes; first finger shorter than second, which is much shorter than fourth; fingers $1 / 3$ to $1 / 2$. webbed; third and fifth toe equal in length; toes nearly entirely webbed, the penultimate phalanx of the fourth being nearly free; subarticular tubercles distinct; an elliptic inner, and a very small or indistinct outer metatarsal tubercle; no tarsal fold; the heel reaches the eye or between eye and tip of snout; tibia half length of head and body.

Skin smooth above, and on the throat and anterior part of belly; posterior part of belly and lower surface of thighs coarsely granulate; a fold above the tympanum and another across the breast between the shoulders. 
Colouration variable. Some specimens dark brown above, with lighter spots and with a light brown streak above the tympanum to the side of the body; lower parts greyish white; throat sometimes mottled with dark; the limbs light brown, spotted on their posterior surface. Other ones are light grey, finely brown speckled; thighs and posterior portion of the sides of the body lemon yellow; sometimes two irregular dark longitudinal streaks on the back and a black streak on each side of the body. From snout to vent $36 \mathrm{~mm}$.

Male with a greyish brown outer subgular vocal sac, and in the breeding season a large, bean-shaped copulatory excrescence on the outer side of the first fingers.

Tadpole. - Body once and a half as long as broad; tail

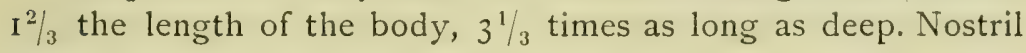
nearer the tip "of the snout than the eye; eyes lateral, nearer the tip of the snout than the spiraculum, the distance between them once and a half the distance between the nostrils and much greater than the width of the mouth; spiraculum a vertical slit on the left side, near the medioventral line, equally distant from the mouth and the hind limbs; vent dextral, near the free border of the subcaudal crest. Tail with an acutely pointed tip; both crests about equally deep, the upper one extending on to the back.

Lips with papillae in many series, especially on the lower lip and the sides; they are absent in the middle part of the upper lip; jaws bordered with black; series of teeth $2 / 3$, the inner series of both upper and lower lip sometimes very feebly interrupted in the middle line; the series of the lower lip are about equal in length.

Back dark brown, spotted with black and often with a very fine medio-dorsal white line from the snout to the base of the tail; belly white, throat and sides dotted with brown; muscular part of tail brown above, grey, dotted with brown, beneath, and with a blackish streak along the middle of the side, reaching to the middle of the tail, and a very distinct clear band above it; crests with numerous black dots. Length $45 \mathrm{~mm}$.

Habitat: Aru islands!; New Guinea (Friedrich Wilhelmshafen; Maopa; Kapa Kapa; Upuli ; Yule isl. ; Borepata; Inawi; Kamali; Merauke !). 


\section{Hyla rubella Gray.}

Hyla rubella Gray, Zool. miscell., London, 1831, p. 57.

Hyla mbella Keferstein, Arch. f. Naturgesch., XXXIV, I, 1868, p. 283, pl. VIII, fig. 29 .

Hyla rubella Boulenger, Cat. Batr. Sal, Brit. Mus., I882, p. 405.

Hyla rubella Spencer, Amphibia, in: Report Horn Scientific Expedition to

Central A.ustralia, Pt. II, Zoology, London and Melbourne, p. I 7o, pl. XV, figs. $26-28$ (tadpole).

Hyla mbella v. Kampen, Bull. Dép. Agricult. Indes néerl., XXV, 1909, p. 6.

Tongue oval, entire; vomerine teeth in two groups close together behind the level of the choanae. Head as long as broad; snout rounded, as long as the diameter of the eye, longer than deep; canthus rostralis obtuse; loreal region nearly vertical, slightly concave; nostril close to tip of snout; interorbital space as broad as, or a little broader than the upper eyelid; tympanum more or less distinct, $1 / 2$ to $2 / 3$ the diameter of the eye. Disks of fingers and toes very variable in size, those of the toes usually smaller than those of the fingers; first finger shorter than second, which is shorter than fourth; fingers free or with a slight rudiment of web; third and fifth toe of equal length; toes $2 / 3$ or $3 / 4$ webbed; subarticular and inner metatarsal tubercles well-developed; no outer metatarsal tubercle; a tarsal fold; the heel reaches between shoulder and tympanum.

Skin smooth above, granulate beneath; a strong fold across the chest.

Greyish or reddish brown above, uniform or speckled with darker; a dark band on the side of head and body; beneath whitish, immaculate. From snout to vent $39 \mathrm{~mm}$.

Male with a brown external subgular vocal sac and during the breeding-season brown rugositics on the inner side of the first finger.

Tadpole. - Length of body about once and a half its width and rather more than half the length of the tail. Nostril considerably nearer to the tip of the snout than to the centre of the eye; eyes superior; spiraculum sinistral, not visible from above and not very prominent; vent dextral. Tail pointed; lower crest deep, the upper one reaching to the base of the tail.

Lips with papillae, which are especially numerous at the sides; along the lower border of lower lip they are arranged in a single row and in the middle of the upper tip they are absent; jaws not very broadly edged with black; series of 
teeth $2 / 3$, the inner series of both upper and lower lip narrowly interrupted in the middle line.

Back and sides dark grey, marbled with umber splotches; ventral surface pearl-coloured, with splotches across the anterior part; muscular part of tail lighter than body, the crests whitish, with faint spots. Length $45 \mathrm{~mm}$.

Habitat: Timorlaut islands! - Australia.

\section{I. Hyla obtusirostris (Meyer).}

Litoria obtusirostris Meyer, Monatsber. Akad. Berlin, I874, p. 139.

Hyla obtusirostris Boulenger, Cat. Batr. Sal. Brit. Mus., I882, p: 412.

Vomerine teeth in two circular groups behind the level of the choanae. Head broad; snout obtuse; canthus rostralis very feeble; loreal region slightly concave; tympanum half the diameter of the eye. Disks of fingers and toes rather large; fingers free; toes entirely webbed; heel reaching beyond the tip of the snout.

Skin finely warty.

Bluish grey above, the warts yellowish; light-coloured beneath. Length $37 \mathrm{~mm}$.

Habitat: Jobi isl.

42. Hyla vagabunda Ptrs. \& Dor.

Hyla vagabunda Peters e Doria, Ann. Mus. Genova, XIII, I878, p. 424, pl. VI, fig. 3 . Hyla vagabunda Boulenger, Cat. Batr. Sal. Brit. Mus., I882, p. 41 IO.

Tongue large, heart-shaped; vomerine teeth in two transverse groups between the choanae. Snout rounded, scarcely longer than the diameter of the eye; canthus rostralis more or less rounded; nostril near the tip of the snout; tympanum half the diameter of the eye. Disks of fingers and toes moderate; fingers free; toes half webbed, the three terminal phalanges of fourth toe free.

Skin smooth above; belly and. lower surface of thighs granulate; a very distinct fold across the chest.

Blue above, speckled with blackish; a whitish line from the tip of the snout, along the canthus rostralis and the border of the upper eyelid, above the tympanum to the shoulder; whitish beneath; posterior surface of thighs spotted with brown. Length $37 \mathrm{~mm}$.

Male with a vocal sac.

Probably based on young specimens.

Habitat: Ceram; New Guinea (Sorong). 


\section{Hyla nasuta (Gray).}

Pelodytes nasutus Gray, Zool. miscell., London, I831, p. 56.

Hyla nasuta Keferstein, Arch. f. Naturgesch., XXXIV, I, 1868, p. 277, pl: VI, fig. I6. Hyla nasuta Boulenger, Cat. Batr. Sal. Brit. Mus., I882, p. 415.

Hyla Semoni Boettger, Jen. Denkschr., VIII, I894, p. II2, pl. V, figs. I $a-d$.

Hyla nasita v. Kampen, Nova Guinea, IX, pt. I, I909, p. 35.

Habit very slender. Tongue subcircular or suboval, nicked behind; vomerine teeth in two transverse or slightly oblique series between the choanae. Head longer than broad; snout acutely pointed, prominent, longer than the upper eyelid and nearly twice the length of the eye, which is equal to the depth of the snout; canthus rostralis distinct; loreal region oblique, concave; nostril equidistant from the tip of the snout and the orbit; interorbital space a little broader than the

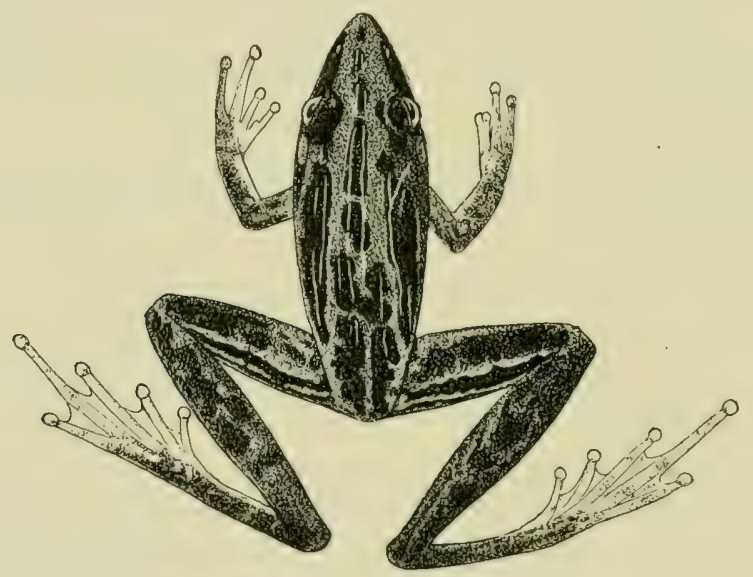

Fig. 6. Hyla nasuta (Gray), $X \mathrm{I}$.

upper eyelid; tympanum very distinct, $2 / 3$ to $3 / 4$ the diameter of the eye. Fingers and toes with very small disks; first finger extending a little beyond second, which is much shorter than fourth; fingers free; third toe hardly longer than fifth; toes half webbed, the terminal phalanx of third and fifth and the three last phalanges of fourth toe being free; subarticular tubercles well developed; a small, oval, inner, and a very small, round, outer metatarsal tubercle; a distinct tarsal fold; the heel reaches far beyond the tip of the snout; tibia $2 / 3$ to $3 / 4$ the length of head and body.

Skin of back with narrow longitudinal ridges; a fold above the tympanum; a distinct oblong gland at each side behind 
the edge of the mouth; belly and posterior surface of thighs granular; a cross-fold between the shoulders usually present.

Brownish or olive above, uniform or with dark markings arranged in longitudinal bands, and a light streak along each side of the middle of the back; loreal and temporal regions and sides of body black, posterior surface of thighs white, black spotted, or with black longitudinal bars; beneath whitish, throat and part of belly sometimes brownish. From snout to vent $48 \mathrm{~mm}$.

Male with an internal subgular vocal sac and during the breeding season an 8 -shaped copulatory excrescence on the first finger.

Habitat: New Guinea (Kamali; Merauke!). - N.- and E.Australia!

\section{Hyla (?) dorsalis (Macl.).}

Litoria dorsalis Macleay, Proc. Linn. Soc. N.-S.-Wales, II, I878, p. I38.

Litoria dorsalis Boulenger, Cat. Batr. Sal. Brit. Mus., 1882, p. 337.

Litoria dorsalis Fry, Mem. Queensland Mus., II, I913, p. 49.

Elongate. Tonguc not notched behind. Vomerine teeth in two very oblique, short series between the choanae. Snout pointed, projecting; nostril in a lateral depression, close to the tip of the snout. Fingers and toes with well defined roundish disks; toes webbed at the base.

Skin smooth above, of belly granular.

Dark above, with a broad whitish band from the snout to the vent; yellowish beneath, much clouded with brown on throat and chest. Length 9 "lines".

Habitat: New Guinea (Katow).

4. Fam. Bufonidae.

Jaws toothless. Diapophyses of the sacral vertebra dilated. Terminal phalanges of fingers and toes obtuse or T-shaped, not claw-shaped.

Omosternum absent, or reduced and cartilaginous; sternum rarely ossified. Vertebrae procoelous. No ribs. Os coccygis articulating by two (rarely one) condyles.

Distribution: cosmopolitan, except the eastern part of the Indo-Australian Archipelago, Polynesia and Madagascar. 


\section{Synopsis of the Genera.}

A. Nostrils lateral.

I. Fingers webbed. .............. r. Nectophryne p. 66.

11. Fingers free................ 2. Bufo p. 72 .

B. Nostrils directed upwards, on upper surface of snout. 3. Pscudolutfo p. 92.

I. Nectophryne Buchh. \& Ptrs.

(Buchuolz und Peters, Monatsber. Akad. Berlin (1875), 1876, p. 202).

Pupil horizontal. Tongue elliptical, entire, free behind. No vomerine teeth. Nostrils lateral. Fingers and tocs webbed, the tips dilated. Outer metatarsals united.

No omosternum; sternum cartilaginous. Diapophyses of sacral vertebra strongly dilated. Terminal phalanges T-shaped.

Distribution: Malay Peninsula; western part of the IndoAustralian Archipelago; Africa.

\section{Synopsis of the Species.}

A. Third finger half webbed ............ I. N. misera p. 66 .

B. Fingers at most $1 / 3$ webbed.

I. Heel not reaching the tip of the snout.

I. A tarsal fold present. . . . . . . . 2. N. hosii p. 67 .

2. No tarsal fold.

a. Diameter of tympanum less than that of the eye. Two metatarsal tubercles.

a. Fingers webbed at the base, first $2 / 3$ the length of second................. everetti p. 68 .

$\beta$. Fingers $1 / 3$ webbed, first hardly half as

long as second. . . . . . . . . 4. N. gucntieri p. 68 .

6. Diameter of tympanum equal to that of the eye. One metatarsal tubercle........ 5. N. macrotis p. 69 .

II. Heel reaching at least the tip of the snout.

I. Tympanum very distinct, $2 / 3$ the width of the eye. 6. N. signata $\mathrm{p} .70$.

2. Tympanum more or less distinct, about $1 / 4$ to $1 / 2$ the width of the eye..........7. N. borbonica p. 70 .

3. Tympanum hidden or absent.

a. Canthus rostralis angular......... 8. N. maculata p. 71 .

b. Canthus rostralis absent.........9. $N$. picturata p. 72 .

\section{Nectophryne misera Mocq.}

Nectophryne misera Mocquard, Nouv. Arch. Mus. d'Hist. nat., (3) II, I S9o, p. I6 I, pl. XI, fig. 7, and: Le Naturaliste, (2) XII, I89o, p. I 82.

Nectophryne misera Roux, Proc. Zool. Soc. London, I906, I, p. 59. 
Habit rather slender. Head small; snout short, as long as the eye; canthus rostralis distinct; loreal region almost vertical; nostril near the tip of the snout; interorbital space a little broader than the upper eyelid; tympanum very distinct, about $2 / 3$ diameter of eye. Fingers much depressed, fingers and toes with small disks; inner finger rudimentary; fingers entirely webbed, except the third, which is half webbed; the three inner toes webbed to the tips; no subarticular tubercles; a rounded, rather large outer metatarsal tubercle, no inner one; no tarsal fold; the heel reaches the tympanum, sometimes a little beyond or not quite so far.

Upper parts with inequal warty tubercles, the largest ones in the middle of the back and on the sides, the latter arranged in two series between the eye and the sacrum; lower parts smooth or granular, the belly with tubercles.

Olive-brown above; beneath lighter, or the belly black, marbled with greyish white. From snout to vent $23 \mathrm{~mm}$.

Habitat: Borneo (Paka Paka, Mt. Kina Balu, 3000 m.).

\section{Nectophryne hosii Blgr.}

Nectophiryne hosii Boulenger, Proc. Zool. Soc. London, 1892, p. 508, pl. XXX, fig. 2. Nectophryne hosii Roux, Proc. Zool. Soc. London, I906, I, p. 59, pl. 1I, fig. I. Nectophryne hosii Boulenger, Vert. Fauna Malay Penins., Rept. and Batr., London, 1912, p. 268.

Habit stout. Head broader than long; snout truncate, short; canthus rostralis strong; loreal region nearly vertical, concave; interorbital space twice as broad as the upper eyelid; tympanum very distinct, vertically oval, about half the diameter of the eye. Fore limb long and strong; fingers much depressed, the tips broad and truncate; disks of toes a little smaller than those of fingers; first finger shorter than second; fingers webbed at the base, the web extending as a margin to the tips; toes extensively webbed, but the three distal phalanges of the fourth toe free; subarticular tubercles small, feebly prominent; two flat metatarsal tubercles, the inner one largest; a tarsal fold; the heel reaches the tympanum or the eye, the tarso-metatarsal articulation reaches the tip of the snout; or not quite so far.

Above with small scattered warts, beneath finely granulate;

a short and narrow, but very prominent parotoid gland.

Male uniform brown, with indistinct spots or cross-bands 
on the limbs, or dark brown with lighter markings, which may form indistinct, coarse vermiculations; belly brown or whitish; throat dark brown or blackish. Female black above, with bright yellow spots or vermiculations, or greenish olive with bright chrome-yellow round spots on the sides and beneath. From snout to vent $0^{7} 65$, $98 \mathrm{~mm}$.

Male with an internal subgular vocal sac.

Eggs laid in long strings.

Habitat: Borneo (Mt. Dulit; Lawas, Brunei; Akar riv.; Serawak riv.; Tandjung). - Malay Peninsula.

\section{Nectophryne everetti Blgr.}

Nectophryne Everetti Boulenger, Ann. Mag. Nat. Hist., (6) XVII, I896, p. 450. Nectophryne everetti Roux, Proc. Zool. Soc. London, 1906, I, p. 6I, pl. II, fig. 2.

Head small, as long as broad; snout obliquely truncate, prominent, short; canthus rostralis strong; loreal region vertical; interorbital space broader than the upper eyelid; tympanum moderately distinct, $1 / 3$ the diameter of the eye. Fore limb nearly as long as the distance between the eye and the vent; fingers feebly dilated and truncate at the end, tips of toes scarcely dilated; first finger $2 / 3$ the length of second; fingers webbed at the base; toes nearly entirely webbed; two very indistinct metatarsal tubercles; the heel reaches the eye or between eye and tympanum.

Upper parts with scattered, small, horny tubercles; lower parts smooth.

Olive-green above, with large, insuliform, reddish-brown, black-edged spots; limbs with reddish-brown cross-bars; upper lip whitish, with reddish-brown vertical bars; dirty white beneath, throat and breast marbled with grey. From snout to vent $33 \mathrm{~mm}$.

Habitat: Borneo (Mt. Kina Balu; Mt. Penrissen).

\section{Nectophryne guentheri Blgr.}

Nectophryne gucntheri Boulenger, Cat. Batr. Sal. Brit. Mus., I882, p. 280, pl. XVIII, fig. 3 .

Pedostibes guentheri Günther, Novit. Zool., II, 1895, p. 501 .

Nectophryne exigua Boettger, Abh. Senckenb. naturf. Ges., XXV, 1901, p. 394. Nectophryne guentheri Roux, Proc. Zool. Soc. London, 1906, I, p. 62.

Nectophryne guentheri Boulenger, Vert. Fauna Malay Penins., Rept. and Batr., London, 1912, p. 268. 
Habit slender. Snout obliquely truncate; loreal region vertical; interorbital space broader than the upper eyelid; tympanum distinct, $1 / 2$ to $3 / 4$ the diameter of the eye (in young specimens smaller). Fore $\operatorname{limb}$ as long as the distance between tympanum and vent; tips of fingers and toes dilated, truncate; fingers much depressed, the first rudimentary, hardly half as long as the second; fingers $1 / 3$ webbed, the web extending as a margin to the tips; web between the toes extending to the tips, but deeply emarginate; subarticular tubercles small; two flat metatarsal tubercles; no tarsal fold; the heel reaches between the eye and the tip of the snout, or not so far, the tarso-metatarsal articulation reaches the tip of the snout, or beyond.

Skin with small tubercles.

Olive-brown above, spotted with yellow and blackish; lower parts yellowish, throat and belly spotted with brown and blackish. From snout to vent $30 \mathrm{~mm}$.

Habitat: Mentawei islands (Sipora); Sumatra (Sandaran Agung, 745 m., in Kurintji valley); Natuna islands (Serasan); Borneo (Baram riv.; Matan). - Malay Peninsula; Singapore; Philippines ${ }^{1}$.

\section{Nectophryne macrotis Blgr.}

Nectophryne macrotis Boulenger, Ann. Mag. Nat. Hist., (6) XVI, I895, p. 17 I. Nectophryne macrotis Roux, Proc. Zool. Soc. London, 1906, I, p. 63, pl. II, fig. 3.

Head small, a little longer than broad; snout prominent, obliquely truncate, short; canthus rostralis strong; loreal region vertical; interorbital space broader than the upper eyelid; tympanum very distinct, as large as and close to the eye. Fore limb as long as the distance between the eye and the vent; fingers dilated and truncate at the end; tips of toes less strongly dilated; first finger very short, half as long as second; fingers webbed at the base; toes $3 / 4$ webbed; a flat inner metatarsal tubercle; the heel reaches the posterior border of the eye.

Above with scattered small warts, irregular in size; beneath granulate.

Olive above, spotted with black; some of the warts red;

1) According to De Elera, Catálogo Sist. de toda la Fauna de Filipinas, I, 1895, p. 45 I. 
limbs barred with black; yellowish beneath, much spotted with black. From snout to vent $28 \mathrm{~mm}$.

$\mathrm{H}$ abitat: Borneo (Akar riv., in Serawak).

\section{Nectophryne signata Blgr.}

Nectophryne signata Boulenger, Proc. Zool. Soc. London, I894, p. 645, pli XL, fig. I.

Habit slender. Snout prominent, obliquely truncate; loreal region vertical; interorbital space broader than the upper eyelid; tympanum very distinct, $2 / 3$ the diameter of the eye. Fore limb as long as the distance between eye and vent; fingers dilated and truncate at the end; disks of the toes smaller than those of the fingers; first finger very short, half as long as second; fingers webbed at the base; toes $3 / 4$ webbed; two small metatarsal tubercles; the heel reaches the tip of the snout.

Above with small scattered warts of unequal size; belly granular.

Olive above, with black spots surrounding an X-shaped light marking on the back; limbs yellowish, barred with black; whitish beneath, spotted with black. From snout to vent $15 \mathrm{~mm}$.

Habitat: Borneo (Rabong mt., Kapuas district).

\section{Nectophryne borbonica (Boie).}

Hylaplesia borbonica (Kuhl et v. Hass.), Schlegel, Isis, XX, I827, p. 294 (nomen nudum).

Hylaplesia borbonica (Boie), Tschudi, Mém. Soc. Sc. nat. Neuchâtel, II, I839, p. 70. Bufo borbonicus part., Boulenger, Cat. Batr. Sal. Brit. Mus., I882, p. 286.

Bufo borbonicus Horst, Notes Leyden Mus., V, $188_{3}$, p. 236.

Nectophryne sumatrana v. Kampen, Nat. Tijdschr. Ned.-Indië, LXIX, Igro, p. I9, pl. I, fig. I.

Nectophryne borbonica v. Kampen, Notes Leyden Mus., XXXIV, I 9 II-I 2, p. 75.

Habit slender. Head as broad as long; snout projecting, shorter than the upper eyelid, as deep as long; canthus rostralis angular, straight or fecbly curved; loreal region vertical, almost flat; nostril nearer the tip of the snout than the eye; interorbital space as broad as the upper eyelid; tympanum more or less distinct, about $1 / 4$ to $1 / 2$ diameter of eye, close to the latter. Tips of fingers and toes swollen, those of the toes a little more than those of the fingers; first finger shorter than second, which is shorter than fourth; fingers very slightly, toes narrowly webbed; subarticular tubercles well developed, single; 
two distinct metatarsal tubercles; a tarsal fold; the heel reaches beyond the tip of the snout; tibia $2 / 3$ length of head and body.

Upper parts with warts and tubercles; parotoid narrow, oblong, sometimes divided into two or three parts and often followed by a series of large tubercles; granular or smooth beneath.

Blackish or yellowish brown, often variegated with dark, above; usually a few large dark brown, light-edged spots present on the back; often a dark cross-bar between the eyes;

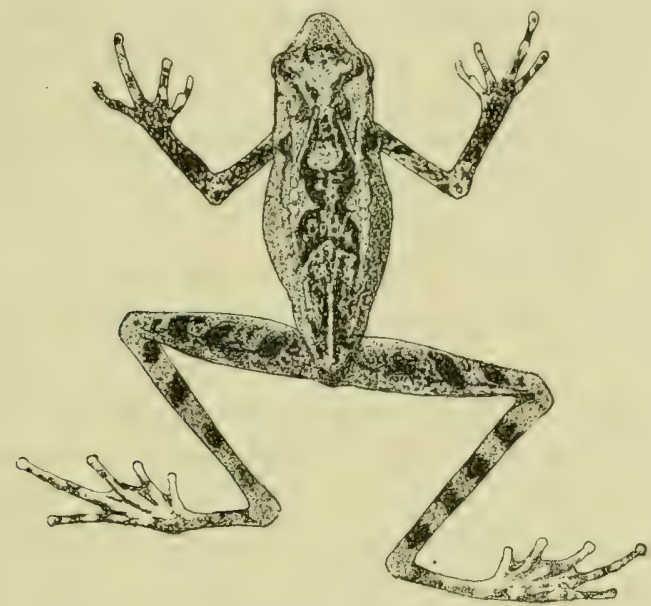

Fig. 7. Nectophryne borbonica (Boie), XI.

yellowish, sometimes variegated with dark brown, below, lower surface of thighs light red; limbs with dark cross-bars. From snout to vent $42 \mathrm{~mm}$.

Male with a subgular vocal sac.

Habitat: Sumatra ${ }^{1}$ ) (Batak mts., \pm 900 m. '; Mt. Ophir, I 200 - I 300 m.!; Ajer Njuruk, Dempu, I 400 m.!; Pasemah, Palembang !); Java ${ }^{2}$ ) (Nusa Kambangan, \pm Io to 30 m. !; Tengger mts., I $200 \mathrm{~m}$.$) .$

\section{Nectophryne maculata Mocq.}

Nectopliryne maculata Mocquard, Nouv. Arch. Mus. d'Hist. nat., (3) 1I, I89o, p. 162, pl. XI, fig. 8 , and: Le Naturaliste, (2) XII, I 890, p. I 82.

I) The specimens mentioned by De Lange (in: Maass, Durch Zentral-Sumatra, I912) from Sumatra do not belong to this species.

2) Barbour (Mem. Mus. Comp. Zoöl. Harvard Coll., XLIV, I9I2, p. 74) mentions a.specimen from Buitenzorg, but the specimen figured by him is from Tjibodas and does not belong to this species, but probably to Bufo asper. 
Habit slender. Head short; snout obliqucly truncate, as long as the eye; canthus rostralis angular; loreal region vertical; interorbital space as broad as the upper eyelid; tympanum hidden. Limbs slender; tips of fingers dilated, truncate; tips of toes less dilated than those of fingers; fingers webbed at the base; toes $2 / 3$ webbed; metatarsal tubercles distinct, the outer more prominent than the inner; the heel reaches far beyond the tip of the snout.

Upper and lower parts with large granulations.

Brownish grey above, with small, irregular, isolated or confluent spots, forming more or less distinct transverse bars on the limbs; lighter beneath. From snout to vent $5 \mathrm{I} \mathrm{mm}$.

Habitat: Borneo (Mt. Kina Balu).

\section{Nectophryne picturata Smith.}

Nectophryne picturata Smith, Jrn. Feder. Malay St. Mus., X, I921, p. I89, pl. II, fig. 2 .

Habit slender. Head as long as broad; snout rounded, projecting, as long as the orbit; no canthus rostralis; loreal region oblique; interorbital space twice the width of the upper eyelid; no tympanum. Disks of fingers well developed, truncated, those of toes a little larger; first finger much shorter than second; fingers and toes webbed at the base; subarticular tubercles well developed; two flat metatarsal tubercles; no tarsal fold; the heel reaches the tip of the snout.

Skin smooth. No parotoid gland.

Above blackish brown, the limbs paler with dark cross-bars; below with large round spots of pale yellow. From snout to vent $22 \mathrm{~mm}$.

Habitat: Borneo (Mt. Dulit, Iooo m.).

\section{Bufo Laur.}

(LAURenti, Synopsis Rept., Viennae, I768, p. 25).

Pupil horizontal. Tongue entire and free behind. No vomerine teeth. Nostrils lateral. Fingers free, toes more or less webbed, the tips simple or dilated into small disks. Outer metatarsals united.

No omosternum; sternum cartilaginous, sometimes more or less calcified. Diapophyses of sacral vertebra moderately dilated. Terminal phalanges obtuse or triangular. 
Some species of Bufo are provided with bony ridges on the upper surface of the head, viz: a canthal ridge along the canthus rostralis; a supraorbital ridge along the inner edge of the upper eyelid, which may be continued into a praeorbital and a postorbital ridge and, backwards, into a parietal ridge; and a supratympanic ridge above the tympanum.

Tadpoles. - Eyes superior. Spiraculum sinistral. Vent median. Upper crest of tail not extending on to the body. Mouth normal, sometimes much enlarged; series of papillae absent along upper border of upper lip; series of teeth $2 / 3$.

Distribution: cosmopolitan, except New Guinea, Polynesia, Australia and Madagascar. In the Indo-Australian Archipelago occurring only in the western part, including Celebes.

\section{Synopsis of the Species.}

$A$. Head without bony ridges.

I. Parotoids not distinct, rarely ${ }^{1}$ ) present, but than very natrow.

I. Tympanum not quite half the width of the eye. Heel reaching the eye or between eye and tip of snout............. I. B. leptopus p. 75 .

2. Tympanum at least half the width of the eye.

$a$. Heel reaching the eye or between eye and tip of snout. ............. 2. B. penangensis p. 75 .

b. Heel reaching far beyond the tip of the snout. 3. B. jerboa p. 76 .

c. Heel reaching the tympanum....... 4. B. fuligineus p. 77 .

II. Parotoids distinct.

1. First finger shorter than second...... 5. B. cruentatus p. 78 .

2. First finger at least as long as second.

a. Tympanum $1 / 4$ the width of the eye. A tarsal fold ..............6. B. sumatranus p. 78 .

b. Tympanum $1 / 2$ to $3 / 4$ the width of the eye.

No tarsal fold...............7. B. valhallae p. 79.

B. Head with bony ridges.

I. No parietal ridge.

I. No parotoids. Only a canthal ridge present. 8 B. spinulifer p. 79.

2. Parotoids and supratympanic ridges present.

a. Supratympanic ridge narrow.

ж. No tarsal fold ............ 9. B. melanostictus p. 80 .

1) See 3. B. jerboa. 
ß. Tarsal fold present. ........ Io. B. gymnauchen p. 8 I.

b. Supratympanic ridge thick.

$\alpha$. Toes nearly entirely webbed.... Ir. B. aspir 1) S2.

$\beta$. Toes nearly half webbed ..... 12. B. celebinsis P. 84 .

II. Parietal ridge present.

I. Supra-orbital and parietal ridge not confluent ................ 13. B. philippinicus p. 86 .

2. Supra-orbital and parietal ridge continuous.

a. Parietal ridge much thickened behind. I4, b. clavigur p. 86.

b. Parietal ridge narrow.

ж. Parotoid long and narrow.

†. Tarso-metatarsal articulation reaching tympanum or eye. 15. 1) quadriporcatus p. 87 .

††. Tarso-metatarsal articulation reaching at least tip of snout. I6. B. divergents p. 88 .

$\beta$. Parotoid shorter.

†. Tarso-metatarsal articulation. reaching between eye and tip of snout, or beyond. First finger longer than second. Snout projecting ....... I7. B. parvus p. SS.

†. Tarso-metatarsal articulation reaching the nostril. First finger as long as second... 18. B. cavator p. 89:

††. Tarso-metatarsal articulation not reaching beyond the eye. First finger usually not longer than second. Snout not projecting. . . . . . 19. B. bipcreatus p. 90.

Doubtful species: 20. B. chlorogaster p. 92.

Synopsis of the Tadpoles.

A. Mouth of normal size........ $\left\{\begin{array}{l}9 . \text { B. melanostictues p. } 80 . \\ \text { 14. F. claviger p. } 86 . \\ \text { 17. B. parvus p. } 88 . \\ \text { 19. B. biporcatus p. } 90 .\end{array}\right.$

B. Mouth large, the lower lip being much' increased in size.

I. Tail acutely pointed. Lower lip thickly studded with papillae............. 2. B. penangensis 1) 75 .

II. Tail rounded. Lower lip bordered with one series of papillae............ II. B. asper p. 82 . 


\section{Bufo leptopus Gthr.}

Bufo leptopus part., Günther, Proc. Zool. Soc. London, 1\$72, p. 598.

Bufo leptopus Boulenger, Cat. Batr. Sal. Brit. Mus, r882, p. 287, pl, XV11I, fig. 4. Bufo leptopues Mocquard; Nouv. Arch. Mus. d'Hist. nat., (3) II, I890, p. 159.

Habit slender. Head small, without bony ridges; snout obliquely truncate; canthus rostralis angular; loreal region vertical; interorbital space slightly broader than the upper eyelid; tympanum distinct, not quite half the width of the eye. Limbs slender; length of fore limb equal to the distance between the eye and the vent; tips of fingers and toes swollen into very small disks; first finger as long as or a little shorter than second, toes webbed at the base in the female, the web reaching the disks of the first and second toe in the male; subarticular tubercles none, two rather indistinct metatarsal tubercles; no tarsal fold; the heel reaches the eye or between eye and tip of snout, the tarso-metatarsal articulation far beyond the tip of the snout; tibia $1 / 2$ length of head and body.

Skin covered with small warts and tubercles; no parotoids.

Brown above, marbled with reddish; throat and chest blackish. From snout to vent $55 \mathrm{~mm}$.

Hardly distinguishable from $B$. penangensis.

Habitat: Borneo (Mt. Kina Balu, 640 and I280 m.; Baram; Matan).

\section{Bufo penangensis (Stol.).}

Ansonia penangensis Stoliczka, Jrn. Asiat. Soc. Bengal, XXXIX, 1S7o, p. I52, pl IX, fig. 4 .

Bufo penangensis Boulenger, Cat. Batr. Sal. Brit. Mus,, I882, p. 287.

Bufo penangensis Flower, Proc. Zool. Soc. London, 1899, p. 9o8, pl. Lx, figs. $3,3 a$ (tadpole).

Bufo penangensis Boulenger, Vert, Fauna Malay Penins., Rept. and Batr., London, I 9 I $2 ;$ P. 270.

Habit slender. Head without bony ridges; snout obliquely truncate, strongly projecting; loreal region vertical; interorbital space as broad as the upper] eyelid; tympanum very distinct, $1 / 2$ to $2 / 3$ the diameter of the eye, close to the latter. Tips of fingers and toes feebly swollen; first finger shorter than second; toes $1 / 2$ to $2 / 3$ webbed; subarticular tubercles none or very indistinct; two flat metatarsal tubercles; no tarsal fold; the heel reaches the eye or between the eye and the tip of the snout; tibia about half the length of head and body. 
Upper parts with small warts of unequal size; no distinct parotoids; lower parts granulate.

Dark brown above, with yellowish spots or symmetrical markings, forming oblique bars across the limbs; brownish beneath, speckled with yellow, or marbled with brown; posterior part of belly and inner side of thighs rose-coloured in life. From snout to vent $50 \mathrm{~mm}$.

Male with a large external gular vocal sac.

Tadpole. - Length of body from rather more than once and a half to rather less than once and two thirds its width, nearly half the length of the tail; tail 6 times as long as deep; nostrils much nearer the eyes than the end of the snout; eyes on the upper surface, the distance between them rather more than once and a half that between the nostrils, and little more than half the width of the mouth; spiraculum sinistral, directed upwards and backwards, rather nearer the eye than the vent; anal opening median. Tail acutely pointed, crests of equal depth or the lower one slightly deeper; lower crest along whole length of tail, the upper only on posterior twothirds of it.

Mouth large; lips forming a sucking-disk, the upper one without, the lower one thickly studded with very small, short, rounded papillae; jaws white, lower one edged with black, the upper one with a black diagonal mark on each side. Series of teeth $2 / 3$, those of the upper lip of equal length, those of the lower one of equal length too, but shorter than the upper series.

Sepia-brown above, mottled darker and lighter, yellowish buff beneath; muscular portion of the tail sepia-brown mottled with yellow; the crests are transparent, finely speckled with sepia-brown towards their dark-brown edges. Length $34 \mathrm{~mm}$.

The tadpoles live in swift-flowing streams and are able to fix themselves to stones by means of their mouth.

Habitat: Borneo (Mt. Kina Balu, 640 and $1280 \mathrm{~m}$. .). Malay Peninsula, 600-I $200 \mathrm{~m}$.

\section{Bufo jerboa Blgr.}

Bufo jerboa Boulenger, Proc. Zool. Soc. London, I8go, p. 328, pl. XXV, fig. 3 . Bufo jerboa Boulenger, Vert. Fauna Malay Penins., Rept. and Batr., London, 1912, p. 271.

Habit very slender. Head without bony ridges; snout obli- 
quely truncate, strongly projecting; loreal region vertical; interorbital space as broad as or a little narrower than the upper eyelid; tympanum very distinct, $1 / 2$ to $2 / 3$ the width of the eye, close to the latter. Fingers with feebly swollen tips, first as long as or a little shorter than second; toes $1 / 3$ to $1 / 2$ webbed; subarticular tubercles very prominent; two small, but prominent metatarsal tubercles; a tarsal fold; the heel reaches far beyond the tip of the snout; tibia about $2 / 3$ the length of head and body.

Upper parts with granules and very small warts; lower parts granulate; parotoids, if at all distinct, very narrow.

Brown above, with dark and light spots or symmetrical markings, often forming an X-shaped figure in front of the sacral region, a yellowish dorsolateral streak sometimes present; dark bars on the limbs and on the lips; yellowish or pale brownish beneath, throat and breast dark-brown or much mottled with dark brown. From snout to vent $50 \mathrm{~mm}$.

Male with an internal subgular vocal sac and brown nuptial asperities on the inner finger.

Habitat: Sumatra (Sandaran Agung, $745 \mathrm{~m}$. , Kurintji valley); Borneo (Mt. Penrissen in Serawak; S. E.-Borneo). Malay Peninsula.

\section{Bufo fuligineus Mocq.}

Bufo fuligineus Mocquard, Nouv. Arch. Mus. d'Hist. nat., (3) II, 1890, p. 158, pl. XI, fig. 5, and: Le Naturaliste, (2) XII, I890, p. 163.

Habit rather stout. Head without bony ridges; snout rounded; canthus rostralis angular; loreal region nearly vertical; interorbital space broader than the upper eyelid; tympanum very distinct, half the width of the eye. Tips of fingers and toes swollen; first finger shorter than second; toes half, the two inner ones almost entirely webbed; subarticular tubercles and inner metatarsal tubercle indistinct, a feebly developed outer metatarsal tubercle; the heel reaches the anterior border of the tympanum.

Upper surfaces with unequal warts; no parotoids; granular beneath.

Sooty black above, light brown beneath, lower surfaces of the limbs dirty white. From snout to vent $38 \mathrm{~mm}$.

Male with small conical spines on the two inner fingers.

Habit at: N.-Borneo. 
5. Bufo cruentatus Tschudi.

Bufo cruentatus T'schudi, Mém. Soc. Sc. Neuchâtel, II, I839, p. 52.

Bufo borbonicus part., Boulenger, Cat. Batr. Sal. Brit. Mus., I882, p. 286.

Bufo cruentatus Horst, Notes Leyden Mus., V, 1883, p. 236.

Bufo montanus Werner, Zool. Anz., XX, 1897, p. 265.

Bufo cruentatus Barbour, Mem. Mus. Comp. Zoöl. Harvard Coll., XLIV, No. I, 1912, p. 75, pl. VIII, fig. 34 .

Habit slender. Head nearly as long as broad, without bony ridges; snout obtusely pointed, somewhat projecting, shorter than the upper eyelid, as long as deep; canthus rostralis angular; loreal region vertical, concave; nostril nearer the tip of the snout than the eye; interorbital space as broad as the upper eyelid; tympanum indistinct, small. Tips of fingers and toes slightly swollen; first finger shorter than second, which is shorter than fourth; fifth toe a little extending beyond third; toes half webbed; subarticular tubercles well developed, single; two distinct metatarsal tubercles; no tarsal fold; the heel reaches between the posterior border of the eye and the tip of the snout, the tarso-metatarsal articulation the tip of the snout or beyond.

Upper surfaces . with small granular tubercles; parotoids distinct, sometimes divided in two parts, situated behind each other; smooth or granular beneath.

Brown or blackish above, variegated with dark spots and white (red in life) patches; beneath yellowish. Length $39 \mathrm{~mm}$.

Habitat ${ }^{1}$ ): Java (Perbawati, Mt. Gedeh!; crater of Mt. Gedeh!; Tjibodas, I400-2000 m.!).

\section{Bufo sumatranus Ptrs.}

Bufo sumatranus Peters, Monatsber. Akad. Berlin, I871, p. 648.

Bufo sumatranus. Boulenger, Cat. Batr. Sal. Brit. Mus., I882, p. 295.

Head without bony ridges; snout subacuminate, short; tympanum distinct, $1 / 4$ the width of the eye. First finger not extending beyond second; toes webbed: at the base; two metatarsal tubercles, the inner larger than the outer; a tarsal fold; hind limb short.

Upper surfaces closely granulate, with large conical warts parotoids oval, twice as long as broad.

I) Peters (Ann. Mus. Genova, III, I872, p. 43) mentions "Hylaplesia cruentatc" from Serawak; probably, however, he has confounded it with some species of Nectophryne. 
Greyish brown above, with brown, dark-edged spots; beneath yellow, black-spotted. Length $34 \mathrm{~mm}$.

$\mathrm{Habitat}$ : interior of Sumatra.

\section{Bufo valhallae Meade-Waldo.}

Bufo valhallae Meade-Waldo, Proc. Zool. Soc. London, I908, p. 786, pl. XLI.

Head broader than long, without bony ridges; snout rounded, vertically truncate, shorter than the upper eyelid; canthus rostralis angular; loreal region nearly vertical; nostril nearer the tip of the snout than the eye; interorbital space as broad as, or a little narrower than the upper eyelid; tympanum very distinct, $1 / 2$ to $3 / 4$ diameter of eye. Tips of fingers and toes blunt; first finger extending beyond second, which is shorter than fourth; third toe longer than fifth; toes halfwebbed; subarticular tubercles single; an elliptic inner, and a smaller, rounded, outer metatarsal tubercle; no tarsal fold; the heel reaches the shoulder, the tarso-metatarsal articulation the eye.

Upper surfaces with pointed tubercles of different sizes; parotoids large, prominent or flat, elliptical or oval; lower parts granular; a conspicuous gland on each calf may be present.

Olive-brown above, with darker markings; sometimes a distinct black line along the inner margin of the parotoid glands. From snout to vent $82 \mathrm{~mm}$.

Habitat: Pulo Weh!

\section{Bufo spinulifer Mocq.}

Bufo spinulifer Mocquard, Nouv. Arch. Mus. d'Hist. nat., (3) II, ISgo, p. r6o; pl. XI, fig. 6, and: Le Naturaliste, (2) XII, I89o, p. I8I.

Habit slender. Head small; canthus rostralis with a prominent ridge, no other ridges; snout obliquely truncate, as long as the eye; loreal region vertical; interorbital space nearly twice' as broad as the upper eyelid; tympanum distinct, half the width of the eye. Tips of fingers and toes very feebly swollen; first finger a little shorter than second; toes webbed at the base; subarticular tubercles none; a large, oval, flattened inner, and a small outer metatarsal tubercle; the heel reaches between the eye and the tip of the snout.

Upper parts with large, unequal, for the greatest part warty, spinose tubercles, sometimes rather regularly placed in four 
longitudinal series; the lateral tubercles confluent into two thick dorsolateral, warty ridges; no parotoids; lower parts granular.

Almost black above; a greyish brown, irregularly oval spot, with pink tubercles, on the back; beneath lighter, with some yellowish white marblings; limbs with some light red spots or narrow bars. From snout to vent $4 \mathrm{I} \mathrm{mm}$.

Habitat: Borneo (Mt. Kina Balu).

\section{Bufo melanostictus Schneid.}

Bufo melanostictus Schneider, Hist. Amph., I, Jena, I799, p. 2 I6.

Bufo scaber (Daud.), Schlegel, Abbild. neuer oder unvollst. bek. Amph., Düsseldorf, $1837-44$, p. 64, pl. XX, fig. 2 .

Bufo melanostictus Boulenger, Cat. Batr. Sal. Brit. Mus,, 1882, p. 306.

Bufo melanostictus Flower, Proc. Zool. Soc. London, I896, p. 91 I, pl, XLIV, fig. 3 (tadpole).

Bufo melanostictus Stejneger, Bull. U.S. Nat. Mus., LVIII, 1907, p. 72, figs. 58-61.

Bufo melanostictus Boulenger, Vert. Fauna Malay Penins., Rept. and Batr., London, 1912, p. 272, with fig.

Habit stout. Head broader than long, with a canthal, a praeorbital, a supraorbital, a postorbital, and a short and narrow supra-tympanic bony ridge; snout shorter than the upper eyelid, deeper than long; canthus rostralis angular; loreal region little oblique, nearly flat; nostril nearer tip of snout than eye; interorbital space broader than the upper eyelid; tympanum close to the eye, very distinct, more than half the diameter of the eye. Tips of fingers and toes blunt; first finger usually extending beyond second, which is shorter than fourth; third toe longer than fifth; toes about half webbed, the three distal phalanges of the fourth one free; subarticular tubercles very small, single; a moderate, elliptic inner and a smaller outer metatarsal tubercle; no tarsal fold; the heel reaches the shoulder, the tarso-metatarsal articulation the tympanum or the eye.

Upper parts with more or less prominent, often spiny warts of various sizes; upper surface of head nearly smooth; parotoids very large, reniform or elliptical, more or less elongate; granular beneath.

Brown or yellowish brown above, sometimes with carminecoloured spots, the tips of the warts and the ridges of the head usually black; beneath yellowish, immaculate or more or less spotted with brown. From snout to vent i $6 \mathrm{~mm}$.

Male with a subgular vocal sac, and in the breeding season with black nuptial excrescences on the two inner fingers. 
In the young the bony ridges of the head are absent.

Tadpole. - Length of body about once and a half its width and about $3 / 4$ the length of the tail; tail 3 to 4 times as long as deep, the depth of the muscular portion about half the greatest total depth. Nostril much nearer to the eye than to the end of the snout; eyes superior, the distance between them about twice that between the nostrils and about equal to the width of the mouth; spiraculum sinistral, directed backwards, visible from above and from below, nearer to the vent than to the end of the snout; vent median. Tail with broadly rounded tip, both crests nearly equal in depth, the upper slightly convex and not extending to the back.

Mouth ventral; lips with papillae only at the sides; jaws white, edged with black; series of teeth ${ }^{1}{ }^{1} I / 3$, the second series in the upper lip nearly as long as the first one, narrowly interrupted in the middle, those of the lower lip about equal in length, the innermost being rather the longest, the outermost the shortest.

Blackish-brown above, grey beneath; muscular portion of tail blackish-brown, crests colourless or pale grey. Length $23 \mathrm{~mm}$.

From sea-level to high up in the mountains. Very common in cities; by day it is hiding in holes, in the evening it may often be seen in and near the houses hunting after insects. The copulation is axillary. The eggs, which are disposed in one file in each mucilaginous string, are laid in stagnant, often muddy water, in which the tadpoles may be found throughout the year (in Batavia).

Habitat: Pulo Weh!; Nias!; Sumatra (Langkat; Medan!; Belawan!; Batak mts., \pm 300 m.!; Radja mts.; Fort de Kock!; Lembok); Riou islands (Bintang)?; Banka; Natuna islands (Bunguran); Borneo (Baram riv.; Pontianak; Bandjermasin!); Java (Serang!; Batavia!; Depok; Buitenzorg!; Sukabumi!; Tjiandjur; Cheribon!; Tjilatjap!; Pekalongan!; Semarang; Ambarawa; Gunung Gamping, Djokjakarta!; Djapara!; Djuana!; Rembang!; Kediri!; Pasuruan!); Madura! - From India and S.-China to the Malay Peninsula and the Philippines.

\section{IO. Bufo gymnauchen Blkr.}

Bufo gymnauchen Bleeker, Nat. Tijdschr. Ned.-Indië, XVI, 1859, p. 46.

Docidophryne spinipes (nomen nudum), Fitzinger, Sitzungsber. Akad. Wien, XLII, I86I, p. 415. 
Bufo spinipes Steindachner, Reise der Novara, Amph., Wien, 1867, p. 43, pl. V, figs. 6, 7 .

Bufo melanostictus part., Boulenger, Cat. Batr. Sal. Brit. Mus., I882, p. 306.

Bufo longecristatus Werner, Zool. Anz., XXVI, 1903, p. $252^{1}$ ).

Habit stout. Head broader than long, with a canthal, a praeorbital, a supraorbital, a postorbital, and a short and narrow supratympanic bony ridge; snout shorter than the upper eyelid, a little deeper than long; canthus rostralis angular, loreal region oblique, slightly concave; nostril nearer to the tip of the snout than to the eye; interorbital space broader than the upper eyelid; tympanum close to the eye, distinct, $2 / 3$ diameter of eye. Tips of fingers and toes blunt; first finger as long as, or slightly shorter than second, which is shorter than fourth; third toe about as long as fifth, toes about $2 / 3$ webbed, the two distal phalanges of fourth one free; subarticular tubercles very small, single; a moderate inner, and a smaller outer metatarsal tubercle; a serrated tarsal fold; the heel reaches the shoulder, the tarsometatarsal articulation the eye.

Upper surface of head and body smooth or with two longitudinal series of warts on the posterior half of the back; parotoids reniform, feebly prominent; granular beneath and on the sides.

Brown or greyish, the ridges of the head sometimes black; beneath yellowish, immaculate, or belly spotted with brown. Length $68 \mathrm{~mm}$.

Male with a subgular vocal sac.

I compared a specimen in the Leiden museum from the collection of Bleeker. The species can be distinguished from B. melanostictus by the nearly smooth back and by the tarsal fold.

Habitat: Riou islands (Tandjongpinang!); interior of Borneo! -- Nicobars.

\section{I. Bufo asper Gravh.}

Bufo asper Gravenhorst, Deliciae Mus. Zool. Vratislav., Fasc. I, Lipsiae, 1829, p. 58. Bufo asper Schlegel, Abbild. neuer oder unvollst. bek. Amph., Diisseldorf, I837-44, p. $63, \mathrm{pl} . \mathrm{XX}$, fig. I.

Bufo asper Boulenger, Cat. Batr. Sal. Brit. Mus., 1882, p. 3I3.

? Nectes obscurus Barbour, Proc. Biol. Soc. Washington, XVII, 1904, p. $5 \mathrm{I}$.

Bufo asper v. Kampen, Nat. Tijdschr. Ned.-Indië, LXIX, 1910, p. 26, 30, pl. II, fig. 2 (tadpole).

I) Type specimen (in the Brussels museum) examined by me; the parietal ridge, described by Werner, is a dermal ridge; the parotoid is longer than the orbit. 
Bufo asper Boulenger, Vert. Fauna Mal. Penins., Rept. and Batr., London, rǵsż, p. 27I, fig. 74 (vertebral column and pectoral arch), fig. 75 (open mouth).

?Bufo obscurus Barbour, Mem. Mus. Comp. Zoöl. Harvard Coll., XLIV, No. I, 1912 , p. 75 , pl. VI, fig. 20.

Habit stout. Head broader than long, with a broad and flat supraorbital and a thick supratympanic bony ridge; snout obliquely truncate, shorter than the upper eyelid, as deep as long; canthus rostralis angular; loreal region nearly vertical, flat; nostril nearer to the tip of the snout than to the eye; interorbital space broader than the upper eyelid; tympanum more or less distinct, vertically oval, its longest diameter $1 / 3$ to $\%$, the width of the eye. Tips of fingers and toes blunt; first and second finger equal in length; toes nearly entirely webbed, the two distal phalanges of fourth toe included only by a narrow fringe; subarticular tubercles well developed, single; a large elliptic inner and a somewhat smaller outer metatarsal tubercle; a distinct tarsal fold; the heel reaches the eye, the tarso-metatarsal articulation the tip of the snout or beyond.

Upper surfaces with very prominent, conical, spinose tubercles of various sizes; parotoids distinct, usually a little shorter than the diameter of the eye ${ }^{1}$ ), subtriangular or roundish; coarsely granular below.

Uniform brown or blackish above, sometimes spotted with crimson; the tubercles with a brownish or yellowish tip; yellowish beneath, uniform or spotted with black. From snout to vent $260 \mathrm{~mm}$.

Male with a subgular vocal sac.

Tadpole. - Length of body about once and a half its width and about $3 / 4$ the length of the tail; tail about 3 times as long as deep, its muscular part more than half as deep as the total depth. Nostril much nearer to the eye than to the tip of the snout; eyes on the upper surface, as far from tip of snout as from spiraculum, the distance between them a little more than once and a half that between the nostrils and half the width of the mouth; spiraculum lateral, sinistral, directed backwards, in the middle between the vent and the anterior border of the eye; vent median. Tail with rounded tip; the crests low, convex, the upper one a little deeper than the lower and not reaching the base of the tail.

I) In some specimens of N.-Borneo they are large, as long or almost as long as their distance from the end of the snout. 
Mouth ventral; it is very large (its posterior border situated almost in the middle of the body) and has the shape of a sucker; lips distinctly separated from each other, bordered with one series of short papillae, which are absent along the upper border; jaws narrowly edged with black, the border of the upper one M-shaped; series of teeth $2 / 3$, those of the same lip equal in length; lower lip with a large, unarmed portion behind the teeth.

Brownish black, lower parts and crests of tail colourless. Length $20 \mathrm{~mm}$.

This toad lives often near human dwellings, as B. melanostictus, but is much less common in low countries.

Habitat: Sumatra (Upper Langkat; Medan!; Bander Baru, Batak mts., \pm 900 m. !; Toba lake; Airbangis!; Talu ; Mt. Ophir, I 500 m.! : Sandaran Agung, 745 m., and Sinlak Deras, 900 m., Kurintji valley; Sungai Kumbang, I 400 m., Kurintji peak; Gunung-Sahilan; Andalas!; Agam; Kalung, Tilatang; Pajakombo!; Ajermantjur!; Alahanpandjang; Batu Sangkar, 450900 m.; Solok!; Sidjundjung; Muarolabu; Kepahiang; upper current of Hari leko riv.; Palembang!); Borneo (Mt. Kina Balu, 460 m.; Baram riv.; Mt. Dulit, I 200 m.; Miri, Serawak; Kapuas riv.; Sintang; Seberuang riv.; Martapura); Java (Pasaruan, Bantam!; Lebak; Batavia!; Buitenzorg!; Mt. Salak; Gadok; Tjibodas!; Sukabumi!; Tjiandjur; Djampang Tengah!; Semarang; Wonosobo!; Gunung Sewu, Djokjakarta!). — Siam; Malay Peninsula, up to $1500 \mathrm{~m}$.

\section{Bufo celebensis Schlg.}

Bufo celebensis (Schlegel), Steindachner, Reise der Novara, Amph.,Wien, I867, p. 44. Bufo celebensis Boulenger, Cat. Batr. Sal. Brit. Mus., 1882, p. 313.

Bufo celebensis Boulenger, Proc. Zool. Soc. London, 1897, p. 236.

Bufo celebensis Boettger, Abh. Senckenb. naturf. Ges., XXV, I901, p. 384 .

Habit stout. Head broader than long, with a broad supraorbital and a thick, elevated (in the young feebly prominent) supratympanic bony ridge; snout obliquely truncate, shorter than the upper eyelid, as deep as long; canthus rostralis angular, with a prominent ridge; loreal region nearly vertical, almost flat; nostril nearer tip of snout than eye; interorbital space in the adult broader than the upper eyelid; tympanum more or less distinct, vertically oval, its longest diameter $2 / 5$ to $3 / 5$ that of the eye. Tips of fingers and toes blunt; first finger 
extending beyond second; toes nearly half webbed; subarticular tubercles small, single; two well-developed metatarsal tubercles, the outer one a little smaller than the inner one; no tarsal fold; the heel reaches the shoulder, or beyond (to beyond tip of snout).

Upper surfaces with more or less prominent conical warts;

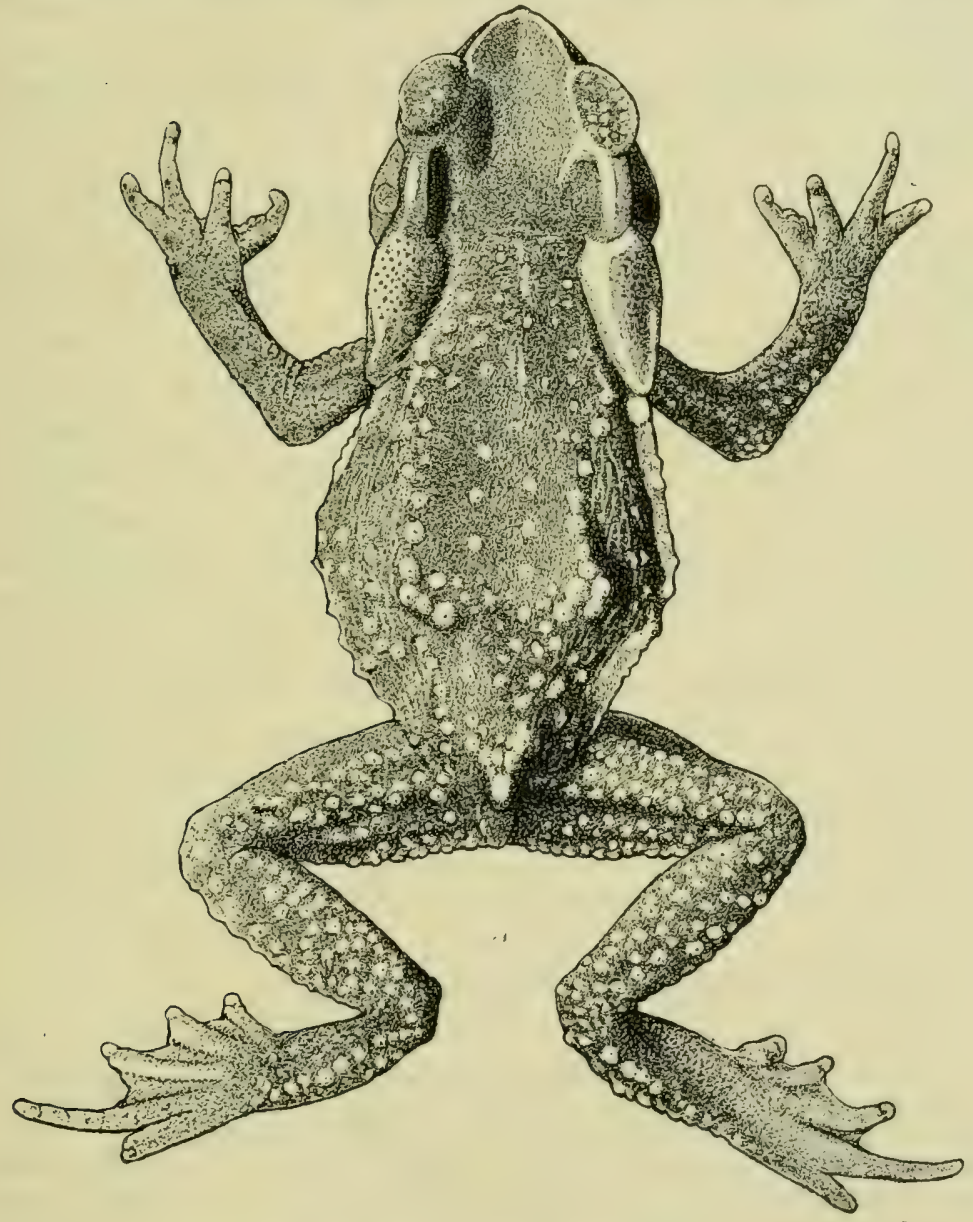

Fig. 8. Bufo celebensis Schlg., $X \mathbf{I}$.

parotoids very prominent, variable in shape, triangular, oval or elliptical, usually continuous with the orbitotympanic bony ridge; granular below.

Olive, greyish, blackish or crimson above, uniform or with 
indistinct darker spots, the warts often with black tips; yellowish, greyish or pale olive beneath, uniform or marbled with dark brown. Length $107 \mathrm{~mm}$.

Male with an internal subgular vocal sac and a black nuptial excrescence on the outer side of the first and second fingers.

Habitat: Celebes (Makasser!; Loka!; Bonthain peak (Bawa Kraeng); Ahua riv.; Rumbia; Mengkoka; Luwu!; Kulawi!; Kantewu!; Sukon!; Bwool; Sumalata; Boliohutu mts.; Gorontalo; Gurupahi!; Bolaang Mongondou!; Tomohon; Rurukan; Menado!; Kema).

\section{I3. Bufo philippinicus Blgr.}

Bufo philippinicus Boulenger, Ann. Mag. Nat. Hist., (5) XIX, I887, p. 348, pl. X, fig. 5 .

Bufo philippinicus Boulenger, Ann. Mag. Nat. Hist., (6) XIV, 1894, p. 88. Bufo philippinicus Taylor, Philipp. Jrn. of Sc., XVI, I920, p. 344, pl. IX, fig. 5 .

Cranial ridges rather similar to those of B. biporcatus, but the supraorbital one ending in a very short branch, directed inwards and distinct from the parietal one; which is more thickened; snout truncate, short; canthus rostralis prominent; interorbital space broader than the upper eyelid; tympanum very distinct, vertically oval, smaller than the eye. First finger extending much beyond second; toes half webbed; subarticular tubercles simple; no tarsal fold; the tarsometatarsal articulation reaches the eye.

Upper parts with small, conical, spiny tubercles; parotoids oval or elliptical, $2 / 3$ to $3 / 4$ the length of the head.

Olive above, with darker, insuliform spots; cranial ridges reddish brown. From snout to vent $76 \mathrm{~mm}$.

Male with an internal vocal sac.

Habitat: Philippines (Pelawan; Balabak).

\section{Bufo claviger Ptrs.}

Bufo claviger Peters, Monatsber. Akad. Berlin, 1863, p. 405.

Bufo claviger Boulenger, Cat. Batr. Sal. Brit. Mus, I882, p. 3 I I (with figure of head). Bufo claviger v. Kampen, in: Kleiweg de Zwaan, Die Insel Nias bei Sumatra,

III, Haag, 1915, p. 278 (tadpole).

Habit rather stout. Head broader than long, with a canthal, a narrow supratympanic, a supraorbital and a parietal bony ridge, the two latter ones forming together a nearly straight line and very elevated and much thickened behind; snout as long as the upper eyelid and as long as deep; canthus rostralis 
angular; loreal region oblique, concave; nostril a little nearer to the tip of the snout than to the eye; interorbital space much broader than the upper eyelid; tympanum $2 / 3$ to $3 / 4$ the width of the eye, close to the latter. Tips of fingers and toes blunt; first finger extending beyond second, which is shorter than fourth; toes not quite half webbed; subarticular tubercles very small, single; a moderate inner, and a narrow outer metatarsal tubercle; no tarsal fold; the heel reaches the shoulder or the tympanum, the tarsometatarsal articulation the eye or to between eye and tip of snout.

Upper parts and sides with conical warts; parotoids small, oblong or roundish; granulate beneath.

Brownish, usually more or less distinctly black spotted above; beneath dark brown, or lighter, spotted with brown. Length S I mm.

Young specimens have the cranial ridges not swollen, but rather more elevated than in B. biporcatus.

Tadpole. - Probably not different from that of B. melanostictus.

Habitat: Nias!; Sumatra! (Pasir Ganting, W.-Coast Sumatra, $2^{\circ}$ S.; Benkulen).

\section{I5. Bufo quadriporcatus Blgr.}

Bufo quadriporcatus Boulenger, Ann. Mag. Nat. Hist., (5) XIX, I887, p. 347, pl. X, fig. 4 .

Bufo quadriporcatus Günther, Ann. Mag. Nat. Hist., (5) XX, I887, p. 3I4, pl. XVI, fig. C.

Bufo quadriporcatus Boulenger, Vert. Fauna Malay Penins., Rept. and Batr., London, 1912, p. 274 .

Habit rather stout. Head broader than long, with a narrow supratympanic and a prominent supraorbital bony ridge, continued into a short parietal one, the two latter ones forming together a nearly straight line; snout truncate, projecting, as long as the upper eyelid and as long as deep; canthus rostralis angular; loreal region nearly vertical, feebly concave; nostril a little nearer to the tip of the snout than to the eye ; interorbital space broader than the upper eyelid; tympanum close to the eye, very distinct, nearly as large as or larger than the eye. Tips of fingers and toes blunt, not dilated; first finger extending beyond second; toes not quite half webbed; subarticular tubercles single; two moderate, rounded metatarsal 
tubercles; no tarsal fold; the heel reaches the shoulder, the tarsometatarsal articulation the tympanum or the eye.

Upper parts more or less warty; parotoids prominent and compressed, ridge-like, much elongate, continuous with the supratympanic bony ridge, and usually followed by a lateral series of large tubercles; some specimens prickly all over with horny spines; granulate beneath.

Brownish above, uniform or marbled with olive; the parotoids sometimes whitish, edged with black; limbs with dark cross-bars; lower parts whitish, uniform or marbled with hrown. From snout to vent $6_{5} \mathrm{~mm}$.

Habitat: Sumatra (Deli!; Palembang!); Natuna islands (Bunguran); Borneo (Baram riv.; Mt. Dulit). - Malay Peninsula, up to $240 \mathrm{~m}$.

\section{I6. Bufo divergens Ptrs.}

Bufo divergens. Peters, Monatsber. Akad. Berlin, 1871, p. 579.

Bufo divergens Boulenger, Cat. Batr. Sal. Brit. Mus., 1882, p. 3 I 2 (with fig. of head). Bufo divergens Boulenger, Vert. Fauna Malay Penins., Rept. and Batr., London, I9I 2, p. 275 .

Closely related to $B$. quadriporcatus, from which it differs in the following points. Parietal ridge forming an angle with the supraorbital one; the tarso-metatarsal articulation reaches the tip of the snout, or beyond; tibia half the length of head and body. Sometimes a yellow vertebral line. From snout to vent $50 \mathrm{~mm}$.

Habitat: Natuna islands (Bunguran); Borneo (Labuan; Serawak; Matan). - Malay Peninsula; Pelawan?

\section{Bufo parvus Blgr.}

Bufo parwus Boulenger, Ann. Mag. Nat. Hist., (5) XIX, I887, p. 346, pl. X, fig. 3 . Bufo claviger Isenschmid, Mitth. naturf. Ges. Bern, I903, p. So.

Bufo parvus Boulenger, Vert. Fauna Malay Penins., Rept. and Batr., London, I912, p. 274.

Bufo parvus Smith, Jrn. Nat. Hist. Soc. Siam, II, 1916, p. 42, with figs. (tadpole). Bufo parvus Annandale, Mem. Asiat. Soc. Bengal, VI, 1917, p. I53, fig. 10 and pl. VI, fig. 8 (tadpole).

Head with a supraorbital, a narrow parietal, and a short supratympanic bony ridge, the two former ones forming together a straight line or diverging behind; snout truncate, projecting, shorter than the upper eyelid, deeper than long; canthus rostralis angular; loreal region vertical; nostril nearer tip of 
snout than eye; interorbital space as broad as or a little broader than the upper eyelid; tympanum very distinct, close to the eye, its vertical diameter $2 / 3$ to $3 / 4$ the width of the eye. Fingers and toes with blunt tips; first finger extending distinctly beyond second, which is shorter than fourth; third toe longer than fifth; toes feebly webbed; subarticular tubercles single; two rather large metatarsal tubercles; no tarsal fold; the tarso-metatarsal articulation reaches to between the eye and the tip of the snout, or a little beyond.

Upper parts rough with very prominent, conical, often spinose tubercles; parotoids small, prominent, round or subtriangular; lower parts with round tubercles of unequal size.

Brown above, with a few darker spots, and often with a few scattered irregular spots of pink colour; limbs with dark cross-bands; lower parts spotted with brown; throat brown in the male. From snout to vent $52 \mathrm{~mm}$.

Male with a subgular vocal sac and black nuptial asperities on the two inner fingers.

Tadpole. - Length of body $\mathrm{I}^{1} / 3$ to $\mathrm{I}^{1} / 2$ times its width and $2 / 3$ the length of the tail, which is about 3 times as long as deep. Nostril nearer the eye than the tip of the snout; eyes superior, the distance between them twice that between the nostrils; spiraculum sinistral, directed upwards and backwards, a little nearer the eye than the vent; vent median, anal tube short. Tail with rounded tip; crests convex, the upper one as deep as or a little deeper than the lower one, not extending on to the back.

Mouth subterminal; lips with short papillae, only at the sides; jaws broadly edged with black, finely serrated; series of teeth $I^{1}{ }^{1} / 3$, the lower series of upper lip may be narrowly interrupted.

Blackish, the muscular portion of the tail pale brown, the crests almost colourless. Length $28 \mathrm{~mm}$.

$\mathrm{H}$ a b i t a t: Sumatra (Upper Langkat!; Bandarbaru, Batak mts., \pm 900 m.!; near Balun and Muarolabu, Padang Highlands!; Benakat and Harileko riv.!, Palembang); Java (Badjulmati in Besuki $\left.{ }^{1}\right)$ ). - Burma; Siam; Malay Peninsula.

\section{I8. Bufo cavator Barb.}

Bufo cavator Barbour, Proc. Biol. Soc. Washington, XXIV, I9II, p. 21.

I) Communicated by Mr. C. Boden Kloss. 
Bufo cavator Barbour, Mem. Mus. Comp. Zoül. Harvard Coll., XLIV, No. I, 1912, P. 74, pl. VI, fig. 22.

Head with a supraorbital, a parietal and a short supratympanic bony ridge, the two former ones forming together a straight, or nearly straight line; snout short; canthus rostralis prominent; interorbital space slightly broader than the upper eyelid; tympanum distinct, circular, about $3 / 5$ the width of the eye. First finger as long as second; toes, except fourth, entirely webbed; subarticular tubercles single; two moderate metatarsal tubercles; no tarsal fold; the tarso-metatarsal articulation reaches the nostril.

Upper parts with scattered warts, which are not spiny; parotoids very prominent, small, almost circular.

Brownish above, marbled with light yellowish; beneath yellowish, throat dark brown.

"This species may be distinguished from Bufo biporcatus at once by its much smaller tympanum, which is almost circular instead of vertical-oval. In $B$. biporcatus the upper boundary of the tympanum is formed by the orbito-tympanic ridge, which is not the case with this species. The shape of the tympanum is quite different in the two species; and in this new one the cephalic crests are not prolonged as far posteriorly as they are in biporcatus." (Barbour).

Habitat: Lombok.

\section{I9. Bufo biporcatus Gravh.}

Bufo biporcatus Gravenhorst, Deliciae Mus. Zool. Vratislav., Fasc. I, Iipsiae, 1829 , p. 53 .

Bufo biporcatzes Boulenger, Cat. Batr. Sal. Brit. Mus., I882, p. 3II (with figure of head).

Bufo biporcatus v. Kampen, Nat. Tijdschr. Ned.-Indië, LXIX, I910, p. 30 (tadpole). Bufo biporcatus Barbour, Mem. Mus. Comp. Zoöl. Harvard Coll., XLIV, No. I, 1912, p. 74, pl. VI, figs. 21 and 35.

Habit rather stout. Head broader than long, with a canthal, a postorbital, a narrow supratympanic, a supraorbital and a parietal bony ridge, the two latter ones forming together a straight or nearly straight line; snout not projecting, as long or nearly as long as the upper eyelid, and as long as deep; canthus rostralis angular; loreal region oblique, concave; nostril nearer the tip of the snout than the eye; interorbital space a little broader than the upper eyelid; tympanum close to 
the eye, very distinct, its diameter equal to the width of the eye or hardly smaller. Tips of fingers and toes blunt; first finger usually as long as, rarely extending beyond second; third and fifth toe of equal length; toes not quite $1 / 2$ to $2 / 3$ webbed; subarticular tubercles very small, single; two moderate metatarsal tubercles, the outer one a little smailer than the inner one; no tarsal fold; the heel reaches the axil, the tarsometatarsal articulation the tympanum or the eye.

Upper parts with very prominent, conical tubercles; paro-

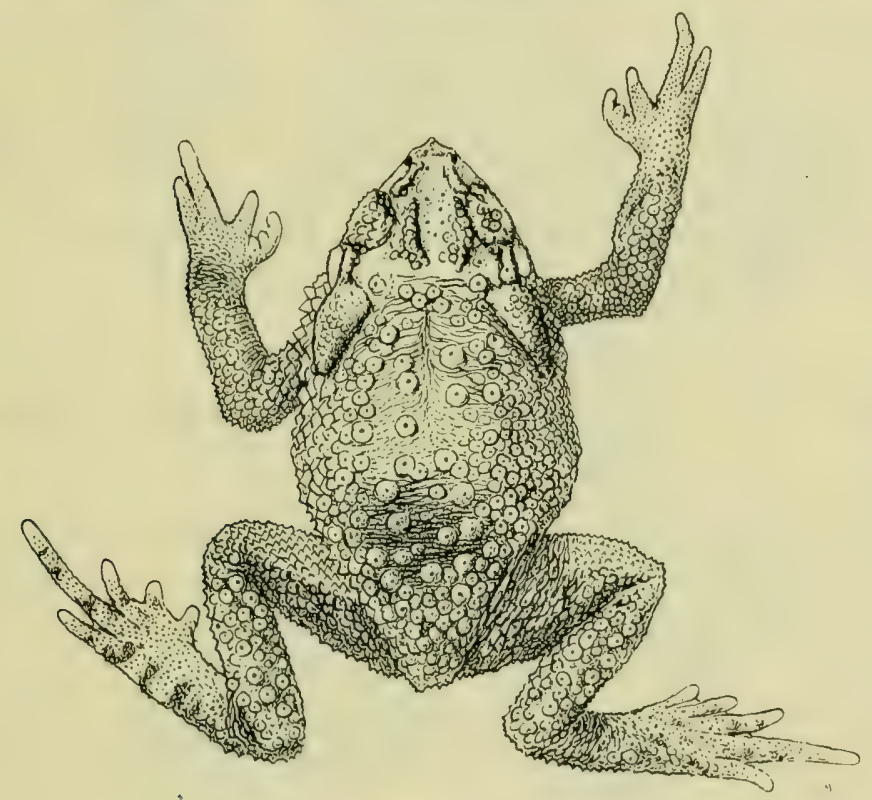

Fig. 9. Bufo biporcatus Gravh., $X \mathbf{I}$.

toids very prominent, small, subtriangular or oval; strongly granulate beneath.

Brownish above, marbled with darker; beneath lighter, more or less spotted with brown. Length $79 \mathrm{~mm}$.

Male with a subgular vocal sac and in the breeding time a black copulatory excrescence at the outer side of the first finger.

Tadpole. - The tadpoles agree in every point with those of $B$. melanostictus; only the two lower series of teeth of the lower lip are perhaps somewhat less different in length.

Habitat: Sumatra (Mt. Simbolon; Talu; Gunung-Sahilan; Ringat; Palembang!); Borneo (Mt. Kina Balu; Baram riv.; 
Mt. Dulit, 300-r 200 m.; Kutjing; Tegora; Bandjermasin); Java (Serang; Lebak; Batavia!; Buitenzorg!; Gadok; Tjibodas!; Pasirdatar, 900 m.!; Sukabumi!; Tjiandjur ; Bandung ; Tjipanas!; Mt. Malabar, I 500 m.!; Mulá, Djokjakarta, \pm I00 m.!; Tengger mts., I 200 m.; Situbondo!); Madura; Baii ; Lombok! (up to $\pm 580 \mathrm{~m}$.); Celebes (Makasser!; Teteadji!; lake Towuti; Luwu!). - Tenasserim ? $\left.{ }^{1}\right)$.

\section{Bufo chlorogaster Daud.}

Bufo chlorogaster Daudin, Hist. nat. des Rainettes, Paris, 1802, p. 74, pl. $\mathrm{XXV}$, fig. 2 .

Snout feebly rounded. Toes half webbed.

Upper surfaces with numerous small warts; parotoids kidneyshaped; beneath with scattered granules.

Ashy grey above, yellow beneath. Length $\pm 4 \mathrm{~cm}$. Habitat: Java.

\section{Pseud o bufo Tschudi.}

(Tschudi, Mém. Soc. Sc. Neuchâtel, II, 1839, p. 49, 87; Nieden, Sitzungsber.

Ges. Naturf. Fr., Berlin, 1914, p. 369).

Nectes Cope, Nat. Hist. Review, V, 1865, p. I03.

Pupil horizontal. Tongue entire and free behind. No vomerine teeth. Nostrils directed upwards, on upper surface of snout. Fingers free or webbed; toes entirely webbed, the tips not dilated. Outer metatarsals united.

No omosternum; sternum cartilaginous, calcified along the centre. Diapophyses of sacral vertebra rather strongly dilated. Terminal phalanges simple.

Distribution: Malay Peninsula; Sumatra; Borneo.

$$
\text { Synopsis of the Species. }
$$

$A$. Fingers free or with a rudimentary web ..... I. P. subasper p. 92. $B$. Outer fingers nearly half webbed......... 2. P. werneri p. 94 .

\section{Pseudobufo subasper Tschudi.}

Pseudobufo subasper Tschudi, Mém. Soc. Sc. nat. Neuchâtel, II, 1839, p. 87. Nectes pleurotaenia (nomen nudum), Bleeker, Nat. Tijdschr. Ned.-Indië, XIII, I 857 , p. 475 .

Nectes subasper Boulenger, Cat. Batr. Sal. Brit. Mus., I882, p. 327 (with figs. of head).

I) Boulenger, Ann. Mus. Genova, (2) V, 1887-88, p. 486 . 
Nectes (Pseudobufo) pleurotaenia Fischer, Arch. f. Naturgesch., LI, I, r885, p. 47. Nectes sumatranus Werner, Zool. Jahrb., Syst., XIII, 1900, p. 497, pl. XXXV, fig. 9. Nectes subasper and pleurolaenia v. Kampen, Zool. Jahrb., Syst, XXII, I 905, p. 71 I. Nectes subasper Boulenger, Vert. Fauna Malay Penins., Rept. and Batr., London, I912, p. 275.

Head broader than long; snout pointed, projecting, as long as the upper eyelid, and as long as deep; canthus rostralis

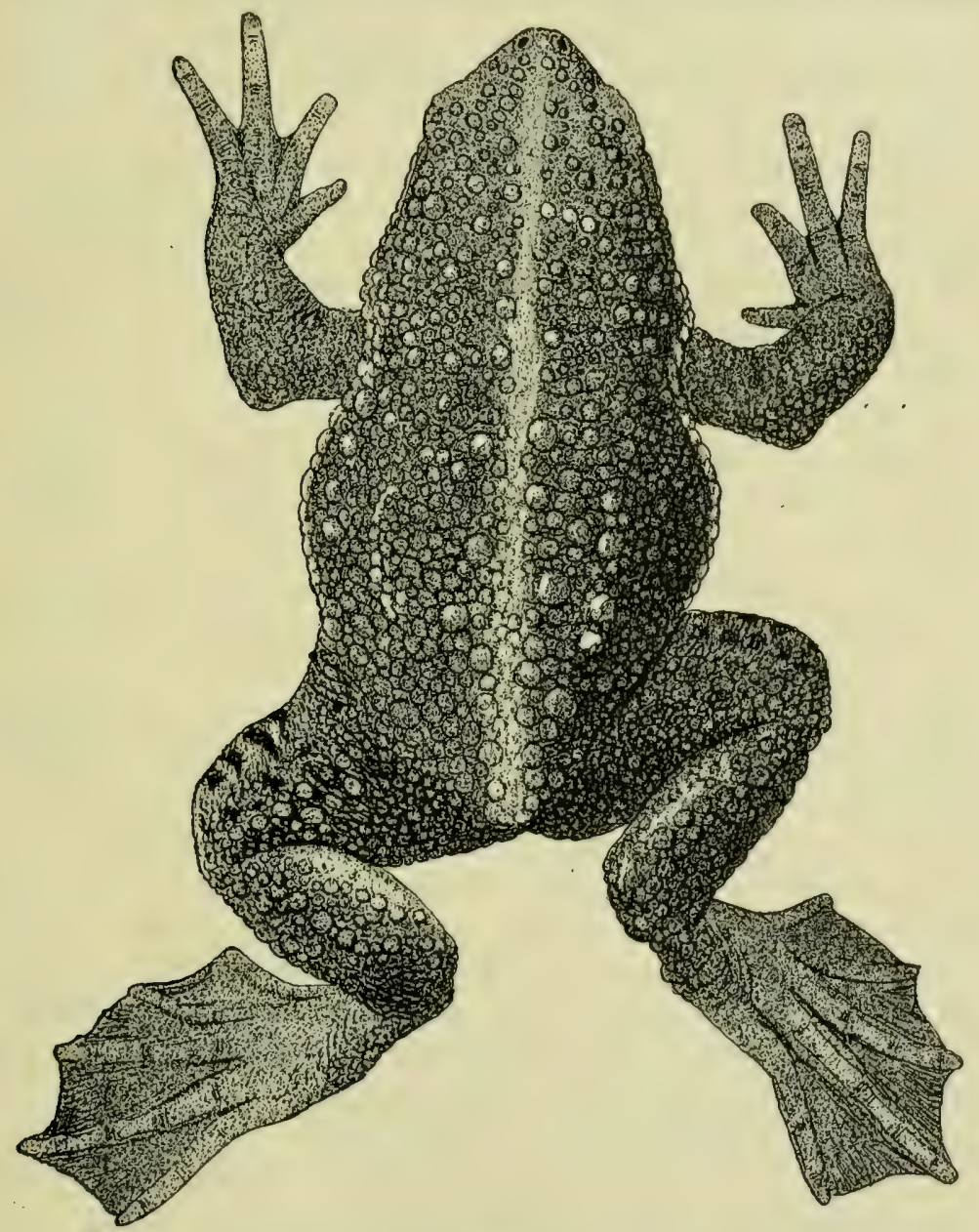

Fig. Io. Psendobufo subasper Tschudi, $\times 4 / 5$.

rounded; loreal region nearly vertical, flat; nostrils close together on the upper surface, near the tip of the snout; interorbital space broader than the upper eyelid; tympanum close to the 
eye, more or less distinct, $2 / 3$ to $3 / 4$ the width of the eye. Fingers and toes obtuse or pointed; first finger shorter than second, which is much shorter than fourth; fingers free or with a rudimentary web; toes webbed to the tips by a very broad and thick membrane; no subarticular, two very indistinct, flat metatarsal tubercles; a rather indistinct tarsal fold; the tarso-metatarsal articulation reaches the shoulder or to between the shoulder and the eye; tibia $1 / 3$ length of head and body.

Upper parts with closely set rounded warts of different sizes; granulate beneath.

Dark brown or blackish above, with or without a more or less distinct whitish or yellowish band along the side of the body and along thigh and metatarsus; a light brown vertebral line may be present; brownish white beneath, with or without minute dark dots. From snout to vent $150 \mathrm{~mm}$.

Male with a large blackish subgular vocal sac.

Aquatic.

Habitat ${ }^{1}$ ): Sumatra (Djapura, Indragiri; Djambi!; Palembang!); Borneo (Tumbang Hiang; Bandjermasin). - Malay Peninsula.

2. Pseudobufo werneri (v. Kamp.).

Nectes subasper Werner, Zool. Jahrb., Syst., XIII, I900, p. 497, pl. XXXV, fig. Io. Nectes werneri v. Kampen, Zool. Jahrb., Syst., XXII, I905, p. 711.

Habit stout. Head broader than long; snout a little longer than the upper eyelid; nostrils close together on the upper surface near the tip of the snout; tympanum oval, close to the eye, its horizontal diameter $1 / 2$, its vertical diameter $2 / 3$ the length of the upper eyelid. Tips of fingers and toes obtuse; first finger shorter than second; the three inner fingers about $1 / 3$, the two outer ones nearly $1 / 2$ webbed; toes entirely webbed; two metatarsal tubercles, the outer one somewhat shorter than the inner one; a rather indistinct tarsal fold; the tarsometatarsal articulation reaches the shoulder.

Upper parts warty, lower ones granulate.

Blackish brown above, with a somewhat lighter band along the side; yellowish beneath. From snout to vent $84 \mathrm{~mm}$.

Description completed by means of notes, taken by Dr. J. Roux from the type specimen.

Habitat: Sumatra (Djapura, Indragiri).

1) The locality Java, mentioned by Boulenger, is probably incorrect. 


\section{Firmisternia.}

Epicoracoid cartilages firmly united in the median line.

\section{Fam. Brevicipitidae.}

\section{(Engystomatidae).}

Diapophyses of the sacral vertebra distinctly dilated. Terminal phalanges of fingers and toes simple or ' $\mathrm{T}$-shaped.

Omosternum rudimentary or none; sternum cartilaginous '); procoracoids and clavicles usually reduced or absent. Vertebrae procoelous. No ribs. Os coccygis usually articulating by two condyles.

Distribution: America; Africa; S.- and E.-Asia, including the entire Indo-Australian Archipelago; N.-Queensland.

\section{Dyscophinae.}

Upper jaw toothed, lower one toothless.

Distribution: Madagascar; India; Sumatra; Borneo.

$$
\text { Synopsis of the Genera. }
$$

A. Clavicles present. Pupil horizontal.......... I. Dyscophina p. 95. $B$. Clavicles absent.

I. Pupil vertical. Tongue forming a plicate pouch behind. 2. Colpoglossus p. 97.

II. Pupil round (or horizontal?). Tongue not forming a pocket................... 3. Calliglutus p. 98 .

\section{Dyscophina v. Kamp.}

(v. Kampen, Zool. Jahrb., Syst., XXII, 1905, p. 708).

Pupil horizontally elliptic, almost circular. Tongue entire and free behind, not forming a pocket. Palatine teeth in two long, somewhat oblique series behind the choanae, close to each other. Two smooth transverse dermal ridges across the palate, in front of the pharynx. Tympanum hidden. Fingers free, toes webbed; tips of fingers and toes slightly dilated. Outer metatarsals united.

No procoracoids; clavicles feeble. Omosternum rudimentary; sternum large, cartilaginous, partly calcified. Terminal phalanges club-shaped.

Distribution: Sumatra.

I) After Boettger there should be an osseous sternum in Cophixalus geislerorum. 
I. Dyscophina volzi v. Kamp.

Dyscophina volzi v. Kampen, Zool. Jahrb., Syst., XXII, 1905, p. 708, pl. XXVI.

Habit stout. Tongue oval; posterior dermal ridge of the palate strong, straight, the anterior one less developed, curved. Head much broader than long; snout as long as the upper eyelid or a little shorter, nearly as deep as long; canthus rostralis obtuse, curved; loreal region very oblique, feebly concave; nostril in the middle between the tip of the snout and the upper eyelid; interorbital space about once and a half the width of the upper eyelid; tympanum invisible. Tips of fingers feebly swollen, of toes distinctly dilated; first finger scarcely shorter than second, which is as long as fourth; third toe much longer than fifth; toes half webbed, the web reaching

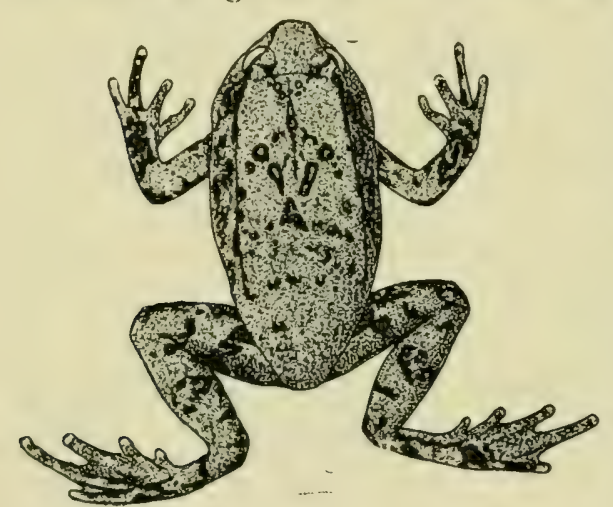

Fig. II. Dyscophina volzi v. Kamp., $\times 1 \frac{1}{4}$. nearly the tip of the fifth one, and that of the first and second ones at their outer side, the second subarticular tubercle in the third and fourth toe, the first tubercle at the inner side of the second toe; a dermal ridge reaches to the swollen tips of all toes and extends along the outer side of the fifth one; subarticular tubercles flat; a strong, compressed inner and a feeble outer metatarsal tubercle; the heel ${ }^{1}$ ) reaches the eye.

Upper parts smooth or very feebly granular, with a few small warts, some of them more or less perfectly confluent on each side of the back into a low and narrow longitudinal ridge from the posterior border of the eye backwards; another, feeble ridge from the eye to the shoulder; a feeble cross fold between the posterior borders of the eyes; smooth below.

Reddish brown, lighter below, with more or less confluent dark spots, which are most numerous on the sides of the

x) Not the tarso.metatarsal articulation, as is erroneously stated in the original description. 
body, the lower surface of the hind limbs, the throat and the posterior part of the belly; on the back they form a sometimes indistinct $\mathrm{X}$-shaped figure; posterior surface of thighs of uniform dark colour. Length $34 \mathrm{~mm}$.

Male with a subgular vocal sac.

Type specimen examined.

Habitat: Sumatra (Tandjong Laut, Palembang!).

\section{Colpoglossus Blgr.}

(Boulenger, Ann. Mag. Nat. Hist.; (7) XIII, I904, p. 42).

Pupil vertically elliptic. Tongue entire and free behind, forming a plicate pouch at the point of its posterior attachment. Palatine teeth in two transverse series, very close to each other. Two denticulate transverse dermal ridges in front of the pharynx. Tympanum hidden. Fingers free, toes webbed, the tips not dilated. Outer metatarsals united.

Procoracoids and clavicles absent, substituted by a ligament. No omosternum; sternum large, cartilaginous.

Distribution: Borneo.

\section{Colpoglossus brooksi Blgr.}

Colpoglossus Brooksii Boulenger, Ann. Mag. Nat. Hist., (7) XIII, I 904, p. 43, pl. II.

Habit stout. Tongue large, oval. Head strongly depressed, once and two thirds as broad as long; interorbital space three times as broad as the upper eyelid; tympanum hidden. Fingers obtusely pointed, toes blunt; first finger shorter than second; toes with a very short web at the base; subarticular tubercles indistinct; a rather large and very prominent inner metatarsal tubercle; the tarso-metatarsal articulation reaches the eye.

Skin of head and body granulate, of belly and limbs smooth.

Yellowish above, marbled with dark brown lines, which form a network on the sides and limbs; a )-(-shaped dark brown, light-edged marking on the head and nape, each of the longitudinal branches bifurcating in front and behind; two chains of small black spots, some with light centra, along the middle of the back; lower parts white, throat with wrinkle-like transverse brown lines. From snout to vent $50 \mathrm{~mm}$.

Habitat: Borneo (Bidi, Serawak). 
3. Calliglutus Barb. \& Noble.

(barbour and Noble, Proc. New England Zoöl. Club, Cambridge, Mass., VI, 1916, p. 20).

Pupil round (or horizontally elliptic?). Tongue entire and free behind, not forming a pocket. Palatine teeth in two transverse series, very close to each other. Tympanum hidden. Fingers free, toes webbed; tips of toes slightly dilated.

Procoracoids, clavicles and omosternum absent; sternum bilobate.

Distribution: Borneo.

I. Calliglutus smithi Barb. \& Noble.

Calliglutus smithi Barbour and Noble, Proc. New England Zoöl. Club, Cambridge, Mass., VI, 19I6, p. 20, pl. II and figs. I-2.

Habit stout. Tongue large, oval, slightly recurved in its posterior margin. Snout rounded, depressed; canthus rostralis indistinct; nostril close to the tip of the snout; interorbital space about thrice the width of the upper eyelid; tympanum hidden. Fingers not, toes slightly dilated; first finger shorter than second; toes with a very short basal web; subarticular tubercles feeble; a large inner, no outer metatarsal tubercle; the heel reaches the anterior border of the eye.

Skin smooth.

Dark brownish grey above, with symmetrical black blotches, edged with pinkish, on the sides and a red X-shaped spot above the vent; sides and throat washed with light brown and stippled with white; belly white.

Habitat: Borneo (Limbang river district, Serawak).

\section{Brevicipitina ${ }^{1}$ ).}

Both jaws toothless.

Distribution: the same as the family.

$$
\text { Synopsis of the Genera }{ }^{2} \text { ). }
$$

A. Procoracoids or clavicles or both of them present.

Pupil horizontal.

I) To this subfamily probably belongs "Bufo" minimus Lesson, Voyage Coquille, Zool., II, I, 1830, p. 62, pl. VII, fig. 4 (Ambon).

2) v. Méhely (Termész. Füzetek, XXIV, 1901, p. 219) divides the Engystomatidae (= Brevicipitinae of this book) in two subfamilies: I. Symphygnathinae: 
1. Vomerine teeth present. Two transverse dermal ridges in front of the pharynx. Toes free... r. Liophryne p. Ióò.

II. Vomerine teeth none.

I. A dermal ridge behind the choanae and two other ones in front of the pharynx. Toes webbed. ............... Calcphrynus p. 102.

2. No dermal ridge behind the choanae, one or two in front of the pharynx.

a. Tips of fingers and toes dilated. Toes free or webbed.

थ. The clavicle reaches the scapula...

3. Sphenophryne p. 104.

$\beta$. The clavicle does not reach the scapula.

4. Oreophryne p. 110.

b. Tips of fingers not, of toes slightly dilated.

Toes free. No clavicles..........

5. Microbatrachus p. 121.

$c$. Tips of fingers and toes not dilated. Toes

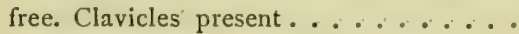

6. Oxydactyla p: $\mathbf{1 2 2 .}$

B. Procoracoids and clavicles absent.

I. Pupil vertical.

I. Each palatine bone with a series of teeth.

7. Callulops p, 123.

2. Palate toothless.............

8. Gastrophryne p. 124.

II. Pupil circular or horizontal.

I. No dermal ridges across the palate. Toes webbed. . . . . . . . . . 9. Phrynilla p. I24.

2. One or two transverse dermal ridges across the palate, in front of the pharynx.

a. Each palatine bone with one or two large tooth-like processes ........... Io. Xenobatrachus p. I26.

b. Palate unarmed. Tympanum more or less distinct.

$\alpha$. Toes free. One dermal ridge across the palate.

†. Tongue large, circular, perfectly attached behind. ........ I1. Xenorhina p. I31.

††. Tongue large, circular, slightly free behind......... 12, Asterophrys p. 133.

††. Tongue small, oval, extensively free behind ......... 13. Copiula p. 134 .

maxillary bones united with each other in front of the prae-maxillaries; 2. Eleuthe rognathinae: maxillary bones not united. As, however, this character is only known for a small part of the genera, it cannot yet be used for a division of the Brevicipitinae. To the Symphygnathinae belong after v. Méhely: Hylophorbus part. (Mantophryne, Gnathophryne) and Xenorhina, to the Elcutherognathinae: Hylophorbus part. (Metopostiva, Phrynixalus), Copiula, Sphenophryne and Oreophryne. 
$\beta$. Toes free ${ }^{1}$ ). Two dermal ridges across the palate.

†. Tips of fingers and toes dilated.

Tongue narrow......... 14. Choerophryne p. 136 .

††. Tips of fingers and toes dilated.

Tongue large......... 15. Hylophorbus p. 137 .

††. Tips of fingers and toes not dilated.

Tongue large.. ......... 16. Aphantophryne p. 145 .

$\gamma$. Toes webbed at the base. One dermal

ridge across the palate....... 17. Cophixalus p. 146.

c. Palate unarmed. Tympanum hidden.

$\alpha$. Upper eyelids involved in a flap of skin. 18. Pomatops p. I47.

$\beta$. Upper eyelid normal.

†. Each palatine bone forming a pro-

minent ridge across the palate.

Habit stout .......... 19. Kuloula p. 147.

††. No such ridges. Habit slender .. 20. Microhyla p. 152.

\section{Liophryne Bigr.}

(Boulenger, Ann. Mag. Nat. Hist., (6) XIX, I897, p. II).

Pupil horizontal. Tongue nicked and extensively free behind. Two oblique series of vomerine teeth behind the level of the choanae. Two transverse dermal ridges across the palate, in front of the pharynx, the posterior one strongly denticulate. Tympanum distinct. Fingers and toes free, the tips slightly swollen or with small disks. Outer metatarsals united.

Clavicles present ${ }^{2}$ ), very slender; no omosternum; sternum small.

Distribution: New Guinea.

\section{Synopsis of the Species.}

A. Heel renching the eye ............. L. . rhododactyla p. 100.

$B$. Heel reaching the shoulder.

I. Tympanum $2 / 3$ or $3 / 4$ diameter of eye.... 2. L. brevipes p. Ior.

II. Tympanum about $1 / 2$ diameter of eye. .... 3. L. kampeni p. IоI.

\section{Liophryne rhododactyla Blgr.}

Liophryne rhododactyla Boulenger, Ann. Mag. Nat. Hist., (6) XIX, I897, p. II, pl. II, fig. 2 .

1) Webbed in Hylophorbus (!) neuhaussi.

2) "Praecoracoid present, ossified" (Boulenger). 
Tongue large, oblong. Head much broader than long; snout rounded, shorter than the upper eyelid; canthus rostralis obtuse; loreal region concave; nostril a little nearer to the tip of the snout than to the eye; interorbital space a little broader than the upper eyelid; tympanum $2 / 3$ or $3 / 4$ the diameter of the eye. Fingers and toes rather elongate, depressed, the tips slightly swollen; first finger shorter than second; subarticular tubercles feebly prominent; a very indistinct inner metatarsal tubercle; the heel reaches the eye.

Skin smooth.

Dark purplish brown, finely powdered with crimson above, spotted with yellowish beneath; a very indistinct, fine, light vertebral line; a crimson spot above the vent; fingers and toes crimson above. From snout to vent $60 \mathrm{~mm}$.

Habitat: New Guinea (Mt. Victoria, Owen Stanley range).

\section{Liophryne brevipes Blgr.}

Liophryne brcvipes Boulenger, Ann. Mag. Nat. Hist., (6) XIX, I897, p. II.

Closely allied to L. rhododactyla, but differing in the much shorter limbs with shorter digits, the heel reaching only the shoulder.

A pair of curved dermal folds from the posterior border of the head to between the shoulders.

Grey-brown above, pinkish on the sides of the back; sides of head dark brown; belly greyish, marbled with brown, with a fine light median line; throat vinaceous red. From snout to vent $22 \mathrm{~mm}$.

Habitat: New Guinea (Mt. Victoria, Owen Stanley range).

\section{Liophryne kampeni Blgr.}

Liophryne kampeni Boulenger, Transact. Zool. Soc. London, XX, 1914, P. 252, pl. XXVII, fig. 4 .

Tongue large, covering the whole floor of the mouth, grooved; two long oblique series of vomero-palatine teeth behind the choanae. Head much broader than long; snout rounded, shorter than the upper eyelid; canthus rostralis obtuse; loreal region oblique, concave; nostril a little nearer the tip of the snout than the eye; interorbital space as broad as the upper eyelid; tympanum about half the diameter of the eye. Fingers and toes moderately elongate, with small disks; first finger shorter 
than second; subarticular and metatarsal tubercles feebly prominent; the heel reaches the shoulder.

Uniform dark brown above, pale brown beneath. From snout to vent $58 \mathrm{~mm}$.

Habitat: New Guinea (Mimika riv.).

\section{Calophrynus Tschudi.}

(Tschudi, Mém. Soc. Sc. nat. Neuchâtel, II, I839, p. 48, 86).

Pupil horizontal. Tongue entire and free behind. Palate toothless. A more or less distinct dermal ridge across the palate behind the choanae, and two other ones in front of the pharynx, the posterior one always, the other ones sometimes denticulate. Tympanum usually distinct. Fingers free, toes webbed, the tips without regular disks. Outer metatarsals united.

Clavicles present; omosternum present; terminal phalanges club-shaped.

Distribution: from S.-China through Cochinchina, Burma, Siam to the Malay Peninsula, Sumatra, Borneo and the Philippines; Madagascar.

\section{Synopsis of the Species.}

A. Third toe longer than fifth; second finger longer

than fourth.

I. Fourth finger normally developed. ........ . C. pleurostigma p. 102.

II. Fourth finger almost reduced to a knob. . . 2. C. heterochirus p. IO4.

$B$. Third toe not extending beyond fifth; second

finger as long as fourth.............. . . punctatus p. I04.

\section{Calophrynus pleurostigma S. Müll.}

Kalophrynus pleurostigma (S. Miiller), Tschudi, Mém. Soc. Sc. nat. Neuchâtel, II, 1839, p. 86.

Calophrynus pleurostigma Boulenger, Cat. Batr. Sal. Brit. Mus., 1882, p. 158.

Calophrynus pleurostigma Boulenger, Fauna Brit. India, Rept. and Batr., London, I 890, p. 490 , with fig. of palate.

Bufo studeri Isenschmid, Mitth. naturf. Ges. Bern., 1903, p. 14, pl. V, fig. 2. Calophrymus pleunostigma v. Kampen, Zool. Jahrb., Syst., XXII, 1905, p. 706.

Calophrynus pleurostigma Boulenger, Vert. Fauna Malay Penins., Rept. and Batr., London, 1912, p. 258.

Tongue elliptic. Head broader than long; snout feebly projecting, as long or nearly as long as the upper eyelid, 
longer than deep; canthus rostralis distinct, straight; loreal region vertical, concave; nostril nearer to the tip of the snout than to the eye; interorbital space broader than the upper eyelid; tympanum nearly as large as the eye, rarely hidden under the granulate skin. Tips of fingers and toes blunt or slightly swollen; first finger a little shorter than second, which is longer than fourth; third toe longer than fifth; toes half or nearly half webbed; subarticular tubercles very prominent; two more or less distinct rounded metatarsal tubercles; the tarso-

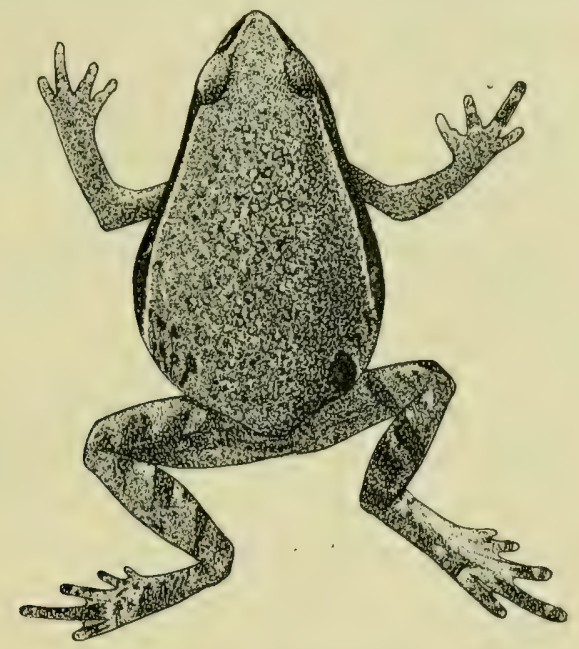

Fig. 12. Calophrynus pleurostigma S. Müll., XI.

metatarsal articulation reaches the shoulder or the eye; tibia $2 / 5$ the length of head and body.

Skin of the back smooth or granular, very thick, glandular; belly and lower surfaces of thighs coarsely granular; a more or less distinct lateral fold, commencing from the eye.

Brown, black or reddish, usually with round, black spots or a large, hour-glass shaped spot above; usually a large dark spot, sometimes bordered with white, in the loin; at each side a light stripe, dark edged beneath, from tip of snout to thigh; limbs with or without dark cross-bars; yellowish beneath, throat and breast sometimes marbled with black. From snout to vent $47 \mathrm{~mm}$.

Male with an internal vocal sac.

Habitat: Sumatra (Deli!; Agam; Padang!; Palembang!); Natuna islands; Borneo (Baram riv.; Mt. Dulit; Seberuang riv.; 
Meratus mts.; Pagat, distr. Batangalai; Semberrah riv.!). S.-China; Burma; Tonkin; Siam; Malay Peninsula, up to 900 m.; Singapore; Philippines ${ }^{1}$.

\section{Calophrynus heterochirus Blgr.}

Calophrynus heterochirus Boulenger, Proc. Zool. Soc. London, 1900, p. 186, pl. XVII, fig. 4 .

Tongue large, pyriform, covering the floor of the mouth. Snout truncate, slightly prominent, very short; canthus rostralis strong; loreal region nearly vertical; interorbital space broader than the upper eyelid; tympanum feebly distinct, about $2 / 3$ the diameter of the eye. Tips of fingers and toes bluntly pointed; first and second fingers very short, not half the length of third, fourth shorter still, almost reduced to a knob; toes short, third longer than fifth; toes $1 / 3$ webbed; subarticular tubercles and the two metatarsal tubercles feebly prominent; the heel reaches the eye.

Skin smooth.

Uniform purplish brown above, yellowish white beneath and on the sides of the head; a few large round yellowish-white spots on the lumbar region and on the back of the thighs. From snout to vent $27 \mathrm{~mm}$.

Eggs large.

Habitat: Borneo.

\section{Calophrynus punctatus Ptrs.}

Calophrynies punctatus Peters, Monatsber. Akad. Berlin, I87I, p. 579. Calophrynus punctatus Boulenger, Cat. Batr. Sal. Brit. Mus., I882, p. 158. Calophrynus punctatus Boulenger, Ann. Mus. Genova, (2) XIV, 1895, p. 6I7.

Fingers and toes remarkably short; fourth finger extending as far as second; third toe not extending beyond fifth.

Dark brown, punctated with black above. Length $27 \mathrm{~mm}$. Habitat: Mentawei islands (Sipora); Borneo (Serawak).

\section{Sphenophryne Ptrs. et Dor.}

(Peters e Doria, Ann. Mus. Genova, XIII, r878, p. 430).

Chaperina Mocquard, Mém. Soc. Zool. France, V, 1892, p. I 94. Austrochaperina Fry, Rec. Australian Mus., IX, No. I, I912, p. 87.

I) According to Peters, Monatsber: Akad. Berlin, 1871, p. 579 (perhaps C. sitellatus Stejn. ?). 
Pupil horizontal. Tongue entire or feebly nicked, and free behind. Palate toothless. One or two transverse dermal ridges across the palate, in front of the pharynx. Tympanum distinct or hidden. Fingers free, toes free or webbed at the base, with disks. Outer metatarsals united.

Procoracoids and clavicles present, the latter reaching the scapulae; no omosternum. Terminal phalanges T-shaped.

Distribution : Borneo; Philippines; New Guinea ; northern Queensland.

\section{Synopsis of the Species.}

A. Disks of fingers larger than those of toes .... I. S. cormuta p. 105.

B. Disks of toes larger than those of fingers.

I. Snout not longer than the eye.

I. The heel reaches to between eye and tip of snout..................... klossi p. 107.

2. The heel reaches the tympanum or the eye. 3. S. macrorhyncha p. 107.

3. The heel does not reach the tympanum .. 4. S. polysticta p. 108.

II. Snout longer than the eye.

1. Tympanum distinct........... 5. S. fusca p. Iog.

2. Tympanum absent ........... 6. S. beyeri p. IIo.

\section{Sphenophryne cornuta Ptrs. \& Dor.}

Cornufer zinicolor part., Tschudi, Mém. Suc. Sc. nat. Neuchâtel, II, 1839, p. 28, 7 I $^{1}$ ).

Sphenophryne cornuta Peters e Doria, Ann. Mus. Genova, XIII, I878, p. 430, pl. VII, fig. 4 .

Sphenophryne cornuta Boulenger, Cat. Batr. Sal. Brit. Mus., 1882, p. 157 .

Chaperina ceratophthalmus v. Kampen, Nova Guinea, IX, pt. I, I909, p. 43, pl. II, fig. 8.

Sphenophryne cormuta Wandolleck, Abh. Zool. Mus. Dresden, XIII, N0.6, I9II, p. 4, figs. $\mathrm{x}-9$.

Chaperina ceratophthalmus v. Kampen, Zool. Jahrb., Syst., XXXVII, I9I4, p. 378. ?Chaperina friedericii Sternfeld, Abh. Senckenb. naturf. Ges., XXXVI, I918, p. 435 , pl. XXXI, fig. 8.

Tongue entire or slightly nicked behind; a denticulated dermal ridge across the palate, and sometimes a median tubercle in front of it. Head as long as broad; snout pointed, projecting, as long as or a little longer than the upper eyelid and much longer than deep; canthus rostralis angular; loreal region vertical, nearly flat; nostril nearer to the tip of the snout

I) I examined the specimen in the Leiden Museum, mentioned by Tschudi, 
than to the eye; interorbital space $1 / \frac{1}{2}$ to 2 times as broad as the upper eyelid; tympanum more or less distinct, $1 / 3$ to $2 / 3$ the diameter of the eye. Second to fourth fingers with large disks (diameter of that of third finger $2 / 3$ of, to equal to that of the tympanum), first finger only swollen at the tip; disks of toes smaller than those of fingers; first finger much shorter than second, which is shorter than fourth; third toe longer than fifth; toes with a very rudimentary web; subarticular and inner metatarsal tubercles flat or very indistinct, no outer metatarsal tubercle; the heel reaches the eye or to between the eye and the tip of the snout; tibia about half length of head and body.

Smooth or finely granulate above; often a small pointed flap on the margin of the upper eyelid and another one at the

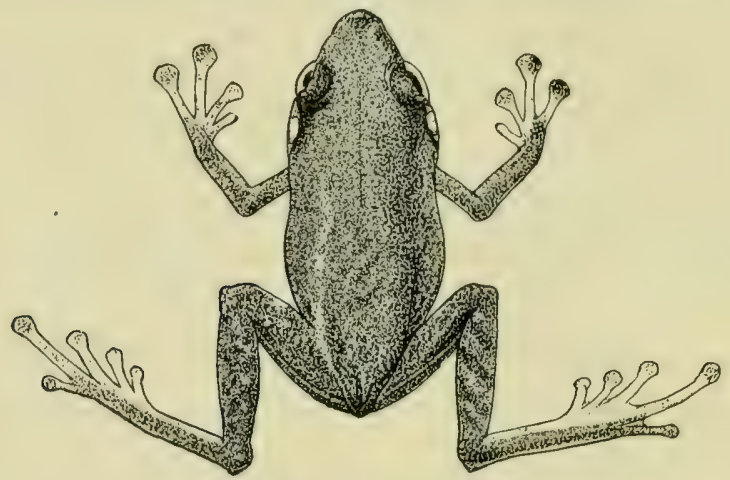

Fig. 13. Sphenophryne cornuta Pts. \& Dor., XI.

heel; a series of small tubercles along the outer side of the tarsus and the fore-arm; beneath with small, scattered, rounded tubercles.

Brown above, sometimes spotted and marbled with blackish; beneath lighter, sometimes vermiculated with dark, and with an irregular dark longitudinal streak on the throat; a fine light mediodorsal and medioventral line may be present. Length $4 \mathrm{I} \mathrm{mm}$.

Clavicles strongly curved.

Eggs large (ovarial eggs $3,5 \mathrm{~mm}$. in diameter).

Habitat: New Guinea (Samson riv.; Mt. Kohari, \pm 600 m.!; Sangke riv.!; Pomora riv., $\pm 760 \mathrm{~m}$. !; Torricelli mts., 650-700 m.; Vikaiku, St. Joseph riv.; Lorentz riv., $40 \mathrm{~m}$. !; Went mts., $800 \mathrm{~m}$. !; Hellwig mts., 900 to $\pm 2500 \mathrm{~m}$. !; Setekwa riv.). 


\section{Sphenophryne klossi Blgr.}

Sphenophryne klossi Boulenger, Transact. Zool. Soc. Londun, XX, pt. 5, I914, p. $25 \mathrm{I}$, pl. XXVII, figs. $3-3$.

Tongue entire. Head broader than long; snout obtusely pointed, projecting and obliquely truncate, as long as the eye; canthus rostralis strong; loreal region moderately oblique, slightly concave; interorbital space broader than the upper eyelid; tympanum moderately distinct, about $2 / 3$ the diameter of the eye. Disks of fingers very small, of toes a little larger; first finger shorter than second; toes free; subarticular and metatarsal tubercles not very prominent; the heel reaches to between the eye and the tip of the snout.

Smooth, with a few small warts above and two chevronshaped fine glandular ridges on the scapular region, pointing towards each other (\rangle\langle)$;$ a narrow glandular fold from behind the eye to the side of the body; a fine glandular ridge along the middle of the back.

Yellow above, with an interrupted blackish bar between the eyes, another, $\wedge$-shaped, on the scapular region, and a third on the sacral region; loreal and temporal regions blackish brown, this shade sometimes continued to the side of the body below the glandular lateral fold; limbs with dark brown cross-bars; hinder side of thighs blackish brown; lower parts white, throat and lower surface of hind limbs mottled with brown; a fine white line from the tip of the snout to the gular region. From snout to vent $42 \mathrm{~mm}$.

Dr. Boulenger informs me, that in this species a slender clavicle, reaching the scapula, is present.

Habitat: New Guinea (Setekwa riv.).

\section{Sphenophryne macrorhyncha (v. Kamp.).}

Chaperina macrorhyncha and basipalmata v. Kampen, Nova Guinea, V, pt. I, 1906, p. 168, 169, pl. VI, figs. 3-5.

Chaperina macrorhyncha v. Kampen, ibid., IX, pt. I, I909, p. 43.

? Sphenophryne schlaginhaufcni Wandolleck, Abh. Zool. Mus. Dresden, XIII, No .6, 1911, p. 5, figs. Io-17.

?Chaperina quatuorlobata Wandolleck, ibid., p. 9, figs. 36-46.

Chaperina punctata and busipalmata v. Kampen, Nova Guinea, IX, pt. 3, I913, p. 463,464 , pl. XI, fig. 7 .

Chaperina basipalmata and punctata v. Kampen, Zool. Jahrb., Syst., XXXVII, 1914, p. 377, 378 .

Tongue entire or feebly nirked behind; a denticulated dermal 
ridge across the palate, between the tubae, and in front of it another smooth one, which may be substituted by one or three tubercles or be entirely absent. Head a little broader than long; snout more or less pointed, projecting, about as long as or shorter than the upper eyelid, and longer than deep; canthus rostralis obtuse; loreal region nearly vertical, feebly concave; nostril equally distant from tip of snout and eye; interorbital space as broad as to twice the width of the upper eyelid; tympanum hidden or feebly distinct, $1 / 4$ to $2 / 3$ the diameter of the eye. Fingers and toes with distinct disks, those of toes a little larger than those of fingers, the largest one at most as large as the tympanum; disk of first finger smaller than the other ones; first finger shorter than second, which is shorter than fourth; third toe longer than fifth; toes free or slightly webbed at the base; subarticular and inner metatarsal tubercies very flat; no outer metatarsal tubercle; the heel reaches the tympanum or the eye; tibia about half the length of head and body.

Skin smooth.

Upper parts brownish or grey, uniform or with dark, round spots or marblings; often a dark streak along loreal and temporal regions, sometimes continued along the side of the body; limbs spotted or cross-barred; whitish beneath, throat and lower surface of limbs usually more or less vermiculated with grey or brown. Length $35 \mathrm{~mm}$.

Clavicles strongly curved.

Type specimen in the Leiden Museum examined.

The existence of specimens intermediate between the three species I formerly distinguished make it necessary to unite them.

Habitat: New Guinea (Mamberamo riv.!; near Doorman riv., \pm 850 m.!; Manikion region!; Tawarin riv.!; Air Mo riv.!; Humboldt bay!; Timena riv.!; Pomora riv., $\pm 760 \mathrm{~m}$. !; Begowre riv.!; ? Torricelli mts., 650-700 m.; Went mts., 800-I0 0 m.!; Hellwig mts., 900- \pm 2500 m.!; Mimika riv.).

\section{Sphenophryne polysticta (v. Méh.).}

Chaperina polysticta v. Méhely, Termész. Füzetek, XXIV, I901, p. 258, pl. X, fig. 3 (shoulder-girdle), XII, fig. 4 .

Tongue large, oblong, entire; a denticulated dermal ridge across the palate behind the tubae, and a round tubercle in 
front of it. Snout obtusely rounded, a little shorter than the eye; canthus rostralis rounded; interorbital space a little broader than the upper eyelid; tympanum distinct, somewhat more than $2 / 5$ the diameter of the eye. Disks of fingers small, that of first finger still smaller than those of the other ones, those of the toes a little larger, but not more than half the diameter of the tympanum; first finger much shorter than second, which is shorter than fourth; third toe much longer than fifth; toes free; subarticular tubercles very indistinct, inner metatarsal tubercle small; the tarso-metatarsal articulation reaches the tympanum.

Skin smooth.

Yellowish red, back more brownish, upper parts with rather large, irregular, reddish brown spots; eyelids and snout blackish; a few light spots on the upper lip; a dark lateral band from the eye to the middle of the body; throat and breast marbled with reddish brown. Length $16,5 \mathrm{~mm}$.

Habitat: New Guinea (Sattelberg).

\section{Sphenophryne fusca (Mocq.).}

Chaperina fusca Mocquard, Mém. Soc. Zool. France, V, 1892, p. 194, pl. VII, figs. $2-2 b$.

Chaperina fasca v. Méhely, Termész. Füzetek, XXIV, I901, p. 257, pl. VI, figs. $4-5$ (skull), X, fig. 7 (terminal phalanx), XII, fig. 3 .

Tongue large, oval, entire; a denticulated dermal ridge across the palate behind the tubae, and a round tubercle in front of it. Head a little broader than long; snout rounded, hardly longer than the eye; canthus rostralis very obtuse; loreal region oblique; nostril nearer to the tip of the snout than to the eye; interorbital space nearly twice the width of the upper eyelid; tympanum distinct, somewhat less than half the diameter of the eye. Fingers and toes with small disks, those of the toes somewhat larger than those of the fingers; first finger shorter than second; third toe longer than fifth; toes free; subarticular and the oblong inner metatarsal tubercle feebly developed; the heel reaches the eye.

Skin smooth; a fold above the tympanum.

Brown above; throat and breast brownish, dotted with white; belly and lower surface of thighs yellowish, finely speckled or marbled with brown. Length $24 \mathrm{~mm}$.

The description given above has been taken from v. Méhely, 
who describes specimens from New Guinea. Probably a comparison of specimens of this island and Borneo will show, that they belong to two different species, if not genera. The specimens of Borneo, after the description of Mocquard, have an other colouration: their upper surfaces are very dark brown, nearly black, their lower parts are covered with a network of brown lines, including yellow meshes. It is possible that they belong to quite another family; they may even be identical with Nectophryne picturata Smith.

Habitat: Borneo (Sintang); New Guinea (Sattelberg).

\section{Sphenophryne beyeri (Taylor).}

Chaperina beyeri Taylor, Philipp. Jrn. of Sc., XVI, r920, p. 333, pl. III, fig. 3.

Tongue entire; a rather indistinct, small dermal ridge across the palate. Head broader than long; snout short, truncate, a little longer than the eye, nostril nearer the tip of the snout than the eye; interorbital space more than $I^{2} / 3$ times the width of the upper eyelid; no tympanum. Fingers and toes with well-developed disks, except that of first finger, which is small; first finger very short, much shorter than second, which is shorter than fourth; subarticular tubercles large; third toe much longer than fifth; toes free; the heel reaches the eye.

Skin smooth; elbows and heels each with a distinct dermal spine.

Above grey-brown to black; sides, posterior part of back and limbs with or without small yellow dots; limbs with irregular dark cross-bars; dermal spines on limbs yellow; lower surface yellow to orange spotted, and reticulated with brownish, forming rather rounded yellow spots. From snout to vent $23 \mathrm{~mm}$.

Tad pole. - Nostril nearer to tip of snout than to eye; eyes lateral, the distance between them more than twice their distance to the end of the snout; spiraculum sinistral. Blackish; lighter below. Length $23 \mathrm{~mm}$.

Habitat: Philippines, incl. Pelawan.

\section{Oreophryne Bttgr.}

(Boettger, Zool. Anz., XVIII, 1895, p. 135, and: Abh. Senckenb. naturf. Ges., XXV, I901, p. 37 I; v. MéHely, Termész. Fiizetek, XXIV, I901, p. 254). Sphenophryne autt., part.

Méhelyia Wandolleck, Abh. Mus. Dresden, XIII, No. 6, I9II, p. 6.

Pupil horizontal. Tongue entire or slightly nicked, and free 
behind. Palate toothless. One or two transverse dermal ridges across the palate, in front of the pharynx. Tympanum indistinct or hidden. Fingers free, toes free or feebly webbed, with disks. Outer metatarsals united.

Procoracoids and clavicles present, the latter not reaching the scapulae; no omosternum ${ }^{1}$ ). Terminal phalanges T-shaped.

Distribution: from Celebes to New Guinea.

A. Toes free.

$$
\text { Synopsis of the Species. }
$$

I. Metatarsal tubercle absent.

I. Tympanum $2 / 3$ or $3 / 4$ the width of the eye.

I. O. variabilis p. $1 \mathbf{I} 2$.

2. Tympanum about $1 / 3$ the width of the eye, or hidden ............

2. O. celebensis p. $\mathbf{1} \mathbf{1 2}$.

II. Metatarsal tubercle present.

1. The heel does not reach the eye. Tympanum hidden ............ 3. O. monticola p. II3.

2. The heel reaches the eye or beyond. Tympanum about $1 / 2$ the width of the eye, or hidden.

a. First finger with a disk....... 4. O. verrucosa p. II3.

b. Tip of first finger not dilated..... 5. O. ateles $\mathrm{F}_{4} \mathrm{II}$

$B$. Toes webbed.

I. The procoracoid reaches the scapula.

I. Interorbital space much broader than the upper eyelid ................

2. Interorbital space as broad as the upper eyelid. ................ 7. O. crucifera p. I16.

II. Procoracoid connected with the scapula by a ligament only.

I. Tympanum about $1 / 2$ the width of the eye. 8. O. anthonyi p. II 7 .

2. Tympanum about $1 / 3$ the width of the eye.

$a$. Fifth toe extending beyond third.

«. The heel reaches the shoulder or the tympanum......... 9. O. loriae p. II7.

$\beta$. The heel reaches the eye ..... Io. O. biroi p. II 8 .

b. Fifth toe as long as third.

ж. Two dermal palatine ridges.... II. O. albopunctata p. II9.

. One dermal palatine ridge .... I2. O. mertoni p. 120.

I) The pectoral arch of $O$. ateles, variabilis and monticola has not been described; as to variabilis and monticola Dr. Boulenger informs me, that a cartilaginous procoracoid is present, but that he cannot find a clavicle. The position of these species in the genus therefore is only provisional. 


\section{Oreophryne variabilis (Blgr.).}

Sphenophryine variabilis Boulenger, Ann. Mag. Nat. Hist., (6) XVIII, 1896, p. 64 : Sphenophryne variabilis Boulenger, Proc. Zool. Soc. London, I897, p. 235; pl. XVI, fig. 5 .

Tongue large, oval, entire. Snout rounded, short; canthus rostralis feebly marked; interorbital space broader than the upper eyelid; tympanum feebly distinct, $2 / 3$ or $3 / 4$ the diameter of the eye. Fingers with very large, toes with much smaller disks; first finger shorter than second; toes free; no subarticular or metatarsal tubercles; the heel reaches the shoulder or the tympanum.

Skin smooth above; belly granulate.

Coloration very variable; grey, brown, purple, pink, or crimson above, uniform or with darker marblings, or with a lighter yellow or pink lateral streak; a light vertebral line sometimes present; sides of head usually dark brown; a dark light-edged ocellus may be present in the lumbar region; beneath uniform whitish, or greyish with yellow spots, or dark brown with yellow spots. From snout to vent $28 \mathrm{~mm}$.

Habitat: Celebes (Peak of Bonthain, I $500-2000$ m.).

\section{Oreophryne celebensis (F. Müll.).}

? Phrynomantis fusca Peters, Monatsber. Akad. Berlin, 1867, p. 35 .

?Phrynomantis fusca Peters e Doria, Ann. Mus. Genova, XIII, 1878, p. 429.

? Phrynomantis fusca Boulenger, Cat. Batr. Sal. Brit. Mus., I882, p. 173.

Sphenophryne celcbcnsis F. Müller, Verh. naturf. Ges. Basel, X, I 895, p. 84 I, with fig. Sphenophryne celebensis Boulenger, Proc. Zool. Soc. London, I897, p. 235, pl. XVI, fig. 4.

Oreophryne celebensis v. Méhely, Termész. Füzetek, XXIV, 1901, p. 256, pl. X, fig. I (shoulder-girdle).

Tongue large, oval, entire. Snout rounded, short; canthus rostralis feebly marked; loreal region nearly vertical; interorbital space as broad as or a little broader than the upper eyelid; tympanum hidden or scarcely distinct, about $1 / 3$ the diameter of the eye. Fingers with very large, toes with much smaller disks; first finger shorter than second; toes free; third toe longer than fifth; no subarticular or metatarsal tubercles; the heel reaches the eye or a little beyond.

Smooth, or with scattered small warts above; a small tubercle sometimes present on the upper eyelid; belly granulate or smooth. 
Colouration very variable; yellowish, reddish, pink, or brown above, uniform or with darker spots or marblings; a triangular dark marking between the eyes, or an X-shaped or hourglassshaped marking from between the eyes to the interscapular region; upper surface of snout sometimes pink; a dark streak on the canthus rostralis; sometimes a light vertebral line; greyish or brownish beneath, uniform or mottled with dark brown. From snout to vent $30 \mathrm{~mm}$.

Male without vocal sac.

The procoracoid reaches the scapula.

$\mathrm{H}$ a b it a t: Celebes (Indrulaman; Bowonglangi peak, $2000 \mathrm{~m}$.; Bua Praeng; Luwu, I0O-500 m.; Takalekadjo mts.; Takala mts., I200-I600 m.; Topapu, I400 m.; Mt. Momi; Matinan mts., 260 m.; Bone mts., I 200 m.; Bulawa mts., \pm 1200 m.; Totoyia valley, Soo m.; Mt. Emponglar; Mt. Masarang; summit of Gunung Sudara); Ambon?; Batanta?

\section{Oreophryne monticola (Blgr.).}

Sphenophryne monticola Boulenger, Ann. Mag. Nat. Hist., (6)XIX, 1897, p. 508.

Tongue large, oval, entire. Snout rounded, short; canthus rostralis feebly marked; interorbital space as broad as or broader than the upper eyelid; tympanum hidden. Fingers with welldeveloped disks; disks of toes hardly smaller than those of fingers; first finger shorter than second; toes free; no subarticular tubercles; a very indistinct inner metatarsal tubercle; the heel reaches the shoulder or the temple.

Smooth or with small warts above; belly indistinctly granulate.

Colouration very variable; grey, brown, or magenta-red above, uniform or with darker spots or marblings, with or without a yellowish-white stripe from the upper eyelid to the groin; sometimes a fine whitish line along the middle of the back and along the hind limb; lower parts whitish or pinkish, inner side of hind limbs usually bright pink; throat speckled with brown or entirely dark brown. From snout to vent $26 \mathrm{~mm}$.

Habitat: Lombok, $1200 \mathrm{~m}$.

\section{Oreophryne verrucosa (Blgr.).}

Sphenophryne verrucosa Boulenger, Ann. Mus. Genova, (2) XVIII, 1898, p. 707, pl. VIII, fig. 2.

Oreophryne verrucosa v. Kampen, Nova Guinea, IX, pt. 3, r9I3, p. 463.

S Sphenophryne wolft Sternfeld, Abh. Senckenb. naturf. Ges., XXXVI, 1918, p. 435 , Pl. XXXI, fig. 9. 
'Tongue entire or slightly nicked behind; a denticulated dermal ridge across the palate and usually another, smooth one, divided into three parts, in front of it. Head a little broader than long; snout obtusely pointed, feebly projecting, as long as the eye, longer than deep; canthus rostralis rather strong; loreal region vertical or nearly so, concave; nostril nearer to the tip of the snout than to the eye ; interorbital space a little broader than the upper eyelid; tympanum hidden or more or less distinct, about half the diameter of the eye. Disk of first finger small, of the other ones large, broader than long, about twice the width of the digit and as large as the tympanum; disks of toes smaller than those of fingers; first finger shorter than second, which is as long as fourth; third toe longer than fifth; toes free; subarticular and inner metatarsal tubercles flat, indistinct; the heel reaches the eye or to between the eye and the tip of the snout.

Skin of upper parts smooth, or uneven, with flat warts and wavy ridges; a more or less distinct conical tubercle near the edge of the upper eyelid often present; lower parts smooth, or belly slightly granulate.

Colour very variable; greyish to blackish above, usually with blackish spots or marblings; sometimes a light transverse bar between the eyes or a light vertebral line; groin and sides of thighs often black, spotted with white; an ill-defined ocellus often present on each side of the lumbar region; lower surface more or less spotted with brown, especially on throat and breast. From snout to vent $33 \mathrm{~mm}$.

Male without vocai sac.

The procoracoid reaches the scapula.

This species has been found by Mr. W. C. van Heurn in the cavities of Hydnophytum (near Idenburg riv., 2400-2900 m.), which in this locality were not inhabited by ants. Each plant usually contained two frogs and a clump of about io to 20 large eggs (about $5 \mathrm{~mm}$. in diameter), which stuck by a string of mucilage to the ceiling of one of the largest cavities. The development is direct.

Habitat: New Guinea (near Idenburg riv., I400 and 2400-2900 m.!; Moroka, Bartholomew range, 700 m.; Mt. Victoria; Hellwig mts., \pm 2500 m.!). 


\section{Oreophryne ateles (Blgr.).}

Sphenophryne ateles Boulenger, Ann. Mus. Genova, (2) XVIII, I\$98, p. 708, pl. VIII, fig. 4 .

Tongue entire. Head broader than long; snout rounded, feebly projecting, a little shorter than the eye; canthus rostralis strong; loreal region slightly oblique, concave; interorbital space a little broader than the upper eyelid; tympanum distinct, half the width of the eye. Tip of first finger not dilated, three outer ones with very large disks, which are broader than long, twice the width of the digit, and half the diameter of the eye; toes with large disks, which are smaller than those of the fingers; first finger very short, not half as long as second; toes free; subarticular and metatarsal tubercles flat, indistinct; the heel reaches the eye.

Upper parts with small warts and longitudinal ridges; lower parts smooth.

Grey or brown above; sides and upper surface of snout usually yellowish; a curved blackish dorso-lateral stripe and a light vertebral line or broad stripe sometimes present; brown or blackish beneath. From snout to vent $15 \mathrm{~mm}$.

I suggest that this species is based on the young of 0 . aerrucosa. $\mathrm{H}$ a b it a t: New Guinea (Moroka, Bartholomew range, $700 \mathrm{~m}$.).

\section{Oreophryne senckenbergiana Bttg.}

: Microhyla achatina var. moluccensis Peters e Doria, Ann. Mus. Genova, XIII, I 878 , p. 428 .

? Callalla frontifasciata Horst, Notes Leyden Mus., V, 1883, p. $243^{1}$ ). Orcophryne senckenbergiana Boettger, Zool. Anz., XVIII, 1895, p. I36.

Oreophryne senckenbergiana Abh. Senckenb. naturf. Ges., XXV, I90I, p. 37I, pl. XVI, figs. II-I I $c$.

Orcophry'ne Senckenbergiana v. Méhely, Termész. Füzetek, XXIV, I 901, p. 254, 255.

Tongue large, oval, entire; a denticulated dermal ridge across the palate, between the tubae, and another one in front of it. Snout obtusely pointed, a little shorter than the eye; interorbital space much broader than the upper eyelid; tympanum hidden or indistinct, about $1 / 3$ the diameter of the eye. Disks of fingers and toes nearly equal in size, large, triangular and truncated; first finger shorter than second; toes slightly,

1) The type specimens have been lost (after communication of Dr, van Lidth de Jeude). 
to almost $1 / 3$ webbed; subarticular tubercles indistinct; an inner very feeble, flat metatarsal tubercle, no outer one; the heel reaches the tympanum or the posterior border of the eye.

Upper surfaces smooth; belly and lower surface of thighs coarsely granulate.

White, marbled with grey; a white cross-bar between the eyes; a black temporal streak, bordered above and below with white; sides of body black and white spotted; a large black spot, broadly bordered with white, in the loin; brownishyellow, spotted and marbled with white, below; sometimes entirely brownish-yellow, without markings. Length $26 \mathrm{~mm}$.

Male with a subgular inner vocal sac.

The procoracoid reaches the scapula.

$\mathrm{Hab}$ it at: Morotai ?; Halmahera; Ternate ?; Batjan?; Salawati ?

\section{Oreophryne crucifera (v. Kamp.).}

Cophixalus crucifer v. Kampen, Nova Guinea, IX, pt. 3, I9I3, p. 462, pl. XI, fig. 6. Oreophryne crucifera v. Kampen, Nova Guinea, XIII, pt. I, I9I5, p. 4I.

Tongue oblong, very feebly nicked behind, free in its postetior half; a denticulated dermal ridge across the palate and in front of it sometimes a feebly developed smooth one. Head broader than long; snout vertically truncate, shorter than the upper eyelid; canthus rostralis sharp, curved; loreal region very oblique, a little concave; interorbital space as broad as the upper eyelid; tympanum hidden or distinct, about $1 / 3$ the diameter of the eye. Fingers and toes with large disks, those of the three outer fingers somewhat more than half the diameter of the eye, of first finger smaller, of toes a little smaller than those of fingers; first finger shorter than second, which is longer than fourth; third and fifth toe about equal in length; toes webbed at the base; subarticular and inner metatarsal tubercles feeble, no outer metatarsal tubercle; the heel reaches the eye, the tarsometatarsal articulation beyond the tip of the snout; tibia half the length of head and body.

Lower surfaces of head and boày entirely granulate, of thighs smooth.

Reddish brown above; an hourglass-shaped figure on the back and a roundish spot in the lumbar region yellowish; a yellow cross-bar between the eyes; upper arm and thigh for the greater part, and belly entirely colourless, or the belly finely powdered with brown. Length $24 \mathrm{~mm}$. 
The procoracoid reaches the scapula.

Type specimen examined in the Amsterdam Museum.

Habitat: New Guinea (Went mts., 800-1050 m.!; Setekwa riv.).

\section{Oreophryne anthonyi (Blgr.).}

Sphenophryne anthonyi Boulenger, Ann. Mag. Nat. Hist., (6) XIX, I897, p. 10, pl. II, fig. I.

Orcophryne anthonyi v. Kampen, Nova Guinea, XIII, pt. I, 1915, p. 40.

Tongue large, oval, entire; a denticulated dermal ridge across the palate and another, smooth one, divided into three parts, in front of it. Head nearly as long as broad; snout rounded, vertically truncate, nearly as long as the eye, as deep as long; canthus rostralis distinct; loreal region nearly vertical, concave; nostril nearer to the tip of the snout than to the eye; interorbital space as broad as or a little broader than the upper eyelid; tympanum distinct, about half the diameter of the eye. Fingers with very large, subtriangular disks, which are broader than long; disks of toes much smaller; first finger shorter than second, which is as long as fourth; third and fifth toe about equal in length; toes with a rudiment of web; subarticular and inner metatarsal tubercles absent or feebly developed; the heel reaches the shoulder or the tympanum.

Upper parts smooth; throat and belly areolate.

Colouration very variable; grey, brown, or reddish above, speckled or spotted with black, or with large light blotches; a fine light vertebral line sometimes present; thighs and lower parts brown, uniform or spotted with yellow, or yellowish, marbled and reticulated with dark brown; male with a light line along the chin and throat. From snout to vent $45 \mathrm{~mm}$.

Male without vocal sacs.

Procoracoid connected with the scapula by a ligament only. Habitat: New Guinea (Mt. Victoria, Owen Stanley range; Lorentz riv., $40 \mathrm{~m}$.!).

\section{Oreophryne loriae (Blgr.).}

Sphenophryne loriae Boulenger, Ann. Mus. Genova, (2) XVIII, 1898, p. 707, pl. VIII, fig. 3 .

Sphenophryne loriae v. Kampen, Nova Guinea, IX, pt. I, I909, p. 4I. Sphenophryne biroi v. Kampen, Nova Guinea, XIII, pt. I, I9I5, p. 40 (nec Sph. biroi v. Méh.). 
Tongue oblong or oval, entirc or very slightly nicked behind; a denticulated dermal ridge across the palate, and another smooth one, very little developed, in front of it. Head broader than long; snout rounded, feebly projecting, shorter than the eye and as long as deep; canthus rostralis obtuse; loreal region nearly vertical, concave; nostril nearer to the tip of the snout than to the eye; interorbital space as broad as or broader than the upper eyelid; tympanum moderately distinct or indistinct, about $1 / 3$ the diameter of the eye. Fingers with very large subtriangular disks, which are broader than long, that of third finger about half the diameter of the eye, that of first one smaller, but well-developed; disks of toes large, scarcely smaller than those of fingers; first finger shorter than second, which is about as long as fourth; fifth toe hardly longer than third; toes webbed at the base; subarticular and inner metatarsal tubercles flat, indistinct; no outer metatarsal tubercle; the heel reaches the shoulder or the tympanum.

Skin smooth.

Colouration very variable; grey, brown, or reddish above, uniform or with dark spots or marblings, with or without a yellow vertebral line; often a dark brown triangular blotch on the back of the head, the base between the eyes; sometimes a semilunar light spot in the lumbar region; lower parts whitish, uniform or powdered with brown. From snout to vent $28 \mathrm{~mm}$.

Procoracoid connected with the scapula by a ligament only.

Habitat: New Guinea (Moroka, Bartholomew range, 700 m.; Lorentz riv.!).

Io. Oreophryne biroi (v. Méh.).

Sphenophryne biroi v. Méhely, Termész. Fiizetek, XX, I897, p. 4I I, pl. X, figs. 3-6. Sphenophryne biroi v. Méhely, Termész. Füzetek, XXIV, 1901, p. 252, pl. X, fig. 2 (shoulder-girdle); pl. XI, fig. 6 (skull).

?Méhelyia lineata Wandolleck, Abh. Zool. Mus. Dresden, XIII, I9II, N0.6, p. 7 , figs. $18-26$.

? Méhelyia affinis Wandolleck, ibid,, p. 8, figs. 27-35.

Sphenophryne biroi v. Kampen, Nova Guinea, IX, pt. 3, I9I3, p. 462.

Tongue oblong, entire, about half free behind; a denticulated dermal ridge across the palate, in front of the pharynx, and three dermal tubercles, sometimes nearly united into a continuous ridge, in front of it. Head nearly as long as broad; 
snout vertically truncate, shorter than the upper eyelid; canthus rostralis obtuse; loreal region slightly oblique, concave; nostril much nearer to the tip of the snout than to the eye; interorbital space broader than the upper eyelid; tympanum feebly distinct, about $1 / 3$ the width of the eye. Disks of fingers ard toes rather large, about as large as the tympanum, those of toes a little smaller than those of fingers; first finger much shorter than second, which is as long as fourth; toes webbed at the base; fifth toe slightly longer than third; subarticular and inner metatarsal tubercles very feeble, no outer metatarsal tubercle; the heel reaches the eye; tibia half length of head and body.

Skin smooth, granulate on the belly and the lower and posterior surfaces of the thighs.

Upper parts yellowish red, with blackish dots and larger spots or longitudinal streaks; limbs with indistinct dark crossbars; beneath light reddish brown, sometimes powdered or marbled with dark brown. Length $25 \mathrm{~mm}$.

Procoracoid connected with the scapula by a ligament only.

Habitat: New Guinea (Torricelli mts.?; near Friedrich Wilhelmshafen ; Sattelberg; Moroka, Bartholomew range, $700 \mathrm{~m}$; Van der Sande riv.!).

\section{I. Oreophryne albopunctata (v. Kamp.).}

Sphenophryne albopunctata v. Kampen, Nova Guinen, IX, pt. I, I909, p. 42, pl. II, fig. 7 .

Tongue oval, entire, about $1 / 3$ free behind; two dermal ridges across the palate, the posterior one denticulated. Head a little broader than long; snout rounded, feebly projecting, shorter than the upper eyelid; canthus rostralis rounded; loreal region nearly vertical, slightly concave; interorbital space much broader than the upper eyelid; nostril much nearer to the tip of the snout than to the eye; tympanum very indistinct, about $1 / 3$ the diameter of the eye. Fingers with large disks, that of third finger larger than half the width of the eye, that of first finger and those of toes a little smaller than those of outer fingers; first finger shorter than second, which is nearly as long as fourth; toes webbed at the base, third and fifth of equal length; subarticular and inner metatarsal tubercles flat, no outer metatarsal tubercle; the heel reaches the tympanum or the posterior border of the eye. 
Skin smooth, or with a few scattered flat warts above; belly granular.

Upper surfaces brownish; a dark cross-bar between the eyes; a dark W-shaped spot behind the head and two semilunar light, dark bordered spots in the lumbar region; all these markings sometimes indistinct; a small white dot in the middle

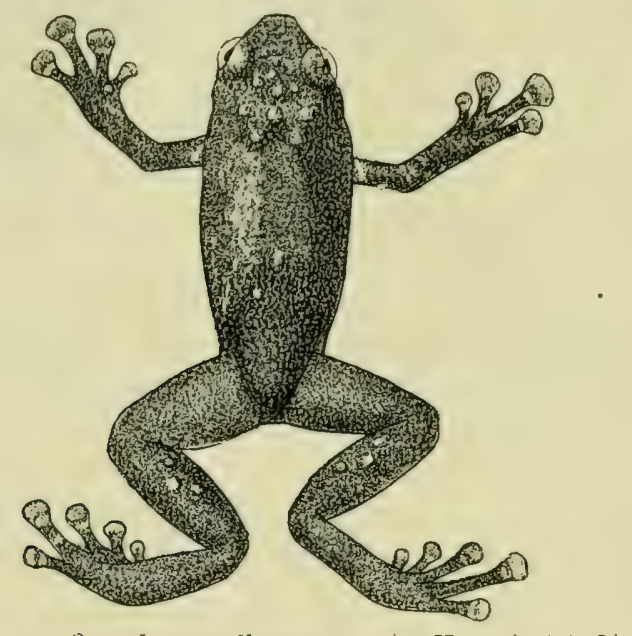

Fig. I4. Oreophryne albopunctata (v. Kamp.), $\times \mathrm{I}^{3} / 4$.

of the upper surface of the tibia; anal region blackish; lower surfaces lighter, more or less clouded with dark, especially on throat and breast. Length $25 \mathrm{~mm}$.

Procoracoid connected with the scapula by a ligament only. Type specimen examined.

Habitat: New Guinea (Lorentz riv. !).

\section{I2. Oreophryne mertoni (Roux).}

Sphenophryne mertoni Roux, Abh. Senckenb, naturf. Ges, XXXIII, I910, p. 227, pl. XIV, figs. $5-56$.

Tongue rather large, entire; a denticulated dermal ridge across the palate in front of the pharynx. Head as long as broad; snout rounded, as long as the eye; canthus rostralis not angular; interorbital space $\mathrm{I}^{2} / 3$ times as broad as the upper eyelid; tympanum very indistinct, hardly $1 / 3$ the diameter of the eye. Fingers rather short, with large disks, the largest one half the diameter of the eye; disks of toes smaller than those of fingers; second finger as long as fourth; toes webbed 
at the base; third and fifth toe of equal length; no subarticular or metatarsal tubercles; the heel reaches the posterior border of the eye.

Upper parts smooth; a very fine; curved, glandular fold above the tympanum; a few feebly prominent granules behind the corner of the mouth; lower surface of body and thighs areolate.

Middle of the back light greyish brown (dark orange-red in life); a $\wedge$-shaped spot in the lumbar region; a white spot upon, and behind the tympanum; snout grey; loreal region brown; a brown, triangular marking between the eyes; thighs and sides of body greyish brown, speckled with brown; beneath greyish, speckled with brown. Length $26,5 \mathrm{~mm}$.

Procoracoid connected with the scapula by a ligament only. Habitat: Aru islands.

\section{Microbatrachus Roux.}

(Roux, Abh. Senckenb. naturf. Ges., XXXIII, 1910, p. 228).

Pupil horizontal. Tongue entire, extensively free behind. Palate toothless. A smooth dermal ridge across the palate, in front of the pharynx. Tympanum hidden. Fingers and toes free; tips of fingers obtuse, of toes slightly dilated.

Procoracoids present; clavicles and omosternum absent; sternum narrow.

Distribution: Aru islands.

\section{Microbatrachus pusillus Roux.}

Microbatrachus pusillus Roux, Abh. Senckenb. naturf. Ges., XXXIII, 1910, p. 228, pl. XIV, figs. 6--6b.

Tongue large, subtriangtilar, about half free behind. Head nearly as long as broad; snout broadly truncated, as long as the eye; no canthus rostralis; nostril in the middle between the orbit and the tip of the snout; interorbital space $\mathrm{I}^{2} / 3$ times the width of the upper eyelid; tympanum hidden. Fingers obtuse; second to fifth toe with very feebly dilated tips; fingers very short, first shorter than second, which is shorter than fourth; toes short, first shorter than second, third longer than fifth; no subarticular or metatarsal tubercles; the heel reaches the posterior border of the eye.

Skin smooth.

Upper parts brown, darker on the head and the anterior 
part of the back; fore limbs greyish white, hind limbs yellowish brown; lower parts yellowish white, the throat a little darker, with small lighter dots. Length $7 \mathrm{~mm}$.

Perhaps a young Sphenophryne or Oreophryne sp.

Habitat: Aru islands.

\section{Oxydacty 1 a v. Kamp.}

\section{(v. KaMpen, Nova Guinea, IX, pt. 3, 1913, p. 464).}

Pupil horizontal. Tongue entire, free behind. Palate toothless. Two dermal transverse ridges across the palate, in front of the pharynx, the posterior one denticulated. Tympanum hidden. Fingers and toes free, the tips not dilated. Outer metatarsals united.

Procoracoids and clavicles present, the latter reaching the scapulae; no omosternum; sternum small. Terminal phalanges club-shaped.

Distribution: New Guinea.

I. Oxydactyla brevicrus v. Kamp.

Oxydactyla brevicrus v. Kampen, Nova Guinea, IX, pt. 3, I9I3, p. 465, pl. XI, fig. 8.

Tongue broad, oblong, half free behind. Head broader than long, its width $2 / 5$ the length of head and body; snout rounded,

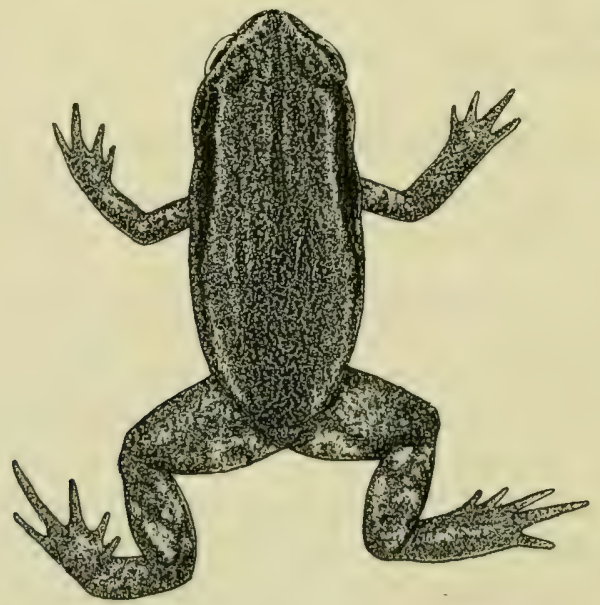

Fig. 15. Oxydactyla brevicrus v. Kamp, $\times \mathbf{x}^{3} / 4$.

feebly projecting, shorter than the eye, about as deep as lons; canthus rostralis rounded; loreal region slightly oblique, 
almost flat; nostril a little nearer to the tip of the snout than to the eye; interorbital space broader than the upper eyelid; tympanum scarcely or not visible in the adult, more distinct and a little more than half the width of the eye in young specimens. First finger shorter than second, which is shorter than fourth; third toe a little longer than fifth; subarticular tubercles very feeble; a feebly developed inner, no outer metatarsal tubercle; the heel reaches the axilla or the shoulder, the tarso-metatarsal articulation the tympanum or the posterior border of the eye; tibia $1 / 3$ length of head and body.

Skin smooth.

Violet above, marbled or spotted with dark, sometimes with a dark band along the sides of head and body; yellowish beneath, usually marbled with brown, especially on throat and limbs. Length $30 \mathrm{~mm}$.

Type specimen examined.

In most points resembling the Australian Bufonid genus Pseudophryne, which seems to be more nearly related to the Brevicipitinae than to Bufo.

Habitat: New Guinea (near Idenburg riv., \pm 1450 and 2400-2900 m.!; Hellwig mts., \pm 2500 m.!; Wichmann mts., $\pm 3000 \mathrm{~m}$. !).

\section{Ca11ulops Blgr.}

(Boulenger, Ann. Mag. Nat. Hist., (6) I, 1888, p. 345).

Pupil vertical. Tongue entire, slightly free behind and on the sides. Palatine bones forming an acute ridge across the palate, armed with a series of small teeth. A denticulated transverse dermal ridge across the palate, in front of the pharynx. Tympanum distinct. Fingers and toes free, the tips with small disks. Outer metatarsals united.

No procoracoids or clavicles. Terminal phalanges simple.

Distribution: New Guinea.

\section{Callulops doriae Blgr.}

Callulops Doriae Boulenger, Ann. Mag. Nat. Hist., (6) I, I888, p. 345.

Tongue oblong. Head rather small, much broader than long, convex or the frontal and occipital region; no canthus rostralis; interorbital space much broader than the upper eyelid; eye small; tympanum much larger than the eye. First and second 
fingers equal; toes moderately elongate; inner metatarsal tubercle indistinct; the heel reaches the shoulder; tibia $2 / 5$ the length of head and body.

Skin smooth, thick and leathery on the back.

Brown; groin and sides of hind limbs yellowish, with" a wide-meshed blackish network. From snout to vent $75 \mathrm{~mm}$.

Habitat: New Guinea (Haveri, in Moroka; Milne gulf).

\section{Gastrophryne Fitz.}

(Fitzinger, Syst. Rept., Vindobonae, fasc. I, 1843, p. 33 ; Stejneger, Proc. biol. Soc. Washington, XXIII (1910), 1911, p. 165).

Engystoma Boulenger, Cat. Batr. Sal., 1882, p. 160, nec Fitzinger, Neue Classif. Rept., Wien, 1826, p. 39.

Pupil vertical. Tongue entire and free behind. Palate toothless. A transverse dermal ridge across the palate between the choanae, and another in front of the pharynx. Tympanum hidden. Fingers and toes free, blunt or with dilated tips. Outer metatarsals united.

No procoracoids or clavicles. Terminal phalanges simple.

Distribution: America; Borneo.

\section{Gastrophryne borneënsis (Blgr.).}

Engystoma borneense Boulenger, Ann. Mag. Nat. Hist., (6) XIX, I897, p. 108.

Snout pointed, strongly projecting, very long (twice and a half the diameter of the eye); interorbital space thrice the width of the upper eyelid; eye small. Fingers swollen at the end; toes with small disks; fingers short, first shorter than second; a very small inner metatarsal tubercle; the heel reaches the posterior border of the eye, the tarso-metatarsal articulation the tip of the snout.

Skin smooth.

Blackish brown above, with scattered minute white dots; brown beneath. From snout to vent $39 \mathrm{~mm}$.

Habitat: Borneo (Baram district, Serawak).

\section{Phryne11a Blgr.}

(Boulenger, Ann. Mag. Nat. Hist., (5) XIX, 1887, p. 346).

Pupil horizontal. Tongue nicked and free behind. Palate toothless. No dermal ridges across the palate. Tympanum hidden. Fingers free, toes webbed, the tips dilated. Outer metatarsals united. 
No procoracoids or clavicles. Terminal phalanges T-shaped. Distribution: Malacca; Mentawei isl.; Sumatra; Borneo.

$$
\text { Synopsis of the Species. }
$$

A. Toes at least $3 / 4$ webbed. Subarticular tubercles flat. I. P. pulchra p. I25.

$B$. Toes hardly half webbed. Subarticular tubercles very prominent. . . . . . . . . p.llicaris p. 125 .

\section{Phrynella pulchra Blgr.}

Phrynclla pulchra Boulenger, Ann. Mag. Nat. Hist., (5) XIX, 1887, p. 346, pl. X, fig. 2 .

Phrynella pulchra Isenschmid, Mitth. naturf. Ges. Bern, 1903, p. 75, pl. V, figs. I, I $a$. Phrynella pulchra Boulenger, Vert. Fauna Malay Penins., Rept. and Batr., London, I 912 ; p. 265.

Habit stout. Head small; snout truncate, projecting, a little longer than the eye; interorbital space much broader than the upper eyelid. Fingers depressed, with large subtriangular disks; toes with feebly dilated tips; first finger shorter than second; toes $3 / 4$ to nearly entirely webbed; subarticular tubercles very large and flat; a small, oval, flat inner metatarsal tubercle; the heel reaches the temple or nearly the posterior border of the eye.

Skin smooth, or with small flat warts on the sides and the posterior part of the back.

Brown above, with symmetrical darker spots, some of which are edged with a pink line; throat and lower surface of foot brown; belly, groin and hinder side of thighs yellowish (in spirit); vent in a large dark brown spot, separated from the dark colour of the back and the upper surface of the thighs by a band of the yellowish colour of the lower surface. From snout to vent $42 \mathrm{~mm}$.

Male with an internal subgular vocal sac.

Ha bitat: Mentawei islands (Sipora); Sumatra (Belu Telang, Lower Langkat; Deli; Batak mts., Soo m.; Benakat, Palembang!). - Malay Peninsula.

\section{Phrynella pollicaris Blgr.}

Prynella pulchra Günther, Ann. Mag. Nat. Hist., (5) $\mathrm{XX}, 1887$, p. 313, pl. XVI, fig. B.

Phrynella pollicaris Boulenger, Proc. Zool. Soc. London, 1890, p. 37.

Phrynella pollicaris Boulenger, Vert. Fauna Malay Penins., Rept. and Batr., London, 1912, p. 266. 
Distinguished from Ph.pulchra by a stouter habit, a shorter head, shorter and thicker digits with much stronger and very prominent subarticular tubercles, hardly half webbed toes, and by the presence, in the male, of a strong, tubercle-like rudiment of pollex.

Colour in life dark olive-brown above; an oblique yellow line from the eye to the angle of the mouth; a pale oliveyellow mark across fore-head, through the eyes, and down the sides of the body to the thighs, this band minutely spotted with dark brown, principally along the centre; a triangular dark-centred pale mark on the anal region; limbs with pale cross-bands; throat of male dark brown, passing into yellow on the breast; belly brown, spotted with whitish. The colour is very changeable, passing to blackish or yellowish. From snout to vent $34 \mathrm{~mm}$.

Lives in holes in trees, containing rain-water. The voice is loud, flute-like.

Habitat: Sumatra; Borneo. - Perak, from 900 m. upwards.

\section{Xenobatrachus Ptrs. \& Dor.}

(Peters.e Doria, Ann. Mus. Genova, XIII, 1878, p. 432).

Choanacantha v. Méhely, Termész. Füzetek, XXI, I898, p. 175.

Xenorhina v. Méhely, Termész. Fịzetek, XXIV, Igor, p. 23 I (partim).

Pupil circular or feebly horizontally elliptic. Tongue large, entire or nicked; perfectly attached or free behind. One or two large tooth-like processes behind each choane. A denticulated transverse dermal ridge across the palate, in front of the pharynx, and sometimes a tubercle in front of it. Tympanum more or less distinct. Fingers and toes free, the tips usually dilated. Outer metatarsals united.

No procoracoids, clavicles or omosternum. Terminal phalanges $\mathrm{T}$-shaped.

The eggs are large and few, the development is thus probably direct.

Distribution: New Guinea.

$$
\text { Synopsis of the Species. }
$$

A. One tooth-like process behind each choane.

I. Snout nearly twice the diameter of the eye. . . I. X. rostratus p. 127 .

II. Snout as long as the upper eyelid.

I. The tarso-metatarsal articulation reaches the eye. 2. X. ocellatus p. I28. 
2. The tarso-metatarsal articulation reaches beyond

the tip of the snout ............... Macrops p. 128 .

B. Two tooth-like processes behind each choane.

I. Tympanum as large as the eye.

I. The tarso-metatarsal articulation reaches beyond

the eye.................. X. Xidens p. I 29.

2. The tarso-metatarsal articulation does not reach

beyond the eye ........... . . X. giganteus p. r 30 .

II. Tympanum half the diameter of the eye. . . . 6. X. ophiodon p. I3I.

\section{Xenobatrachus rostratus (v. Méh.).}

Choanacantha rostrata v. Méhely, Termész. Füzetek, XXI, I898, p. 175, pl. XII. Choanacantha mehelyi Boulenger, Ann. Mus. Genova, (2) XVIII, 1898, p. 709, pl. VIII, fig. 5 .

Xenorhina rostrata v. Méhely, Termész. Fiizetek, XXIV, I90I, p. 233, pl: IX, fig. Io (situs viscerum); pl. XI, figs. I-2 (skull).

Xenorhina rostrata v. Kampen, Zool. Jahrb., Syst., XXXVII, I9I4, p. 373.

Habit stout. Tongue perfectly attached behind; one toothlike process behind each choane. Head broader than long; the side of the head, from tip of snout to shoulder, forms a strongly curved line; snout pointed, strongly projecting, nearly twice the diameter of the eye (in the adult); canthus rostralis indistinct; loreal region very oblique, feebly concave; nostril nearer to the tip of the snout than to the eye; interorbital space thrice the width of the upper eyelid; tympanum more or less distinct, its diameter equal to the length of the upper eyelid. Tips of fingers not or feebly dilated, toes with very small disks; fingers short, first a little shorter than second, which is about as long as fourth; length of the fourth toe contained $3 \frac{1}{2}-4$ times in the distance between the vent and the posterior border of the eye; third toe much longer than fifth; subarticular tubercles and the small inner metatarsal tubercle indistinct; no outer metatarsal tubercle; hind limb of various length: the heel does not reach the axil, or reaches farther, to the tip of the snout.

Skin smooth, with a few scattered small tubercles on the upper surface; the snout may be covered with small warts.

Brown or slate-coloured above, sometimes with some dark spots, each with a light centre, arranged in two or four longitudinal series; a dark spot behind the tympanum; a fine white or red line along the middle of the back and usually along the hind limbs; posterior surface of thighs with a dark blackish 
band; yellowish white (in life fiery red) beneath, dotted or marbled with grey or brown. Length $46 \mathrm{~mm}$.

Habitat: New Guinea (near Idenburg riv., $\pm 800-1000 \mathrm{~m}$. !; Sermowai riv., $\pm 70 \mathrm{~m}$. !; Humboldt bay!; mouth of Tami riv.; Erima; Sattelberg; Vikaiku).

\section{Xenobatrachus ocellatus (v. Kamp.).}

Xenorhina ocellata v. Kampen, Nova Guinea, IX, pt. 3, 1913, p. 46I, pl. XI, figs. $4-5$.

Habit more or less stout. Tongue a little free behind; one tooth-like process behind each choane. Head broader than long; snout pointed, projecting, as long as the upper eyelid, about as long as deep; canthus rostralis rounded; loreal region oblique, concave; nostril nearer to the tip of the snout than to the eye; interorbital space one and a half to twice the width. of the upper eyelid; tympanum rather distinct, as large as the eye or hardly smaller. Tips of fingers blunt, of toes hardly swollen; fingers short, first shorter than second, which is as long as fourth; length of the fourth toe contained $3-3^{1} \frac{1}{2}$ times in the distance between vent and posterior border of the eye; third toe longer than fifth; subarticular and inner metatarsal tubercles very feeble; the heel reaches the shoulder, the tarso-metatarsal articulation the eye.

Skin smooth, the tip of the snout covered with small warts; a strong fold above the tympanum.

Brownish (in spirit) above; a white spot, bordered with bluish black, around the vent; a large, light spot, bordered with dark, in the loin; a similar spot, sometimes divided into smaller spots, on the posterior surface of the thighs; uniform brownish beneath. Length $42 \mathrm{~mm}$.

Habitat: New Guinea (Hellwig mts., \pm 2500 m.!).

\section{Xenobatrachus macrops (v. Kamp.).}

Xenorhina rostrata v. Kampen, Nova Guinea, IX, pt. I, 1909, p.39, pl. II, fig. 6. Xenorhina macrops v. Kampen, Nova Guinea, IX, pt. 3, I9I3, p. 460.

Habit stout. Tongue nearly perfectly attached behind; one tooth-like process behind each choane. Head broader than long; snout pointed, projecting, as long as the upper eyelid; canthus rostralis rounded; loreal region oblique, concave; nostril nearer to the tip of the snout than to the eye; interorbital space twice 
the width of the upper eyelid; tympanum nearly invisible, not distinctly defined. Fingers slender, with swollen tips; toes with small disks; first finger shorter than second, which is a little shorter than fourth; length of the fourth toe contained about 3 times in the distance between the posterior border of the eye and the vent; third toe extending beyond fifth; subarticular and inner metatarsal tubercles feeble, no outer metatarsal tubercle; the heel reaches the eye, the tarso-metatarsal articulation far beyond the tip of the snout.

Skin smooth, with small warts on the tip of the snout; a strong fold above the tympanum and sometimes a fold between the posterior borders of the upper eyelids.

Brownish violet (in spirit); lips and lower surface, except the throat, marbled with lighter; vent bordered with black. Length $53 \mathrm{~mm}$.

Habit at: New Guinea (near Idenburg riv., 2400 m.! ; summit of the Hellwig mts., $\pm 2500 \mathrm{~m}$. !).

\section{Xenobatrachus bidens (v. Kamp.).}

Xenorhina bidens v. Kampen, Nova Guinea, IX, pt. I, I909, p. 39.

Xenorhina bidens v. Kampen, Nova Guinea, IX, pt. 3, I913, p. 460.

Habit stout. Tongue perfectly attached behind; two toothlike processes behind each choane. Head broader than long; snout pointed, projecting, longer than the upper eyelid; canthus rostralis rounded; loreal region oblique; nostril close to the tip of the snout; interorbital space twice the width of the upper eyelid; tympanum feebly distinct, as large as the eye. Fingers with slightly swollen tips, toes with small disks; first finger shorter than second, which is a little shorter than fourth; length of the fourth toe contained about 3 times in the distance between the posterior border of the eye and the vent; third toe longer than fifth; subarticular tubercles indistinct; inner metatarsal tubercle none or feeble, no outer one; the heel reaches the shoulder or the eye, the tarso-metatarsal articulation to between eye and tip of snout or beyond.

Skin smooth; tip of the snout sometimes with small warts.

Light brown above, uniform or with a few small black dots; a dark band along the canthus rostralis and some dark spots on the lips and the limbs sometimes present; white beneath, finely marbled with brown. Length $29 \mathrm{~mm}$.

The food consists of ants.

Habitat: New Guinea (Digul riv.!; Lorentz riv.!). INDO-AUSTRALIAN AMPHibia. 
5. Xenobatrachus giganteus (v. Kamp.).

Xenorhina gigantea v. Kampen, Nova Guinea, XIII, pt. I, I9I5, p. 40.

Habit stout. Tongue perfectly attached behind; in front of the denticulated dermal ridge of the palate a transverse tubercle; two tooth-like processes behind each choane. Head much

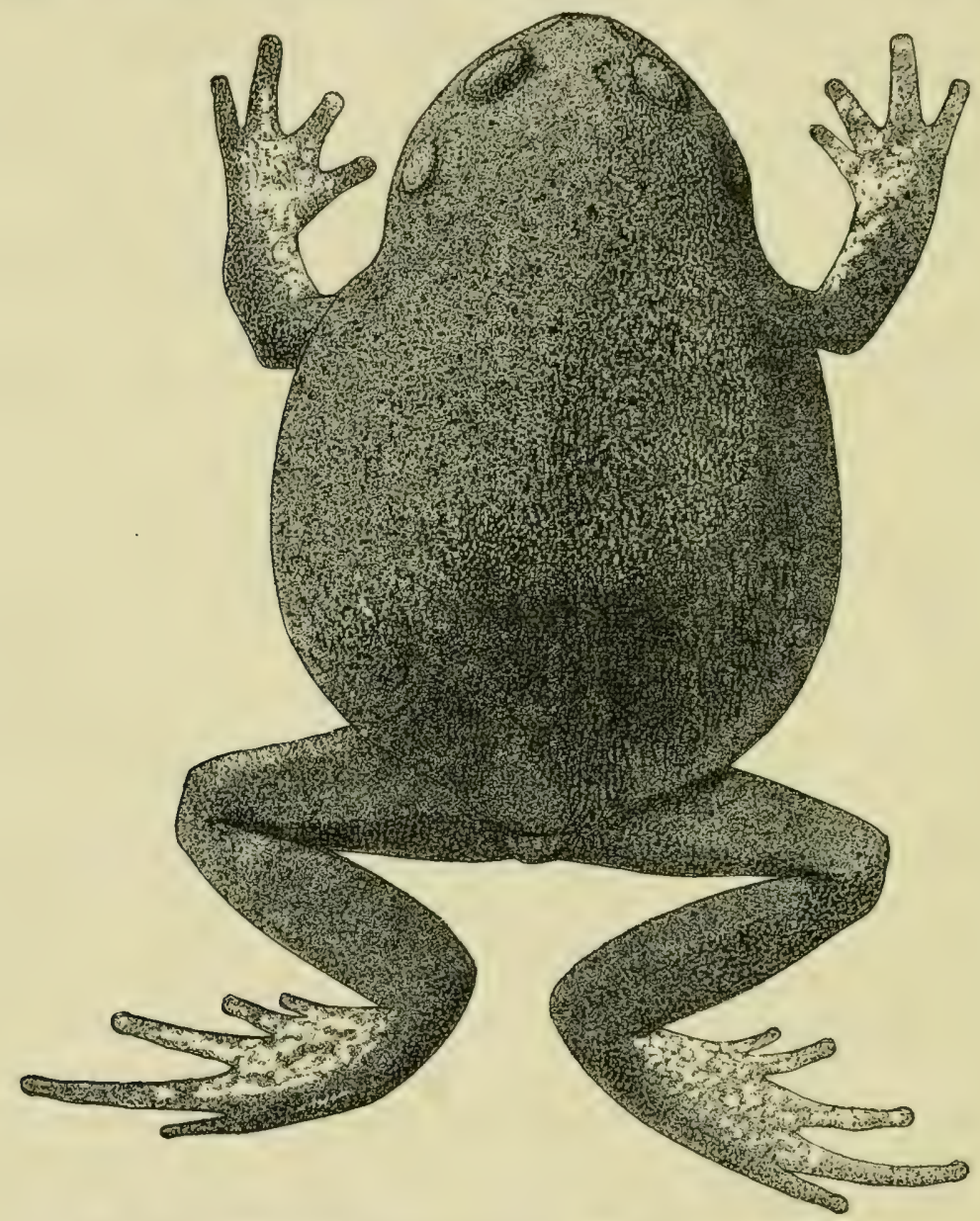

Fig. 16. Xenobatrachus sigantens (v. Kamp.), type specimen, $X \mathrm{I}$.

broader than long, its width twice the distance between the tip of the snout and the angle of the mouth; snout truncate, not projecting, as long as the upper eyelid; canthus rostralis rounded; loreal region oblique, concave; nostril close to the 
tip of the snout; interorbital space twice to twice and a half the width of the upper eyelid; tympanum moderately distinct, as large as the eye. Fingers and toes with slightly swollen tips; first finger shorter than second, which is shorter than fourth; length of the fourth toe contained about $3 \frac{1}{2}$ times in the distance between the posterior border of the eye and the vent; third toe longer than fifth; subarticular and inner metatarsal tubercles feeble, no outer metatarsal tubercle; the heel reaches at most the shoulder, the tarso-metatarsal articulation the axil or to between tympanum and eye.

Skin very finely granular; tip of snout with small warts.

Brownish violet (in spirit); yellowish beneath, marbled with dark brown. Length $86 \mathrm{~mm}$.

Type specimen examined.

Habitat: New Guinea (Snow mts., I700 m.!).

\section{Xenobatrachus ophiodon Ptrs. \& Dor.}

Xenubatrachus ophiodon Peters e Doria, Ann. Mus. Genova, XIII, I878, p. 432, pl. VII, fig. 5 .

Xenobatrachus ophiodon Boulenger, Cat. Batr. Sal. Brit. Mus., 1882, p. 172.

Tongue nicked, free behind and on the sides; two large, curved teeth behind each choane. Head small; snout prominent, a little longer than the eye; canthus rostralis not distinctly developed; nostril lateral, close to the tip of the snout; tympanum half the diameter of the eye. Fingers and toes with small disks; first finger shorter than second, which is about as long as fourth; third toe longer than fifth; no metatarsal tubercles; the heel reaches the tip of the snout.

Skin smooth.

Dark brown above, irregularly spotted and marbled with blackish; whitish beneath, throat and chest reticulated with brown. Length $30 \mathrm{~mm}$.

Habitat: New Guinea (Hatam, Arfak mts.).

\section{Xenorhina Ptrs.}

(PEters, Monatsber. Akad. Berlin, 1863, p. 82).

Pupil horizontal, nearly circular. Tongue large, circular, entire, free only at the sides, perfectly attached behind. Palate toothless. A denticulated transverse dermal ridge across the palate, in front of the pharynx. Tympanum more or less distinct. 
Fingers and toes free, the tips dilated. Outer metatarsals united.

No procoracoids, clavicles, or omosternum. Terminal phalanges $\mathrm{T}$-shaped.

Distribution: New Guinea.

\section{Xenorhina oxycephala (Schlg.).}

Bombinator axycephalus Schlegel, Handl. Dierk., Breda, 1858, II, p. 58, pl. IV, fig. 74. Xenorhina oxycephala Boulenger, Cat. Batr. Sal. Brit. Mus., 1882, p. 179. Xenorhina atra Günther, Novit. Zool., III, I896, p. 184, pl. VIII, fig. I. Xenorhina oxycephala v. Méhely, Termész. Füzetek, XXIV, I901, p. 236. Xenorhina oxycephala v. Kampen, Zool. Jahrb., Syst., XXXVII, 1914, p.374.

Habit stout. Head broader than long, the side of the head, from tip of snout to shoulder, forms a feebly curved line; snout pointed, strongly projecting, twice the length of the eye; canthus rostralis indistinct; loreal region very oblique, feebly

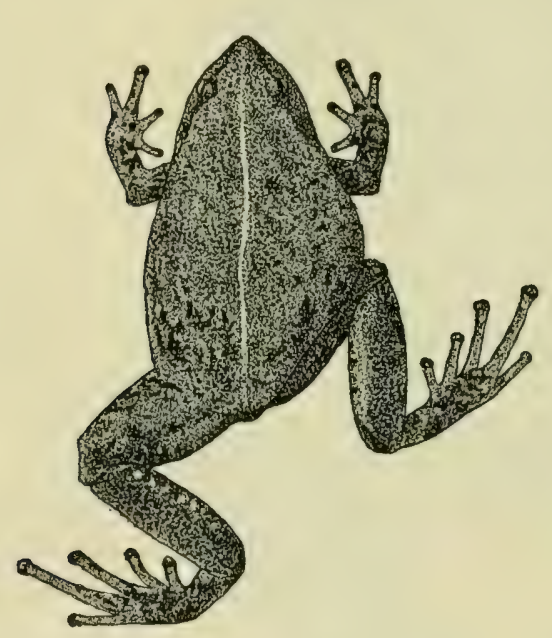
concave; nostril nearer to the tip of the snout than to the eye; interorbital space about thrice the width of the upper eyelid; tympanum hidden or more or less distinct, about as large as the eye. Fingers with slightly swollen tips, toes with small disks; fingers short, first shorter than second, which is about as long as fourth; length of the fourth toe contained about 3 to $31 / 2$ times in the distance be-

Fig. 17. Xenorthina oxycephala (Schlg.), $\times \mathbf{I}$. tween vent and posterior border of the eye; third toe much longer than fifth; subarticular tubercles and the small nner metatarsal tubercle indistinct, no outer metatarsal tubercle; the heel reaches the axil or the eye, the tarso-metatarsal articulation the tip of the snout or beyond.

Skin smooth; snout with or without small warts.

Black, brown, greyish violet or red above (in life), with or without a light vertebral line; grey, brick-red, or orange, more or less marbled with brownish, beneath; a dark spot around the vent and on a part of the posterior "surface of the thighs; the sides sometimes white. Length $47 \mathrm{~mm}$. 
Type specimens in the Leiden Museum examined.

Habitat: New Guinea (Lobo; Idenburg riv.!; Sermowai riv., \pm 70 and 400 m.!; Humboldt bay!; Mosso riv.!; Clyde riv.).

\section{I2. Asterophrys Tschudi.}

(Tschudi, Mém. Soc. Sc. nat. Neuchâtel, II, I839, p. 45, 82).

Pupil horizontal. Tongue large, circular, entire, free at the sides and slightly behind. Palate toothless. A dęnticulated transverse dermal ridge across the palate, in front of the pharynx. Tympanum feebly distinct. Fingers and toes free, the tips feebly dilated. Outer metatarsals united.

No procoracoids, clavicles or omosternum. Terminal phalanges obtuse.

Distribution: New Guinea.

\section{Asterophrys turpicula (S. Müll.).}

Ceratophrys turpicola (S. Müll.), Schlegel, Abbild. neter oder unvollst. bek. Amph., Düsseldorf, 1837-44, p. 30, pl. X, fig. 4 .

Asterophrys turpicola Boulenger, Cat. Batr. Sal. Brit. Mus., 1882, p. 444.

Habit stout. Dermal ridge of the palate with about ten strong, triangular denticles. Head large, triangular, with convex crown, its length $3 / 4$ of its width, which is half the length of head

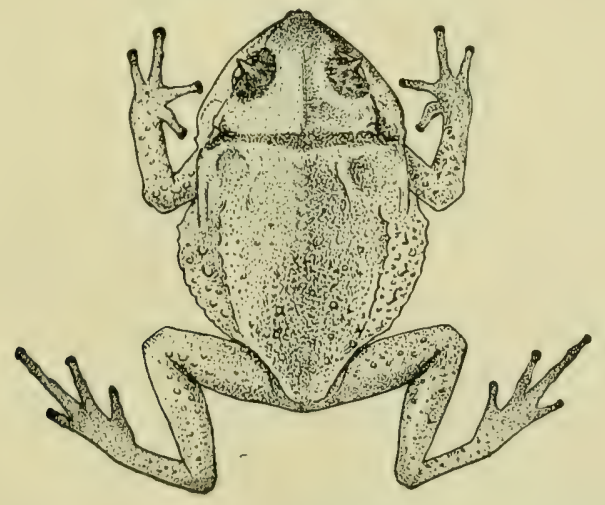

Fig. I8. Asterophrys turpicula (S. Müll.), type specimen, $X \mathbf{I}$.

and body; snout vertically truncated, feebly projecting, as long as the eye; canthus rostralis angular; loreal region high, vertical, concave; nostril lateral, close to the tip of the snout; interorbital space twice the width of the upper eyelid; tym- 
panum fecbly distinct, vertically oval, its vertical diameter $2 / 3$ the diameter of the orbit and as large as the distance from eye to tympanum. Fingers and toes with very small disks; first finger a little shorter than second; third toe much longer than fifth; subarticular tubercles distinct; an indistinct oval inner metatarsal tubercle; the heel reaches the tympanum or the eye, the tarso-metatarsal articulation the eye or the tip of the snout.

Smooth above, with some scattered small tubercles on back and limbs; some pointed dermal appendages on the upper eyelid, one of which, situated close to the middle of the outer border, being more prominent than the other ones; a bony ridge from the eye to the anterior border of the tympanum and a stronger one from the eye to above and behind the tympanum; a median low bony ridge on the head; almost smooth beneath; sides with rather large tubercles.

Brown above (in life brownish green, with a few dark dots); sides and lower surface lighter, with dark marblings; sides of head dark brown. From snout to vent $48 \mathrm{~mm}$.

Type specimens in the Leiden Museum examined. This examination has shown that this species belongs to the Brevicipitidae and the genus is closely allied with Xenorlina. The sacral diapophyses are moderately dilated.

Habitat: New Guinea! (Lobo; Torricelli mts. ? ')).

\section{I3. Copiula v. Méh.}

(v. Ménely, Termész. Füzetek, XXIV, I901, p. 242).

Pupil horizontal. Tongue small, oval, entire and extensively free behind. Palate toothless. A denticulated transverse dermal ridge across the palate, in front of the pharynx. Tympanum distinct. Fingers and toes free, with disks. Outer metatarsals united.

No procoracoids, clavicles or omosternum. Terminal phalanges T-shaped.

Distribution: New Guinea.

$$
\text { Synopsis of the Species. }
$$

$A$. Snout not or hardly longer than the upper eyelid, I. C. oxyrfina p. I35.

$B$. Snout $2 \frac{1}{3}$ times the length of the eye .... 2. C. (?) rostellifera p. 135 .

I) After Wandolleck, Abh. Mus. Dresden, XIII, No. 6, IgIo, p. I4. 


\section{Copiula oxyrhina (Blgr.).}

Phrynixalus oxyrhinus Boulenger, Proc. Zool. Soc. London, I898, p. 476, 480, pl. XXXVIII, fig. 3 .

Copiula oxy'rhina v. Méhely, Termész. Füzetek, XXIV, I90I, p. 243, pls. VIII, (mouth, skull \&c.); $\mathrm{X}$, fig. 6 (terminal phalanx).

Copizula oxyrhina v. Kampen, Nova Guinea, V, pt. I, 1906, p. I68.

Habit slender. Tongue oval, narrow, free in its posterior third or half. Head small, as long as broad; snout rather pointed, projecting, as long as or hardly longer than the upper eyelid, longer than deep; canthus rostralis distinct, obtuse; loreal region nearly vertical; nostril about equally distant from end of snout and eye; interorbital space much broader than the upper eyelid; eye small; tympanum distinct, $1 / 2$ to $3 / 4$ the diameter of the eye. Disks of fingers small, of toes larger, but smaller than the tympanum; first finger shorter than second, which is shorter than fourth; third toe longer than fifth; subarticular tubercles and the elliptic inner metatarsal tubercle feebly prominent, no outer metatarsal tubercle; the heel reaches the eye or the tip of the snout; tibia

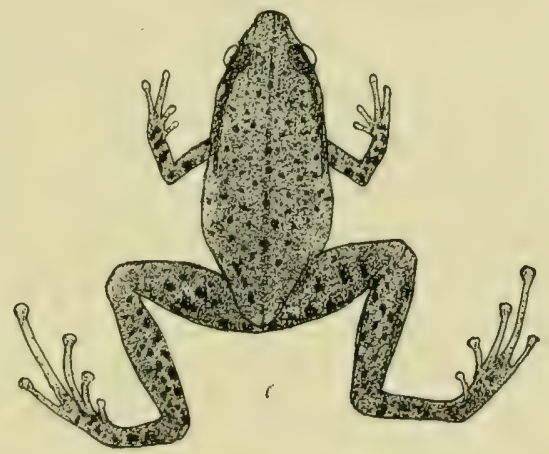
a little more than half the rig. 19. Copiula oxyrhina (Blgr.), $\times 11 / 2$. length of head and body.

Back smooth or finely granulate; lower parts smooth.

Grey to brown above, with or without dark brown spots and marblings, which are largest on the sides; a brown or blackish streak along each side of the head and some distance along the side of the body; groin and posterior surface of thighs whitish, with black spots or marblings; whitish beneath, the throat often dark marbled. Length $37 \mathrm{~mm}$.

Habitat: New Guinea (Cycloop mts.?!; Humboldt bay!; Timena riv.!; Njao!; Begowre riv.!; Sattelberg; Went mts., 1050 m.!; Hellwig mts.!). — St. Aignan isl.

\section{Copiula (?) rostellifera Wand.}

Copiula (?) rostcllifer Wandolleck, Abh. Zool. Mus. Dresden, XIII, No. 6, I9I i p. II, figs. $47-49$ and text-figs. $A-B$. 
Habit very stout. Dermal ridge of palate divided into four parts. Snout very prominent, long, $2^{1 / 3}$ times the length of the eye; the distance from eye to nostril twice the diameter of the eye and equal to the width of the interorbital space; tympanum feebly distinct. Fingers and toes with disks, except the first finger and the first and second toe, which have the tips not dilated.

Bluish grey; an hour-glass shaped brownish marking on the back; a small yellow spot at each side in the lumbar region and a yellowish streak between the eyes; beneath yellow, finely mottled with grey. Length $19^{1 / 2} \mathrm{~mm}$.

Perhaps identical with Chocropluryne proboscidea, which has, nowever, two dermal ridges across the palate.

Habitat: New Guinea (Torricelli mts.).

\section{I4. Choerophryne v. Kamp.}

\section{(v. Kampen, Zool. Jahrb., Syst., XXXVII, 1914, p. 376).}

Pupil horizontal. Tongue narrow, oblong, slightly nicked, and free behind. Palate toothless. Two denticulated transverse dermal ridges across the palate, in front of the pharynx. Tympanum distinct. Fingers and toes free, with large disks. Outer metatarsals united.

No procoracoids or clavicles. Terminal phalanges T-shaped. Distribution: New Guinea.

\section{Choerophryne proboscidea v. Kamp.}

Choerophryne proboscidea v. Kampen, Zool. Jahrb., Syst., XXXVII, I9I4, p. 376.

Habit slender. Head small, its width $1 / 3$ the length of head and body; snout acutely pointed, strongly projecting, once and a half the length of the upper eyelid, twice as long as deep; canthus rostralis rounded; loreal region nearly vertical, flat; nostril close to tip of snout; interorbital space twice and a half the width of the upper eyelid; eye small; tympanum $2 / 3$ the diameter of the eye. Disks of fingers and toes equal in size and about as large as the tympanum, that of first finger a little smaller than the other ones; first finger shorter than second; fifth toe a little longer than third; subarticular and inner metatarsal tubercles feeble; the heel reaches the tympanum; tibia a little less than half the length of head and body.

Varty above, belly and lower surface of thighs granulate. 
Brownish above; back with ill-defined dark spots; limbs with dark cross-bars; a light spot, bordered with black, in the loin; beneath speckled with white. Length $19 \mathrm{~mm}$.

Habitat: New Guinea (Tor riv.!; Njao!).

\section{I5. Hylophorbus Macl.}

(Macleay, Proc. Linn. Soc. N.-S.-Wales, II, 1878, p. 136; Fry, Mem. Queensland Mus., II, I9I3, p. 48).

Phrynixalus Boettger, Zool. Anz., XVIII, I895, p. 133 .

Mantophryne Boulenger, Ann. Mag. Nat. Hist., (6) XIX, I897, p. I 2.

Gnathophryne v. Méhely, Termész. Füzetek, XXIV, 1901, p. 225.

Metopostira v. Méhely, ibid., p. 238.

Pupil horizontal. Tongue large, oval, more or less free behind. Palate toothless. Two transverse dermal ridges across the palate, in front of the pharynx, the posterior one denticulated, the anterior one smooth. Tympanum more or less distinct. Fingers and toes free ${ }^{1}$ ), the tips dilated. Outer metatarsals united.

No procoracoids or clavicles. Terminal phalanges T-shaped.

Distribution: Philippines; Halmahera; New Guinea; Australia.

\section{Synopsis of the Species.}

A. Disks of fingers large.

I. The tarso-metatarsal articulation reaches the anterior border of the eye........... I. H. birói p. 138 .

II. The tarso-metatarsal articulation reaches beyond the eye.

I. Interorbital spice broader than the upper eyelid.

a. Tympanum $2 / 3$ the width of the eye. . 2. H. variegatus p. 138.

b. Tympanum less than $1 / 2$ the width of the eye............. 3. H. montanus p. I39.

2. Interorbital space as broad as the upper eyelid. 4. H. bocttgeri p. I40. R. Disks of fingers small.

I. Loreal region nearly vertical.

I. Tympanum as large as the eye..... 5. H. mufescens p. 140.

2. Tympanum about $1 / 2$ to $3 / 4$ the width of the eye. 6. H. ocellatus p. 141 .

II. Loreal region oblique.

I. Interorbital space once to $I^{1 / 2}$ times the width of the upper eyelid.

I) See however $H$. (?) neuhaussi p. 144 . 
a. Tympanum about $1 / 2$ the width of the eye. 7. H. dubitus p. 143 .

b. 'Tympanum about $2 / 3$ the width of the eye. 8. H. robustus p. 143 .

2. Interorbital space twice the width of the upper eyelid.

a. Tympanum about $1 / 3$ the width of the eye. 9. H. microtis p. 144 .

b. Tympanum $5 / 8$ the width of the eye. . . Io. H. (?) neuhaussi p. 144 .

\section{Hylophorbus birói (v. Méh.).}

Phrynixalus Birói v. Méhely, Termész. Füzetek, XXIV, I90I, p. 247, pl. IX, figs. I-4 (eggs); XI, figs. 3-5 (palate, skull); XII, fig. 2.

Tongue very feebly nicked and half free behind. Head about as long as broad; snout obtusely pointed, about as long as the upper eyelid, much longer than deep; canthus rostralis strong; loreal region almost vertical, concave; nostril twice as far from the eye as from the tip of the snout; interorbital space twice the width of the upper eyelid; tympanum not very distinct, about $1 / 3$ the diameter of the eye. Disks of fingers rather large, of toes smaller; first finger much shorter than second; third toe longer than fifth; subarticular tubercles indistinct; a large and oblong, rather indistinct inner metatarsal tubercle; the heel reaches the tympanum, the tarsometatarsal articulation the anterior border of the eye.

Skin smooth; lower surface granulated, at least on posterior part of belly.

Upper parts dirty pink-coloured, finely and rather densely dotted or marbled with reddish brown; a dark streak along the side of the head, which may be continued along the anterior part of the body, and sometimes another along each side of the back; whitish or reddish yellow below, throat and anterior part of breast sometimes blackish brown. Length $33 \mathrm{~mm}$.

As is stated by v. Méhely the egg-strings are deposited in the water, though the development is direct; the embryo has no gills, but breathes by the aid of the large tail.

Habitat: New Guinea (Tor riv.!; Sattelberg, 750 m.).

\section{Hylophorbus variegatus nova spec.}

Tongue feebly nicked and nearly half free behind. Head as long as broad; snout obtusely pointed, projecting, as long as the eye, longer than deep; canthus rostralis obtuse; loreal region nearly vertical, almost flat; nostril nearer the tip of the snout than the eye; interorbital space a little broader 
than the upper eyelid; tympanum distinct, $2 / 3$ the width of the eye. Disks of fingers and toes large, triangular, those of second to fourth finger about as large as the tympanum, of first finger and of toes smaller; first finger much shorter than second, which is about as long as fourth; fifth toe longer than third; subarticular tubercles very feebly developed, no metatarsal tubercles; the heel reaches the eye, the tarsometatarsal articulation beyond the tip of the snout.

Skin smooth.

Rufous brown with white markings, viz. a streak along the canthus rostralis; a cross-bar between the eyes; a longitudinal streak along each side of the back, each of them confluent with a spot at the side of the middle of the back; a large spot on the posterior part of the back; cross-bars on the limbs; whitish beneath. Length i $8 \mathrm{~mm}$.

Distinguished from $H$. montanus by a larger tympanum and the characteristic design.

Type specimen in the Amsterdam Museum.

Habitat: New Guinea (Digul riv.!).

\section{Hylophorbus montanus (Bttgr.).}

Phrynixalus montanus Boettger, Zool. Anz., XVIII, I895, p. I33.

Phrynixalus montanus (part.) Boettger, Abh. Senckenb. naturf. Ges., XXV, I 901, p. 368 .

Phrynixalus montanus v. Méhely, Termész. Füzetek, XXIV, I90I, p. 251.

Habit stout. Head broader than long; snout obtusely pointed, shorter than the eye; canthus rostralis rounded; loreal region distinctly concave; interorbital space broader than the upper eyelid; tympanum rather distinct, $1 / 3$ to $\% / 5$ the diameter of the eye. Fingers with very large, triangular disks, the largest of which is about as large as the tympanum; disks of toes large, triangular, much smaller than those of fingers; first finger much shorter than second; subarticular tubercles very feebly developed; a feeble, oblong, compressed inner metatarsal tubercle, outer metatarsal tubercle indistinct or none; the heel reaches to between eye and nostril.

Skin slightly wrinkled and warty, the sides with more distinct warts; smooth below, or posterior part of the belly feebly granulate.

Reddish brown (green in life), spotted and marbled with blackish; a blackish triangular spot between the eyes, and a 
broad, W-shaped figure of the same colour on the anterior part of the back; sometimes a broad, white vertebral line; limbs dark spotted, without distinct transverse bars; fingers and toes yellow, with blackish rings; brownish yellow below, throat, breast and thighs powdered or spotted with blackish. Length $26 \mathrm{~mm}$.

Habitat: Halmahera, $670-760 \mathrm{~m}$.

\section{Hylophorbus boettgeri (v. Méh.).}

Phrynixalus montanus (part.) Boettger, Abh. Senckenb. naturf. Ges., XXV, I 901, p. 368, pl. XVI, figs. 9-9b.

Gnathophryne Boettogeri v. Méhely, Termész. Füzetek, XXIV, I901, p. 229.

Habit stout. Tongue large, broadly oval, with a longitudinal furrow, hardly free behind. Snout rounded, a little shorter than the eye, high; canthus rostralis rounded; nostril much nearer the tip of the snout than the eye; interorbital space as broad as the upper eyelid; eye large; tympanum rather distinct, about half the diameter of the eye. Fingers and toes with large triangular disks, those of toes smaller than those of fingers; first finger much shorter than second, which is shorter than fourth; third toe longer than fifth; subarticular and inner metatarsal tubercles feebly developed; the heel nearly reaches the nostril.

Skin smooth, with smaller and larger tubercles on the posterior part of the head, the upper eyelids, the shoulders and the sides of the body.

Brown above, with a yellowish white vertebral line and some dark markings, among which a W-shaped spot on the head, two white spots on the chin and one such spot in the middle of the lower jaw; limbs with transverse series of black spots; lower parts light brown; chin, throat, breast and lower surface of limbs with large, chestbrown spots. Length $39 \mathrm{~mm}$.

Probably Boettger is right in not separating this species from $H$. montanus.

Habitat: Halmahera, $670 \mathrm{~m}$.

\section{Hylophorbus rufescens Macl.}

Hylophorbus rufescens Macleay, Proc. Linn. Soc. N.-S.-Wales, II, 1878, p. 136. Mantophryne lateralis Boulenger, Ann. Mag. Nat, Hist., (6) XIX, 1897, p. I2, pl. II, fig. 3 . 
Mantophryne lateralis v. Méhely, Termész. Füzetek, XXIV, I901, p. 220, pls. IV; V; X, fig. 4 .

Hylophorbus mefescens Fry, Mem. Queensland Mus., II, I913, p. 48.

Tongue broadly oval, entire, with a longitudinal furrow, slightly free behind. Head subtriangular, a little broader than long; snout obtusely pointed, shorter than the orbit; canthus rostralis distinct; loreal region nearly vertical, concave; nostril nearer the tip of the snout than the eye; interorbital space as broad as the upper eyelid; tympanum as large as the eye. Fingers and toes with small disks; first finger shorter than second; subarticular tubercles strong; a feeble oval inner metatarsal tubercle; the heel reaches the eye.

Skin smooth; sometimes several fine folds along the back; chin with a pair of more or less distinct small warts.

Grey or brown above, with small blackish spots and a broad black streak on each side of the back from the eye to the groin; a dark blotch below the eye; the warts of the chin white; a black streak on the posterior surface of the thighs; brownish or white beneath, dotted and spotted with blackish. Length $55 \mathrm{~mm}$.

Male with a subgular vocal sac.

The ovary contains but few, large eggs (diameter $4,3-5 \mathrm{~mm}$.); the development is therefore probably direct ( $v$. Méhely).

Habitat: New Guinea (Sattelberg; Mt. Victoria, Owen Stanley range; Rigo, near Kapa Kapa; Moroka, Bartholomew range, $700 \mathrm{~m}$.; Katow).

\section{Hylophorbus ocellatus (v. Méh.).}

Metopostira ocellata v. Méhely, Termész. Füzetek, XXIV, I90I, p. 239, pl. VII (skull, shoulder girdle, vocal sac); X, fig. 5 (terminal phalanx); XII, fig. I.

Metopostira macra v. Kampen, Nova Guinea, V, pt. I, 1906, p. I67, pl. VI, figs. I, 2.

Metopostir a ccellata v. Kampen, Nova Guinea, IX, pt. I, I909, p. 40; IX, pt. 3, 1913, p. 461; Zool. Jahrb., Syst., XXXVII, I9I4, p. 375 .

Tongue free in its posterior fourth or fifth part. Head broader than long; snout obtusely pointed, prominent, shorter than the eye and about as deep as long; canthus rostralis distinct, obtuse; loreal region nearly vertical, concave; nostril lateral, nearer the tip of the snout than the eye; interorbital space as broad as the upper eyelid; eye large; tympanum distinct, about $1 / 2$ to $3 / 4$ the width of the eye. Fingers and toes slender, disks of fingers small, of toes somewhat larger, but much 
smaller than the tympanum; first finger shorter than second, which may be shorter to longer than fourth; third toe longer than fifth; subarticular tubercles well developed; a small inner, no outer metatarsal tubercle; the heel reaches the eye or farther, to beyond the tip of the snout.

Skin smooth or finely granulate above; back and sides of the body sometimes with small warts, usually arranged in more or less distinct longitudinal series; two small warts behind the chin may be present; smooth beneath, sometimes with small warts in the loin.

Greenish brown in life; a black spot, bordered by a red one in front and a larger, yellow one behind, in the lumbar

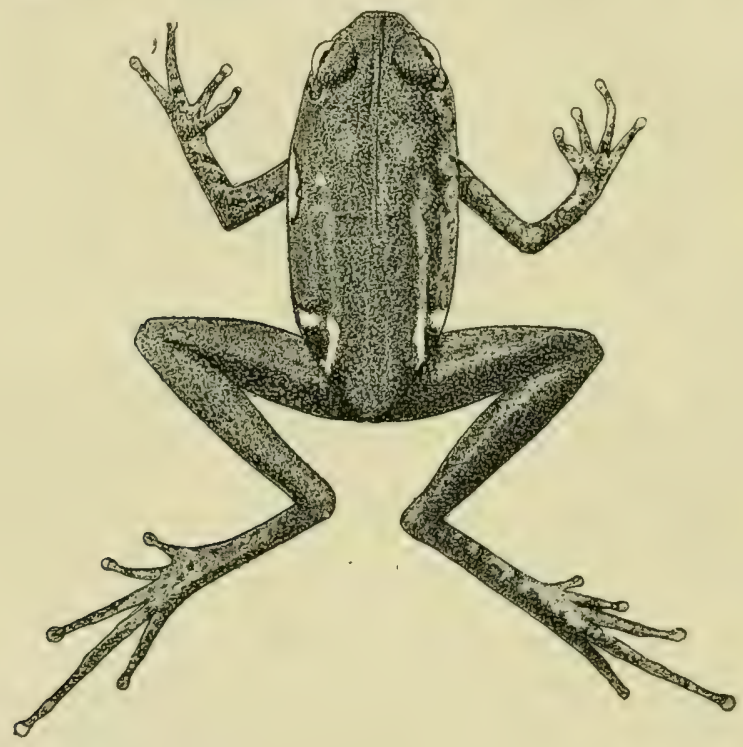

Fig. 20. Hylophorbus ocellatus (v. Méh.), $\times \mathrm{I}^{1} / 4$.

region; often some ill-defined light spots on the back, behind the tympanum, at the insertion of the fore limbs and near the vent; posterior surface of thighs and lower parts of body marbled with reddish brown or blackish, helly usually immaculate. From snout to vent $42 \mathrm{~mm}$.

Male with a subgular vocal sac.

The eggs in the ovary are few and large.

Habitat: New Guinea (Humboldt bay!; Mosso riv.!; Mt. Kohari, \pm 600 m.!; Bewani riv.!; Begowre riv.!; Sattelberg; Digul riv.!; Lorentz riv.!; Went mts., Soo-1360 m.!). 


\section{Hylophorbus dubius (Bttgr.).}

Aenorhina dubia Boettger, Zool. Anz., XVIII, 1895, p. I34.

Xenorhina dubia Boettger, Abh. Senckenb. naturf. Ges., XXV, 19or, p. 369, pl. XVI, fig. ro.

Gnathopliryne dubia v. Méhely, Termész. Füzetek, XXIV, I90I, p. 23 I.

Habit stout. Tongue large and broad. Head broader than long, its width about $3 \frac{1}{2}$ times in the length of head and body; snout triangular, somewhat pointed, as long as the diameter of the eye; canthus rostralis rounded; loreal region oblique; nostril much nearer the tip of the snout than the eye; interorbital space about once and a half the width of the upper eyelid; tympanum feebly distinct, about half the diameter of the eye. Fingers and toes with very small disks; first finger shorter than second, which is as long as fourth; third toe much longer than fifth; subarticular tubercles feebly developed; a feeble, compressed inner, no outer metatarsal tubercle; the heel reaches to about the middle of the eye.

Skin smooth, somewhat warty on the sides of the body; a fold above the tympanum.

Greyish black above, uniform or indistinctly spotted and marbled with lighter; limbs with a few indistinct, whitish grey bars, transverse spots and rings; lower parts brownish yellow, reticulated with brown, or brown, marbied and spotted with brownish yellow. Length $24 \mathrm{~mm}$.

Habitat: Halmahera (up to $670 \mathrm{~m}$.).

\section{Hylophorbus robustus (Blgr.).}

Mantophryne robusta Boulenger, Proc. Zool. Soc. London, I898, p. 476, 480, pl. XXXVIII, fig. 4 .

Gnathophryne robusta v. Méhely, Termész. Fiizetek, XXIV, I9or, p. 225, pl. VI, figs. I-3 (skull); pl. IX, figs. $6-9$ (eggs and embryos).

Habit stout. Tongue with a median furrow, little free behind, more so on the sides. Head subtriangular, much broader than long; snout obtusely pointed, prominent, shorter than the upper eyelid, as deep as long; canthus rostralis indistinct; loreal region oblique, nearly flat; nostril lateral, nearer the tip of the snout than the eye; interorbital space as broad as to once and $a$ half the width of the upper eyelid; tympanum rather distinct, about $2 / 3$ the diameter of the eye. Fingers and toes with small disks, which are much smaller than the tympanum; first finger a little shorter than second, which is about as long 
as fourth; third toe longer than fifth; subarticular tubercles and the oval inner metatarsal tubercle feebly prominent; no outer metatarsal tubercle; the heel reaches the shoulder or the tympanum.

Skin smooth; a strong fold above the tympanum and sometimes a cross fold between the eyes.

Reddish or purplish brown above, uniform or with small, roundish, black spots; loin, thigh and lower side of tibia sometimes with large, circular, white spots; pale brown or yellowish beneath. Length $100 \mathrm{~mm}$.

The eggs are large $(7 \times 5,5 \mathrm{~mm}$.) and united by a gelatinous string; they are deposited on the land and watched by the male; the embryo has no gills: respiration takes place by the tail; the development is direct (v. Méhely).

Habitat: New Guinea! (Sattelberg, \pm Soo m.; Simbang). -St. Aignan isl.

\section{Hylophorbus microtis (Wern.).}

Mantophryne microtis Werner, Zool. Anz., XXIV, I90I, p. Iо2.

Habit stout. Head triangular, broader than long, its width $2 / 5$ the length of head and body; occiput somewhat swollen; snout truncated, a little shorter than the eye; canthus rostralis distinct; loreal region oblique, feebly concave; nostril much nearer the tip of the snout than the eye; interorbital space twice the width of the upper eyelid; tympanum feebly distinct, about $1 / 3$ the width of the eye. Fingers with hardly distinct, toes with distinct small disks; first finger shorter than second; subarticular tubercles feeble; a small, elliptic, flat inner metatarsal tubercle; the heel reaches the anterior border of the tympanum.

Skin smooth, with small tubercles on the sides and on the back; a strong fold above the tympanum.

Upper parts rather dark olive green; snout and upper eyelids blackish; sides and hind limbs with scattered white dots; greenish yellow beneath. Length $56 \mathrm{~mm}$.

Habitat: N.-E.-New Guinea.

\section{Hylophorbus (?) neuhaussi (Vogt) ").}

Manthophryne neuhaussi Vogt, Sitzungsber. Ges. naturf. Fr. Berlin, I9I I, p. 425 .

I) Description completed by informations from Mr. Vogt. 
Habit stout. Both dermal ridges behind the level of the tubae. Snout short, obliquely truncate; loreal region oblique, feebly concave; interorbital space twice the width of the upper eyelid; eye small; tympanum distinct, $5 / 6$ the width of the eye. Fingers and toes with smail, but distinct disks; first and second finger about equal in length. Toes distinctly webbed; the heel reaches the tympanum.

Skin rough, with several longitudinal rows of large warts; smooth beneath; a fold above the tympanum.

Back light brown; its posterior part and upper parts of the limbs blackish brown; large, light yellow spots in the lumbar region and on the posterior suriace of the thighs and the outer side of the tibiae; faded brown beneath. Length $65 \mathrm{~mm}$.

For this species the establishment of a new genus should perhaps be justified, the webbed toes distinguishing it from the other species of Hylopliorbus.

Habitat: New Guinea (Sattelberg).

\section{Aphantophryne Fry.}

(Fry, Proc. Linn. Soc. N.-S.-Wales (1916), I917, p. 770).

Pupil horizontal. Tongue large, oval, entire and free behind and slightly free on the sides. Two transverse dermal ridges across the palate in front of the pharynx, the posterior one always, the anterior one usually denticulated and sometimes represented by a median dermal lobe only. Tympanum slightly visible. Fingers and toes free, the tips not dilated. Outer metatarsals united.

No clavicles; procoracoid replaced by a ligament. Omosternum and sternum absent. Terminal phalanges T-shaped.

Distribution: New Guinea.

\section{Aphantophryne pansa Fry.}

Aphantophryne pansa Fry, Proc. Linn. Soc. N.-S.-Wales (1916), 1917, p. 772, pl. LIV; LV, fig. 2).

Tongue free for about one-half its length posteriorly. Head triangular, much broader than long; snout rounded, slightly prominent, as long as or slightly shorter than the orbit; canthus rostralis feeble, rounded; loreal region oblique, slightly concave; nostril much nearer the tip of the snout than the eye; interorbital space broader than the upper eyelid; tympanum INDO-AUSTRALIAN AMPHIBIA. 
about $1 / 2$ the width of the eye. Tips of fingers and toes not dilated; first finger a little shorter than second; no subarticular tubercles; a very feeble inner metatarsal tubercle; the heel reaches the axilla.

Skin smooth.

Uniform dark brown above. Beneath also uniform dark brown, or creamy-white, variously clouded and speckled with dark brown.

From snout to vent $27 \mathrm{~mm}$.

Habitat: New Guinea (Mt. Scratchley, Owen Stanley range, $\pm 3700 \mathrm{~m}$.).

\section{I7. Cophixalus Bttgr.}

(BoetTger, Kat. Batr.-Samml. Senckenb. naturf. Ges., Frankf, a/M., 1 892, p. 24).

Pupil horizontal. Tongue long, entire and free behind. Palate toothless. A denticulated dermal ridge across the palate, in front of the pharynx. Tympanum distinct. Fingers free, toes webbed at the base, with large disks.

No procoracoids or clavicles. Sternum ossified (?).

Distribution: New Guinea.

\section{Cophixalus geislerorum Bttgr.}

Cophixalus geislerom. Boettger, Kat. Batr.-Samml. Senckenb. naturf. Ges., Frankf. a/M., 1892, p. 24.

Snout truncated, shorter than the diameter of the eye; canthus rostralis feeble; loreal region feebly concave; interorbital space broader than the upper eyelid; eye strongly projecting; tympanum distinct. Disks of fingers and toes large; first finger shorter than second; toes distinctly webbed; subarticular tubercles feebly distinct; a feeble, compressed inner metatarsal tubercle; the heel reaches hardly beyond the shoulder, the metatarsal tubercle hardly the anterior border of the eye.

Upper surfaces smooth, belly and thighs granular.

Blackish brown above, on the sides and the limbs with many smaller and some larger yellowish dots and spots; a distinct light marking in the lumbar region; a white curved streak from the posterior border of the eye to the shoulder; beneath yellowish white, the throat and posterior surface of the thighs finely powdered with brown. Length $26 \mathrm{~mm}$.

Probably a renewed examination will show that this species belongs to Oreopluryne or Spluenophryne and the genus Cophixalus has to be cancelled.

Habitat: N.-E.-New Guinea. 


\section{I8. Pomatops Barb.}

(Barbour, Proc. Biol. Soc. Washington, XXIII, I9Io, p. 89).

Pupil circular. Tongue large, entire, extensively free on the sides and behind. Palate toothless. Two feebly developed papillose ridges across the palate in front of the pharynx. Upper eyelids involved in a flap of skin, extending for some distance anterior and posterior to the position of the eye. Tympanum hidden. Fingers and toes free, the tips slightly dilated.

No procoracoids, clavicles or omosternum. Terminal phalanges $\mathrm{T}$-shaped.

The only known specimen of the only species of this genus was taken from the stomach of a snake. It seems possible, that the genus is identical with Hylophorbus, the curious flaps of skin above the eyes and other peculiarities then being caused by compression.

Distribution: New Guinea.

\section{Pomatops valvifera Barb.}

Pomatops valvifera Barbour, Proc. Biol. Soc. Washington, XXIII, I910, p. 89, pl. I.

Habit rather slender. Head short; snout not prominent; the flaps of skin above the eyes may be laid down and thus completely cover the eyes. First finger shorter than second; third toe longer than fifth; subarticular tubercles very indistinct; no metatarsal tubercles; the heel reaches the posterior border of the eye.

Skin smooth.

Slaty grey above, with lighter marblings; a semilunar white spot below each eye; lower surface ochraceous buff.

Habitat: New Guinea (Fakfak).

\section{Kaloula Gray.}

(Gray, The zoological miscellany, No. I, London, I831, p. $3^{8}$ ). Hylatactylus Tschudi, Mém. Soc. Sc. nat. Neuchâtel, II, 1839, p. 85 . Callula (Gthr.) Boulenger, Cat. Batr. Sal. Brit. Mus., I882, p. 167.

Habit stout. Pupil circular. Tongue oblong, entire or feebly nicked, free behind and on the sides. Palate toothless ${ }^{1}$ ). Each palatine bone forms a prominent ridge across the palate; two dermal ridges across the palate, in front of the pharynx, the

I) See however $K$. (?) sundana p. I5I. 
anterior one smooth, the posterior one denticulated. Tympanum hidden. Fingers free ${ }^{1}$, toes free or webbed, the tips usually more or less dilated. Outer metatarsals united.

No procoracoids, clavicles or omosternum. Terminal phalanges triangular or $\mathrm{T}$-shaped.

Tadpoles. - Eyes lateral. Spiraculum and vent median. Tip of tail simply pointed. Mouth terminal, the upper lip feebly developed; papillae and teeth absent.

Distribution: eastern Asia, to western part of the Malay Archipelago.

Synopsis of the Species.

A. Metatarsal tubercles present.

I. Inner metatarsal tubercle blunt-edged. Diameter of disk of third finger more than half that of eye. I. $K$. baleata p. I 48 .

II. Inner metatarsal tubercle sharp-edged. Diameter of disk of third finger less than half that of eye. 2. $K$. pulchra p. I50.

B. Metatarsal tubercles absent ............... $K$. (?) sundana p. I5I.

\section{Kaloula baleata (S. Müll.).}

Bombinator baleatus S. Müller, Verh. Batav. Gen., XVI, 1836, p. 96.

?Hylacdactylus lividus (nomen nudum) Bleeker, Nat. Tijdschr. Ned.-Indië, XIV, 1857, p. 239.

Calohyla celebensis (Gthr.) Peters, Monatsber. Akad. Berlin, 1872, p. 585.

Callula baleata Boulenger, Cat. Batr. Sal. Brit. Mus., 1882, p. I69 (with figs. of hand and foot).

Callula baleata v. Kampen, Nat. Tijdschr. Ned.-Indië, LXIX, I909, p. 47 (tadpole). haloula baleata Barbour, Proc. Acad. Nat. Sc. Philadelphia, 1909, pl. XVIII, fig. 6 (terminal phalanx).

Kaloula baleata Barbour, Mem. Mus. Comp. Zoöl. Harvard Coll., XLIV, I, 1912, p. 72 .

Head much broader than long; snout short, rounded, as long as or a little shorter than the upper eyelid; canthus rostralis rounded; loreal region oblique; nostril nearer the tip of the snout than the eye; interorbital space broader than the upper eyelid. Tips of fingers with large, triangular disks; diameter of the disk of the third finger more than half the diameter of the eye, of second and fourth finger nearly as large, of first finger a little smaller; tips of toes feebly dilated, first finger shorter than second, which is a little shorter than fourth; third toe distinctly longer than fifth; toes webbed at the base, the web not extending beyond the first phalanx;

I) See $K$. (P) sundana p. I5r. 
subarticular tubercles distinct; two metatarsal tubercles, the inner one large, compressed, with blunt edge, the outer one smaller; the tarso-metatarsal articulation reaches the shoulder (in the adult) or the eye (in the young).

Upper parts smooth, or with small, flat warts; a fold from the eye to the shoulder, and sometimes another one, more or less indistinct, between the posterior borders of the eyelids; beneath smooth or wrinkled, except the throat, which may be finely granulate.

Brown, olive or blackish above, uniform or variegated with darker; a few large, whitish (in the living animal red) spots

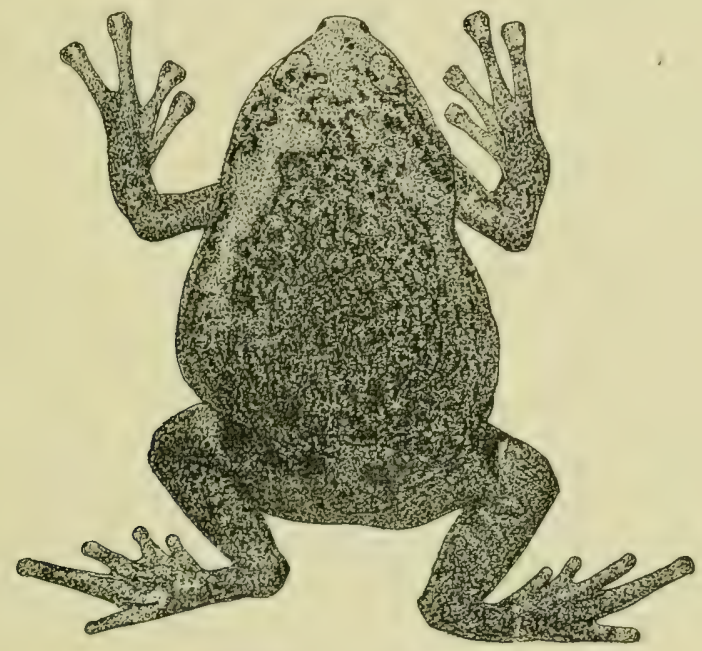

Fig. 21, Kaloula baleata (S. Müil!.), X I.

on the arm pits, on the loins, and on the limbs; beneath darker or lighter brown, variegated with whitish. Length $76 \mathrm{~mm}$.

Male with a subgular vocal sac.

Tadpole. - Agreeing in the position of the eyes, vent and spiracle, and in the characters of the mouth with the tadpole of $K$. pulchra.

In Batavia, when the weather is rainy, this toad in the evening and night makes a terrible noise in the ditches. By day it probably lives in holes. The eggs are laid in clumps, in the rainy season. The tadpole generally lives at the surface of the water.

Habitat: Nias!; Sumatra (Agam; Matur!; Batu Sangkar, 
460-9I5 m.!; Kalung, Tilatang!); Borneo (Mt. Dulit; Pontianak); Java (Batavia!; Krawang; Buitenzorg; Sukabumi!; Leuwih Gadjah; Tjilatjap!; E.-Java); Sumba; Celebes(Indrulaman; near Borau, coast of Luwu; Kulawi!; Lindu lake, rooo m.; Bwool; Gorontalo; Minahasa; Tomohon ; Kema). - Philippines; Malay Peninsula.

\section{Kaloula pulchra Gray.}

Kaloula pulchra Gray, The zoological miscellany, No. I, London, 183I, p. 38 . Callula pulchra Boulenger, Cat. Batr. Sal. Brit. Mus., 1882, p. I70 (with figs. of hand and foot).

Callula pulchra Flower, Proc. Zool. Soc. London, 1896, p. 908.

Callula pulchra Flower, Proc. Zool. Soc. London, 1899, p. 906.

Callula pulchra Butler, Jrn. Bombay Nat. Hist. Soc., XV, 1904, p. 390.

Kaloula pulchra Barbour, Proc. Acad. Nat. Sc. Philadelphia, I909, pl. XVIII, fig. 7 (terminal phalanx).

Callula pulchra Boulenger, Vert. Fauna Malay Penins., Rept. and Batr., London, I912, p. 264, fig. 73 .

Kaloula pulchra Barbour, Mem. Mus. Comp. Zoöl. Harvard Coll., XLIV, I, I9I2, p. 7I, pl. VII, fig. 29.

Callula pulchra Smith, Jrn. Nat. Hist. Soc. Siam, II, I9I7, p. 40, figs. BI-B3 (tadpole).

Kaloula pulchra Annandale, Mem. Asiat. Soc. Bengal, VI, 1917, p. 152, fig.9, pl. VI, figs. $7-7 b$ (tadpole).

Head much broader than long; snout short, rounded, as long as or shorter than the upper eyelid; canthus rostralis rounded; loreal region oblique; nostril a little nearer tip of snout than eye; interorbital space broader than the upper eyelid. Tips of fingers with well-developed triangular disks, the diameter of which is less than half that of eye; tips of toes feebly dilated; first finger shorter than second, which is a little shorter than fourth; third toe much longer than fifth; toes slightly webbed at the base; subarticular tubercles well developed; two metatarsal tubercles, the inner one large, compressed, with rather sharp edge, the outer one smaller; the tarsometatarsal articulation reaches the axil, the shoulder, or a little beyond.

Upper parts smooth or with flat, smooth tubercles; a fold from the eye to the shoulder, and another one, more or less distinct, between the posterior borders of the eyelids; lower parts smooth.

Yellow or pink above, usually with a large dark-brown spot covering nearly the whole of the back, and a dark lateral band; sometimes with irregular yellowish spots; a narrow dark 
vertebral line may be present; beneath dirty buff, chin and throat black in the male. From snout to vent $76 \mathrm{~mm}$.

Male with an external subgular vocal sac.

Tadpole. - Length of body about $\mathrm{I}^{1} / 2$ times its width; tail twice the length of the body. Nostril much nearer the eye than the tip of the snout; eyes lateral, the distance between them 6 times that between the nostrils; spiraculum median, large, its transparent sheath opening below the posterior end of the body; anal tube long, median, projecting below the edge of the subcaudal crest. Tail obtusely pointed; crests convex, about equal in depth.

Mouth terminal, very small, with a straight upper, and a contractile lower lip; jaws and teeth absent.

Dark, olive-brown to black, with or without fine golden speckles; sometimes a pale curved bar across the snout, and light markings on the sides; caudal crests colourless, or with small dark patches; below often speckled with white. Length $40 \mathrm{~mm}$.

The eggs are united into strings.

Nocturnal. The croak is very loud. "The males croak while floating on the surface of the water, the mouth, head and inflated sides of the body just above the surface, the single vocal sac under the mouth inflated like a globe and the arms and legs extendeci. They can hop well on land, and are good swimmers" (Flower). "The embrace is axillary: the eggs are expelled in masses of the size of a cherry; the development is very rapid." (Butler). The tadpole, after Smith, is unable to remain below the surface of the water; it lives upon animal and vegetable matter.

Ha bitat: Sumatra (Atjeh; Indragiri); Borneo (Serawak) ${ }^{1}$ ); Flores; Celebes (Makasser!). - From India and S.-China to the Malay Peninsula.

\section{Kaloula (?) sundana Ptrs.}

Calohyla sundana Peters, Monatsber. Akad. Berlin, 1867, p. 35. Nectophryne? sundana Boulenger, Cat. Batr. Sal. Brit. Mus., r882, p. 281 . Callula sundana Roux, Zool. Anz., XXXV, 1910, p. 716.

Each palatine ridge with 4 or 5 curved teeth. Snout subtriangular, prominent, a little longer than the eye; nostril

I) According to Peters (Ann. Mus. Genova, III, 1872, p. 44). 
close to the tip of the snout; interorbital space twice the width of the upper eyelid. Fingers with large, truncated disks; disks of toes small; first finger shorter than second; fingers webbed at the base; toes nearly entirely webbed, the web reaching the disks, except that of the fourth toe; subarticular tubercles present; no metatarsal tubercles; the heel reaches the tympanum.

Upper parts with a few small, flat warts or almost entirely smooth; a curved fold from the eye to the tympanum; lower surfaces wrinkled and with some tubercles or granules.

Brown; upper parts indistinctly spotted with black; beneath spotted with white. Length $23 \mathrm{~mm}$.

Two vocal sacs.

Very different from the other species of Callula by the toothed palatine ridges, the webbed fingers, and the absence of metatarsal tubercles. Probably a new genus ought to be created for it.

Habitat: Borneo (Pontianak).

\section{Microhyla Tschudi.}

(Tschudi, Mém. Soc. Sc. nat. Neuchâtel, II, 1839, p. 28, 7I).

Hylaplesia (Boie) Schlegel, Isis, XX, I827, p. 294 (part.).

Diplopelma Günther, Cat. Batr. Sal. Brit. Mus., 1858, p. 50.

Habit slender. Pupil circular. Tongue elliptic, entire and free behind. Palate toothless. Palatine bones not forming ridges across the palate; one or two dermal ridges across the palate, in front of the pharynx. Tympanum hidden. Fingers free, toes free or more or less webbed, the tips usually more or less dilated. Outer metatarsals united.

No procoracoids, clavicles or omosternum. Terminal phalanges $T$-shaped.

Tadpoles. - Eyes lateral. Spiraculum and vent median. Tip of tail ending in a flagellum. Mouth terminal; upper lip absent or feebly developed; papillae and teeth absent.

Distribution: south eastern Asia, including western part of the Malay Archipelago.

$$
\text { Synopsis of the Species. }
$$

A. Toes free, the tips feebly dilated ......... I. M. inornata p. 153 .

$B$. Toes webbed at the base.

I. Fingers and toes without disks........2. M. bungurana p. 154 .

II. Fingers and toes with disks. 
I. The heel reaches at least the tip of the snout. 3. M. achatina p. I54.

2. The heel reaches the eye or to between eye and

tip of snout................. M. leucostigma p. $15^{6}$.

C. Toes $1 / 2$ webbed. The heel reaches beyond the tip of the snout................. M. annectens p. 156 .

$D$. Toes at least $2 / 3$ webbed.

I. The heel reaches the tip of the snout ....6. M. palmipes p. 157 .

II. The heel reaches beyond the tip of the snout. $7 . M$. berdmorii p. 158 .

Synopsis of the Tadpoles.

$A$. Distance between the eyes about 4 times that between the nostrils ................... achatiniz p. I54.

B. Distance between the eyes about 6 times that between the nostrils .............. 7. M. berdmorii? p. 158 .

\section{Microhyla inornata Blgr.}

Microhyla inornata Boulenger, Proc. Zool. Soc. London, 1890, p. 37.

Microhyla inornata Boulenger, Vert. Fauna Malay Penins., Rept. and Batr., I9J 2, p. 259.

Head as broad as long; snout obtuse, projecting, shorter than the upper eyelid; canthus rostralis rounded, straight; loreal region vertical; nostril in the middle between eye and tip of snout; interorbital space broader than the upper eyelid. Tips of fingers and toes feebly dilated; first finger much shorter than second, which is a little shorter than fourth; third toe longer than fifth; toes free; subarticular tubercles distinct; a very small, round, inner, no outer metatarsal tubercle; the heel reaches the temple or the eye; tibia $2 / 5$ to $1 / 2$ length of head and body.

Back smooth or with small smooth warts.

Grey above, spotted or marbled all over with dark brown, the spots sometimes forming longitudinal streaks; sides of head black, with a series of white spots on the upper lip, sometimes confluent into a streak; lower parts brown, sometimes spotted with whitish. Length $27 \mathrm{~mm}$.

Male with an internal vocal sac.

Habita ${ }^{1}$ ): Sumatra (Deli!). -- Burma; Siam; Cochinchina; Malay Peninsula.

I) Boulenger (1912) must have made a mistake in mentioning Borneo among 


\section{Microhyla bungurana (Gthr.).}

Diplopelma bunguranum Günther, Novit. Zool., II, 1895, p. 501.

Diplopelma bunguranum Günther, Novit. Zool,, III, 1896, pl. VIII, figs. 2, 3.

Snout somewhat projecting, rather longer than the eye; canthus rostralis angular; interorbital space broader than the upper eyelid. Fingers and toes without disks; first toe very short, third one a little longer than fifth; toes very slightly webbed; metatarsal tubercles very indistinct; the heel does not reach the eye.

Skin of the back minutely granular, nearly smooth; sides and lower parts of the body with larger tubercles.

Back dark purplish brown; a reddish-rose-coloured band along the upper outline of the snout and above eye and tympanum to the sides of the body; on the loins it encloses an oval black spot; sides of the head black; throat and part of the belly black, the remainder of the belly being of a yellowishrose-colour; small pointed tubercles of an intense yellow scattered on the sides and lower parts, sometimes two on the chest particularly conspicuous and symmetrically placed; hind limbs rose-coloured; thighs with round yellow spots, calves with one brownish band across the middle, and sometimes a second one nearer to the knee. Length $24 \mathrm{~mm}$.

Habitat: Natuna islands (Bunguran).

\section{Microhyla achatina Boie.}

Hylaplesia achatina (Kuhl et v. Hass.) Schlegel, Isis, XX, I827, p. 294 (nomen nudum).

Microhyla achatina (Boie) Tschudi, Mém. Soc. Sc. nat. Neuchâtel, II, 1839, p. 28. Microhyla achatina Boulenger, Cat. Batr. Sal. Brit. Mus., 1882, p. I66.

Microhyla achatina v. Kampen, Nat. Tijdschr. Ned.-Indië, LXIX, 1909, p. 45 (tadpole).

Microhyla achatina Boulenger, Vert. Fauna Malay Penins., Rept. and Batr., London, 1912, p. 261 .

Microhyla achatina Smith, Jrn. Nat. Hist. Soc. Siam, II, 1917, p. 37, figs. A I-A4 (tadpole).

Microhyla achatina Annaudale, Mem. Asiat. Soc. Bengal, VI, 1917, p. I50, text-fig. 8 and pl. VI, fig. 6 (tadpole).

Head about as broad as long; snout obtusely pointed, projecting, as long as or a little longer than the upper eyelid; canthus rostralis obtuse, straight; loreal region vertical; nostril equidistant from eye and tip of snout; interorbital space much broader than the upper eyelid. Disks of fingers very small, 
of toes a little larger; first finger much shorter than second, which is about as long as fourth; third toe longer than fifth; toes feebly webbed at the base; subarticular tubercles distinct; two small metatarsal tubercles; the heel reaches the tip of the snout or a little beyond; tibia $1 / 2$ to $3 / 5$ length of head and body.

Skin smooth.

Brownish, reddish or greyish above, usually with dark brown spots or symmetrical markings, or with chevron-shaped darker and lighter lines; a light vertebral line sometimes present; sides of head and body dark brown or black; limbs usually with more or less distinct dark cross-bars; anal region blackish; lower parts purplish buff, the throat sometimes powdered with brownish or blackish. Length $28 \mathrm{~mm}$.

Male with a subgular vocal sac.

Tadpole. - Length of body $\mathrm{I}^{3} / 4$ times to twice its width; tail twice the length of the body, varying in depth (about $2 \frac{1}{3}$ to 4 times as long as deep). Nostril in the middle between eye and upper lip;

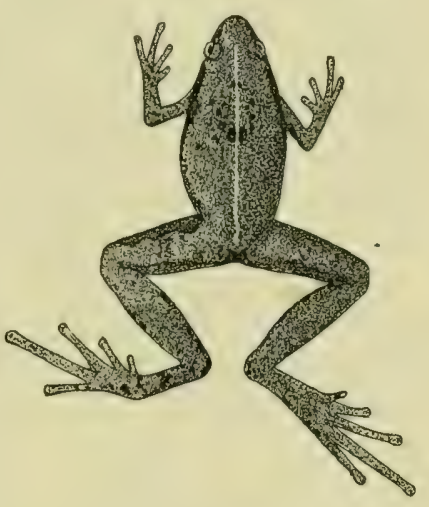

Fig. 22.

Microhyla achatina Boie, $\times 1$. eyes lateral, the distance between

them about 4 times that between the nostrils; spiraculum median, its transparent sheath opening below the belly; anal tube median, long; opening at the lower edge of the subcaudal crest. Tail ending in a fine flagellum; crests moderate, the upper one convex, about $1 / 2$ to nearly equal to the depth of the lower one, extending on to the base of the tail.

Mouth terminal, without upper lip; lower lip large, with undulated border; jaws colourless; papillae and teeth absent.

Body colourless, with the back and lip brown, a brown streak between eye and mouth and a small brown spot at the base of the spiracular sheath; muscular part of tail, except the tip, brownish, the crests colourless. Length $25 \mathrm{~mm}$.

Habitat: Simalur!; Nias!; Sumatra (Takengan, Gajo countries!; Medan!; Brastagi, Karo highland, 1400 m.!; Laut tador; Agam; Singkarah!); Java (Posata, Bantam; Buitenzorg!; Tjibodas, $\pm 1200 \mathrm{~m}$. ; Sukabumi, $\pm 900 \mathrm{~m}$. !; Tjiandjur; Mt. 
Papandajan, $\pm \mathrm{I} 500 \mathrm{~m}$.; Wonosobo !; Tengger mts., I $200 \mathrm{~m}.) .-$ Tenasserim; Tonkin; Siam; Cochinchina; Malay Peninsula; Philippines.

\section{Microhyla leucostigma Blgr.}

Microhyla lencostigma Boulenger, Ann. Mag. Nat. Hist., (7) III, I899, p. 275, pl. XII, fig. I.

Microhyla leucostigma Flower, Proc. Zool. Soc. London, 1899, p. 905.

Microhyla leucostigma Boulenger, Vert. Fauna Malay Penins,, Rept. and Batr., London, 1912, p. 260.

Snout rounded, shorter than the orbit; interorbital space broader than the upper eyelid. Fingers and toes with small, but very distinct disks; first finger much shorter than second; toes with a slight rudiment of web; subarticular and inner metatarsal tubercles flat, very feebly prominent; the heel reaches the eye or to between the eye and the tip of the snout; tibia half the length of head and body.

Skin smooth.

Colour in life black above, with very small scattered bluishwhite spots, which increase in size towards the sides and in the anal region; upper surface of limbs reddish brown, with black cross-bands, and thickly studded with very small white spots; hands and feet with bright yellow spots; below dark brown, blacker on the throat, redder on the belly and thighs, nearly covered with large, very distinctly defined spots of intense yellow, the ground colour appearing as a dark network between them. From snout to vent $27 \mathrm{~mm}$.

Flower describes the copulation as being axillary, the fingers of the male not meeting on the breast of the female.

Habitat: Borneo (Baram riv.). - Malay Peninsula, I070 m.

\section{Microhyla annectens Blgr.}

Microhyla annectens Boulenger, Ann. Mag. Nat. Hist., (7) VI, 1900, p. I88. Microhyla anncctens v. Kampen, Weber's Zool. Ergebn., Leiden, IV, I907, p. 404. Microhyla annectens Boulenger, Vert. Fauna Malay Penins., Rept. and Batr., London, I912, p. 262.

Microhyla niasensis v. Kampen, in: Kleiweg de Zwaan, Die Insel Nias bei Sumatra, III, Haag, I9I5, p. 279.

Head broader than long; snout rounded, projecting, as long as the upper eyelid, as long as deep; canthus rostralis obtuse; loreal region nearly vertical; nostril in the middle between eye and tip of snout; interorbital space broader than the 
upper eyelid. Fingers with small, toes with rather large disks; first finger much shorter than second, which is about as long as fourth; third toe extending beyond fifth; toes half webbed; subarticular tubercles feebly prominent; metatarsal tubercles small, the outer one may be absent; the heel reaches beyond the tip of the snout; tibia $2 / 3$ length of head and body.

Skin smooth, or with small warts above.

Brown or pinkish above, with more or less distinct symmetrical, blackish, light-edged markings, among which usually a large one on the back and a transverse bar between the eyes, both sometimes confluent; side of body, from the shoulder to the lumbar region, usually black, with sharply defined upper outline; an oblique whitish streak from the eye to the base of the fore limb; a narrow, pale, vertebral line may be present; limbs with black cross-bars; lower parts whitish, or marbled with dark brown. Length $22 \mathrm{~mm}$.

Perhaps not different from $M$. palmipes.

Ha bitat: Nias!; Sumatra (Deli!; Sungai Kumbang, I 400 m., Kurintji peak; Kurintji!); Borneo (Kidi district in Serawak); Java (near Tjibodas, \pm I400-2000 m.!). - Siam; Malay Peninsula, up to $\pm \mathrm{I} 200 \mathrm{~m}$.

\section{Microhyla palmipes Blgr.}

Microhyla palmipes Boulenger, Ann. Mag. Nat. Hist., (6) XIX, I897, p. Io8.

Head broader than long; snout rounded, feebly projecting, as long as or shorter than the upper eyelid; canthus rostralis rounded; loreal region nearly vertical; nostril in the middle between eye and tip of snout; interorbital space broader than the upper eyelid. Disks of fingers and toes very small; first finger much shorter than second, which is about as long as fourth; third toe extending beyond fifth; toes $2 / 3$ or $3 / 4$ webbed; subarticular tubercles distinct; two small metatarsal tubercles; the heel reaches the tip of the snout; tibia nearly $2 / 3$ length of head and body.

Skin smooth, or with small warts above.

Grey-brown above, with or without symmetrical, darker, light-edged markings, viz. a triangle between the eyes, a large $\bigwedge$-shaped figure on the back, and a dark oblique figure from the eye to the middle of the side; a dark oblique bar on the thigh and another one on the tibia; anal region black; a black 
spot on the inner side of the tibia, a little above the heel; lower parts whitish, throat and belly with a few brown specks; lower lip dark brown with white dots. From snout to vent i $\$ \mathrm{~mm}$.

Ha bitat: Java (Pengalengan, I $200 \mathrm{~m}$.; Diëng, $2000 \mathrm{~m} . !)$; Madura!

\section{Microhyla berdmorii (Blyth).}

Engystoma (?) Berdmorei Blyth, Jrn. Asiat. Soc. Bengal, XXIV, 1855, p. 720. Microhyla berdmorii Boulenger, Cat. Batr. Sal. Brit. Mus., I882, p. I66.

Microhyla berdmorii Werner, Zool. Jahrb., Syst., XIII, I90o, p. 496.

Microhyla berdmorii Boulenger, Vert. Fauna Malay Penins., Rept. and Batr., London, I912, p. 263.

Snout subacuminate, as long as or a little longer than the orbit; interorbital space broader than the upper eyelid. Fingers with very small, toes with rather large disks; first finger much shorter than second; toes webbed to the tips; subarticular tubercles very distinct; two very small metatarsal tubercles; the heel reaches beyond the tip of the snout; tibia $2 / 3$ length of head and body.

Skin smooth, or with a few scattered tubercles on back and sides.

Brownish, olive or pinkish above; a darker, light-edged, hourglass-shaped, large spot on the head and anterior part of the back, beginning between the eyes, sometimes continued on the hind part of the back; black spots on the sides of the limbs and occasionally on the flanks; a chevron-shaped black marking on the anal region; lower surface whitish, throat and breast clouded with brown. From snout to vent $45 \mathrm{~mm}$.

Male with an internal vocal sac.

Ta d pole. - Flower (Proc. Zool. Soc. London, 1899, p. 903 , pl. LX, figs. $2,2 a-c$ ) has described tadpoles of a Microliyla sp. from Penang, which Annandale (Mem. Asiat. Soc. Bengal, VI, 1917, p. I5I) suggests to belong to $M$. berdmorii. Their description runs as follows:

Length of body about $\mathrm{I}^{1} / 3$ times its width; tail $\mathrm{I}^{4} / \tau$, to $\mathrm{I}^{5} / 6$ the length of the body. Nostril nearer the tip of the snout than the eye; cyes lateral, visible from above and from below, the distance between them about 6 times that between the nostrils; spiraculum median, the opening of its transparent sheath in a vertical line drawn behind the body; anal tube median. Tail ending in a very fine pointed filament; the upper crest 
convex, not extending on to the back, lower than the lower one, the edge of which forms a double curve.

Mouth terminal; the lower lip projects beyond the upper one and has a deep notch in the centre; papillae, jaws and teeth absent.

Very transparent in life; upper surfaces generally yellowish brown, mottled along the vertebral line with dark brown; lower surfaces colourless or pale dirty buff; muscular part of tail pale yellowish brown, getting darker towards the point; the crests buff, mottled with yellowish brown and with irregular dark brown markings along the edges; the brown mottling gets more continuous and darker towards the point of the tail and ends abruptly in front of the tip; iris yellow. Length $37^{1 / 2} \mathrm{~mm}$.

Habitat: Sumatra (Deli!; Laut tador). - Burma; Siam; Malay Peninsula.

\section{Genyophryninae.}

Lower jaw toothed, upper one toothless.

Distribution: Sud-Est isl. (east of New Guinea).

\section{Genyophryne Blgr.}

(Boulenger, Proc. Zool. Soc. London, I89o, p. 326).

Pupil horizontal. Tongue entire, free at the sides. Teeth on the palatine bones and eight or nine small teeth on the anterior extremity of each mandible. A denticulated transverse dermal ridge across the palate in front of the pharynx. Tympanum hidden. Fingers free, toes webbed at the base, the tips slightly dilated. Outer metatarsals united.

No procoracoids or clavicles.

Distribution: Sud-Est isl.

\section{Genyophryne thomsoni Blgr.}

Genyophryne Thomson: Boulenger, Proc. Zool. Soc. London, I89o, p. 327, pl. XXV, figs. I, $\mathbf{I} a, \mathbf{I} b$.

Tongue oblong. Head large, much depressed; eyes wide apart, small. First finger shortest, third much longer than second or fourth; inner metatarsal tubercle indistinct.

Skin smooth; heel with a triangular dermal process.

Pinkish brown above, variegated with blackish; temples 
whitish; a light line on each side from the eye along the back; hinder side of thighs and lower surface of tarsus black. From snout to vent $32 \mathrm{~mm}$.

$\mathrm{H}$ a bitat: Sud-Est isl.

\section{Fam. RANidne.}

Upper jaw toothed, lower one nearly always toothless. Diapophyses of the sacral vertebra not or very slightly dilated. Terminal phalanges of fingers and toes of various shape.

Omosternum and sternum with or without bony style. Vertebrae procoelous. No ribs. Os coccygis articulating by two condyles.

Distribution: cosmopolitan, except the southern part of S.-America, the southern part of Australia, New Zealand and eastern Polynesia.

Synopsis of the Genera.

A. Pupil horizontal. No intercalary ossicle between the two distal phalanges of the digits.

I. Digital disks, if present, devoid of transverse groove. When the toes are free, as is rarely the case, vomerine teeth are always present.

I. Sternum with bony style.

a. No dermal fold across the palate. No teeth in the lower jaw. Vomerine teeth rarely absent .....................

6. No dermal fold across the palate. Lower jaw toothed. Vomerine teeth present... 2. Cratobatrachus p. 228.

c. A dermal fold between the choanae. No vomerine teeth .......... 3. Oreobatrachus p. 229.

2. Sternum cartilaginous. No vomerine teeth. 4. Oxyglossus p. 230.

II. Digital disks with a transverse groove along the lower surface. Toes webbed.

I. Outer metatarsals entirely separated by web.

a. Fingers free .......... 5. Staurois p. 234.

b. Fingers webbed......... 6. Simomantis p. 237.

2. Outer metatarsals united. . . . . . . 7. Cormufer p. 238 .

III. Digital disks? Toes free. No vomerine teeth. 8. Batrachylodes p. 24I.

B. Pupil horizontal. An intercalary ossicle between the two distal phalanges of the digits. 
1. Vomerine teeth present ......... 9. Rhacophorus p. 242 .

II. No yomerine teeth. . . . . . . . . . Io. Philautus p. 268.

C. Pupil vertical. No intercalary ossicle between the

two distal phalanges. No vomerine teeth. . . . II. Nyctixalus p. 277.

\author{
I. Ra n a L. ${ }^{1}$ ) \\ (LinNé, Syst. Nat., ed. Io, I758, p. 210 ).
}

Pupil horizontal. Tongue notched and free behind. Vomerine teeth present (rarely absent). Tympanum distinct or hidden. Fingers free; toes usually webbed; tips of fingers and toes simple or dilated, the disks without transverse groove. Outer metatarsals usually separated by web.

Omosternum and sternum with a bony style. No intercalary ossicle between the penultimate and terminal phalanges; the latter obtuse or T-shaped.

Tadpoles. - Eyes superior, rarely lateral. Spiraculum sinistral. Vent dextral, near the lower edge of the subcaudal crest, rarely median. Upper crest of tail not extending beyond the base of the tail. Mouth normal; sometimes a large sucking disk behind it; papillae absent along the upper border of the upper lip, rarely entirely absent; number of series of teeth variable.

Distribution: that of the family.

\title{
Synopsis of the Subgenera.
}

$A$. Tips of fingers and toes not dilated, or with dilatations devoid of horizontal groove ............... Rana p. I67.

B. Tips of toes, and usually also of fingers, with disks, which have a crescentic or horseshoe-shaped horizontal gruove between upper and lower surface.

I. Omosternum with forked base.

1. Toes strongly webbed ............. b. Discodeles p. 183 .

2. Toes free or slightly webbed.......... Platymantis p. 187.

II. Omosternum entire ............... d. Hylarana p. 193.

I) Rana mackloti Schlg. (Boulenger, Cat. Batr. Sal. Brit. Mus., i882, p. 72) has been omitted: the specimens of this species, preserved in the Museum at Leiden and according to the label collected by S. Miiller in Java, evidently are males of Rhacophorus bürgeri Schlg. from Japan; probably there has been made some error with the label, the species never being found again in Java.

INDO-AUSTRALIAN AMPHIBIA. 


\section{Synopsis of the Species ${ }^{1}$ ).}

A. No continuous glandular dorsolateral fold.

I. Tips of fingers and toes not dilated.

1. Two metatarsal tubercles..... 1. R. limnocharis p. 167.

2. No outer metatarsal tubercle.

$a$. Back with longitudinal ridges.. 2. $R$. cancrivora p. I 70.

b. Back with oblong warts .... 3. R. verruculosa p. 172 .

II. Tips of toes, and nearly always of fingers also, more or less dilated.

I. Outer metatarsals united.

a. First finger extending beyond second. Interorbital space in the adult broader than the upper eyelid.

«. Subarticular tubercles much developed ......... 15. R. boulengeri p. 187 .

$\beta$. Subarticular tubercles small .. I6. R. moszkowskii p. 188.

$b$. First finger extending beyond second. Interorbital space not broader than the upper eyelid.

$\alpha$. Tongue with a conical papilla. 17. $R$. beauforti p. 189 .

$\beta$. Tongue without papilla.

$\dagger$. The heel reaches beyond the eye ......... I8. R. rugata p. I90.

t†. The heel reaches the eye.

No fold above the tympanum 18 . R. rugata var. rubristriata p. I 9 I.

t†t The heel reaches the eye.

A strong fold above the tympanum........ 19. R. solomonis p. I9I.

$c$. First and second finger equal . 20. $R$. punctata p. 192.

2. Outer metatarsals separated in their distal third or less. Tongue with an obtuse papilla.

$a$. Vomerine teeth extending outwards

beyond the borders of the choanae. II. R. guppyi p. I $\delta_{3}$.

$b$. Vomerine teeth not so.

«. Toes $2 / 3$ webbed. Heel reaching the temple.......... $R$. $R$. bufoniformis p. 184 .

- I) For practical reasons the division in subgenera has not been taken in consideration in this synopsis. It differs in this point from the synoptic tables of the South Asian, Papuan, Melanesian and Australian species of Rana, which Boulenger (Rec. Ind. Mus., XX, 1920) has given and which may be compared with my synopsis. 
$\beta$. Toes $2 / 3$ to $3 / 4$ webbed. Heel reaching the eye ............ I3. $R$. opisthodon p. I 85 .

$\gamma$. Toes webbed to the disks. Heel reaching the eye ........ 14, R. ventricosa p. 186 .

3. Outer metatarsals separated at least in their distal half. Tongue without papilla. Toes entirely or nearly entirely webbed. Usually no outer metatarsal tubercle.

a. Dilatations of fingers and toes without groove between upper and lower surface. «. Tympanum distinct.

†. Heels not overlapping. Male without vocal sacs .......... 4. R. grunniens p. 172 . ††. Heels overlapping. Male without vocal sacs ............ ††t. Heels overlapping or meeting. Male with internal vocal sacs .... 6. R. modesta p. I76.

$\beta$. Tympanum hidden. Heels not overlapping. Male without vocal sacs... 7. R. kuhli p. 178.

6. Dilatations of fingers and toes with a groove between upper and lower surface. $\alpha$. First finger shorter than second.

†. Dorsolateral fold present ......(42. R. labialis p. 220). ††. No dorsolateral fold. ....... 37. R. kampeni p. 212.

$\beta$. First finger as long as second. Nostril slightly nearer to the eye than to the tip of the snout......... 36, R. cavitympanum p. 21 I. $\gamma$. First fingers as long as second. Nostril nearer to the tip of the snout than to the eye. Disks of toes smaller than those of fingers.

†. Heel reaching far beyond tip of snout. $38 . R$. crassiovis p. 213. ††. Heel reaching between eye and nostril ............ 39. R. everetti p. 214.

$\delta$. First finger as long as or longer than second. Nostril in the middle between tip of snout and eye, or nearer to the first. Disks of toes not smaller than those of fingers.

†. Heel reaching far beyond tip of snout. $35 . R$. whiteheadi p. 210 . ††. Heel reaching slightly beyond tip of snout, or not so far. . . . . . . (27. R. arfaki p. 199).

4. Outer metatarsals separated at least in their 
distal half. Tongue without papilla. Toes not more than $3 / 4$ webbed.

a. Dilatations of fingers and toes without groove between upper and lower surface. $\alpha$. Toes $2 / 3$ to $3 / 4$ webbed........ 8. R. microdisca p. 180 . $\beta$. Toes $1 / 3$ to $1 / 2$ webbed....... 9. $R$. hascheana p. $18 \mathrm{r}$.

b. Dilatations of fingers and toes with a groove between upper and lower surface. «. Outer metatarsal tubercle absent. Toes $2 / 3$ webbed. . . . . . . . 21. R. macrops p. 193.

$\beta$. Outer metatarsal tubercle absent or indistinct. Toes $3 / 4$ (to entirely) webbed. Disks of outer fingers large......(42. R. labialis p. 220). $\gamma$. Outer metatarsal tubercle present. Toes $1 / 2$ to $3 / 4$ webbed. Disks small.

†. A light line along canthus rostralis and upper eyelid. Male with internal vocal sacs .............. (46, R. signata p. 226).

††. No such line. Male with external vocal sacs. . . . . . . . 22. R. glandulosa p. 194.

$\delta$. Outer metatarsal tubercle present. Toes less than $1 / 2$ webbed.

†. Interorbital space not broader than the upper eyelid. Nostril nearer to tip of snout than to eye. Head longer than broad ...........23. R. baramica p. 195.

†. Interorbital space broader than the upper eyelid. Nostril in the middle between eye and tip of snout. Head as long as broad........... 24. R. luctuosa p. 196.

††. Interorbital space broader than the upper eyelid. Nostril a little nearer to tip of snout than to eye. Head longer than broad. Outer metatarsal tubercle smaller than inner one ..25. R. debussyi p. 197.

+++ . Interorbital space slightly broader than the upper eyelid. Nostril much nearer to tip of snout than to eye. Outer metatarsal tubercle as long as the inner one........ 26. R. laterimaculata p. 198 .

B. A continuous glandular dorsolateral fold.

I. Dilatations of fingers and toes, when present, without groove. 
I. Toes $2 / 3$ webbed ........... Io. $R$. palavancnsis p. 182 .

2. Toes entirely or nearly entirely webbed. . (5. R. macrodon p. 174).

II. Dilatations of fingers and toes with a groove between upper and lower surface. Toes $1 / 2$ to $3 / 4$ webbed.

I. A light line along canthus rostralis and border of upper eyelid. Disks small. Toes $2_{3}^{\prime}$ or $3 / 4$ webbed. ..........46. R. signata p. 226.

2. No such line.

a. Disks small. Toes $1 / 2$ to $2 / 3$ webbed.

$\alpha$. Interorbital space narrower than the upper eyelid. .........44. R. persimilis p. 223.

$\beta$. Interorbital space at least as broad as the upper eyelid. . . . . . . 45. $R$. nicobariensis p. 224.

6. Disks small. Toes $3 / 4$ (or entirely) webbed. (43. R. erythraca p. 222).

c. Disks of outer fingers large. Toes $3 / 4$ (to entirely) webbed............(42. R. labialis p. 220).

III. Dilatations of toes, and usually also of fingers, with a groove between upper and lower surface. Toes entirely or nearly entirely webbed. I. First finger extending beyond second.

$a$. Dorsolateral fold narrow.

$\varkappa$. Sides of head not darker than the upper surface ............. 27. K. arfaki p. 199.

$\beta$. Loreal and temporal region entirely or partly black or brown.

†. Tips of fingers feebly dilated, devoid of groove. . . . . . . . 28, R. elberti p. 200.

††. Tips of fingers with small disks, bearing a groove........29. R. papua p. 201.

$b$. Dorsolateral fold broader. Heel not reaching beyond the nostril.

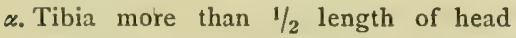
and body. . . . . . . . . 30. R. celebensis p. 204 .

$\beta$. Tibia $1 / 2$ length of head and body or less.

†. Vocal sacs of male internal ...31. R. daemeli p. 205. $\dagger \dagger$. Vocal sacs of male external ... 32. R. kreffiti p. 206.

c. Dorsolateral fold broader. Heel reaching beyond tip of snout.

a. Interorbital space narrower than the upper eyelid. Male with large external vocal sacs . . . . . . . 33. R. grisea p. 207.

$\beta$. Interorbital space about as broad as 
the upper eyelid. Male with small external vocal sacs ......... 34. R. jerboa p. 208.

d. Dorsolateral fold broader. Heel reaching tip of snout ............ (43. R. erythraea p. 222).

2. First finger not extending beyond second.

a. Disks less than $1 / 2$ diameter of tympanum.

a. Heel reaching tip of snout ....43. R. erythraea p. 222.

$\beta$. Heel reaching far beyond tip of snout. (34. R. jerboa p. 208).

b. Disks of third finger at least about $1 / 2$ diameter of tympanum, of second finger much smaller.

«. Toes webbed to the disks......40. $R$. hosii p. 215 .

$\beta$. Two phalanges of fourth toe free from web............. 41, R. chalconota p. 217.

c. Disk of third finger $1 / 2$ to $2 / 3$ diameter of tympanum, of second finger not much smaller................ 42. R. labialis p. 220.

\section{Synopsis of the Tadpoles.}

A. No sucking disk.

I. Eyes lateral. Series of teeth $\mathrm{I} / 2$ or $2 / 2 \ldots 43 . R$. crythraca p. 222.

II. Eyes more or less superior.

I. Series of teeth $1 / 2 \ldots \ldots . \ldots .45 . R$. nicoburiensis? p. 224 .

2. Series of teeth $2-5 / 3$, rarely $2 / 2$.

a. Series of papillae interrupted in the middle of the lower lip. Series of teeth $2 / 3 \cdots\left\{\begin{array}{l}1 . R \text {. limnocharis p. } 167 . \\ 2 . R \text {. cancrivora p. } 170 .\end{array}\right.$

b. Series of papillae of lower lip not interrupted.

«. Body without granular patches, immaculate (tail sometimes dark spotted). t. Spiraculum nearer to the posterior end of the body than to the tip of the snout. Series of teeth 2-4/3.29. R. papux p. 201. $\dagger$. Spiraculum equally distant from tip of snout and base of hind limbs.

Series of teeth $2 / 2-3 \ldots \ldots .6$. R. modesta p. 176 .

$\beta$. Body without granular patches, with dark markings. Series of teeth $2 / 3$.

†. Tail acutely pointed...... 5. R. macrodon p. 174 . ††. Tail obtusely pointed ...... 7.R. kuhli p. 178 .

$\gamma$. Body with granular patches. Series of teeth $3-5 / 3$. 
†. Nostril nearly in the middle between

eye and tip of snout .....4 I $R$. chalconota p. 217.

††. Nostril nearer tip of snout than eye. 42. $R$. labialis p. 220.

3. Series of teeth $4-6 / 4$.

a. Tail acutely pointed ........24. R. luctuosa p. 196.

b. Tail rounded........... 25. R. debussyi p. 197 .

B. A. large sucking disk behind the mouth.

I. Lips with papillae.

I. Both jaws undivided. Series of teeth

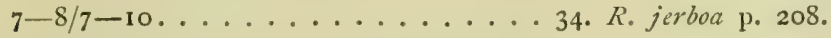

2. Both jaws divided into two pieces. Series

of teeth $5 / 5 \ldots \ldots . . . .35$. . . whiteheadi p. 210.

II. Lips devoid of papillae.

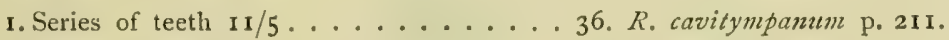

2. Series of teeth $4 / 4 \ldots \ldots . . . .40 . R$, hosii ? p. 215 .

Subg. $a . \mathrm{R}$ a na L.

Fingers and toes not dilated at the tip, or with dilatations devoid of horizontal groove. Outer metatarsals separated by web, at least in their distal half. Dorsolateral fold present or absent.

Distribution: that of the genus.

\section{Rana limnocharis Boie.}

Rana limnocharis (Boie) Wiegmann, N. Acta Acad. Leop.-Carol., XVII, I, I835, p. 255 .

Rana gracilis (Wiegm.) Boulenger, Cat. Batr. Sal. Brit. Mus., I882, p. 28.

Rana limnocharis Boulenger, Fasciculi Malayenses, Zool., pt. I, 1903, p. I34.

Rana limnocharis Stejneger, Bull. US. Nat. Mus., LVIII, 1907, p. I27, figs. ro7-I Io (head, hand and foot).

Rana limnocharis v. Kampen, Nat. Tijdschr. Ned.-Indië, LXIX, I909, p. 35 (tadpole).

Rana limnocharis Boulenger, Vert. Fauna Malay Penins., Rept. and Batr., London, 1912, p. 236.

Rana (Fejérvárya) limnocharis Bolkay, Anat. Anz., XLVIII, I915-16, p. I8I. Rana limnocharis Smith, Jrn. Nat. Hist. Soc. Siam, II, 1917, p. 165 (tadpole). Rana wasl Annandale, Mem. Asiat. Soc. Bengal, VI, 19I7, p. 13I, pl. V, fig. 5 (head) and text-fig. $3 \mathrm{~A}$ (foot).

Rana limnocharis Annandale, Mem. Asiat. Soc. Bengal, VI, 1917, p. 132, pl.V, fig. 6 (head), pl. VI, fig. 2 (tadpole) ${ }^{1}$ ), text-fig. 26 (mouth of tadpole ${ }^{1}$ ) and $3 b$ (foot).

Rana limnocharis Boulenger, Rec. Ind. Mus., XX, 1920, p. 28.

I) After a specimen from Madras, which in some respects differs from those of the Indian Archipelago. 
Vomerine teeth in two oblique series between the choanae or extending a little beyond their posterior level. Head as long as broad; snout pointed or rounded, at least as long as the upper eyelid; canthus rostralis obtuse, but distinct; loreal region very oblique, concave; nostril equidistant from eyc and tip of snout or nearer the latter; interorbita! space narrower than the upper eyelid; tympanum distinct, $1 / 2$ to $\% / 3$ the width of the eye. Fingers and toes obtusely pointed; first finger extending beyond second; toes about half webbed; terminal phalanx of third and fifth, two or three phalanges of fourth toe free from web; outer metatarsals $1 / 2$ or $1 / 3$ united; a narrow

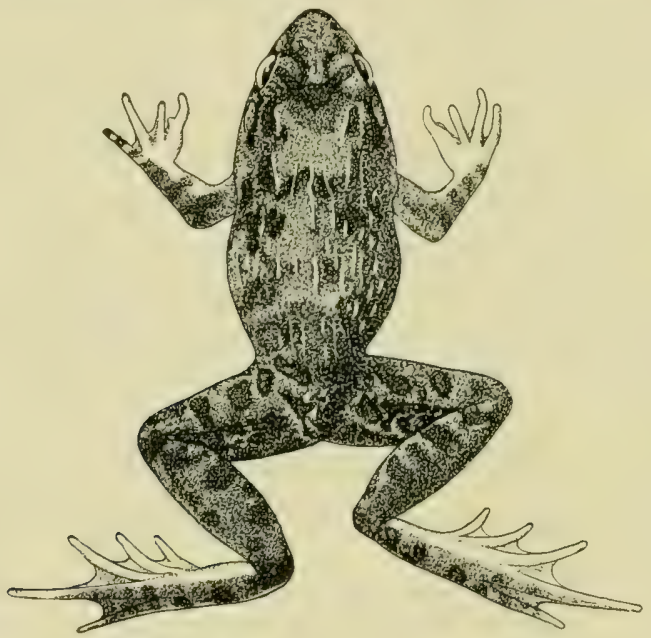

Fig. 23. Rana limnocharis Boie, $X \mathbf{r}$.

fringe along the outer side of metatarsus and fifth toe; subarticular tubercles well developed; a prominent, oblong inner and a very small, round, rarely very indistinct outer metatarsal tubercle; the heel reaches the tympanum, the eye, or between eye and tip of snout; tibia about half length of head and body; when the hind limbs are folded at right angles to the body, the heels are more or less overlapping.

Skin of back with narrow longitudinal ridges; a fold above the tympanum; a more or less distinct transverse fold behind the eyes; posterior surface of thighs granular; smooth below.

Upper surface grey, brown or olive green, with darker spots, among which a V-shaped one between the eyes; sometimes a broader or narrower yellow, white, pink or green vertebral 
line; hinder surface of thighs yellow, marbled with dark brown; hind limbs, with irregular dark cross-bars; lips with dark vertical bars; white below; the $\sigma^{\top}$ with a M-shaped black spot on the throat. From snout to vent $65 \mathrm{~mm}$.

Male with two external vocal sacs.

Omosternum forked at the base. Terminal phalanges obtusely pointed.

Tadpole. - Length of body about once and a half its width; tail less than twice the length of the body, about 4 times as long as deep. Nostril about equally distant from eye and tip of snout; eyes superior, in the middle between tip of snout and spiraculum, the distance between them about $2 \%$ times that between the nostrils and larger than the width of the mouth; spiraculum sinistral, directed upwards and backwards, visible from above and from below, as far from tip of snout as from base of tail; vent dextral, anal tube long, projecting beyond lower border of crest of tail. Tail pointed, the inferior crest low, the upper one about twice as high and reaching to the base of the tail.

Mouth ventral, small; sides of upper lip bordered with one, lower lip (except a small portion in the middle, along the lower șeries of teeth) with two rows of papillae; jaws narrowly edged with black; series of teeth ${ }^{1}{ }^{1} \mathrm{I} / 3$, the inner series of the upper lip broadly interrupted, the outer series of the lower lip much shorter than the two other ones, which are nearly equal in length.

Back and sides dark grey; tail brown, with colourless crests; the back, sides and tail may be spotted or finely mottled with dark brown; posterior half of tail often dark grey; white beneath. Length $42 \mathrm{~mm}$.

Habitat: Pulo Weh!; Sumatra (Atjeh!; Gajo countries!; Upper and Lower Langkat; Medan!; Paneh !; Brastagi, Karo Highland, 1400 m.!; Batak mts., 300-I000 m.!; Lauttador; Mt. Simbolon; Tebing Tinggi!; Talu ; Gunung Sahilan; Matur!; Cleft of Arau!; Pajakombo!; Baso!; Ajer Teganang!; Telago apabilo!; Lembok; Kalung!; Indragiri; Kepahiang; Rawas riv.; Hari leko riv.!); Banka!; Natuna islands (Bunguran); Borneo (N.-Borneo; Kutjing ; Singkawang; Bengkajang; Mandor); Java (Batavia!; Krawang!; Buitenzorg!; Gadok; near Tjibodas!, I 400-2000 m.; Pasirdatar, 900 m.!; Sukabumi!; Mt. Malabar, I 500 m.!; Tjilatjap!; Babakan!; Wonosobo!; 
Djokjakarta!; Mula!; Pasuruan!; Nongkodjadjar, I 200 m.!; Situbondo!); Bali!; Lombok!; Sumbarva, I 40 m. - From India, the Himalayas (up to $2100 \mathrm{~m}$.) and Ceylon, S.-China and Japan to the Malay Peninsula and the Philippines.

\section{Rana cancrivora Gravenh.}

Rana cancrivora Gravenhorst, Deliciae Mus. Zool. Vratislav., Fasc. I, Iipsiae, I 829 , p. 4 I.

Rana tigrina part. Boulenger, Cat. Batr. Sal. Brit. Mus., I882, p. 26.

Rana Schliuteri Werner, Zool. Anz., XVI, I894, p. 84.

Rana tigrina and $R$. t. var. angzestopalmata v. Kampen, Weber's Zool. Ergebn., Leiden, IV, 1907, p. 388, pl. XVI, figs. 3b, c (feet) (with tadpole).

Rana tigrina v. Kampen, Nat. Tijdschr. Ned.-Indië, LXIX, I909, p. 33 (tadpole). Rana tigrina part. Boulenger, Vert. Fauna Malay Penins., Rept. and Batr., London, I912, P. 234 (not the figure, nor the tadpole).

Rana cancrivora Annandale, Mem. Asiat. Soc. Bengal, VI, 1917, p. 128, pl. V, figs. $4,4^{a}, 4^{b}$ (head), textfig. Ic (foot).

Rana tigrina var. cancrivora Boulenger, Rec. Ind. Mus., XV, pt. II, I918, p. 55,58 .

Rana cancrivora Annandale, Rec. Ind. Mus., XV, pt. II, I9I8, p. 63, figs. $3,3^{a}$ (tadpole).

Rana sancrivora Boulenger, Rec. Ind. Mus.: XX, I920, p. 23.

Vomerine teeth in two shorter or longer oblique series beginning close to, or at a short distance from the anterior borders of the choanae, usually extending beyond the level of their posterior borders; lower jaw with two feeble prominences in front. Head broader than long or as long as broad, rarely slightly longer; snout rounded, or pointed, projecting, as long as or a little longer than the upper eyelid, longer than deep; canthus rostralis obtuse, straight; loreal region very oblique, concave; nostril equidistant from eye and tip of snout, or nearer the latter; interorbital space much narrower than the upper eyelid; tympanum distinct, about $1 / 2$ to $\pi / 8$ the width of the eye. Fingers and toes obtusely pointed; first finger extending beyond second; toes $3 / 4$ to nearly entirely webbed, one or two phalanges of fourth toe being free, the web distinctly emarginate; subarticular tubercles moderate; a blunt inner, no outer metatarsal tubercle; a dermal fringe along the outer side of fifth toe; the heel reaches the eye or to between eye and nostril; tibia $\mathrm{I}^{3} / 4$ to $2 \frac{1}{3}$ times in the length from snout to vent; when the hind limbs are folded at right angles to the body, the heels strongly overlap.

Back with small warts and with longitudinal ridges; a strong fold above the tympanum; smooth beneath. 
Brown or olive above, usually with dark spots and often a broader or narrower light (in life yellowish, greenish or red) vertebral line; rarely a light streak along the side of the body; lips with black vertical bars; limbs with dark cross-bars; posterior surface of thighs yellow, marbled with black; throat often, and sometimes the entire lower surface marbled with brown. From snout to vent $92 \mathrm{~mm}$.

Male with two gular vocal sacs, forming folds on the sides of the throat.

Tadpole. - Length of body about once and a half its width and more than half the length of the tail, which is about four times as long as deep. Nostril about equally distant from tip of snout and eye; eyes superior, as far from tip of snout as from spiraculum, the distance between them about $2^{1 / 2}$ times that between the nostrils, and larger than the width of the mouth; spiraculum sinistral, directed upwards and backwards, visible from above and from below, nearly equally distant from tip of snout and base of tail; vent dextral, close to the lower border of the subcaudal crest. Tail pointed; lower crest low, the upper one about twice as deep, reaching to the base of the tail.

Mouth ventral, small; sides of upper lip bordered with one, lower lip (with the exception of its central part) with two series of papillae; jaws narrowly edged with black; series of teeth $I^{1} I / 3$, the outer series of the lower lip shorter than the two inner ones, which are not interrupted.

Back and sides dark grey, spotted with brown; white below; tail brown, spotted with darker; old specimens often with a light vertebral line and a dark transverse streak between the eyes. Length $42 \mathrm{~mm}$.

Habit at: Sumatra (Belawan!; Airbangis!; Gunung Sahilan; Agam; Alahan Pandjang; Batu Sangkar, between 460 and 900 m.; Solok; Muarolabu; Padang; Trusan; Palembang); Riou arch. (Bintang); Banka; Borneo (Padas, N.-Borneo; Baram riv.; Kutjing; Singkawang; Sintang; Seberuang riv.; Bandjermasin; Balikpapan!); Pulo Laut!; Java (Serang; Lebak; Batavia!; coast of Krawang!; Buitenzorg!; Gadok; Tjisarua, near Sindanglaja!; Pasirdatar, 900 m.!; Sukabumi!; Tjiandjur; Situ Bagendit!; Indramaju!; Cheribon!; Semarang; Ambarawa; Wonosobo; Djokjakarta; Djapara; Kediri!; Pasuruan!); Madura!; Bali!; Lombok!, up to 680 m.; Sumbawa; Flores!; Ombai; Sumba!; 
Roti!; Timor; Saleier!; Buton; Celebes (Makasser!; Maros!; Boni; Pampanua!; Pare Pare!; Tempe!; Kandari; Luwu!; Katjang!; Rumbi Mengkoka; Lake Poso; Toli Toli; Lake Limboto; Gorontalo; Menado; Kema). - S.-China; Siam; Malay Peninsula; Philippines.

\section{Rana verruculosa Roux.}

Rana tigrina var, verruculosa Roux, Zool. Jahrb., Syst., XXX, I911, p. 504. Rana verruculosa Boulenger, Rec. Ind. Mus., XX, 1920, p. 16.

Vomerine teeth in two short oblique series extending a little behind the level of the choanae. Head a little broader than long; snout more or less pointed, feebly projecting, as long as the upper eyelid, longer than deep; canthus rostralis obtuse, straight; loreal region oblique, concave; nostril equidistant from eye and tip of snout or a little nearer the first; interorbital space much narrower than the upper eyelid; tympanum distinct, $1 / 2$ to $2 / 3$ width of eye. Tips of fingers and toes obtuse; first finger extending beyond second, which is as long as fourth; toes nearly entirely webbed; outer metatarsals separated nearly to the base; subarticular tubercles moderate; a blunt, oblong inner, no outer metatarsal tubercle; a very feeble dermal ridge along the outer side of fifth toe; a tarsal fold; the heel reaches the eye or the tip of the snout; tibia about $1 / 2$ length of head and body; when the hind limbs are folded at right angles to the body, the heels are overlapping.

Upper surfaces with oblong warts; a transverse fold between the posterior edges of the eyelids may be present; a fold above the tympanum; smooth beneath.

Olive, indistinctly marbled with dark, above; lips with dark vertical bars; limbs with dark cross bars; posterior surface of thighs yellow, marbled with black; white or brownish beneath, with or without small grey spots on the throat. Length $66 \mathrm{~mm}$.

Male with external vocal sacs, forming blackish folds on the throat.

Distinguished from $R$. cancrivor $a$, with which it is closely allied, by the presence of oblong warts instead of longitudinal ridges on the back, and the rudimentary ridge along the outer toe.

Habitat: Wetar; Timor!.

\section{Rana grunniens Daud.}

Rana grunniens part. Daudin, Hist. Nat. des Rainettes ....., Paris, ISoz, p. $65, \mathrm{pl}$. XXI. 
Rana grumiens Boulenger, Cat. Batr. Sal. Brit. Mus., r882, p. 23.

Rana macrodon (non Kuhl) v. Kampen, Nova Guinea, IX, pt. 3, I9I3, p. 458. Rana grunnicns Boulenger, Ann. Mag. Nat. Hist., (9) I, I9r8, p. 240.

Rana grunniens Boulenger, Rec. Ind. Mus., XX, 1920, p. 39.

Vomerine teeth in two long oblique series extending much behind the level of the choanae; lower jaw without or with two more or less developed bony processes in front. Head nearly as long as broad, occiput more or less swollen on the sides; snout rather pointed, feebly projecting, as long as or hardly longer than the upper eyelid and longer than deep; canthus rostralis angular, straight; loreal region oblique, concave; nostril a little nearer to tip of snout than to eye; interorbital space as broad as or a little broader or narrower than the upper eyelid; tympanum rather distinct, $1 / 3$ to $2 / 3$ the diameter of the eye. Tips of fingers obtuse or slightly swollen, of toes with small disks; first finger extending beyond second, which is a little shorter than fourth; third toe longer than fifth; toes entirely webbed; subarticular tubercles well developed; inner metatarsal tubercle oblong, about $1 / 2$ to $3 / 5$ the length of first toe (measured from the tubercle); no outer metatarsal tubercle; a well-developed dermal fringe along outer side of $5^{\text {th }}$ toe; a tarsal fold; the heel reaches the eye; tibia less than half the length of head and body; when the hind limbs are folded at right angles to the body, the heels do not overlap.

Skin of upper surface smooth or with small tubercles, intermixed with larger ones, especially on the posterior part of the back and on the hind limbs; upper eyelid tubercular; a fold above the tympanum, and some short longitudinal folds along the sides of the back; smooth beneath.

Brownish or greyish above; sometimes a rufous spot on the loin; limbs with or without dark cross-bars; thighs marbled with dark brown; white below, the throat sometimes spotted or marbled with brown. From snout to vent $146 \mathrm{~mm}$.

Male without vocal sacs.

Omosternum with forked base. Terminal phalanges with feebly expanded tip.

Distinguished from $R$. macrodon by the shorter hind limbs.

$\mathrm{Habitat}$ : Celebes (Lojnang Pinapuan, in eastern Celebes!); Ambon!; Nusa Laut! '); New Guinea (Lorentz riv. !; Mimika riv.).

I) Mentioned as $R$. modesta by me in Weber's Zool. Ergebn., Leiden, IV, I907, p. 386 . 


\section{Rana macrodon Kuhl.}

Rana macrodon (Kuhl) Duméril et Bibron, Erpét. gén., Paris, VIII, 184I, p. 382. Rana macrodon Blanford, Proc. Zool. Soc. London, I88I, p. 225, pl. XXI, fig. 4 (head).

Rana macrodon part. Boulenger, Cat. Batr. Sal. Brit. Mus., 1882, p. 24, pl. I, fig. 4 (inside of mouth).

Rana macrodon Flower, Proc. Zool. Soc. London, r896, p. 898, pl. XLV, fig. I. Rana macrodon Flower, Proc. Zool. Soc. London, 1899, p. 888, pl. LIX, figs. I, I $a$ (tadpole).

Rana macrodon Boulenger, Vert. Fauna Malay Penins., Rept. and Batr., London, 1912, p. 233.

Rana macrodon Boulenger, Rec. Ind. Mus., XX, I920, p. 40.

Vomerine teeth in two long oblique series between the choanae and extending beyond the level of their hinder borders; lower jaw with two bony prominences in front, feebly developed in the female, large and acutely pointed in the adult male. Head as long as or broarler than long, rarely slightly longer than broad; occiput much swollen in the male; snout obtusely pointed, feebly projecting, as long as or longer than the upper eyelid, longer than deep; canthus rostralis obtuse, straight; loreal region oblique, concave; nostril nearer to end of snout than to eye; interorbital space narrower than, to $1 \frac{1}{2}$ the width of the upper eyelid; tympanum distinct, $2 / 5$ to $5 / 6$ the diameter of the eye. Tips of fingers obtuse or feebly swollen, those of toes with very small disks; first finger extending beyond second, which is shorter than fourth; third toe longer than fifth; toes entirely or nearly entirely webbed; subarticular tubercles well developed; inner metatarsal tubercle oblong, blunt, about $2 / 5$ to $3 / 5$ the length of the first toe; no outer metatarsal tubercle; a dermal fold along outer side of fifth toe; tarsal fold present or absent; the heel reaches the eye or the tip of the snout; tibia about half the length of head and body; when the hind limbs are folded at right angles to the body, the heels are more or less overlapping.

Skin smooth, or with small rounded warts above; upper eyelid tubercular, a fold above the tympanum; young with a narrow glandular fold on each side of the back, beginning behind the upper eyelid. Smooth below.

Olive-brown, bronze, green or yellowish- to chocolate-red above, with or without small darker spots and sometimes with a broader or narrower yellow or orange vertebral line; loreal and temporal regions, and a cross-bar between the eyes some- 
times dark brown; lips usually with dark spots or vertical bars; limbs with more or less distinct dark brown cross-bars; hinder side of thighs spotted or marbled with black; lower surfaces yellow or pale orange, uniform or spotted with brown. Length $230 \mathrm{~mm}$.

Omosternum with forked base. Terminal phalanges with slightly expanded tip.

Male without vocal sacs.

The food consists of snails, crabs, scorpions and insects (Flower).

Tadpole. - Length of body about $\mathrm{I}^{1} / 2$ times its width; tail about twice the length of the body, about 4 times as long as deep, the depth of the muscular portion at its base about 0,7 the greatest total depth. Nostril about halfway between eyes and end of snout; eyes superior, nearer to the end of the snout than to the spiraculum, the distance between them once and a half to twice that between the nostrils, and slightly greater than the width of the mouth; spiraculum sinistral, directed upwards and backwards, visible from above and from below, nearer to the vent than to the end of the snout; vent dextral, close to the lower border of the subcaudal crest. Tail acutely pointed; upper crest convex, slightly deeper than the lower one, not extending to base of tail.

Lower lip and sides of upper lip bordered with papillae; jaws broadly edged with black; series of teeth $I^{1} I_{I} / I_{2} I$, the outer row of lower lip very short, the inner one the longest and narrowly interrupted.

In life light reddish brown above, mottled with darker brown; a dark brown line through the eye, sometimes other dark lines radiating from the eye; crests of tail colourless, with irregular dark brown vertical bars; belly buff, transparent. Length $37 \mathrm{~mm}$.

Blanford, Flower and Boulenger distinguish two forms of Rana macrodon, the "forma typica" and var. blythii Blgr. (1920), which are, however, not sharply separated. In the var. blythii, after Boulenger, the head is narrower than usually in the typical form; the eye is usually larger, the canthus rostralis more distinct, the loreal region less oblique; the tympanum is often smaller $(2 / 5$ to $3 / 5$ the width of the eye, in the typical form $3 / 5$ to ${ }^{5} / 6$ ), the toes are often less broadly webbed, the heel is sometimes reaching the tip of the snout (in the forma typica the eye or between 
eye and tip of snout). The typical form inhabits: Singapore, Engano, the Natuna islands, Borneo, Java '), the var. blythii: the Continent, Sumatra, Borneo and the Philippines.

Habitat ${ }^{2}$ ): Simalur!; Pulo Babi!; Nias!; Mentawei islands (Sipora); Engano; Sumatra (Lho Sukon, Atjeh!; Gajo countries!; Sukaranda, Upper Langkat; Deli!; Batak mts.; Lauttador; Sibolga!; Talu!; Matua!; near Solok and Singkarah!; Sungai Kumbang, I600 m.! and Sandaran Agung, 745 m., Kurintji!; Muarasako, Kurintji!; Indragiri; Ajer Njuruk, Dempu, I 400 m.!; Pasemah!; Rawas riv.); Natuna islands (Bunguran); Borneo (Baram riv.; Mt. Dulit; Seberuang riv.; Balikpapan!); Java (Buitenzorg!; Pasirdatar, 900 m.!; Sukabumi!; Babakan!). Burma; Annam; Siam; Malay Peninsula, up to $1200 \mathrm{~m}$.; Singapore; Philippines.

\section{Rana modesta Blgr.}

Rana modesta Boulenger, Cat. Batr. Sal. Brit. Mus., I882, p. 25, pl. I, fig. 3 . Rana modesta F. Müller, Verh. naturf. Ges. Basel, X, I895, p. 867.

Rana modesta Boulenger, Proc. Zool. Soc. London, I897, p. 228.

Rana microtympanum v. Kampen, Weber's Zool. Ergebn., Leiden, IV, I907, p. 386 (with tadpole), pl. XVI, fig. 2 (head).

Rana magna Stejneger, Smithson. Misc. Coll., LII, I910, P. 437.

Rana modesta v. Kampen, Bijdr. t. d. Dierk., pt. 19, I9I3, p. 89 (tadpole).

Rana modesta Roux, Revue Suisse Zool., XXVI, I9I8, p. 4II.

Rana magna, R. modesta and R. microtympanum Boulenger, Rec. Ind. Mus., XX, I 920, p. 45,46 .

Vomerine teeth in two moderately long oblique series between the choanae and extending beyond the level of their posterior borders, or entirely behind them; lower jaw with two bony processes in front, which are feebly developed in the female, larger and acutely pointed in the male. Head larger in the male than in the female, as broad as or broader than long; snout rounded or obtusely pointed, feebly projecting, as long as the upper eyelid, longer than deep; canthus rostralis angular, straight; loreal region oblique, concave; nostril in the middle between the tip of the snout and the eye, or nearer the first; interorbital space about as broad as the upper eyelid in the adult, usually narrower in the young; tympanum distinct, $1 / 4$

I) After Boulenger also Lombok, Flores, Halmahera en Batjan; see, however, the next note.

2) The specimens described by various authors from Lombok, Flores, Celebes, the Moluccas and the Philippines probably belong to $R$. modesta and grumiens. 
to $1 / 3$ the diameter of the eye. Tips of fingers swollen or with very small disks, of toes with very small to rather large disks (up to $2 / 3$ the width of the tympanum); first finger as long or nearly as long as, or extending beyond second, which is a little shorter than fourth; third toe longer than fifth; toes entirely or nearly entirely webbed; subarticular tubercles well developed; an oblong inner metatarsal tubercle, measuring $2 / 5$ to $1 / 2$ the length of the inner toe; no outer metatarsal tubercle; a dermal fringe along the outer side of the fifth toe; a tarsal fold, sometimes absent; the heel reaches the tip of the snout or between the eye and the tip of the snout; tibia about half as long as the distance between tip of snout and vent; when the hind limbs are folded at right angles to the body, the heels are overlapping or just meeting.

Back with small granules and larger warts or short longitudinal folds, sometimes nearly smooth; a fold above the tympanum; upper eyelids tubercular; a more or less distinct ridge between the latter usually present; smooth beneath.

Brown, grey-brown, or blackish olive above, with or without rather indistinct darker spots; sometimes two lighter stripes on the back and the canthi rostrales, meeting on the tip of the snout; sometimes a light vertebral stripe; often a dark cross-bar between the eyes; sometimes a black spot on the tympanum; upper lip with dark vertical bars; limbs with dark cross-bars; posterior surface of thighs dark brown, with light spots or marblings; lower parts white, uniform or speckled or spotted with brown. From snout to vent $102 \mathrm{~mm}$.

Omosternum with forked base. Terminal phalanges with slightly expanded tip.

Male with two small internal vocal sacs.

Tadpole. - Length of body about $\mathrm{I}^{1} / 2$ times its width or somewhat less; tail not quite twice the length of the body and 4 to 5 times as long as deep. Nostril nearer to the eye than to the tip of the snout; eyes superior, as far from tip of snout as from spiraculum, the distance between them hardly greater than that between the nostrils, which equals the width of the mouth; spiraculum sinistral, directed upwards and backwards, equally distant from tip of snout and hind limbs; vent dextral, close to the lower border of the subcaudal crest. Tip of tail rounded; crests low, the upper one a little deeper than the lower one and reaching to base of tail.

INDO-AUSTRALIAN AMPUIBIA. 
Mouth ventral; lower lip and sides of upper one with papillae, which are small in number; jaws narrowly black-edged; series of teeth $\mathrm{I}^{1} \mathrm{I} / \mathrm{I}_{1-2} \mathrm{I}$.

Upper surface, muscular part of tail and sometimes part of the crests brown; other parts white. Length $38 \mathrm{~mm}$.

Closely related to $R$. grunniens, from which it is distinguished by the generally shorter series of vomerine teeth and the presence of vocal sacs in the male.

Boulenger (1920) distinguishes 3 species, but the differences are slight:

First finger much longer than second. Tympanum $1 / 4$ to $2 / 5$ diameter of eye. Heels not overlapping. Disks of toes rather large: R. magna Stejn. (Celebes; Philippines).

First finger much longer than second. Tympanum $2 / 5$ to $3 / 5$ diameter of eye. Heels overlapping. Disks of toes very small: R. modesta Blgr. (Saleyer; Celebes; Talaut islands; Nusa Laut).

First finger as long as or a little shorter than second. Tympanum $1 / 3$ diameter of eye: $R$. microtympanum v. Kamp. (Celebes) (based on young specimens).

Habitat: Lombok ( \pm 680 m.); Flores!; Saleyer!; Celebes (Loka!; Bontorio; Bwoöl; Matinan mts.; Pinapuan!; Kwandang!; Gorontalo; Gurupahi!; Tomohon; Menado!); Talaut islands!; Halmahera!; Batjan; Buru, up to I 200 m.!; Ceram!; Ambon!; Uliaser!). — Philippines.

\section{Rana kuhli Schlg.}

Rana Kuhzii (Schlegel), Duméril et Bibron, Erpét. gén., Paris, VIII, I 841 , p. $384 ;$ IX, I 854, lp. 394 .

Rana conspicillata Günther, Proc. Zool. Soc. London, I872, p. 597, pl. XL, fig. A. Rana kuhlii part., Boulenger, Cat. Batr. Sal. Brit. Mus., 1882, p. 20.

Rana paradoxa Mocquard, Nouv. Arch. Mus. d'Hist. nat., (3) II, I890, p. I48, pl. $\mathrm{X}$, figs. $3-3 c$.

Rana Kuhlii Boulenger, Ann. Mag. Nat. Hist., (6) VII, I89I, p. 344.

Rana Kuthli Mocquard, Mém. Soc. Zool. France, V, I892, p. 198.

Rana Kuhlii Boulenger, Vert. Fauna Malay Penins., Rept. and Batr., Londor, 1912, p. 229.

Rana kuhlii Smith, Jrn. Nat. Hist. Soc. Siam, II, 1917, p. 262, figs. I-I $b$ (tadpole). Rana kululii Boulenger, Rec. Ind. Mus., XX, 1920, p. 62.

Vomerine teeth in two oblique series just behind the level of the choanae; lower jaw with two tooth-like processes, feebly developed in the female, large, obtuse and fitting into deep pits of the upper jaw in the adult male. Head broader than long, 
larger in the male than in the female; snout rounded or obtusely pointed, feebly projecting, as long as or shorter than the upper eyelid; canthus rostralis indistinct or none; loreal region oblique, slightly concave; nostril a little nearer to the tip of the snout than to the eye; interorbital space as broad as or broader than the upper eyelid; tympanum hidden (in preserved specimens it can sometimes be distinguished below the skin), $1 / 2$ to $2 / 3$ the width of the eye. Fingers obtuse or with slightly swollen tips, toes with small, but distinct disks; first finger as long as, or extending a little beyond second, which is a little shorter than fourth; third toe longer than fifth; toes entirely webbed or terminal phalanx of fourth toe free; subarticular tubercles well developed; inner metatarsal tubercle narrow, $2 / 5$ to $2 / 3$ the length of the inner toe; no outer metatarsal tubercle; a dermal ridge along outer side of fifth toe; a tarsal fold; the heel reaches the temple or the eye; tibia $2 / 5$ to $1 / 2$ the length of head and body; when the hind limbs are folded at right angles to the body, the heels do not overlap.

Above with short longitudinal folds or roundish tubercles, sometimes nearly smooth, except upon the tibia, which is coarsely granulate; a fold above the tympanum; smooth beneath.

Brown or olive-green above, with or without irregular small black spots; often a black transverse bar, preceded by a yellowish one, between the eyes; sometimes a yellow vertebral stripe; lips and limbs mottled or spotted with dark olivebrown; lower parts buff, the throat often marbled or reticulated with brown. From snout to vent $105 \mathrm{~mm}$.

Omosternum with forked base. Terminal phalanges with transversely expanded tips.

Male without vocal sacs.

Tadpole. - Length of body $\mathrm{I}^{1} / 2$ times its width; tail 4 times as long as deep. Nostril halfway between eye and tip of snout; eyes superior, the distance between them $\mathrm{I}^{1} / 2$ times that between the nostrils; spiraculum sinistral, nearer to the eye than to the vent, which is dextral. Tail obtusely pointed, the crests rather low, the upper one a little deeper than the lower one, not extending on to the back.

Mouth with short papillae at the sides and below; jaws broadly edged with black; series of teeth ${ }^{1}{ }^{1} \mathrm{I} / 3$, the outer row of lower lip about $1 / 2$ the length of the two inner ones, which are subequal, the first one sometimes narrowly interrupted. 
In life olive above, speckled with blackish, nearly colourless below. Length $45 \mathrm{~mm}$.

Habitat: Mentawei islands (Sipora); Sumatra (Sukaranda, Upper Langkat; Deli!; Brastagi, Karo highland, I400 m.!; Bandarbaru, Batak mts., \pm 900 m.!; Mt. Simbolon; Korintji valley, 900 m.; Korintji peak, I 400 m.; Muarolabu; Barisan mts., 1200 m.); Borneo (Mt. Kina Balu; Mt. Kalawat and Mt. Kappa, Brit. N.-Borneo; Baram riv.; Matang; S.-E.-Borneo); Java (near Tjibodas!, I400-2000 m.; Pasirdatar, 900 m. !; Sukabumi!; Mt. Malabar, I 500 m.!); Celebes (Bua Praeng; Minahasa). - S.-China, Loo Choo islands and Formosa to Malay Peninsula.

\section{Rana microdisca Bttgr.}

Rana microdisca Boettger, Ber. Offenb. Ver. f. Naturk. (I887-9I), r892, p. I 37 . Rana microdisca Boettger, Jen. Denkschr., VIII, 1894, p. I13, pl. V, figs. 2a-d. Rana leytensis Boettger, Zool. Anz., XVI, 1894, p. 365 .

Rana microdisca Boulenger, Proc. Zool. Soc. London, 1897, p. 230.

Rana microdisca v. Kampen, Zool. Jahrb., Syst., XXII, I905, p. 702.

Rana microdisca Boulenger, Rec. Ind. Mus., XX, 1920, p. 57.

Vomerine teeth in two oblique series, beginning between the choanae, and extending beyond their hinder level, or entirely behind them; lower jaw with two acute, tooth-like processes in the male, with feeble prominences in the female. Head as long as broad or somewhat broader than long; snout rounded, vertically truncate or feebly projecting, as long as the upper eyelid, longer than deep; canthus rostralis distinct, obtuse; loreal region oblique, feebly concave; nostril as far from the tip of the snout as from the eye or a little nearer the first; interorbital space about as broad as the upper eyelid; tympanum more or less distinct, $2 / 5$ to $3 / 4$ the diameter of the eye. Tips of fingers feebly swollen or with very small disks, toes with very small disks; first finger extending as far as or beyond second, which is shorter than fourth; third toe longer than fifth; toes $2 / 3$ to $3 / 4$ webbed, two or three phalanges of fourth one free; subarticular tubercles moderate; inner metatarsal tubercle small, oblong, no outer metatarsal tubercle; a feeble dermal fringe along the outer side of the fifth toe may be present; no tarsal fold; the heel reaches the nostril, the tip of the snout, or beyond; tibia a little more than $1 / 2$, to $2 / 3$ the length of head and body; when the hind limbs are folded at right angles to the body, the heels are strongly overlapping. 
Back and sides smooth or with some rounded warts or longitudinal ridges; dorsolateral fold, if present, beginning behind the upper eyelid, not extending beyond the scapular region; a curved fold above the tympanum; smooth below, or posterior part of vent and lower surface of thighs feebly granulate.

Brown or olive above, marbled or spotted with hlack; a broad, black cross-bar, sometimes light-bordered in front, between the eyes; a broad, light vertebral line or two broad dorsolateral stripes may be present; lips with dark vertical bars; limbs with numerous, narrow, black cross-bands; posterior surface of thighs dark marbled; white beneath, throat and breast often powdered or marbled with blackish. From snout to vent $56 \mathrm{~mm}$.

Omosternum with forked base.

Male without vocal sacs.

Habitat: Mentawei islands (Sipora); Sumatra (Palembang!); Borneo (Sandakan; Semberrah!); Java (Tjibodas!; Tengger mts., I 200 m.); Flores; Celebes (Loka!; above Kolaka, 500 m.; Rumbi-Mengkoka; Luwu; Takalekadjo mts., towards Lake Poso, $900 \mathrm{~m}$.; Koro valley, 500-700 m.; Bone mts.; Bulawa mts., $\pm \mathrm{I} 200 \mathrm{~m}$. ; Tomohon). - Sulu islands; Philippines.

\section{Rana hascheana (Stol.).}

Polypedates Hascheanus Stoliczka, Jrn. Asiat. Soc. Bengal, XXXIX, I87o, p. I47, pl IX, fig. 3 .

Rana hascheana Boulenger, Vert. Fauna Malay Penins., Rept. and Batr., London, 1912, p. 232.

Rana hascheana Boulenger, Rec. Ind. Mus., XX, 1920, p. 54.

Vomerine teeth in two oblique oval groups just behind the level of the choanae; lower jaw without bony prominences. Head as long as broad or a little broader than long; snout rounded, scarcely projecting, as long as the eye; canthus rostralis obtuse; loreal region oblique, slightly concave; nostril equidistant from eye and tip of snout; interorbital space as broad as the upper eyelid; tympanum distinct, $1 / 2$ to $2 / 3$ the diameter of the eye. Tips of fingers scarcely dilated, toes with small, but very distinct disks; first and second finger equal or first slightly the longer; toes $1 / 3$ to $1 / 2$ webbed; subarticular tubercles moderate; inner metatarsal tubercle feebly prominent, $2 / 5$ to $3 / 5$ length of inner toe; no outer one; a feeble tarsal fold; the 
heel reaches the tip of the snout, or between the eye and the tip of the snout; tibia $1 / 2$ to $5 / 8$ the length of head and body; when the hind limbs are folded at right angles to the body, the heels are overlapping.

Skin smooth or with small flat warts or feeble corrugations; a strong fold above the tympanum.

Rich yellow to orange brown above, in life, with dark brown spots, with or without a light vertebral streak; a dark brown cross-band between the eyes, edged with pale yellow in front, followed by a faint W-shaped marking, the ends of which extend behind the eyes; sides of body finely spotted with very dark brown and white; lips with dark vertical bars; limbs with dark cross-bands; lower parts white, with pale purple and golden shades, with or without dark brown spots on the throat. From snout to vent $38 \mathrm{~mm}$.

Male without vocal sacs.

Habitat: Natuna islands (Bunguran); Java? (Tjibodas, I $\left.\left.400-2000 \mathrm{~m} .{ }^{2}\right)^{1}\right)$. - Andamans; Malay Peninsula (up to $\mathrm{I} 600 \mathrm{~m}$.).

\section{Io. Rana palavanensis Blgr.}

Rana palavanensis Boulenger, Ann. Mag. Nat. Hist., (6) XIV, I894, p. 85. Rana palazanensis Boulenger, Proc. Zool. Soc. London, 1897, p. 230. Rana palavanensis Boulenger, Rec. Ind. Mus., XX, 1920, p. 59.

Vomerine teeth in two short oblique series just behind the level of the choanae; lower jaw without bony prominences. Head as broad as long, or slightly broader; snout rounded, scarcely projecting, as long as the eye; canthus rostralis distinct; loreal region oblique, slightly concave; nostril equidistant from the eye and the end of the snout; interorbital space as broad as or a little narrower than the upper eyelid; tympanum distinct, $1 / 2$ to $2 / 3$ the diameter of the eye. Tips of fingers swollen or with very small disks, those of toes with small, but very distinct disks; first finger as long as or extending slightly beyond second; toes $2 / 3$ webbed, 2 or 3 phalanges of fourth free; subarticular tubercles moderate; inner metatarsal tubercle elliptical, flat, $2 / 5$ or $1 / 2$ the length of the inner toe; no outer

I) Mr. Malc. Smith, who has examined the specimens from Tjibodas, identified by Annandale (Jrn. Feder. Malay States Mus., VII, I917, p. 108) as R. granniens, is of opinion that they are $R$. hascheana (after a cummunication by Mr. C. Boden Kloss). 
metatarsal tubercle; no tarsal fold; the heel reaches the tip of the snout or beyond; tibia $\mathrm{I}^{3} / 5$ to nearly 2 times in length from snout to vent; when the hind limbs are folded at right angles to the body, the heels are strongly overlapping.

Skin nearly smooth; posterior half of upper eyelid warty; a fold above the tympanum, and a narrow glandular dorsolateral fold, beginning behind the upper eyelid.

Brown or greyish brown above; sides of snout blackish or dark grey, with dark vertical bars on the lips; supratemporal and dorsolateral folds edged with dark brown or black on the outer side; a dark cross-bar between the eyes and a dark $\wedge$-shaped marking between the shoulders usually present; limbs with regular dark cross-bands; lower parts whitish, uniform, or throat and breast spotted with brown. From snout to vent $43 \mathrm{~mm}$.

Male with internal vocal sacs.

Habitat: Borneo (Mt. Kina Balu; Matang and Mt. Penrissen, Serawak); Celebes (Loka; Tasosso, 1200 m.; Takala mts., I 200-1600 m.; Poso; Matinan mts.; Tomohon; Rurukan; Mt. Masarang). - Pelawan.

$$
\text { Subg. b. Discodeles Blgr. }
$$

(Boulenger, Ann. Mag. Nat. Hist., (9) I, 1918, p. 238; Rec. Ind. Mus, $\mathrm{XX}$, 1920, P. I09).

Tongue with a large, obtuse papilla in the middle. Toes, and usually fingers also, with disks, the upper surface of which is separated from the lower one by a groove. Toes strongly webbed. Outer metatarsals bound together or only separated in their distal third. Dorsolateral fold, if present, not confluent with the temporal one.

Omosternal style forked at the base.

Distribution: India; Solomon islands.

\section{I. Rana guppyi Blgr.}

Rana guppyi Boulenger, Proc. Zool. Soc. London, 1884, p. 21 I.

Rana guppyi Boulenger, Transact. Zool. Soc. Londun, XII, pt. 2, 1886, p. 48, pl. IX. Rana guppyi Boulenger, Ann. Mag. Nat. Hist., (9) I, 1918, p. 240.

Rana guppyi Boulenger, Rec. Ind. Mus., XX, 1920, p. II3.

Vomerine teeth in two short, straight or curved, transverse or slightly oblique series behind the level of the choanae and extending outwards beyond the vertical of their inner edges, 
the space between the two series greater than the length of one of them; no tooth-like processes in the lower jaw. Head very large, broader than long; snout obtusely pointed, a little projecting, much longer than the eye; canthus rostralis angular, very slightly curved; loreal region very oblique, not or feebly concave; nostril much nearer to the tip of the snout than to the eye; interorbital space as broad as the upper eyelid; tympanum distinct, $1 / 3$ to $1 / 2$ the diameter of the eye. Fingers and toes with small disks, with a groove in front, between upper and lower surface, those of toes a little larger than those of fingers; first finger longer than second, slightly longer than fourth, a little shorter than third; toes $3 / 4$ to entirely webbed, the web penetrating between the outer metatarsals; subarticular tubercles large; an elliptical, flattened, inner, and a smaller, roundish, less distinct outer metatarsal tubercle; no tarsal fold; heel reaching the eye or the tip of the snout; tibia $I^{4} / 5$ to $2 \frac{1}{6}$ times in the length from snout to vent; when the hind limbs are folded at right angles to the body, the heels are meeting or feebly overlapping.

Upper surfaces smooth or feebly warty; sometimes an inter. rupted dorso-lateral fold on the anterior part of the back; a strong fold above the tympanum; posterior half of upper eyelids warty; smooth beneath.

Dark olive or brown above, uniform or with rather indistinct darker spots; upper lip sometimes with vertical bars; limbs sometimes with cross-bars; white or brownish below, uniform or spotted with dark brown. From snout to vent $220 \mathrm{~mm}$.

Terminal phalanges with a feeble transverse expansion at the tip.

Male with two large external vocal sacs.

$\mathrm{H}$ abitat: Solomon islands.

\section{Rana bufoniformis Blgr.}

Rana bufoniformis Boulenger, Proc. Zool. Soc. London, 1884, p. 210.

Rana bufoniformis Boulenger, Transact. Zool. Soc. London, XII, pt. 2, I886, p. 47, pl. VIII.

Rana bufoniformis Boulenger, Rec. Ind. Mus., XX, I920, p. IIo.

Habit very stout, toad-like. Vomerine teeth in two short oblique series behind the choanae and not extending outwards beyond the vertical of their inner edges; the space between the two series equal to the length of one of them; lower jaw 
without tooth-like processes. Head very large, much broader than long; snout rounded, slightly projecting, as long as or slightly longer than the eye; canthus rostralis distinct, obtuse, straight; loreal region very oblique, concave; nostril nearer to end of snout than to eye; interorbital space flat, as broad as the upper eyelid; tympanum distinct, about $1 / 3$ the diameter of the eye. Fingers with slightly swollen tips, toes with small disks; first finger extending beyond second, nearly as long as third; second one a little shorter than fourth; toes ${ }^{2 / 3}$ webbed, the web reaches the disks, except that of fourth toe, two phalanges of which are free; the web penetrating between the outer metatarsals; subarticular tubercles large; an oval, flattened inner, and a rather indistinct, roundish outer metatarsal tubercle; no tarsal fold; the heel reaches the temple; tibia about $2 \frac{1}{3}$ times in the distance from snout to vent; when the hind limbs are folded at right angles to the body, the heels do not overlap.

Upper surfaces covered with prominent porous warts of different size; on each side of the back they are more elongate and confluent, so as to form an interrupted dorsolateral fold, which, however, does not extend beyond the sacrum; a strong fold above the tympanum; belly and lower surface of thighs feebly granulate, otherwise smouth below. From snout to vent $150 \mathrm{~mm}$.

Uniform brown above, yellowish beneath.

Terminal phalanges with a feeble transverse expansion at the tip.

Habitat: Solomon islands.

\section{I3. Rana opisthodon Blgr.}

Rana opisthodon Boulenger, Proc. Zool. Soc. London, I884, p. 2 II I.

Rana opisthodon Boulenger, Transact. Zool. Soc. London, XII, pt. 2, 1886, p. 50, pl. X.

Rana opisthodon Boulenger, Rec. Ind. Mus., XX, 1920, p. III.

Vomerine teeth in two short oblique series behind the level of the choanae and not extending outwards beyond the vertical of their inner edges; the space between the two series equal to or less than the length of one of them; lower jaw without tooth-like processes. Head large, a little broader than long; snout rounded, hardly projecting, as long as or slightly longer than the eye; canthus rostralis obtuse, slightly curved; loreal 
region oblique, concave; nostril much nearer to tip of snout than to eye; interorbital space as broad as or narrower than the upper eyelid, convex in the female, plane in the male; tympanum distinct, $2 / 5$ to $1 / 2$ the diameter of the eye. Fingers blunt or with slightly swollen tips, toes with small disks; first finger not or slightly extending beyond second; toes $2 / 3$ to $3 / 4$ webbed, the web reaching the disks, except that of fourth toe, two phalanges of which are free; the web penetrating between the outer metatarsals; subarticular tubercles large, oval; inner metatarsal tubercle elliptic, flat, outer tubercle, if distinguishable, small and rounded; no tarsal fold; heel reaching the eye; tibia $2 \frac{1}{6}$ to $2^{2} / 5$ times in length from snout to vent; when the hind limbs are folded at right angles to the body, the heels do not overlap.

Upper surfaces smooth or with numerous small, flat, porous warts, which may be elongate on the anterior part of the back; a strong fold above the tympanum; no dorsolateral fold; belly and lower surface of thighs slightly granulate, otherwise smooth below.

Olive or dark brown above, the warts blackish, or with a few dark spots and cross-bars on the limbs, vertical bars on the upper lip, and a cross-bar between the eyes; hinder side of thighs with small whitish dots; lower parts brownish white, the throat light brown. From snout to vent $125 \mathrm{~mm}$.

Male with two internal vocal sacs.

Terminal phalanges with a feeble transverse expansion at the tip.

Development without free larva. Eggs large (6 to Io $\mathrm{mm}$. in diameter).

Perhaps identical with $R$. bufoniformis, as Barbour (Proc. New England Zoöl. Club, VII, I92 I, p. 98) states.

$\mathrm{Habitat}$ : Solomon islands.

\section{I4. Rana ventricosa Vogt.}

Rana ventricosıs (sic!), Vogt, Sitzungsber. Ges. naturf. Fr., Berlin, I9I2, p. 8.

Vomerine teeth in two oblique series, beginning at the inner edge and extending a little behind the level of the choanae. Head broad; snout blunt; canthus rostralis rather indistinct; loreal region oblique; nostril near the tip of the snout; interorbital space as broad as the upper eyelid; tympanum $2 / 5$ the 
width of the eye. Fingers and toes with small disks; first and second finger equal in length; toes webbed to the disks; subarticular tubercles large; a rather large, elliptic, blunt inner and a smaller, round outer metatarsal tubercle; the heel reaches the eye.

Back coarsely granulate; flat warts on the upper eyelids, the temporal region, the sides, near the vent and on the hind limbs; no dorsolateral fold; a strong fold above the tympanum; smooth beneath.

Dark olive green above; posterior surface of thighs rusty brown, with numerous white dots; white below, throat and belly marbled with light brown. From snout to vent $158 \mathrm{~mm}$.

Description completed by means of informations from Mr. VoGT. Differing from $R$. opisthodon in the entirely webbed toes; it may be, however, that both species are identical.

Habitat: Bismarck archipelago.

Subg. c. Platymantis Gthr.

(Günther, Cat. Batr. Sal. Brit. Mus, 1858, p. 93; Boulenger, Ann. Mag. Nat. Hist., (9) I, 1918, p. 372).

Fingers and toes with disks, the upper surface of which is separated from the lower one by a groove. Toes free or slightly webbed. Outer metatarsals united. Dorsolateral fold absent.

Omosternal style forked at the base.

Distribution: Philippines; Halmahera; Kei islands; New Guinea and neighbouring islands; New Britain; Solomon islands; Fiji islands.

\section{5. Rana boulengeri (Bttgr.).}

Cornufor boulengeri Boettger, Kat. Batr.-Samml. Senckenb, naturf. Ges., Frankf. a/M., I892, p. I8.

Cormufer boulengeri Werner, Mitt. Mus. f. Naturk. Berlin, I, 1900, p. II4, fig. 115 (sternal apparatus).

Platymantis boulengeri Boulenger, Ann. Mag. Nat. Hist., (9) I, 1918, p. 373.

Vomerine teeth in two very long, curved series behind the level of the choanae. Head large, strongly depressed, broader than long; snout $I^{1} / 4$ to $1 / 2$ times the length of the eye; canthus rostralis more or less indistinct (in the young sharp and distinct, straight); loreal region concave; nostril equidistant from tip of snout and eye, or nearer the latter; interorbital space twice, in the young equal to the width of the upper eyelid; crown 
flat; tympanum vertically oval, $2 / 5$ to $3 / 4$ the diameter of the eye. Tips of fingers and toes hardly dilated; first finger extending beyond second; toes slightly webbed; subarticular tubercles much developed; an oblong inner and a very indistinct, rounded outer metatarsal tubercle; the heel reaches the anterior border of the eye (the tip of the snout in the young).

Posterior part of back granulate, otherwise smooth, or with rather sharp longitudinal folds, above; a narrow dorsolateral fold, extending backwards to the sacral region; a fold above the tympanum; sides, belly and lower and posterior surfaces of thighs granulate.

Yellowish, greyish, brown or greyish violet above, marbled with brown; a brown cross-bar between the eyes; loreal and temporal regions black, with a light border above; upper lip red; limbs and sides of body reddish, the limbs with dark cross-bars; throat, breast and lower surface of limbs powdered and spotted with brown. Length $75 \mathrm{~mm}$.

Habitat: Bismarck archipelago.

\section{Rana moszkowskii (Vogt).}

Cormufer moszkowskii Vogt, Sitzungsber. Ges. naturf. Fr., Berlin, 1912, p. 35 .

Vomerine teeth in two widely separated transverse groups behind the choanae; snout rather pointed; canthus rostralis strong; loreal region concave; nostril nearer to the tip of the snout than to the eye; interorbital space somewhat broader than the upper eyelid; tympanum vertically elliptic, $2 / 3$ the width of the eye. Fingers and toes with dilated tips; first finger longer than second; toes free; subarticular tubercles small; a cylindrical inner, and a small, round outer metatarsal tubercle; the heel reaches a little beyond the eye.

Granulate above, with sharp, short, longitudinal ridges; a sharp fold above the tympanum; upper eyelid warty; smooth beneath.

Dark above; upper surface of snout light coloured; two reddish white dorsolateral streaks; lips spotted; limbs with indistinct bars; yellowish beneath, chin and throat dark spotted. Length $56 \mathrm{~mm}$.

Probably identical with $R$. rugata or boulengeri. It can perhaps be distinguished from rugata by the broader interorbital space, from boulengeri, as Mr. Vogt informs me, by less developed subarticular tubercles.

Habitat: interior of Dutch New Guinea. 
I7. Rana beauforti (v. Kamp.).

Cornufer beauforti v. Kampen, Bijdr. t. d. Dierk., pt. 19, 1913, p. 91.

Platymantis bcauforti Boulenger, Ann. Mag. Nat. Hist., (9) I, I918, p. 373.

Tongue with a conical papilla; vomerine teeth in two oblique

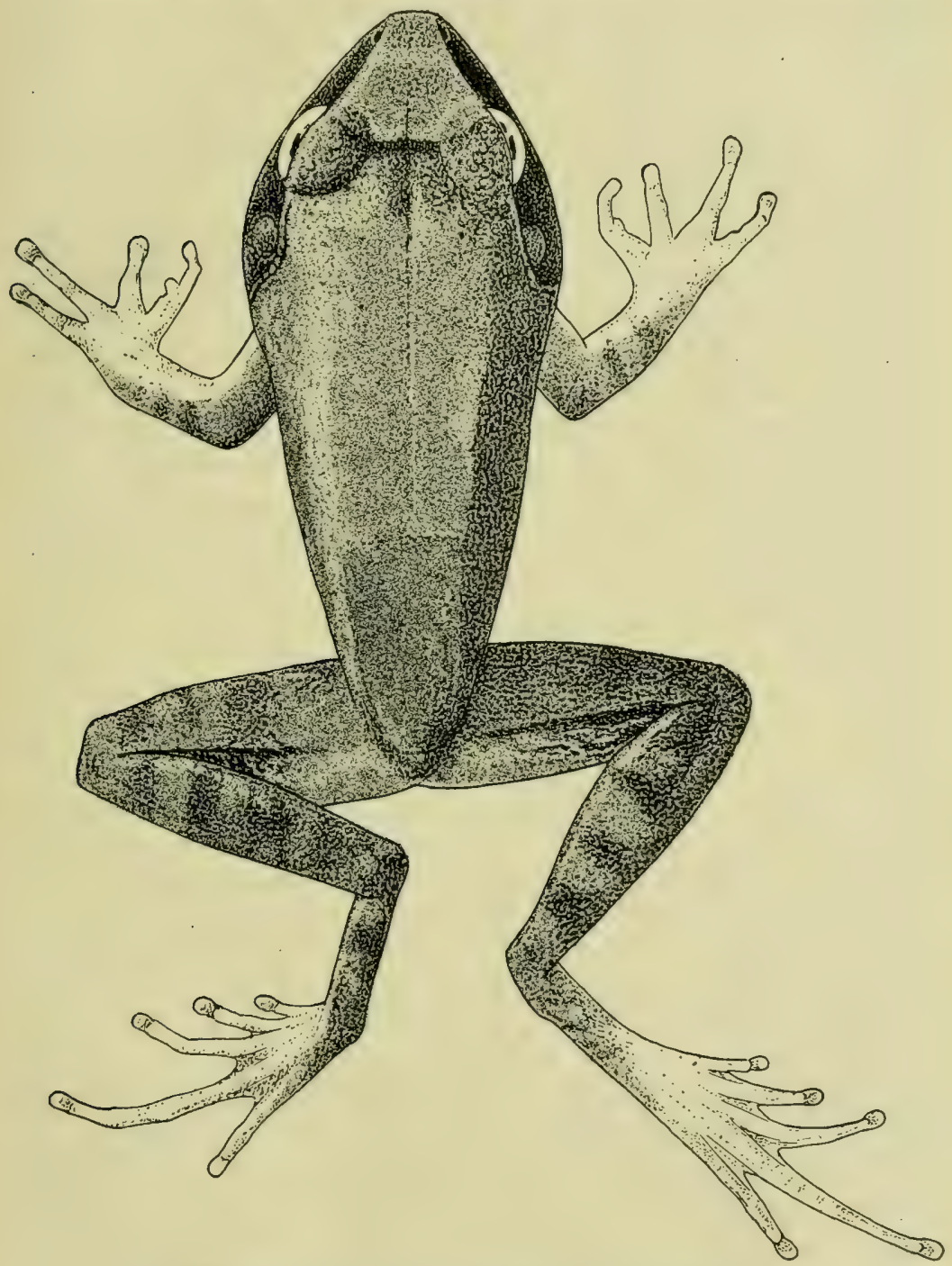

Fig. 24. Rana beauforti (v. Kamp.), type specimen, $\pm X \mathrm{I}$.

series behind the level of the choanae. Head as long as or hardly longer than broad; snout a little longer than the upper 
eyelid, longer than deep; canthus rostralis strong; loreal region oblique, concave; nostril nearer to the tip of the snout than to the eye; interorbital space as broad as or somewhat narrower than the upper eyelid; crown flat; tympanum $1 / 2$ to $\frac{2}{3}$ the width of the eye. Fingers and toes with small disks; first finger extending beyond second, which is much shorter than fourth; third toe longer than fifth; toes webbed at the base; subarticular tubercles strong; an oblong inner, and a small, round outer metatarsal tubercle; the heel reaches between the eye and the tip of the snout.

Skin smooth or finely granulate; the posterior half of the upper eyelid somewhat warty; a fold above the tympanum.

Upper parts reddish violet, more or less spotted or marbled with bluish violet; a dark cross-bar between the eyes; sometimes a light vertebral line; a part of the tympanum and the posterior part of the temporal region, sometimes the loreal region also, darker; lips with dark spots; limbs with dark cross-bars; sides of the body and posterior and superior surfaces of the thighs marbled with blackish; yellowish beneath, sometimes dark marbled. Length $78 \mathrm{~mm}$.

Type specimens examined.

Habitat: Waigeu!

\section{Rana rugata nomen novum ').}

Hylodes corrugatus A. Duméril, Ann. Sc. nat., (3) XIX, 1853, p. I76.

Platymantis plicifera Gtinther, Cat. Batr. Sal. Brit. Mus., 1858, p. 95, pl. VIII, fig. B. Platymantis plicifera var. Pelewensis Peters, Monatsber. Akad. Berlin, 1867, p. 33 . Platymantis corrugata var. papuensis, Meyer, Monatsber. Akad. Berlin, I874, p. I39. Cornufor corrugatus Boulenger, Cat. Batr. Sal. Brit. Mus., I882, p. I Io.

Cornufer corrugatus v. Méhely, Termész. Füzetek, XX, I 897, p. 4 I I, pl, X, figs. I, 2 (sternal apparatus and terminal phalanx).

Platymantis corrugata Boulenger, Ann. Mag. Nat. Hist., (9) I, I9I8, p. 373.

Vomerine teeth in two oblique series behind the level of the choanae. Head about as long as broad; snout pointed, as long as, to $I^{1} / 3$ the length of the upper eyelid, longer than deep; canthus rostralis angular, straight; loreal region oblique, concave; nostril nearer to the tip of the snout than to the eye; interorbital space as broad as the upper eyelid (narrower in the young); crown flat; tympanum circular or vertically oval, $2 / 3$ the width of the eye. Tips of fingers and toes feebly dilated;

I) Rana corrugata and $R$. plicifera are preoccupied. 
first finger extending beyond second, which is as long as fourth; third toe much longer than fifth; toes with a very rudimentary web; subarticular tubercles much developed; an inner, oblong and a distinct, round, outer metatarsal tubercle; the heel reaches between eye and tip of snout, rarely beyond.

Granulate above, with symmetrical longitudinal ridges on the back; a strong fold above the tympanum; a tarsal fold; smooth below.

Brownish, olive or greyish above, with indistinct darker markings; loreal and temporal region blackish or with blackish vertical streaks; sometimes a light vertebral streak or two light dorso-lateral ones; white beneath, immaculate or the throat speckled with brown; limbs with dark cross-bars. Length $66 \mathrm{~mm}$.

Male with two internal vocal sacs.

Habitat: Halmahera, up to $700 \mathrm{~m}$.; Kei islands; Batanta isl.; New Guinea (Dore; Andai; Mansiman; Arfak mts.; Manikion region!; Geelvink bay; Etna bay!; Mamberamo riv.!; near Idenburg riv., 400 m.!; Doorman riv.!; Tawarin riv.!; Sermowai riv., \pm 70 and $\pm 400 \mathrm{~m}$. !; Walckenaer bay!; Tanahmerah bay!; Tor riv.!; Jaona!; Humboldt bay!; Tami riv.!; Sentani lake!; Oinake!; upper current of Kaiserin Augusta riv.!; Erima; Stephansort; Sattelberg, \pm 800 m.; Bara Bara; Bukana; Mimika riv.; Setekwa riv.); Jobi isl.; Meisor isl.; Schouten islands; Ferguson isl.; St. Aignan isl.; Duke of York isl.; Goram isl.; Faor isl.; Bertrand isl.; Bismarck arch.; Solomon islands. - Philippines; Pelew islands.

\section{Rana rugata, var. rubristriata (Barb.).}

Cormufer corrugatus rubristriatus Barbour, Proc. Biol. Soc. Washington, XXI 1908 , p. 190.

Cormefer cormgatus rubristriatus Barbour, Mem. Mus. Comp. Zoöl. Harvard Coll, XLIV, I, I912, p. 7o, pl. V, fig. I4.

Distinguished from the type by shorter legs, the heel reaching the eye, and by the absence of the fold above the tympanum.

Brownish olive above, with a brick red vertebral stripe; inner sides of thighs yellow.

Perhaps identical with $P$. solomonis.

Habitat: Roön island, Geelvink bay.

19. Rana solomonis (Blgr.).

Comner solomonis Boulenger, Proc. Zool. Soc. London, 1884, p. 212. 
Cornufer solomonis Boulenger, Transact. Zool. Soc. London, XII, pt. 2, 1886, p. 54, pl. XI, fig. 2 .

Platymantis solomonis Boulenger, Ann. Mag. Nat. Hist., (9) I, 1918, p. 373.

Platymantis solomonis Barbour, Proc. New England Zoöl. Club, VII, I92I, p. 96, pls. II-IV.

Tongue without papilla; vomerine teeth in two rather long, transverse or slightly oblique, feebly arched series behind the level of the choanae. Head very large, moderately depressed, as long as broad, its length contained $2 \frac{1}{2}$ to $2^{3} / 4$ times in the distance from snout to vent; snout rounded, not projecting, as long as, or slightly longer than the upper eyelid; canthus rostralis distinct, obtuse, straight; loreal region oblique, concave; nostril much nearer to tip of snout than to orbit; interorbital space about $3 / 4$ the width of the upper eyelid, with a median ridge; tympanum very distinct, about half the width of the upper eyelid. Tips of fingers and toes swollen; first finger extending beyond second, and as long as third; second and fourth ones equal in length; toes with a very slight rudiment of web; subarticular tubercles very strong and prominent; an oval inner and a smaller, rounded outer metatarsal tubercle; the heel reaches the centre or the anterior border of the eye.

Upper surfaces more or less corrugated, with irregularly scattered, short, longitudinal folds, or smooth; a strong fold above the tympanum; belly and lower surface of thighs feebly granulate, otherwise smooth below.

Grey-brown or purplish brown above, with more or less distinct darker markings; sometimes a white vertebral line, extending along the hind limbs; loreal and temporal regions dark brown; lips with more or less marked dark vertical bars; tympanum chestnut-brown; limbs with dark cross-bars; whitish below, throat more or less mottled with brown. Length $78 \mathrm{~mm}$.

Male with two internal vocal sacs.

Eggs large (ripe egg $5 \mathrm{~mm}$. in diameter).

Habitat: Bismarck arch.; Solomon islands.

20. Rana punctata (Ptrs. \& Dor.).

Platymantis punctata Peters e Doria, Ann. Mus. Genova, XIII, 1878, p. 420, pl. VII, fig. 3 .

Cormufer punctatus Boulenger, Cat. Batr. Sal. Brit. Mus., I882, p. IIO.

Platymantis punctata Boulenger, Ann. Mag. Nat. Hist., (9) I, I9r8, p. 373.

Distinguished from $R$. corrugata by the equal length of the two inner: fingers. 
Dark brown above, lighter on the snout and beneath; sides of head and body, the throat and the outer surfaces of the limbs dotted with orange; posterior surfaces of thighs vermiculated with the same colour. Length $50 \mathrm{~mm}$.

Habitat: New Guinea (Hatam, Arfak mts.). - Bismarck arch. $\left.{ }^{1}\right)$.

$$
\text { Subg. d. Hylaran a Tschudi. }
$$

(Tschudi, Mém. Soc. Sc. Neuchâtel, II, 1839, p. 37).

Hylorana Boulenger, Rec. Ind. Mus., XX, 1920, p. 123.

Toes, and usually fingers also, with disks, the upper surface of which is separated from the lower one by a groove. Outer metatarsals separated nearly to the base, or, rarely, only in their distal half. Dorsolateral fold present or absent.

Omosternal style not forked at the base, sometimes with a very small notch.

Distribution: Africa; southern Asia, including the Indoaustralian Archipelago to the Solomon islands; northern Australia.

\section{Rana macrops Blgr.}

Rana macrops Boulenger, Proc. Zool. Soc. London, I897, p. 233, pl. XVI, fig. I. Rana macrops boulenger, Rec. Ind. Mus, XX, 1920, p. 203.

Vomerine teeth in two very small oblique groups between the choanae, or close together just behind them. Head as long as broad; snout rounded, projecting, shorter than the eye; canthus rostralis strong; loreal region nearly vertical, concave; nostril a little nearer to the tip of the snout than to the eye; interorbital space as broad as the upper eyelid; eye very large; tympanum distinct, half the diameter of the eye. Disks of fingers rather large, $2 / 3$ to $3 / 4$ the diameter of the tympanum, of toes a little smaller; first finger as long as second; toes $2 / 3$ webbed; outer metatarsals separated nearly to the base; subarticular tubercles moderate; a small oval inner, no outer metatarsal tubercle; no tarsal fold; the heel reaches the nostril or the tip of the snout; tibia $4 / 7$ to $3 / 5$ length of head and body; when the hind limbs are folded at right angles to the body, the heels are overlapping.

I) According to Sternfeld, Abh. Senckenb. naturf. Ges., XXXVI, I9I8, p. 434. INDO-AUSTRALIAN AMPHiBIa. 
Skin smooth or finely granulate above, sometimes with a few small flat warts on the back; a very feebly developed and only anteriorly distinct dorsolateral fold; lower parts smooth.

Olive-green above; a blackish streak below the canthus rostralis; a blackish band on the temporal region and above the shoulder, broken up into spots posteriorly; sides greyish, marbled with dark brown; a whitish streak from below the eye to above the arm; limbs with more or less distinct dark cross-bands; hinder side of thighs marbled with dark brown; brownish beneath, throat dark brown, with or without small white spots. From snout to vent $45 \mathrm{~mm}$.

Male with internal vocal sacs and an oval flat gland at the base of the arm.

Habitat: Celebes (Takalekadjo mts., towards Lake Poso, 900 m.; Matinan mts., I000 m.; Mt. Masarang).

\section{Rana glandulosa Blgr.}

Rana glandulosa Boulenger, Cat. Batr. Sal. Brit. Mus., I882, p. 73, pl. VII.

Rana glandulosa Boulenger, Vert. Fauna Malay Penins., Rept. and Batr., London, I 912 , p. 236.

Rana glandulosa Boulenger, Rec. Ind. Mus., XX, I920, p. I8I.

Vomerine teeth in two short oblique series between the choanae or extending a little behind the level of their posterior borders. Head as long as broad or a little broader; snout rounded or obtusely pointed, hardly projecting, as long as or slightly longer than the eye; canthus rostralis distinct, straight; loreal region oblique, concave; nostril nearer to the tip of the snout than to the eye; interorbital space as broad as or slightly narrower than the upper eyelid; tympanum very distinct, $3 / 5$ to $3 / 4$ the diameter of the eye. Fingers and toes with very small disks; first finger extending much beyond second, which is shorter than fourth; third toe extending beyond fifth; toes $1 / 2$ to $2 / 3$ webbed; outer metatarsals separated nearly to the base; subarticular tubercles very prominent; an oval inner, and a smaller, round, outer metatarsal tubercle; no tarsal fold; the heel reaches the eye or the tip of the snout; tibia about half the length from snout to vent; when the hind limbs are folded at right angles to the body, the heels are overlapping.

Upper parts smooth or more or less distinctly granulate, with large flat warts, at least on the sides.

Olive-brown or reddish brown, often spotted and speckled 
with blackish; lips dark, with large whitish spots or bars; limbs with more or less distinct dark cross-bars; beneath whitish or buff, uniform or spotted with brown; eye fiery red. From snout to vent $95 \mathrm{~mm}$.

Male with two external vocal sacs, forming folds, and a large oval gland on the inner surface of the arm.

Habitat: Sumatra (Deli!; Serbadjadi, Serdang!); Borneo (Bongon; Baram riv., Mt. Mubu, Spitang, Mt. Batu Song and Miri in Serawak). - Burma; Siam; Malay Peninsula; Singapore; Pelawan.

\section{Rana baramica Bttgr.}

Rana baramica Boettger, Abh. Senckenb. naturf. Ges., XXV, I90I, p. 39I.

Rana baramica v. Kampen, Weber's Zool. Ergebn, Leiden, IV, 1907, p. 399.

Rana baranica Boulenger, Rec. Ind. Mus., XX, 1920, p. I82.

Vomerine teeth in two short oblique series between the posterior borders of the choanae, or extending a little behind them. Head a little longer than broad; snout somewhat pointed, feebly projecting, as long as the upper eyelid; canthus rostralis angular; loreal region slightly oblique, concave; nostril nearer to the tip of the snout than to the eye; interorbital space as broad as or a little narrower than the upper eyelid; tympanum very distinct, $2 / 3$ to $3 / 4$ the width of the eye; fingers and toes with very small disks, those of toes a little larger; first finger much longer than second, which is shorter than fourth; third toe extending beyond fifth; toes webbed at the base; subarticular tubercles very strong; two strong metatarsal tubercles, the inner one elliptic, the outer one round; no tarsal fold; the heel reaches between eye and nostril; tibia half the length of head and body.

Strongly granulate above; sides with granules and longitudinal warts; fold above the tympanum indistinct or absent; smooth beneath.

Light brown or dark greenish grey above; back and sides spotted and marbled with dark brown or black; sometimes a few lighter spots on the lips and around the brown tympanum; hind limbs with dark cross-bars; throat and breast, sometimes the belly also, densely powdered or spotted with dark grey or blackish; a very distinct light median stripe from the chin to the middle of the breast may be present. Length $62 \mathrm{~mm}$.

Male with a flat giand on the inner side of the upper arm and with two outer vocal sacs. 
Distinguished from $R$. glandulosa by the shorter web between the toes.

Habitat: Banka!; Borneo (Baram riv.).

\section{Rana luctuosa (Ptrs.).}

Limnodytes luchuosus Peters, Monatsber. Akad. Berlin, 1871, p. 579.

Limnodytes luctuosus Peters, Ann. Mus. Genova, III, I872, p. 43, pl. VI, fig. I.

Rana luctuosa Boulenger, Cat. Batr. Sal. Brit. Mus., 1882, p. 68.

Rana decorata Mocquard, Nouv. Arch. Mus. d'Hist. nat., (3) II, I89o, p. I 45 , pl. X, figs. $\mathbf{I}-\mathbf{I} b$.

Rana luctuosa Flower, Proc. Zool. Soc. London, 1896, p. 904, pl. XLVI (tadpole).

Rana luctuosa Flower, Proc. Zool. Soc. London, 1899, p. 896.

Rana luctuosa Boulenger, Vert. Fauna Malay Penins,, Rept. and Batr., London, 191 2, p. 238.

Rana luctuosa Boulenger, Rec. Ind. Mus., XX, I920, p. 183.

Vomerine teeth in two small oblique groups or short series between the choanae. Head as long as broad; snout rounded, as long as or a little shorter than the eye, feebly projecting; canthus rostralis indistinct; loreal region scarcely oblique, feebly concave; nostril in the middle between the eye and the tip of the snout; interorbital space broader than the upper eyelid; tympanum distinct, $2 / 3$ to $3 / 4$ the diameter of the eye. Fingers with very small, toes with a little larger disks; first finger extending beyond second; toes $1 / 3$ webbed; outer metatarsals $2 / 3$ separated; subarticular tubercles moderate; a small, oval inner, and a very small outer metatarsal tubercle; no tarsal fold; the heel reaches the tip of the snout or between eye and tip of snout; tibia $1 / 2$ the length from snout to vent or a little longer; when the hind limbs are folded at right angles to the body, the heels are overlapping.

Skin smooth.

Upper surfaces of head and back bright red or rich dark chocolate-brown, bordered on each side, from the end of the snout to the base of the hind limbs, by a very distinct white or yellow line; sides of head and body very dark brown or black; tympanum dark reddish brown to nearly black; sides of body with a few white or yellow spots, sometimes forming an irregular line from angle of mouth to thigh; limbs very dark brown or bluish black with light marblings or transverse lines; beneath dirty buff, darker on the limbs, sometimes with small light spots; throat brown or black. From snout to vent $50 \mathrm{~mm}$.

Male without vocal sacs. 
Tadpole. - Length of body once and a half its width and more than half the length of the tail, which is 3 to 4 times as long as deep. Nostril nearer to the end of the snout than to the eye; eyes superior, nearer to the end of the snout than to the spiraculum, the distance between them at least twice that between the nostrils, and much larger than the width of the snout; spiraculum sinistral, directed upwards and backwards, visible from above and from below, nearer to the vent than to the tip of the snout; vent dextral, close to the lower edge of the subcaudal crest. Tail acutely pointed, the upper crest convex, about equal in depth to the lower one, not extending on the back.

Sides and lower border of lips bordered with papillae; jaws broadly edged with black; series of teeth $4^{1} 4 / \mathrm{I}_{3} \mathrm{I}$ or $5^{1} 5 / \mathrm{I}_{3} \mathrm{I}$, inner series of lower lip very narrowly interrupted.

Younger larvae blackish brown above, white beneath, tail mottled with grey; the older ones have the upper parts brown, mottled with darker, the sides and lower parts yellow, mottled with brown, the tail mottled brown and yellow. Length $77 \mathrm{~mm}$.

Habitat: Borneo (Mt. Kina Balu!; Koung, Br. N.-Borneo; Akar riv. and Matang, Serawak). - Malay Peninsula, up to 1200 m.; Philippines ${ }^{1}$ ).

\section{Rana debussyi v. Kamp.}

Rana debussyi v. Kampen, Nat. Tijdschr. Ned.-Indië, LXIX, r909, p. 23, pl. I, fig. 3. Kana debussyi v. Kampen, ibid., p. 40 (tadpole).

R'ana debussyi Boulenger, Rec. Ind. Mus., XX, I920, p. I\$4.

Vomerine teeth in two short, oblique series between the choanae. Head longer than broad; snout rounded, projecting, once and a half as long as the eye; canthus rostralis rather sharp; loreal region somewhat oblique; nostril a little nearer to the tip of snout than to the eye; interorbital space broader than the upper eyelid; tympanum distinct, $2{ }_{3}$ the diameter of the eye. Disks of fingers and toes small, but distinct, those of toes a little larger; first finger extending beyond second; toes webbed at the base, the web reaching only the proximal subarticular tubercles; only between fourth and fifth toe it reaches a little farther, at the fifth toe almost to the second tubercle; subarticular tubercles well developed; a small, oblong inner, and

I) According to: De Elera, Catálogo Sist, de toda la Fauna de Filippinas, I, I 895 , p. 448 . 
a still smaller, round outer metatarsal tubercle; no tarsal fold; heel reaching the tip of the snout.

Skin very finely granulate.

Brown above; sides, from tip of snout to vent, black, with a. white streak from the tip of the snout along the upper lip, below the tympanum, to the thighs; limbs pale brown, with dark cross-bars; yellowish white beneath. Length $50 \mathrm{~mm}$.

T ad pole. - The tadpoles, here described, probably belong to this species.

Length of body $\mathrm{I}^{3} / 4$ times its width; tail nearly twice the length of the body and almost 4 times as long as deep. Nostril in the middle between the tip of the snout and the eye; eyes superior, equally distant from tip of snout and spiraculum, the distance between them once and a half that between the nostrils, which equals the width of the mouth; spiraculum sinistral, directed upwards and backwards, visible from above and from below, nearer to the hind limbs than to the tip of the snout; vent dextral, close to the lower border of the tail. Tail with rounded tip; the upper crest a little higher than the lower one, not reaching the base of the tail.

Lips with papillae, which are arranged in two or three series along the sides and the lower border, not interrupted in the median line; jaws edged with black; series of teeth $4^{1} 4 / /^{1} 3^{1}$ (in younger specimens $\left.3^{1} 3 /{ }^{1} 3^{1}\right)$, the four rows of the lower lip nearly equal in length, the inner one hardly interrupted.

Grey, lower surface of body a little lighter, and finely mottled with white; tail yellowish brown, darker marbled. Length $65 \mathrm{~mm}$.

Habitat: Sumatra (Bandarbaru, Batak mts., $\pm 900 \mathrm{~m}$. !).

\section{Rana laterimaculata Barb. \& Noble.}

Rana laterimaculata Barbour and Noble, Proc. New England Zoöl. Club, Cambridge, Mass., VI, I9I6, p. 2I, text-fig. 3 (foot).

Vomerine teeth in two small oblique groups, not extending behind the level of the choanae, the distance between them slightly greater than the diameter of each of the choanae. Canthus rostralis distinct; loreal region concave; nostril much nearer to tip of snout than to eye; interorbital space slightly broader than the upper eyelid; tympanum more than half the diameter of the eye. Tips of fingers and toes dilated, of toes a little 
more than those of fingers; first finger extending much beyond second; toes slender, nearly free; two metatarsal tubercles, the outer one oblong, as long as the inner one; heel reaching tip of snout.

Skin shagreened above, with numerous scattered tubercles; smooth below; posterior surface of thighs finely granular.

Light umber above, indistinctly darker marbled; tympanum almost black; sides with dark brown spots; anterior surface of thighs spotted; a narrow light line from beneath the eye along the upper lip to the posterior border of the tympanum; lower lip dark brown with a few light spots; uniform dirty yellowish brown beneath. Length $\left.\pm 50 \mathrm{~mm} .{ }^{1}\right)$.

Perhaps indentical with $R$. debussyi.

Habitat: Borneo (Sadong, Serawak).

\section{Rana arfaki Meyer.}

Rana Arfaki Meyer, Monatsber. Akad. Berlin, I874, p. 138.

Limnodytes arfaki (part.) Peters e Doria, Ann. Mus. Genova, XIII, I878, p. 4 I8. Rana arfaki Boulenger, Cat. Batr. Sal. Brit. Mus., r882, p. 66.

Rana macroscelis Boulenger, Ann. Mag. Nat. Hist.g (6) I, I888, p. 345.

Rana arfaki v. Kampen, Nova Guinea, V, pt. I, 1906, p. I65.

Rana waigeënsis v. Kampen, Bijdr. t. d. Dierk., pt. 19, I9I3, p. 90.

Rana waigënsis v. Kampen, Nova Guinea, IX, pt. 3, I9I3, p. 459, pl. XI, fig. 2. Rana macroscelis Boulenger, Transact. Zool. Soc. London, XX, pt. 5, 1914, p. 249. Rana arfaki Boulenger, Ann. Mag. Nat. Hist., (9) I, I918, p. 24 I.

Rana arfaki Boulenger, Rec. Ind. Mus, XX, 1920, p. 173.

Vomerine teeth in two straight or feebly curved oblique series, on a level with or extending behind the posterior borders of the choanae; lower jaw without bony processes. Head large, as long as broad, or, in the adult, broader than long, nearly half as broad as the distance from snout to vent; snout rounded or obtusely pointed, feebly projecting, as long as the upper eyelid, longer than deep; canthus rostralis distinct, straight or nearly so; loreal region a little oblique, concave; nostril equidistant from eye and tip of snout or nearer to the latter; interorbital space as broad as or a little narrower than the upper cyelid; with a longituoinal groove extending along the occiput; tympanum distinct, $1 / 2$ to $2 / 3$ the width of the eye. Disks of fingers small, of toes a little larger; first finger extending beyond second, which is shorter than fourth,

I) After notes taken from the type specimen by Mr. Dunn, 
the two terminal phalanges of the third one extending beyond the second one, only one of them beyond the fourth; the web between the toes reaches all disks or the last phalanx of fourth toe remains free; outer metatarsals separated nearly to the base; subarticular tubercles large, prominent; inner metatarsal tubercle oblong, outer one absent or feeble; a dermal fold along the inner border of the first, and another one along the outer border of the fifth toe; the latter one extending in the male along a part of the metatarsus; no tarsal fold; heel reaching between eye and tip of snout, or to the tip of the snout or slightly beyond; tibia $1 / 2$ to $3 / 5$ length of head and body; when the hind limbs are folded at right angles to the body, the heels are overlapping.

Smooth, or with large, flat warts and small granules, above; posterior part of the upper eyelid rugose; in young specimens a very narrow dorsolateral fold may be present; a feeble fold above the tympanum; smooth beneath.

Upper surface (in spirit) greenish blue, or more or less reddish or lilac brown, marbled with darker; hind limbs sometimes with indistinct dark cross-bars; back, sides and limbs usually with a few roundish, yellowish-white spots or vermiculations; whitish below, throat and breast usually marbled with brown; border of lower lip yellowish-white, bordered with blue. Length $162 \mathrm{~mm}$.

Male in the breeding time with two external vocal sacs and a large oval gland on inner side of arm.

H a bit a t: Aru islands; Waigeu!; New Guinea (Andai; Hatam, Arfak mts.; Mamberamo riv.!; Idenburg riv.!; Sermowai riv., \pm 300 m.!; Tor riv.!; Moaif riv.!; Moso riv.!; Air Mo riv.!; Sekanto region!; Albert Edward range; Madew ; Astrolabe mts.; Haveri; Soghere, 530 m.; Lorentz riv., $30 \mathrm{~m}$. !; Went mts., \pm I 300 m.!; Setekwa riv., I50 m.; Mimika riv.).

\section{Rana elberti Roux.}

Rana elberti Roux, Zool. Jahrb., Syst., XXX, I9II, p. 504. Rana elberti Boulenger, Rec. Ind. Mus., XX, I9zO, p. 142.

Vomerine teeth in two oblique groups between the choanae, extending somewhat behind their posterior borders. Head about as long as broad; snout truncate, projecting, as long as the eye; canthus rostralis rounded; loreal region vertical, feebly concave; nostril nearer to the tip of the snout than to the eye; 
interorbital space as broad as the upper eyelid; tympanum very distinct, $3 / 5$ the diameter of the eye. Tips of fingers feebly dilated, without distinct disks; disks of toes small, but distinct; first finger extending beyond second; toes nearly entirely webbed; subarticular tubercles prominent; a welldeveloped, oval, blunt inner, and a small, oval outer metatarsal tubercle; no tarsal fold; the heel reaches beyond the tip of the snout; tibia $2 / 3$ the length from snout to vent.

Smooth or rather rough above; a very narrow dorsolateral fold; sides with a few folds; smooth beneath.

Uniform olive above; a rather broad brown streak below the canthus rostralis and a large brown temporal spot; limbs with brown cross-bars; posterior surfaces of thighs with large and long black spots in a white network; lower parts uniform yellowish white. From snout to vent $48 \mathrm{~mm}$.

The absence of real disks on the fingers is the only character separating this species from $R$. papua, with which it probably must be united.

Habitat: Wetar.

\section{Rana papua Less.}

Rana papua Lesson, Voyage Coquille, Zool., II, I, I830, p. 59, pl. VII, fig. I. Lymnodytes arfaki (part.) Peters e Doria, Ann. Mus. Genova, XIII, I878, p. 418, pl. VI, fig. I.

Rana papua (part.) Boulenger, Cat. Batr. Sal. Brit. Mus., 1882, p. 64.

Rana varians Boulenger, Ann. Mag. Nat. Hist., (6) XIV, I894, p. 86.

Rana moluccana Boettger, Zool. Anz., XVIII, 1895, p. 132.

Rana florensis Boulenger, Ann. Mag. Nat. Hist., (6) XIX, I897, p. 508.

Rana varians Boettger, Abh. Senckenb. naturf. Ges., XXV, I90I, p. 336, pl. XV, fig. 8 .

Rana papua v. Kampen, Nova Guinea, V, pt. I, I906, p. I64 (with tadpole). Rana papua and Rana spec. (tadpole) Roux, Abh. Senckenb. naturf. Ges., XXXIII, I910, p. 224, 225, pl. XIV, figs. $7,7 a$ (tadpole).

Rana papua, moluccana and varians Barbour, Mem. Mus. Comp. Zoöl. Harvard

Coll., XLIV, I, I9I2, p. 65, pl. V, figs. I2, I5 and text-figs.

Rana fallax v. Kampen, Nova Guinea, IX, pt. 3, I9r3, p. $45^{8}$.

Rana papıa v. Kampen, Zool. Jahrb., Syst, XXXVII, I914, p. 37 I (with tadpole). Rana florensis, varians and papua Boulenger, Rec. Ind. Mus., XX, 1920, p. I60, 165, 188 .

Vomerine teeth in two oblique series or groups, between or extending behind the level of the choanae. Head as long as or longer than broad; snout more or less pointed, projecting, as long as or longer than the eye, longer than deep; canthus 
rostralis angular, straight; loreal region ncarly vertical, concave; nostril equidistant from eye and tip of the snout, or nearer to the latter; interorbital space as broad as or a little narrower or a little broader than the upper eyelid; tympanum distinct, $2 / 3$ to equal to the width of the eye. Disks of fingers small, of toes as large or slightly larger; first finger extending beyond second, which is a little shorter than fourth; toes entirely or nearly entirely webbed, the web reaching all disks or the two distal phalanges and sometimes part of the next phalanx of fourth toe are free; outer metatarsals separated nearly to the base; subarticular tubercles well developed; a distinct, oblong inner, and a smaller, round outer metatarsal tubercle; no tarsal fold; the heel reaches to between the anterior border of the eye and the tip of the snout or beyond; tibia about $1 / 2$ to $2 / 3$ the length of head and body; when the hind limbs are folded at right angles to the body, the heels are strongly overlapping.

Smooth or finely granulate above; a narrow dorsolateral fold and a glandular fold from below the eye to the shoulder, sometimes followed by one or two glandules; sometimes a few scattered warts on back and sides; smooth below.

Greyish, brownish, pink, or blackish above, sometimes marbled with darker, the warts usually dark; loreal region or a streak below the canthus rostralis often dark brown or black; a more or less distinct dark temporal spot, sometimes (especially in the young) continued into a black streak along the side of the body, bordered above by the often light-coloured dorsolateral fold; sides rarely reticulated with blackish; tympanum usually reddish brown; a narrow light vertebral line, and another light line along the tibia may be present; often a white streak along the upper lip, continued to the shoulder; limbs with dark cross-bars; beneath white, often powdered or reticulated with brown or blackish, especially on throat and breast; often a pair of dark spots on the breast and an oblique dark bar on the shoulders. From snout to vent i IO $\mathrm{mm}$.

Male with two vocal sacs, which are usually internal, rarely external, but feebly developed, and sometimes (in the breeding season?) with humeral glands.

Ta d p $\left(\mathrm{e}^{1}\right)$. - Length of body about $1 \frac{1}{2}$ to 2 times its width;

I) Known only from specimens from New Guinea and the Aru islands (Rana sp., Roux). 
tail $1 \frac{1}{2}$ to 2 times the length of the body, 3 to 4 times as long as deep. Nostril about equally distant from the eye and the tip of the snout; eyes superior, in the middle between tip of snout and spiraculum, or a little nearer to the first; the distance between them equal to that between the nostrils and a little smaller than the width of the mouth (including the lips); spiraculum sinistral, directed upwards and backwards, visible from above and from below, nearer to the posterior end of the body than to the tip of the snout; vent dextral, close to the lower border of the subcaudal crest. Tip of tail rounded; the upper crest higher than the lower one, and extending on to base of tail.

Mouth ventral, with papillae along the entire lower border and the sides of the lips; jaws edged with black; series of teeth $I^{1} I^{1} / 2^{1}$ to $3^{1} 3 / 1^{1} 2^{1}$, the rows of the lower lip nearly equal in length (the outer one but little shorter), the inner one very slightly, sometimes not interrupted.

Dark brown or grey above; lower surfaces and tail lighter; muscular part of tail and the upper crest sometimes more or less dark spotted. Length $65 \mathrm{~mm}$.

Boulenger (1. c., 1920) considers R. varians and florensis as distinct species. The differences, however, are very slight:

$R$. florensis: Disks of fingers and toes equal, not twice as broad as the narrowest part of the corresponding penultimate phalanx. Heel reaching the tip of the snout. Male with a flat gland on the inner side of the arm and internal vocal sacs. - Hab.: Flores.

$R$. varians (= moluccana): Disks as in $R$. florensis. Heel reaching beyond the tip of the snout. Male without humeral glands ${ }^{1}$ ) and with internal vocal sacs. - Hab.: Celebes; Halmahera; Ternate; Batjan; Philippines; Pelawan.

$R$. papua: Disks of toes a little larger than those of fingers, at least twice as broad as the narrowest part of the penultimate phalanx. Heel reaching the nostril, the tip of the snout, or beyond. Male without humeral glands ${ }^{1}$ ), with internal, rarely feebly developed external vocal sacs. - Hab.: Timorlaut islands; Kei islands; Aru islands; New Guinea; Ferguson isl.; Murray isl., etc.

I) Boettger (l.c., I90I), however, mentions a humeral gland in specimens of $R$ varians, and I myself (1.c., 1906) and Barbour (1.c., I912) in $R$. papua from New Guinea and Jobi. 
Perhaps further researches will show, that still other species (elberti, celebensis, grisect, daemeli, kreffti) belong to the same variable species. On the other hand $R$. fallax, described by me after a specimen from Waigeu and distinguished by a small tympanum (half the width of the eye) and slate blue colour (in spirit) and which Boulenger (Ann. Mag. Nat. Hist., (9) I, I9I8, p. 242, and l.c., 1920) unites with papua, may be an proper species; it is even possible, that this is the real $R$. papua (described by Lesson, after specimens from Waigeu, as bluish green), and that the specimens usually described as $R$. papua are another species, which then must be named $R$. waigeensis Dum. et Bibr. (Erpétologie générale, VIII, I84I, p. 5I4).

$\mathrm{Ha}$ b i t a t: Flores, above $900 \mathrm{~m}$.; Celebes (Lake Poso; Lindu!; Bwool; Uangkahulu valley; Gorontalo?!; Tomohon; Rurukan; Menado!; Mt. Masarang); Morotai!; Halmahera, up to 250 m.; Ternate; Batjan; Buru, up to 750 m.!; Ceram!; Timorlaut islands; Kei islands; Aru islands; Waigeu!; Batanta; New Guinea (Sorong; Dore Hum; Manokwari; Andai; Mansiman!; Hatam, Arfak mts.; Wendesi!; Etna bay!; Jamur lake!; Rubi, Geelvink bay; Mamberamo riv.!; near Idenburg riv., \pm I 450 m.!; Doorman riv.!; Sermowai riv.!; Tor riv.!; Tanahmerah bay!; Waipopa riv.!; Jaona!; Humboldt bay!; Sekanto region!; Tami riv.!; Sentani lake!; Ibaïso!; Jåga!; Timena riv.!; Rienjamur riv. and Garup riv., Torricelli mts.!; Eitape ; Berlinhafen; Kaiserin Augusta riv.!; westward from Finschhafen, in the interior; Astrolabe bay; Stephansort; Sattelberg, $\pm 800 \mathrm{~m}$.; Moroka, 700 m.; Bara Bara; Rigo; Vikaiku; Pt. Moresby; Merauke!; Digul riv.!; Lorentz riv.!; Van der Sande riv.!; Went mts., I050 m.!; Hellwig mts., $2000 \mathrm{~m}$.!; Utakwa riv., $640-760 \mathrm{~m}$.; Setekwa riv.; Mimika riv.); Frederik Hendrik isl.!; Jobi isl.; Ferguson isl.; Murray isl. — Philippines; Pelawan.

\section{Rana celebensis (Schlg.).}

Limnodytes celebensis (Schlegel), Peters, Monatsber. Akad. Berlin, I872, p. 585 . ? Rana celebensis Boulenger, Cat. Batr. Sal. Brit. Mus., 1882, p. 70.

Rana celebcnsis v. Kampen, Weber's Zool. Ergebn., Leiden, IV, I907, p. 395. Rana celebensis Boulenger, Rec. Ind. Mus., XX, 1920, p. I69.

Vomerine teeth in two short series extending a little behind the level of the choanae. Head longer than broad; snout rounded or somewhat pointed, projecting, as long as the upper eyelid; canthus rostralis strong; loreal region nearly vertical, 
concave; nostril nearer to the tip of the snout than to the eye; interorbital space as broad as the upper eyelid; tympanum distinct, nearly as large as the eye. Fingers and toes with small, but distinct disks; first finger extending beyond second, which is shorter than fourth; toes nearly entirely webbed, the web reaching all disks, except that of fourth toe, two phalanges of which are free; subarticular tubercles well developed; an oval inner, and a not much smaller round outer metatarsal tubercle; no tarsal fold; the heel reaches the nostril; tibia more than $1 / 2$ length of head and body.

Finely granulate above, with or without large warts on the back; a broad dorsolateral fold; lower parts smooth.

Brown above; the warts, dorsolateral folds, loreal and temporal regions darker; a white streak along the upper lip; limbs with dark cross-bands. Length $5 \mathrm{I} \mathrm{mm}$.

Boulenger (Cat. Batr. Sal. Brit. Mus., 1882, p. 70, and Proc. Zool. Soc. London, 1897, p. 232) describes as $R$. celebensis a specimen of unknown origin, which has the first finger not extending beyond the second one and shows some other differences with the above description. It is thus uncertain, if it belongs to the same species. It is a male, with internal vocal sacs and an oval flat gland on the inner side of the arm.

Habitat: Celebes (Menado!; Gorontalo?!; Gurupahi!).

\section{I. Rana daemeli (Steind.).}

Hylorana Daemeli Steindachner, Sitzungsber. Akad. Wien, LVII, I868, p. 532, figs. $\mathbf{I}-4$.

Rana papua (Fart.) Boulenger, Cat. Batr. Sal. Brit. Mus., I882, p. 64.

Rana novae-guineae v. Kampen, Nova Guinea, IX, pt. I, I 909, p. 37, pl. II, fig. 5 . Rana daemeli Boulenger, Transact. Zool. Soc. London, XX, pt. 5, 1914, p. 250. :Rana papua Barbour, Proc. Biol. Soc. Washington, XXVII, I9r4, p. 201.

Rana dacmeli Boulenger, Rec. Ind. Mus., XX, I920, p. I90.

Vomerine teeth in two oblique groups or short series between the choanae or extending a little behind them. Head a little longer than broad; snout obtusely pointed, projecting, at least as long as the eye, about once and a half as long as high; canthus rostralis distinct; loreal region feebly oblique, concave; nostril equally distant from eye and tip of snout or a little nearer to the latter; interorbital space as broad as or a little narrower than the upper eyelid; tympanum distinct, $2 / 3$ to $4 / 5$ the diameter of the eye. Fingers and toes with small, but 
distinct disks; first finger extending slightly beyond second, which is shorter than fourth; toes almost entirely webbed, the web reaching all the disks except fourth, the second and third ones however only at their outer borders; two phalanges of fourth toe free; outer metatarsals separated nearly to the base; subarticular tubercles strong; an inner, oblong, and an outer, smaller, round metatarsal tubercle; no tarsal fold; the heel reaches the eye or between eye and nostril; tibia half the length of head and body or a little shorter; when the hind limbs are folded at right angles to the body, the heels are feebly overlapping.

Finely granulate above; a moderately broad dorsolateral fold; back, sides of the body and hind limbs with or without scattered small warts; a fold from below the eye to the shoulder, sometimes followed by one or two glandules; smooth below.

Upper parts greyish or reddish brown; sides of head and sometimes of body also blackish, darker in young specimens than in older ones; the dorsolateral folds may be a little lighter than the back; warts of back and cross-bars on the hind limbs black; border of the upper lip unspotted, usually white; the glandular fold behind it white; beneath white, sometimes powdered with brownish, especially on throat and breast; usually a pair of dark spots between the shoulders and an oblique bar on the upper arm. From snout to vent $80 \mathrm{~mm}$.

Male with humeral glands and internal vocal sacs.

Very closely allied and perhaps identical with. $R$. papux, from which, however, it seems to be distinct by broader dorsolateral folds.

Habitat: New Guinea (Humboldt bay!; Pt. Moresby; Lorentz riv.!; Mimika riv.). - ? Thursday isl. '); northern Queensland.

\section{Rana kreffti Blgr.}

Rana kreffiti Boulenger, Cat. Batr. Sal. Brit. Mus., 1882, p. 64, pl. III, fig. 2. Rana kreffiii Boulenger, Transact. Zool. Soc. London, XII, pt. 2, I886, p. 52. Rana novae-britanniae Werner, Zool. Anz., XVII, I894, p. 155.

Rana novae-britanniae (part.) Werner, Mitt. Mus. f. Naturk. Berlin, I, I900, p. II I, fig. 42 .

Rana kreffii Roux, Revue Suisse Zool, XXVI, 1918, p. 4 II.

Rana kreffiti Boulenger, Rec. Ind. Mus., XX, I920, p. 186.

1) „Rana papua (Hy'lorana Dämclii Steind.)”, F. Müller, Verh, naturf. Ges. Basel, VII, I885, p. 670. 
Vomerine teeth in two oblique oval groups or short series in the middle between the choanae. Head slightly longer than broad; snout obtusely pointed, somewhat projecting, as long as the eye or a little longer; canthus rostralis angular, straight; loreal region a little oblique, concave; nostril somewhat nearer to tip of snout than to eye; interorbital space as broad as or a little narrower than to the upper eyelid; tympanum very distinct, about $2 / 3$ the width of the eye. Fingers with small, toes with a little larger oval disks; first finger longer than second and fourth ones; toes nearly entirely webbed, two phalanges of fourth one free; outer metatarsals separated nearly to the base; subarticular tubercles prominent, oval; a small, oval inner and a small, round outer metatarsal tubercle; no tarsal fold; the heel reaches the eye or between eye and nostril; tibia half the length of head and body or a little shorter; when the hind limbs are folded at right angles to the body, the heels are overlapping.

Skin smooth or finely granulated, sometimes with small warts, above; posterior surface of thighs granulate; a moderately broad dorsolateral fold, a less distinct fold above the tympanum and a fold from below the eye to the shoulder, followed by a small glandule. Lower parts smooth.

Olive or chestnut-brown above, the glandular fold not lighter; sides of head and body dark brown to blackish; a white streak along the upper lip, extending backwards to the shoulder; limbs with dark cross-bars; posterior surfaces of thighs yellow, marbled with dark brown or black; white beneath, uniform or spotted or marbled with blackish brown. Length $77 \mathrm{~mm}$.

Male with two large external vocal sacs and a large flat gland on the arm.

Habitat: N.E.-New Guinea? '). - Bismarck arch.; Solomon islands.

\section{Rana grisea v. Kamp.}

? Rana novae-britanniae (part.) Werner, Verh. zool.-bot. Ges. Wien, LI, I901, p:614. Rana grisea v. Kampen, Nova Guinea, IX, pt. 3, I9I3, p. 460, pl. XI, fig. 3 . Rana grisea Boulenger, Transact. Zool. Soc. London, XX, pt. 5, 1914, p. 250. Rana grisea Boulenger, Rec. Ind. Mus., XX, 1920, p. 185.

R'ana grisea var. ceramensis Smith and Procter, Ann. Mag. Nat. Hist., (9) VII, I921, p. 353.

I) According to Werner (Verh. zool.-bot. Ges. Wien, LI; 190I, p. 6r4); these specimens, however, perhaps belong to $R$, papua or grisea. 
Vomerine teeth in two oblique groups or series between the choanae or extending behind the level of their posterior borders. Head as long as broad or a little longer than broad; snout obtusely pointed, a little projecting, as long as the eye or the upper eyelid, longer than deep; canthus rostralis strong; loreal region oblique, concave; nostril equally distant from eye and tip of snout or nearer to tip of snout; interorbital space narrower than the upper eyelid; tympanum distinct, $1 / 2$ to $\frac{2}{3}$ the diameter of the eye. Disks of fingers small, of toes a little larger; first finger hardly extending beyond second, which is much shorter than fourth; fifth toe longer than third; toes entirely webbed or two phalanges of fourth one free; outer metatarsals separated nearly to the base; subarticular tubercles well developed; a distinct, elliptic inner and a feebly prominent round outer metatarsal tubercle; no tarsal fold; the heel reaches beyond the tip of the snout; tibia $2 / 3$ length of head and body; when the limbs are folded at right angles to the body, the heels are strongly. overlapping.

Smooth or finely granulate above, with a few scattered small warts; a rather broad dorsolateral fold and a fold from the mouth to the shoulder; smooth below.

Light grey or brown above, uniform or with some small ill-defined dark spots on the back; upper half of loreal region, tympanum and temporal region dark brown; hind limbs with narrow dark cross-bars; yellowish or brown beneath, more or less spotted or marbled with dark; a dark streak on each shoulder. Length $85 \mathrm{~mm}$.

Male with large external vocal sacs and humeral glands.

Habitat: Ceram (900 m.); New Guinea (Went mts., \pm I 300 m.!; Utakwa riv., 750-900 m.).

\section{Rana jerboa (Gthr.).}

Hylorana jerboa Günther, Proc: Zool. Soc. London, I872, p. 599, pl. XL, fig. B.

Rana jerboa Boulenger, Cat. Batr. Sal. Brit. Mus,, I882, p. 67.

Rana Masonii Boulenger, Ann. Mag. Nat. Hist., (5) XIII, I884, p. 397.

Rana jerboa Boulenger, Ann. Mus. Genova, (2) XIII, I893, p. 335.

"Unbestimmbare Froschlarve", Weber, Ann. Jardin Bot. Buitenzorg, Suppl. II, 1898, p. ro, fig. 6 (tadpole).

Rana jerbca v. Kampen, Weber's Zool. Ergebn., Leiden, IV, I907, p. 397 (tadpole). Rana jerboa v. Kampen, Nat. Tijdschr. Ned.-Indië, LXIX, I909, p. 39, pl. II, figs. $3-6$ (tadpole). 
Rana jerboa Botlenger, Vert. Fauna Mal. Penins., Rept. and Batr., London, I9I2, p. 244 (not the tadpole).

Rana jerboa Boulenger, Rec. Ind. Mus., XX, 1920, p. 196.

Vomerine teeth in two short, transverse or oblique series between the choanae or extending behind the level of their posterior borders. Head as long as broad or slightly longer; snout rounded or obtusely pointed, scarcely projecting, as long as or a little longer than the upper eyelid, longer than deep; canthus rostralis angular; loreal region slightly oblique, concave; nostril about equally distant from the eye and the tip of the snout; interorbital space about as broad as the upper eyelid; tympanum very distinct, $1 / 2$ to $4 / 5$ the diameter of the eye. Disks of fingers and toes moderate, less than half the diameter of the tympanum, those of toes as large as or a little larger than those of fingers; first finger equal to, or slightly longer than second; fifth toe longer than third; toes entirely or nearly entirely webbed; outer metatarsals separated nearly to the base; subarticular tubercles well developed; a small, elliptic inner metatarsal tubercle, outer metatarsal tubercle more or less distinct, or absent; no tarsal fold; the heel reaches far beyond the tip of the snout; tibia $2 / 3$ to $4 / 5$ length of head and body; when the hind limbs are folded at right angles to the body, the heels are strongly overlapping.

Upper parts smooth or finely granulate, with or without scattered warts; a moderately broad, continuous, glandular dorsolateral fold, extending to the hip; lower parts smooth.

Brown or greyish above, uniform or marbled with darker; darker on the sides, especially of the head; sometimes a black streak on canthus rostralis and along the outer side of the dorsolateral fold, with a downward process in front of, and another one behind the tympanum; a more or less distinct light streak along the upper lip; limbs with dark cross-bars, which may be very indistinct; lower parts white, uniform, or throat and breast spotted or speckled with brown. From snout to vent or 50 , ㅇ $102 \mathrm{~mm}$.

Terminal phalanges $\mathrm{T}$-shaped.

Male with small external vocal sacs.

Tadpole. - Length of body nearly $1 \frac{1}{2}$ times its width; tail about $\mathrm{I}^{3} / 4$, times as long as body, $3 \frac{1}{2}$ times as long as deep. Nostril nearer to the eye than to the tip of the snout; eyes superior, in the middle between the spiraculum and the tip INDO-AUSTRALIAN AMPHIBIA. 
of the snout, or a little nearer to the first, the distance between them larger than that between the nostrils and half the width of the mouth; spiraculum sinistral, lateral, directed upwards and backwards, much nearer to the posterior than to the anterior extremity of the body; vent median. Tip of tail rounded; the crests low, not reaching the base of the tail.

A large sucking disk behind the mouth, extending to below the spiracular tube; lower lip bordered with one, sides of upper lip with three series of papillae; jaws feebly denticulated, composed of one piece each, bordered with black; series of teeth $4^{3-4} 4 / \mathrm{I}_{6-9} \mathrm{I} /$, the outer series in both lips very feeble and sometimes incomplete.

Blackish brown above, colourless below; tail brown, more or less variegated with lighter; crests colourless. Length $56 \mathrm{~mm}$.

In swift running brooks.

Habitat: Sumatra (Karo countries, $\pm 400 \mathrm{~m}$. !; Tandjongberingin, Batak mts., $\pm 300 \mathrm{~m}$. !; Panjinggahan!; Barisan range, I 200 m.; Sandaran Agung, 745 m., and Sinlak Daras, 900 m., in Kurintji valley; Muarasako, Kurintji!); Borneo (Brunei; Mt. Dulit; Kidi distr. and Matang in Serawak); Java (Batavia?; Buitenzorg; Tjibodas!, I400-2000 m.; Pasirdatar, 900 m.!; Djampang!; Tjitalahab! ; Mt. Ungaran, I000-I 300 m.! ; Tengger mts., I 200 m.). - Burma; Siam; Malay Peninsula; Philippines ${ }^{1}$ ).

\section{Rana whiteheadi Blgr.}

Rana Whiteheadi Boulenger, Ann. Mag. Nat. Hist,, (5) XX, 1887, p. 96.

Rana Whiteheadi Mocquard, Nouv. Arch. Mus. d'Hist. Nat., (3) II, I89o, p. 146, pl. X, fig. 2 .

Rana Whiteheadi Boulenger, Ann. Mag. Nat. Hist., (6) VII, I 89 I, p. 344.

Rana Whiteheadi Mocquard, Mém. Soc. Zool. France, V, I892, p. 205.

? Rana masoni Boettger, Ber. Offenb. Ver. f. Naturk. (1887-9r), I892, p. 138. Rana Whiteheadi Boulenger, Proc. Zool. Soc. London, 1893, p. 526 (tadpole). Rana whiteheadi Boulenger, Rec. Ind. Mus., XX, 1920, p. 195.

Vomerine teeth in two short transverse or oblique series between the posterior borders of the choanae, or just behind them. Head as long as broad or slightly longer than broad; snout rounded or obtusely pointed, feebly projecting, about as long as the eye; canthus rostralis strong; loreal region feebly oblique, deeply concave; nostril nearer to tip of snout

I) According to: De Elera, Catálogo Sist. de toda la Fauna de Filippinas. I. 1895, p. 448 . 
than to eye; interorbital space $2 / 3$ to equal to the width of the upper eyelid; tympanum very distinct, $2 / 5$ to $3 / 5$ the diameter of the eye. Disks of fingers and toes well developed, $1 / 2$ to $4 / 5$ the diameter of the tympanum; first finger as long as or extending slightly beyond second; toes entirely or nearly entirely webbed, two phalanges of fourth one sometimes being free; outer metatarsals separated nearly to the base; subarticular tubercles rather large; a small, oval inner metatarsal tubercle, outer tubercle very small and indistinct, or absent; no tarsal fold; the heel reaches far beyond the tip of the snout; tibia $2 / 3$ to $3 / 4$ length from snout to vent; when the hind limbs are folded at right angles to the body, the heels are strongly overlapping.

Finely granulate or shagreened above; sides sometimes warty; a fold above the tympanum; dorsolateral fold, if present, short, not extending to the sacrum, or represented by a series of warts.

Grey or brown above, sometimes with darker spots or marblings or with scattered small light spots; tympanum yellowish or pale brown; a blackish streak below canthus rostralis and on supratemporal fold; temporal region blackish or with blackish spots; upper lip whitish or brown; limbs with or without more or less distinct dark cross-bands; hinder side of thighs purplish brown, uniform or speckled with lighter; lower surface white, throat and breast sometimes spotted or marbled with brown. From snout to vent $93 \mathrm{~mm}$.

Terminal phalanges $\mathrm{T}$-shaped.

Male with small external vocal sacs; no humeral glands.

Tadpole. - Tail obtusely pointed, the upper crest not extending to base of tail.

A large sucking disk behind the mouth, free on its borders, truncate in front; lower lip bordered by papillae; both jaws composed of two black pieces, which are ribbed and strongly toothed; series of teeth $3^{2} 3 /{ }^{1} 4^{1}$.

$\mathrm{H}$ a bit at: Borneo (Mt. Kina Balu!, 640 and $280 \mathrm{~m}$.; Bongon; Baram riv.; Pata riv., Serawak; Serawak riv.); Java (Tjibodas!).

\section{Rana cavitympanum Blgr.}

Rana cavitympanum Boulenger, Proc. Zool. Soc. London, 1893, p. 525, pl. XLIII, fig. I (with tadpole).

Rana cavitympanum Boulenger, Rec. Ind. Mus., XX, I920, p. I93.

Vomerine teeth in two short, slightly oblique series between 
the choanae. Head as long as broad; snout rounded, scarcely projecting, a little shorter than the eye; canthus rostralis strong; loreal region feebly oblique, deeply concave; nostril slightly nearer to the eye than to the tip of the snout; interorbital space $2 / 3$ the width of the upper eyelid; tympanum distinct, deeply sunk, $1 / 2$ the diameter of the eye. Disks of fingers and toes $1 / 2$ the diameter of the tympanum; first finger as iong as second; toes entirely webbed; outer metatarsals separated nearly to the base; subarticular tubercles of fingers rather large, of toes rather small; a very small oval inner metatarsal tubercle, no outer one; no tarsal fold; the heel reaches far beyond the tip of the snout; tibia $3 / 4$ the length of head and body; when the hind limbs are folded at right angles to the body, the heels are strongly overlapping.

Skin smooth; no dorsolateral fold.

Pale grey-brown above; a broad dorsal area blackish brown, sharply defined on the sides; a dark bar between the eyes; a black streak from the lip to the shoulder, passing through nostril and eye and above the tympanum; lips with black spots; limbs with narrow dark brown cross-bars; lower parts white. From snout to vent $44 \mathrm{~mm}$.

Male with two external vocal sacs; no humeral gland.

Tadpole. - A large ventral sucking disk, free on its borders, truncate in front; lips much developed, without papillae; jaws black, angular, smooth, very finely denticulated at the edge; series of teeth $8^{3} 8 /{ }^{1} 4^{1}$.

$\mathrm{H}$ ab it at: Borneo (Mt. Kina Balu; Inuman riv., Brit. N.-Borneo; Bongon, N.-Borneo).

\section{Rana kampeni Blgr.}

Rana pantherina (non Fitz.), v. Kampen, Nat. Tijdschr. Ned.-Indië, LxIX, I909, p. 22 , pl. I, fig. 2 .

Rana kampeni Boulenger, Rec. Ind. Mus., XX, I920, p. 213.

Vomerine teeth in two short, oblique series, extending a little behind the level of the choanae. Head as long as broad; snout rounded, feebly projecting, as long as the upper eyelid, longer than deep; canthus rostralis strong, curved; loreal region oblique, deeply concavc; nostril equidistant from eye and tip of snout; interorbital space somewhat narrower than the upper eyelid; tympanum distinct, about $1 / 2$ to $2 / 3$ the diameter of the eye. Disks of fingers (except first) large, dia- 
meter of largest about $2 / 3$ to $3 / 4$ that of tympanum; disks of toes smaller than those of fingers; first finger shorter than second, which is shorter than fourth; third toe shorter than fifth; toes nearly entirely webbed, only the extreme tip of fourth toe free; outer metatarsals separated nearly to the base; subarticular tubercles well-developed; a distinct, oblong inner, no outer metatarsal tubercle; no tarsal fold; the knee reaches the axil, the heel far beyond the tip of the snout; tibia $2 / 3$ to $3 / 4$ length of head and body; when the hind limbs are folded at right angles to the body, the heels are strongly overlapping.

Smooth, or finely granulate, or with a few tubcrcles on the back; no dorsolateral fold; belly granulate or smooth, the proximal part of the posterior surface of the thighs granulate.

Upper parts bluish grey or purplish; back and sides sometimes covered with roundish and oblong, dark spots, most of which have a light centre; dark spots along the borders of the lips; limbs with dark cross bars; whitish beneath, immaculate or vermiculated with brown. Length $73 \mathrm{~mm}$.

Habitat: Sumatra (Bandarbaru, Batak mts., \pm 900 m.!; Serepai and Sungai Kring in Kurintji!).

\section{Rana crassiovis Blgr.}

Rana crassiovis Boulenger, Jrn. Fed. Malay St. Mus, VIII, I920, p. 292. Rana crassiozis Boulenger, Rec. Ind. Mus., XX, 1920, p. 212.

Vomerine teeth in two short oblique series between the choanae. Head as long as broad; snout rounded, feebly projecting, as long as or slightly longer than the eye; canthus rostralis distinct; loreal region feebly oblique, very concave; nostril a little nearer to tip of snout than to eye; interorbital space as broad as the upper eyelid; tympanum very distinct, about $3 / 5$ the diameter of the eye. Disks of fingers moderately large, as long as broad, $2 / 3$ the diameter of the tympanum; disks of toes similar to, but smaller than those of fingers; first finger as long as second; toes webbed to the disks of third and fifth, two phalanges of fourth one free; outer metatarsals separated nearly to the base; subarticular tubercles of fingers rather large, of toes rather small, prominent; an oval, feebly prominent inner, no outer metatarsal tubercle; no tarsal fold; the heel reaches far beyond the tip of the snout; tibia $3 / 5$ to $2 / 3$ the length from snout to vent; when the hind limbs 
are folded at right angles to the body, the heels are strongly overlapping.

Smooth or finely granulate above, coarsely granulate on the sides; a short fold above the tympanum; lower parts smooth.

Dark purplish brown above, with large darker spots or marblings, yellowish on the sides, with round black spots; hind limbs with numerous, very regular dark cross-bands; hinder side of thighs blackish brown, with white vertical bars. White beneath, throat and breast speckled or spotted with brown. From snout to vent $63 \mathrm{~mm}$.

Habitat: Sumatra (Barisan range in Kurintji, I200 m.). Eggs very large $(3 \mathrm{~mm}$. in diam.), unpigmented.

\section{Rana everetti Blgr.}

Rana Everetti Boulenger, Cat. Batr. Sal. Brit. Mus, 1882, p. 72, pl. VI. Rance everetti Boulenger, Rec. Ind. Mus., XX, 1920, p. 210.

Vomerine teeth in two short oblique series, on a level with and extending behind the posterior borders of the choanae. Head as long as broad; snout rounded, scarcely projecting, a little longer than the eye; canthus rostralis angular; loreal region slightly oblique, concave; nostril nearer to the tip of the snout than to the eye; interorbital space as broad as the upper eyelid; tympanum very distinct, $4 / 5$ the diameter of the eye. Disks of fingers large, of third and fourth ones $2 / 3$ the width of the tympanum, those of toes smaller than those of fingers; first and second fingers equal; toes entirely webbed; outer metatarsals separated nearly to the base; subarticular tubercles well developed; a small oval inner, and a very indistinct outer metatarsal tubercle; no tarsal fold; the heel reaches between eye and nostril; tibia hardly more than half the length of head and body; when the hind limbs are folded at right angles to the body, the heels are strongly overlapping.

Skin smooth above; a rather indistinct fold above the tympanum and a fold from below the eye to the shoulder, followed by a glandule; belly and posterior half of lower surface of thighs granulate.

Light greyish brown above, with round dark spots; a dark band on the side of head and body; limbs with indistinct dark cross-bars; white beneath, the hind limbs speckled with greyish brown. From snout to vent $87 \mathrm{~mm}$.

Ha bitat: Borneo (Mt. Kina Balu; Baram riv.). - Philippines. 
40. Rana hosii Blgr.

Hyla chalconotzs (part.) Schlegel, Abbild, neuer oder unvollst. bek. Amph.,

Düsseldorf, I $837-44$, p. 23 , pl. IX, fig. I.

Rana Hosii Boulenger, Ann. Mag. Nat. Hist., (6) VIII, I89I, p. 290.

Rana Hosii v. Kampen, Weber's Zool. Ergebn., Leiden, IV, 1907, p. 398.

Rana hosii Boulenger, Vert. Fauna Malay Penins., Rept. and Batr., London,

1912, p. 243.

Rana durheini Baumann, Zool. Jahrb., Syst., XXXIV, I9I3, p. 275, textfigs. D, E. Rana hosii Boulenger, Rec. Ind. Mus., XX, I920, p. 199.

Vomerine teeth in two strong, oblique series between the choanae and extending behind the level of their posterior borders. Head as long as broad or slightly longer; snout obtusely pointed, projecting, as long as the upper eyelid, much longer than deep; canthus rostralis angular, straight; loreal region nearly vertical, concave; nostril nearer to the tip of the snout than to the eye; interorbital space about as broad as the upper eyelid; tympanum very distinct, $2 / 5$ to $3 / 4$ the diameter of the eye. Disks of the two outer fingers from slightly more than half to as large as the tympanum, of first and second fingers and of toes much smaller; disks of second finger elliptic (longer than broad); first finger as long as or a little shorter than second, which is shorter than fourth; fifth toe longer than third; toes webbed to the disks; outer metatarsals separated nearly to the base; subarticular tubercles strong; an elliptic, feebly prominent inner, no outer metatarsal tubercle; no tarsal fold; the heel reaches beyond the tip of the snout; tibia $2 / 3$ length of head and body, or nearly so long; when the hind limbs are folded at right angles to the body, the heels are strongly overlapping.

Upper parts granulate; a feebly developed glandular dorsolateral fold; a fold from below the eye to the shoulder, often followed by one or two glandules; smooth beneath.

Uniform purplish brown (green in life ?) above, usually darker on the sides, especially of the head; a white or whitish streak along the upper lip, extending to the shoulder and followed by a spot of the same colour; limbs usually with dark crossbars, which however may be very indistinct; white (in life yellow?) beneath, uniform, or spotted or marbled with brown. From snout to vent $97 \mathrm{~mm}$. (the of much smaller that the 9 ).

Terminal phalanges $\mathrm{T}$-shaped.

Male with internal vocal sacs. 
Tadpole. - The tadpoles from Posata in Bantam (Java), described and figured by Boulenger (Cat. Batr. Sal., I882, p. 89)

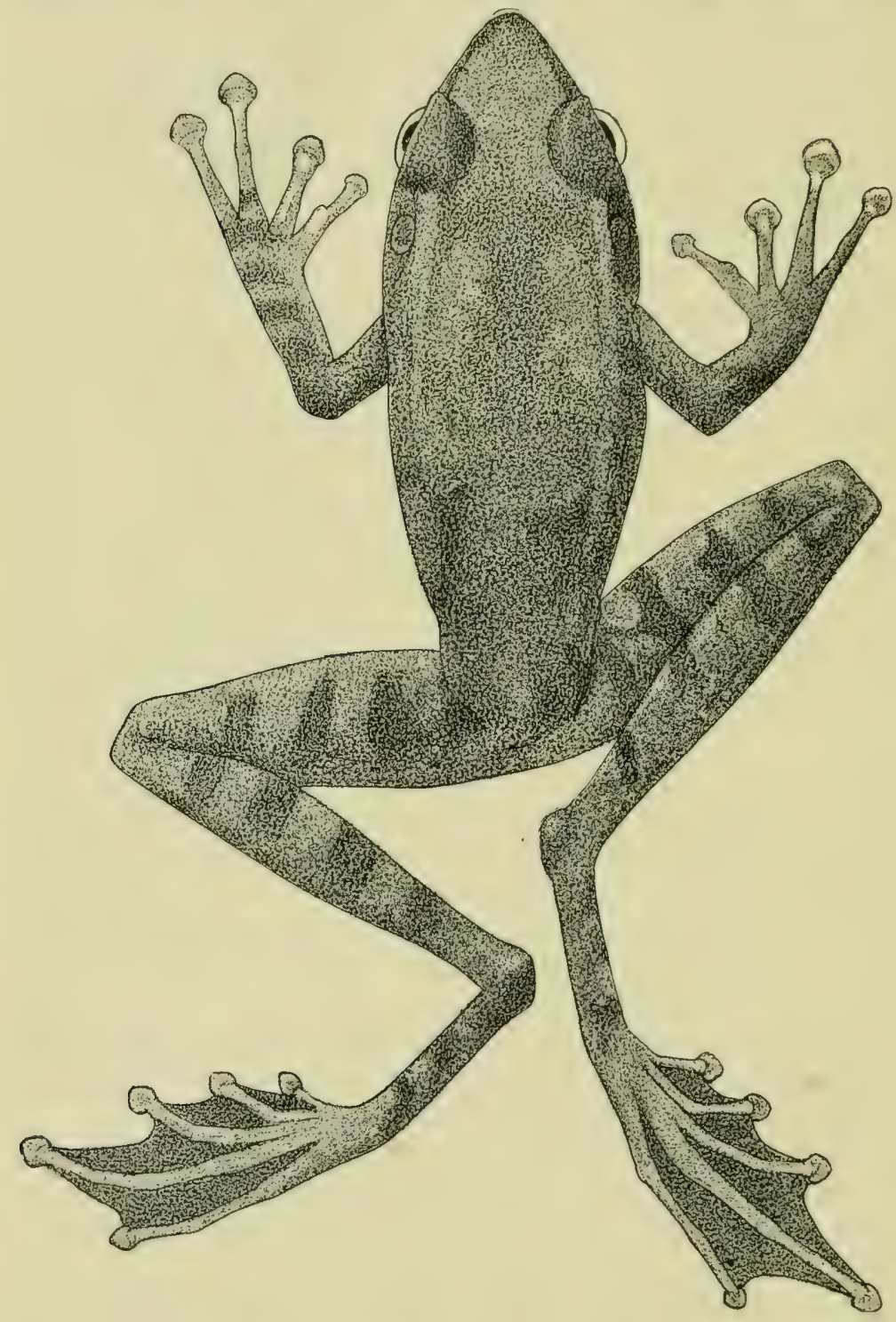

Fig. 25. Rana hosii Blgr., $X \mathbf{I}$.

and considered by him to belong to Rhacophorus reinwardti, afterwards (Proc. Zool. Soc. London, I S93, p. 526) to Rana jerboa, probably belong to $R$. hosii: 
Length of body twice its width; tail $\mathrm{I}^{2} / 3$ to $\mathrm{I}^{3} / 4$ the length of the body, its depth (without crests) about $1 / 5$ its length. Spiraculum sinistral, lateral, nearer to the base of the tail than to the end of the snout. Tail pointed; the crests beginning at a considerable distance from the base of the tail.

Behind the mouth a ventral sucking disk, which is free on its borders, truncate in front, and the posterior border of which is situated below the spiraculum; lips much developed, without papillae; jaws black, the edge feebly denticulated, formed of one piece each; rows of tecth $3^{1} 3 /^{1} 3^{1}$.

Greyish brown above, whitish beneath; tail light-spotted. Length $46 \mathrm{~mm}$.

Habitat: Simalur!; Sumatra (Brastagi, Karo highland, $1400 \mathrm{~m}$. !; Tandjongberingin, Batak mts., $300 \mathrm{~m}$. !; Batak mts., Soo m.; Andalas!; Fort de Kock!; Singkarah!; Danau diatas!; Sandaran Agung, $745 \mathrm{~m} . !$, and Sinlak Daras, $900 \mathrm{~m}$. , in Kurintji valley; Sungai Kring! and Sungai Kumbang, I 4 Co m. !, Kurintji); Borneo! (Mt. Dulit and Mt. Batu Song, Serawak); Java (? Posata, Bantam; Perbawati, Mt. Gedeh!; Djampang Kulon!). - Malay Peninsula.

\section{I. Rana chalconota (Schlg.).}

Hy'la chalconolus (part.) Schlegel, Abbild. neuer oder unvollst. bek. Amph., Diisseldorf, I $8_{37}-44$, p. 23, pl. L, fig. 3? (not pl. IX, fig. I).

Polypedates Funghuhnii Bleeker, Nat. Tijdschr. Ned.-Indië, XI, I856, p. $469^{1}$ ). Rana chalconota Boulenger, Cat. Batr. Sal. Brit. Mus., 1882, p. 66 (with fig. of hand). R'ana chalconota Boettger, Ber. Offenb. Ver. f. Naturk. (I887-9I), I892, p. I4I. Rirna Everetti (part.) Boulenger, Proc. Zool. Soc. London, I897, p. 232 (tadpole). Kana Mocquardi Werner, Zool. Anz., XXIV, Igor, p. 98.

Rana tytleri (part.) Isenschmid (nec Theob.), Mitth. naturf. Ges. Bern, I903, p. 72. Rana chalconota and Everetti, v. Kampen, Weber's Zool. Ergebn., Leiden, IV, I907, p. 392, 394 (with tadpole).

Kana chalconota v. Kampen, Nat. Tijdschr. Ned.-Iudië, LXIX, I909, p 37 (tadpole). Rana Everctti Roux, Zool. Jahrb., Syst., XXX, I9Ir, p. 506 (tadpole). Rana chulconota (part.) Boulenger, Rec. Ind. Mus., XX, 1920, p. 201. ?Rına sanchezi Taylor, Philipp. Jrn. of Sc., XVI, 1920, p. 256.

Vomerine teeth in two oblique series between the choanae, often extending beyond their posterior borders. Head longer than broad; snout pointed, projecting, as long as the upper eyelid; canthus rostralis angular, straight; loreal region slightly oblique, concave; nostril much nearer to end of snout than to eye;

I) Specimen in the Leiden Museum, collected by Bleeker, examined by me. 
interorbital space as broad as the upper eyelid; tympanum very distinct, $3 / 4$ to nearly equal to the width of the eye. Disks of third and fourth finger large, $1 / 2$ to $2 / 3$ diameter of tympanum, of first and second finger and of toes smaller; disks of second finger elliptic (longer than broad); second finger as long as or extending hardly beyond first, shorter than fourth; fifth toe longer than third; toes nearly entirely webbed, two phalanges of fourth one free; outer metatarsals separated nearly to the base; subarticular tubercles well developed; a small oval inner and a still smaller, sometimes indistinct, round outer metatarsal tubercle; the heel reaches between eye and tip of snout, to the tip of the snout or a little beyond; tibia more than half length of head and body; when the hind limbs are folded at right angles to the body, the heels arc strongly overlapping.

Finely granulate above; a dorsolateral fold of variable width, but usually rather broad; a fold from below the eye to the shoulder, followed by a glandule; back and sides often with some large warts; belly and lower surface of thighs often granular.

Brown above, the warts and glandular folds often somewhat darker; white beneath, throat sometimes marbled with brown; tympanum brown; upper lip and the glandule behird each mouth-edge white; hind limbs sometimes indistinctly crossbarred. Length $68 \mathrm{~mm}$.

Distinguished from the nearly allied R. labialis, with which it probably has been often confounded, by shape and size of the disk of the second finger and usually by a broader and more distinct dorsolateral fold; from $R$. hosii it is distinguished by the less extensively webbed toes, shorter legs and also the more developed dorsolateral folds. The specimens in the Museum at Leiden, on which Schlegel has founded his species, partly belong to $R$. hosii, and it is a specimen of this species, which has been figured by him on his pl. IX.

Lives on the leaves of shrubs. The eggs are laid in a mass of mucilage, forming a sort of nest out of the water (Sarasin).

Tadpole. - Length of body $\mathrm{I}^{1} / 3$ to $\mathrm{I}^{2} / 3$ times its width, tail $1 \frac{1}{2}$ to nearly 2 times as long as the body, about 3 to 5 times as long as deep. Nostril about equally distant from eye and tip of snout; eyes superior, in the middle between tip of snout and spiraculum, the distance between them greater than that between the nostrils, about I to $I^{1} / 2$ times the width 
of the mouth and about half the width of the body. Spiraculum sinistral, directed upwards and backwards, visible from above and from below, equally distant from the vent and the tip of the snout, or a little nearer to the vent; vent dextral, close to the lower border of the tail. Tail more or less pointed; lower crest low, the upper one higher, extending to the root of the tail.

Lower lip and sides of upper one bordered with papillae, which are arranged in two or three rows, not interrupted in the median line; jaws edged with black; series of teeth $2-4^{1} 2-4 / 3$, the inner rows of upper lip broadly interrupted, decreasing in size inwards, the innermost one usually very short; rows of lower lip almost equal in length (the outermost a little shorter), the inner one sometimes very narrowly interrupted.

Skin very transparent; there are some more or less distinct granular patches, viz. on the back a round one behind each eye and an oblong one at each side of the base of the tail, on the ventral surface two round ones (in older specimens sometimes confluent) beside each other behind the mouth and an oblong one at each side on the belly.

Back darker or lighter grey or brown, sometimes spotted or marbled with darker brown; muscular part of tail colourless or light brown; belly and crests colourless. Length $64 \mathrm{~mm}$.

Habitat: Sumatra (Bandarbaru, Batak mts., $\pm 900 \mathrm{~m}$. !; Lauttador; Toba lake; Mt. Simbolon; Agam; Kajutanam?!; Batu Sangkar, betw. 460 and 900 m.; Sandaran Agung, 730 m., in Kurintji valley ${ }^{1}$ ); Sungei Kumbang, I430 m., Kurintji peak!; Muarolabu; Palembang!; Lampong distr.!); Borneo (Danau Sriang; Matang); Java (Buitenzorg!; Mt. Pangeranggo; Perbawati, Mt. Gedeh!; Tjibodas!, 1400-2000 m.; Pasirdatar, 900 m.!; Sukabumi!; Tjiandjur; Djampang Tengah!; Mt. Malabar, I 500 m.!; Gunung Sesuru!; Tjitalahab!; lake Patengan; Babakan! and Idjen!, Bageien; Wonosobo!; Tengger mts., I 200 m.); Celebes (Indrulaman; Loka!; Bua Praeng; Pundidaha; Kandari; Rumbi Mengkoka; Luwu; Pinapuan!; Uangkahulu valley; Bone valley; Tomohon; Mt. Masarang; Menado). - Philippines.

I) The specimens from Kurintii, identified by Boulenger (Jrn. Fed. Malay St. Mus., VIII, pt. II, 1920, p. 292) as $R$. nicobariensis, according to Mr. Malc. Smith are certainly $R$. chalconota (communicated to me by $\mathrm{Mr}$. C. Boden Kloss). 


\section{Rana labialis Blgr.}

Polypedates raniceps Peters, Monatsber. Akad. Berlin, I871, p. 580.

Polypedates raniceps, Peters, Ann. Mus. Genova, III, I 872 , p. 44, pl. VI, figs. 3, $3 a$. Rana labialis Boulenger, Ann. Mag. Nat. Hist., (5) XIX, I887, p. 345, pl. X, fig. 1.

Rana labialis Flower, Yroc. Zool. Soc. London, 1896, p. 903, pl. XLV, fig. 3 (tadpole).

Rana labialis Flower, Proc. Zool. Soc. London, I899, p. 896.

Rana labialis Boulenger, Vert. Fauna Malay Penins., Rept. and Batr., London, 1912, p. 242.

Rana labialis Annandale, Mem. Asiat. Soc. Bengal, VI, 1917, p. 148, pl. VI, fig. 5 (tadpole).

Rana chalconota (part.) Boulenger, Rec. Ind. Mus., XX, I920, p. 201.

Vomerine teeth in two oblique series between the posterior borders of the choanae. Head longer than broad; snout pointed, projecting, as long as or somewhat longer than the upper eyelid; canthus rostralis angular, straight; loreal region slightly oblique, concave; nostril much nearer to the end of the snout than to the eyc; interorbital space as broad as or broader than the upper eyelid; tympanum very distinct, from $3 / 4$ to equal to the width of the eye. Disks of three outer fingers large, nearly circular, of third finger $1 / 2$ to $2 / 3$ the diameter of the tympanum, of first finger and of toes smaller; second finger extending distinctly beyond first, but shorter than fourth; fifth toe longer than third; toes $3 / 4$ to entirely webbed; outer metatarsals separated nearly to the base; subarticular tubercles well developed; inner metatarsal tubercle small, the outer one rather indistinct, rarely absent; the heel reaches tip of snout or a little beyond; tibia a little more than half the length of head and body.

Finely granulate above; a dorsolateral fold, sometimes distinct only anteriorly; a fold from below the eye to the shoulder, followed by one or two glandules; back sometimes with some large warts; smooth beneath, or posterior part of belly and lower surface of thighs granular; when the hind limbs are folded at right angles to the body, the heels are strongly overlapping.

Bright green or bronze brown, with or without some darker spots above, the colour in life being rapidly changeable (brown or purple in spirit), sides dark green or dark brown, with rather indistinct darker spots; tympanum chestnut-brown; a white or light golden streak on the upper lip, extending to the shoulder and followed by a spot of the same colour; 
limbs with more or less distinct dark cross-bars; whitish beneath, throat and breast usually spotted or marbled with brown, hinder side of thighs and lower surface of hind limbs with brown reticulation. Length $7 \mathrm{I} \mathrm{mm}$.

Male with internal vocal sacs.

Tadpole. - Length of body about $\mathrm{I}^{1} / 2$ times its width; tail about $1 \frac{1}{2}$ times the length of the body and 3 to 4 times as long as deep, its total depth at most about twice the depth of the muscular portion at its base. Nostril nearer to the tip of the snout than to the eye; eyes superior, rather nearer to the end of the snout than to the spiraculum; distance between them twice that between the nostrils, and greater than the width of the mouth; spiraculum sinistral, directed upwards and backwards, visible from above and from below, nearer to the vent than to the end of the snout; vent dextral, close to the lower edge of the subcaudal crest. Tail ending in a rounded point; upper crest convex, slightly deeper than the lower one, not extending on to the back.

Sides and lower edge of lips bordered with papillae, those of the lower border being long and prominent; jaws edged with black; series of teeth $3^{1} 3 /{ }^{1} 2^{1}$, the three inner rows of the upper lip broadly interrupted and very short, decreasing in size towards the mouth, the innermost series sometimes very small and inconspicuous; the three rows of lower lip slightly different in length (the outermost the shortest, the innermost the longest), the inner one narrowly interrupted.

Skin very transparent; on each side of the back behind the eyes a patch of granular skin, sometimes a similar strip on each side of hinder part of back and a large patch on each side of the belly.

Colour (in life) bright yellow or brick-red above, pale yellow beneath. Length $37 \mathrm{~mm}$.

BOULENGER recently (1.c., I920) considers $R$. labialis as a variety of $R$. chalconota; I think, however, that it is well distinguished from this species by the characters mentioned under $R$. chalconota.

Habitat: Nias!; Mentawei islands (Sipora); Sumatra (Deli; Balun!; Fort de Kock, 900 m.!; Muarolabu!; Muara Sako! and Sungai Kumbang!, Kurintji); Borneo? (Pulo Matjan?; Serawak?). - Siam; Malay Peninsula; Singapore. 


\section{Rana erythraea (Schlg.).}

Hyla erythraea Schlegel, Abbild. neuer oder unvollst. bek. Amph., Düsseldorf, 1837-44, p. 27 , pl. IX, fig. 3 .

Limnodytes erythracus Duméril et Bibron, Erpét. gén., Paris, VIII, 1841, p. 5 II, pl. LXXXVIII, figs. I, I $a$.

Rana erythraea Boulenger, Cat. Batr. Sal. Brit. Mus., 1882, p. 65 (with fig. of hand). Rana erythraea Flower, Proc. Zool. Soc. London, I896, p. 902, pl. XLV, fig. 2. Rana erythraea v. Kampen, Weber's Zool. Ergebn., Leiden, IV, 1907, p. 390 (tadpole).

Kana erythraea v. Kampen, Nat. Tijdschr. Ned.-Indie, LXIX, I 909, p. 35 (tadpole). Rana erythraea Boulenger, Vert. Fauna Malay Penins., Rept. and Batr., London, 1912 , P. 241.

Rana erythraea Boulenger, Rec. Ind. Mus., XX, I920, p. I52.

Vomerine teeth in two short oblique series between the choanae. Head as long as broad; snout obtusely pointed, projecting, as long as or a little longer than the upper eyelid; canthus rostralis strong; loreal region feebly oblique, concave; nostril nearer to the end of the snout than to the eye ; interorbital space as broad as or a little broader than the upper eyelid; tympanum very distinct, $2 / 3$ to nearly once the diameter of the eye. Fingers and toes with small disks, first finger not or slightly extending beyond second; toes rarely $3 / 4$, usually entirely webbed, the web reaching all disks, but deeply emarginate between the toes; outer metatarsals separated nearly to the base; subarticular tubercles well developed; a small, oval inner, no outer metatarsal tubercle; no tarsal fold; heel reaching the tip of the snout; tibia half the length from snout to vent, or a little more; when the hind limbs are folded at right angles to the body, the heels are strongly overlapping.

Skin smooth; a rather broad glandular dorsolateral fold; an other fold from beneath the eye to the shoulder, followed by a strong gland; posterior surface of thighs granular.

Bright or dull green or yellowish brown above (rufous brown or greyish blue in spirit); a dark brown stripe along each side of head and body may be present; dorsolateral fold and border of lips white or yellowish white; tympanum reddish brown; limbs marbled with brown, without cross-bars; white beneath. From snout to vent $78 \mathrm{~mm}$.

Terminal phalanges with feebly expanded tips.

Male with internal vocal sacs, without humeral glands.

Essentially a water frog, living nearly always at low elevations.

Tadpole. - Length of body about $\mathrm{I}^{3} / 4$ times its width; 
length of tail about twice that of body and $3 \frac{1}{2}$ to 4 times its depth. Nostril nearer to the tip of the snout than to the eye, which is lateral and equally distant from the tip of the snout and the spiraculum; distance between the eyes about $2 / 3$ the width of the body and more than twice the distance between the nostrils, which is a little less than the width of the mouth; spiraculum sinistral, lateral, directed upwards and backwards, nearer to the vent than to the tip of the snout; vent dextral, close to the lower border of the tail. Tail pointed; upper crest extencling to the base of the tail, somewhat higher than the lower one, which is about half as deep as the muscular part of the tail at its base.

Sides and lower border of lips with papillae; jaws narrowly edged with black; rows of teeth $\mathrm{I} /{ }^{1} \mathrm{I}^{1}$ or $\mathrm{I}{ }^{1} \mathrm{I} /{ }^{1} \mathrm{I}^{1}$, outer series of lower lip short, inner one hardly interrupted.

Back and tail (including the crests) metallic green, marbled with dark; belly white or yellowish, with small rusty red spots, throat dark grey; body with a few scattered silvery dots. More developed tadpoles have three white longitudinal stripes on the back. Length $58 \mathrm{~mm}$.

Habitat: Simalur!; Nias!; Sumatra (Takengan, Gajo countries!; Lower Langkat; Medan!; Brastagi, Karo highland, $1400 \mathrm{~m}$. !; Bandarbaru, $\pm 900 \mathrm{~m} . !$, and Tandjungberingin, \pm 300 m.! Batak mts.; Airbangis!; Talu!; Gunung Sahilan!; Andalas!; Agam ; Matur!; Baso!; Ajer Teganang!; near Padangpandjang and Kajutanam!; Batu Sangkar, betw. 460 and 900 m.; near Solok and Singkarah!; Kalung, Tilatang!; Padang; Painan!; Indragiri; Ringat; Benakat, Palembang); Banka; Natuna islands (Laut isl.; Bunguran); Borneo (Panjut, Br. N.-Borneo; Baram; Kutjing; Bengkajang; Kapuas riv.; Bandjermasin!); Java (Lebak; Darı; Batavia!; Depok; Buitenzorg!; Tjitajam!; Sukabumi!; Tjitalahab!); Celebes (Makasser). - Bengal; Assam; Yunnan; Burma; Siam; Cochin-China; Malay Peninsula; Singapore; Philippines.

\section{Rana persimilis nova spec.}

Rana novae-britanniae (part.) Werner, Zool. Jahrb., Syst., XIII, 1900, p. 493, pl. XXXII, fig. 3 .

Rana lateralis'(part.) Roux, Revue Suisse Zool., XXVI, I9I8, p. 409.

Vomerine teeth in two oblique series between, and close to the choanae, not extending behind the level of their poste- 
rior borders. Head as long as broad; snout obtusely pointed, feebly projecting, as long as the upper eyelid, much deeper than long; canthus rostralis very distinct; loreal region distinctly oblique, concave; nostril a little nearer to tip of snout than to eye; interorbital space narrower than the upper eyelid; tympanum very distinct, $4 / 5$ the width of the eye. Disks of fingers and toes very small, not more than about $1 / 5$ the diameter of the tympanum; first finger much longer than second, which is longer than fourth; third toe as long as fifth; toes $2 / 3$ webbed, two phalanges of fourth, and one phalanx of the other ones being free; subarticular tubercles very prominent; a distinct, oval inner and a very small, round outer metatarsal tubercle; the heel reaches the nostril; tibia about $1 / 2$ the length of head and body.

Skin finely granulate above; a very narrow, but prominent glandular dorsolateral fold; some narrow oblique folds on the back; lower parts smooth; posterior surfaces of thighs granular. From snout to vent $\sigma_{3} \mathrm{~mm}$.

Dark brown above; temporal region and cross-bands on the limbs black. Lower parts lighter, uniform.

Male with internal vocal sacs and humeral glands.

I examined the specimen described by Werner and Roux and now preserved in the Basle museum. The species is nearly related to $R$. temporalis from Malabar, but distinguished by the position of the vomerine teeth, and the shorter web between the toes. From R. nicobariensis it may be distinguished by the broader head and the narrower interorbital space.

Habitat: Sumatra (Laut tador!).

\section{Rana nicobariensis (Stol.).}

?Hyla bilineata Daudin, Hist. Nat, des Rainettes....., Paris, I8oz, p. I7, pl. II. Hylorana Nicobariensis Stoliczla, Jrn. Asiat. Soc. Bengal, XXXIX, pt. 2, 187o, p. 150, pl. IX, fig. 2 .

Rana macularia var. javanica Horst, Notes Leyden Mus., V, 1883, p. 243.

Rana erythraca var. clongata Werner, Jahresber. Ver. Magdeburg (I892), 1893, p. 253 .

Rana lemniscata Boettger, Zool. Anz., XVI, 1893, p. 337.

Rana tytleri (part.), Isenschmid (nec Theob.), Mitth. naturf. Ges. Bern, I903, p. 72. Rana javanica v. Kampen, Weber's Zool. Ergebn., Leiden, IV, I907, p. 392.

Rana javanica v. Kampen, Nat. Tijdschr. Ned.-Indië, LXIX, I909, p. 36 (tadpole).

Rana nicobariensis Boulenger, Vert. Fauna Malay Penins., Rept. and Patr., London, 1912, p. 240. 
Rana javanica Annandale, Jrn. Feder. Malay States Mus., VII, 1917, p. 108. Rana nicobaricnsis Boulenger, Rec. Ind. Mus., XX, 1920, p. 162.

Vomerine teeth in two oblique groups or short series between the choanae or extending a little beyond their hinder borders. Head longer than broad; snout more or less pointed, projecting, as long as to nearly twice the length of the upper eyelid; canthus rostralis distinct; loreal region nearly vertical, concave; nostril nearer to tip of snout than to eye; interorbital space as broad as to about $\mathrm{I}^{1} / 2$ times the width of the upper eyelid; tympanum distinct, $3 / 5$ to $4 / 5$ the diameter of the eye. Fingers and toes slender, with small, but distinct disks, first finger extending beyond second, which is shorter than fourth; toes $1 / 2$ to $2 / 3$ webbed; first and second toe nearly free or webbed to the tip of the first phalanx; of the third and fifth toe two phalanges may be free or the web may reach to the disks; of the fourth toe 2 or 3 phalanges are free; outer metatarsals separated nearly to the base; subarticular tubercles distinct; a small, oval inner, and a round outer metatarsal tubercle; no tarsal fold; the heel reaches the nostril or the tip of the snout; tibia $1 / 2$ to $3 / 5$ the length from snout to vent; when the hind limbs are folded at right angles to the body, the heels are strongly overlapping.

Smooth or finely granular above, back and sides sometimes with a few small warts; a narrow or moderately broad dorsolateral fold; another fold from the upper lip to below the tympanum, followed by a wart; posterior part of thighs granulate; smooth beneath.

Greyish or reddish brown above, uniform or with dark spots, which in the middle of the back may be united into a more or less distinct longitudinal streak, bifurcating in the sacral region; sides of head and usually of body also dark brown or black; a white streak along the upper lip; dorsolateral folds whitish; a light vertebral line may be present; hind limbs with dark cross-bars, posterior surface of thighs spotted with dark; whitish beneath, uniform or spotted with brown; an oblique brown streak on the shoulder. From snout to vent $55 \mathrm{~mm}$.

Male with internal vocal sacs and a flat, oval gland on the upper arm.

The Javanese specimens ( $R$. javanica Horst) are generally distinguished especially by a narrow web between the toes, great length of the snout and broaci interorbital spare; after INDO-AUSTRALIAN AMPHIBIA. 
Boulenger, however, the extremes are connected by intermediate forms.

At Batavia.I found this species in brackish water near the sea, where it seems to depose its spawn in the small cisterns of rain water, contained in the axils of the leaves of the Nipa-palm (Nipa fruticans).

T a d pole. - The following tadpoles of Java (Djampang tengah in the Preanger Regencies) seem to belong to this species ${ }^{1}$ ):

Length of body once and a half its width; tail twice the length of the body, about $3 \frac{1}{2}$ times as long as deep. Nostril as far from the tip of the snout as from the eye; eyes superior, nearer to the tip of the snout than to the spiraculum, the distance between them greater than that between the nostrils and than the width of the mouth; spiraculum sinistral, directed upwards and backwards, visible from above and from below, much nearer to the vent than to the tip of the snout; vent dextral, near to the lower border of the tail. Tail pointed; upper crest twice as deep as the lower one, extending to the base of the tail.

Mouth ventral; lower lip and sides of upper one with papillae; along the lower lip they are arranged in three not interrupted series; jaws narrowly edged with black; series of teeth I $/{ }^{1}{ }^{I}{ }^{1}$, the inner series of the lower lip hardly interrupted.

Body and tail, including the crests, grey, darker marbled; belly colourless.

H a bitat: Simalur isl.!; Pulo Babi !; Nias!; Mentawei islands (Sipora); Engano isl.; Sumatra (Deli; Gunung Sahilan!; Fort de Kock!; Sandaran Agung, $730 \mathrm{~m}$., in Kurintji valley; Sungei Kumbang, 1430 m., Kurintji peak; Tandjung Laut, Palembang!); Borneo (Bongon); Java (Batavia!; Mt. Salak; Tjibodas!; MIt. Malabar, I 500 m.!; Tjisurupan). - Nicobars; Tenasserim; Malay Peninsula.

\section{Rana signata (Gthr.).}

Poly'pedates signatus Günther, Proc. Zool. Soc. London, I872, p. 600, pl. XL, fig. C. Rana signata Boulenger, Cat. Batr. Sal. Brit. Mus, 1882, p. $7 \mathrm{I}$.

Rana obsoleta Mocquard, Nouv. Arch. Mus. d'Hist. nat., (3) II, 1890, p. 147. Rana moellendorffi Boettger, Zool. Anz., XVI, I893, p. 363.

1) Boulenger (1.c., I920) describes tadpoles from Tenasserim, not certainly belonging to this species, which are entirely different from those described by me from Java. 
Rana signata Boulenger, Vert. Fauna Malay Penins., Rept. and Batr., London, 1912, p. 237.

Rana signata and picturata Boulenger, Rec. Ind. Mus., XX, 1920, p. 177, 179. Rana moellendorffi Taylor, Philipp. Jrn. of Sc., XVI, I920, p. 270, pl. I, fig. 4.

Vomerine teeth in two short, oblique series or groups between the choanae, or just behind them. Head as long as broad or a little longer; snout rounded or rather pointed, feebly projecting, as long as or a little shorter than the upper eyelid; canthus rostralis distinct; loreal region feebly oblique, concave; nostril nearer to tip of snout than to eye; interorbital space a little narrower to a little broader than the upper eyelid; tympanum very distinct, $3 / 5$ to $3 / 4$ the width of the eye. Fingers and toes with small disks; first finger extending beyond second; toes $2 / 3$ or $3 / 4$ webbed, the web reaching or not quite reaching the disks of third and fifth toe, two phalanges of fourth toe free; outer metatarsals separated nearly to the base; subarticular tubercles well developed; a small, oblong inner and a small, round outer metatarsal tubercle; no tarsal fold; the heel reaches the tip of the snout or between eye and tip of snout; tibia a little more than half the length from snout to vent; when the hinds limbs are folded at right angles to the body, the heels are overlapping.

Skin smooth or granular above; a flat dorsolateral glandular fold, which may be little distinct or absent, or represented by a chain of large warts; smooth beneath.

Back and sides dark olive to black, sometimes with scattered small light spots or large yellow or pale brown spots or marblings, or olive, largely spotted or marbled with black; a light line from the tip of the snout along the canthus rostralis and the border of the upper eyelid, usually continued, uninterrupted or as a series of oblong spots, along each side of the back; a light streak or small yellowish spots on the upper lip may be present; hind limbs with light cross-bars, or orange spotted or barred with black; brownish beneath, uniform, or spotted with white, or with dark marblings. In life the light lines and spots are emerald green and red. From snout to vent $70 \mathrm{~mm}$.

Male with internal vocal sacs and a more or less distinct oval humeral gland.

With $R$. signata I have united $R$. picturata Blgr. from Borneo: the description of Boulenger gives only very slight differences with $R$. signata, the principal one being the shape of 
the head, which in $R$. picturata is as long as broad (a little longer than broad in $R$. signata).

Habitat: Sumatra (Mt. Simbolon; Airbangis!); Borneo (Mt. Kina Balu; Lawas, Brunei; Akar riv. and Bidi caves, Serawak; Matang; Barabai). - Malay Peninsula; Philippines.

\section{Ceratobatrachus Blgr.}

(Boulenger, Proc. Zool. Soc. London, 1884, p. 212).

Pupil horizontal. Tongue deeply notched and extensively free behind. Vomerine teeth present; lower jaw with teeth. Tympanum distinct. Fingers free, toes nearly so, the tips not dilated. Outer metatarsals united.

Omosternum and sternum with a bony style, the first bifurcated at the base. Terminal phalanges simple.

Distribution: Solomon islands.

\section{Ceratobatrachus guentheri Blgr.}

Ceratobatrachus Guentheri Boulenger, Proc. Zool. Soc. London, I884, p. 212. Ceratobatrachus Guentheri Boulenger, Transact. Zool. Soc. Londun, XII, pt. 2, I886, p. 56, pls. XII and XIII.

Tongue large, free in its posterior half; vomerine teeth in two short, transverse, sometimes crescentic series behind the level of the choanae; teeth of upper jaw minute, of lower jaw larger, conical, acute, slightly directed backwards, inserted on the edge of the mandible. Head very large, strongly depressed, broader than long, its length contained $\mathrm{I}^{2} / 5$ to $\mathrm{I}^{3 / 5}$ in the length of the body; snout not projecting, $\mathrm{I} / 4$ to $\mathrm{I} 1 / 3$ the diameter of the orbit; canthus rostralis distinct, straight; loreal region very oblique, concave; nostril twice as far from eye as from tip of snout; interorbital space much broader than the upper eyelid, deeply concave; tympanum distinct, vertically elliptic, nearly as large as the eye. Tips of fingers and toes slightly swollen; first finger much longer than second, which is slightly shorter than fourth; fifth toe much shorter than third; toes with a very slight rudiment of web; subarticular tubercles very strong; of toes smaller than of fingers; an inner large, oval, a little compressed and very prominent metatarsal tubercle, and an outer small, rather indistinct one; the heel reaches the posterior border of the eye, or between the latter and the tympanum; tibia nearly as long as the head. 
The skin may be adherent to the skull on the cheeks and the fronto-parietal region; it has some prominent ridges, and a small spine, curved forwards, at the angle of the mouth; back with more or less numerous short glandular folds and generally a pair of very prominent narrow curved ridges from the upper eyelid along the middle of the back; a triangular dermal flap on the tip of the snout, another one on the edge of the upper eyelid, and a smaller one above the vent and at the heel; a curved dermal ridge between the eyes; a fold above the tympanum; a small, frequently denticulated fringe a!ong the outer side of tarsus and fore-arm; throat and belly granular.

Colouration very variable. Upper parts yellowish, pinkish, brown, black, grey or olive, variously marked with darker and lighter; a black temporal band, two short black longitudinal bands on the middle of the back, and a black crossband between the eyes may be present; sometimes with a broad light band along each side of the back and between the eyes, or with whitish dots; limbs with dark cross-bars; hinder side of thighs, and lower surface of foot and tarsus dark; lower surfaces brownish, dotted or clouded with dark brown; throat generally dark brown, sometimes with white dots; a pair of round white spots on the breast; axilla and groin bright yellow. From snout to vent $\sigma^{7} 75$, $96 \mathrm{~mm}$.

Male with two internal vocal sacs.

Eggs very large, development probably without tadpole.

Habitat: Solomon islands.

\section{Oreobatrachus Blgr.}

(Boulevger, Ann. Mag. Nat. Hist., (6) XVII, r896, p. 40r).

Pupil horizontal. Tongue small, oval, very slightly notched and free behind. Vomerine teeth none. A strong transverse dermal fold between the choanae. Tympanum hidden. Fingers free, toes webbed, the tips dilated into small disks. Outer metatarsals separated by web.

Omosternum and sternum with a bony style. No intercalary ossicle between the penultimate and distal phalanges; the latter T-shaped.

Distribution: Borneo.

Oreobatrachus baluensis Blgr.

Oreobatrachus bahuensis Boulenger, Ann. Mag. Nat. Hist., (6) XVII, I896, p. 40I, pl. XVII, figs. I, I $a$. 
Head small; snout obtusely pointed, shorter than the orbit; no canthus rostralis; nostril equally distant from the eye and the tip of the snout; interorbital space as broad as the upper eyelid. Fingers short, first and second equal; hind limb stout; toes moderate, $3 / 4$ webbed; subarticular tubercles very feebly developed; a feebly prominent elliptical inner metatarsal tubercle; the heel reaches the tip of the snout.

Skin smooth.

Dark brown above; limbs with darker cross-bars; a yellowish vertical streak on the tip of the snout and an oblique one from the eye to the angle of the mouth; white beneath, largely marbled with black. From snout to vent $33 \mathrm{~mm}$.

Habitat: Borneo (Mt. Kina Balu, 640 m.).

\section{Oxyglossus Tschudi.}

(Tschudi, Mém. Suc. Sc. nat. Neuchâtel, II, I839, p. 48, 85).

Pupil horizontal. Tongue narrow, entire and free behind. Vomerine teeth none. Tympanum indistinct. Fingers free, toes webbed, the tips not or feebly dilated. Outer metatarsals separated by web.

Omosternum with a bony style; sternum cartilaginous. No intercalary ossicle between the penultimate and distal phalanges; the latter simple.

Tadpoles. - Eyes superior. Spiraculum sinistral. Vent median. Lip small; papillae and teeth absent.

Distribution: Bengal and southern China to the western part of the Indo-Australian Archipelago.

$$
\text { Synopsis of the Species. }
$$

A. Tips of toes dilated. Belly smooth. .......... I. O. Taevis p. 230. B. Toes pointed. Belly warty ............ 2. O. lima p. 232.

$$
\text { Synopsis of the Tadpoles. }
$$

A. Distance between the eyes twice that between the nostrils. I. O. Iaevis p. 230 .

$B$. Distance between the eyes 3 to 4 times that between the nostrils.................... . O. lima p. 232 .

\section{Oxyglossus laevis Gthr.}

Oxyglossiis laeriis Günther, Cat. Batr. Sal. Brit. Mus., 1858 , p. 7, pl. I, fig. A. Microdiscopus sumatranus Peters, Monatsber. Akad. Berlin, IS 77, p. 422, figs.4-4b. Oxyglossus laevis Boulenger, Cat. Batr. Sal. Brit. Mus., I882, p. 6. 
Oxyglossus laevis Boulenger, Proc. Zool. Soc. London, 1897, p. 228 (with tadpole). Oxyglossus laevis Boulenger, Vert. Fauna Malay Penins., Rept. and Batr.,

London, I912, p. 225.

Oxyslossus laevis Taylor, Philipp. Jrn. of Sc., XVI, 1920, p. 230, pl. I, fig. I.

Tongue oval, rounded behind. Head broader than long; snout rounded, feebly projecting, shorter than the upper eyelid, longer than deep; no canthus rostralis; loreal region oblique, flat; nostril equidistant from eye and tip of snout; interorbital space narrower than the upper eyelid; tympanum hidden. Fingers blunt, toes with very small disks; first finger not or

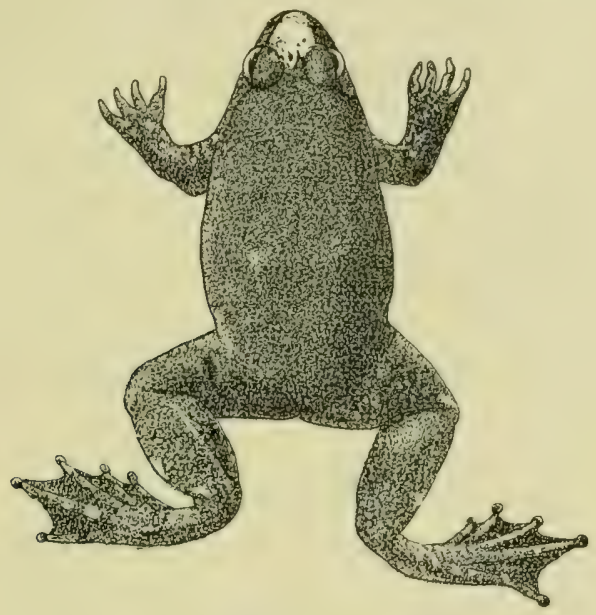

Fig. 26. Oxystossus laevis Gthr., XI.

but slightly extending beyond second, which is as long as fourth; third toe a little longer than fifth; toes entirely or nearly entirely webbed; subarticular tubercles small; inner metatarsal tubercle elliptic, compressed, outer one absent or very indistinct; a short tarsal fold; the heel reaches the temple or the posterior border of the eye, the tarso-metatarsal articulation the tip of the snout or a little beyond; tibia about $2 / 5$ length of head and body.

Skin smooth or with small warts on back and hind limbs.

Brownish above, with or without rather indistinct darker spots; sometimes a light vertebral line, or a light spot on the snout; a light streak from the eye to the commissure of the mouth often conspicuous; hind limbs with dark cross-bands, which may be indistinct; lower parts whitish, throat often speckled with brown. From snout to vent $42 \mathrm{~mm}$. 
Male with an internal vocal sac.

Tadpolc. - Length of body $\mathrm{I}^{1} / 2$ to $\mathrm{I}^{2} / 3$ times its width; tail $2 \frac{1}{2}$ times as long as body, 4 to 5 times as long as deep. Nostril nearer to the eye than to the tip of the snout; eyes superior, nearer to the end of the snout than to the spiraculum, the distance between them twice that between the nostrils; spiraculum sinistral, directed upwards and backwards, equally distant from the eye and the posterior extremity of the body; vent median. Tail acutely pointed, the crests low.

Mouth small, with a horseshoe-shaped lip without horny teeth, the closed mouth appearing as a vertical slit; jaws black.

Olive above, white beneath; tail speckled with dark brown. Length 5 I $\mathrm{mm}$.

Habitat ${ }^{1}$ ): Simalur!; Mentawei islands (Sipora); Sumatra (Laut tador; Gunung Sahilan!; Lahat); Borneo (Mt. Dulit; Baram riv.; Seberuang riv.); Flores; Celebes (S.-Celebes, 600 m.; Luwu; Takalekadjo mts., I $100 \mathrm{~m}$.; Lembongpangi, $520 \mathrm{~m}$; Matinang mts., \pm 250 m.; Mongondou!; Minahasa; Kakas, Tondano lake; Mt. Masarang). — Burma; Siam; Malay Peninsula; Philippines.

\section{Oxyglossus lima (Kuhl).}

Rana lima (Kuhl), Gravenhorst, Deliciae Mus. Zool. Vratislav., Fasc. I, Lipsiae, I 829, p. 4I.

Oxyglossus lima Boulenger, Cat. Batr. Sal. Brit. Mus., I882, p. 5.

Oxyglossus lima Flower, Proc. Zool. Soc. London, 1899, p. 886.

Oxyglossus lima v. Kampen, Weber's Zool. Ergebn., Leiden, IV, 1907, p. 384, pl. XVI, fig. I (tadpole).

Oxyglossus lima v. Kampen, Nat. Tijdschr. Ned.-Indië, LXIX, I909, p. 44, pl. II, fig. 9 (tadpole).

Oxyglossus lima Boulenger, Vert. Fauna Malay Penins., Rept. and Batr., London, 1912 , p. 225, with figs.

Oxyglosszes lima Smith, Jrn. Nat. Hist. Soc. Siam, II, 1917, p. 173 (tadpole; with figs.).

Tongue oblong, pointed behind. Head broader than long; snout rounded or obtusely pointed, shorter than the upper eyelid, as deep as long; no canthus rostralis; loreal region oblique, nearly flat; nostril equidistant from eye and tip of snout; interorbital space narrower than the upper eyelid; tympanum hidden. Fingers and toes acutely pointed; first finger

I) The Museum of Leiden possesses two specimens labelled NJava (Boie and Macklot leg.)". As, however, the species since never has been found in Java, this locality is probably erroneous. 
not extending beyond second, which is as long as fourth; fifth toe extending beyond third and nearly as long as fourth; toes entirely webbea; subarticular tubercles very small; an oval, compressed inner, a smaller, subconical outer metatarsal tubercle, and a small tarsal tubercle near the heel; a short tarsal fold; the heel reaches the eye, the tarso-metatarsal articulation the tip of the snout; tibia $2 / 5$ length of head and body.

Back, lower surfaces and legs with numerous small, conical tubercles of unequal size, the largest ones forming a few longitudinal rows on throat and belly.

Greenish brown above, with small darker markings; sometimes a light (yellow or green) vertebral line; yellow beneath, with a dark brown band on the arm and along the hinder side of the thigh, and sometimes a brown L-shaped mark on each side at the base of the thighs; sometimes a brown band on each side from the chin to the breast. Length $35 \mathrm{~mm}$.

Male with an internal vocal sac.

Tadpole. - Length of body $I^{1} / 3$ to $I^{2} / 3$ times its width; tail about $2 \frac{1}{2}$ times as long as body, about 4 times as long as deep. Snout pointed; nostril equally distant from eye and tip of snout; eyes superior, nearer to the end of the snout than to the spiraculum, the distance between them 3 to 4 times that between the nostrils; spiraculum sinistral, lateral, nearer to the posterior extremity of the body than to the eye; vent median. Tail pointed, the lower crest low, the upper one high, reaching the base of the tail.

Mouth small, terminal, with a horseshoe-shaped lower, and a small upper lip; horny teeth and papillae absent; jaws edged with black.

Whitish, with brown markings; throat with four brown longitudinal bands, the outer ones connected with the eye by a vertical bar; crests of tail with dark spots, which are continued on the upper and lower parts of the muscular portion, which has also a brown lateral streak at its base; belly immaculate. Length $39 \mathrm{~mm}$.

Habitat: Java (Tambun, Bantam; Batavia!; Krawang!; Buitenzorg!; Gadok; Sukabumi!; Djampang!; Gunung Sesuru!; Tjitalahab!; Situ Bagendit!; Kediri!; Pasuruan). - From Bengal and S.-China to Malay Peninsula (and Philippines?). 


\section{Staurois Cope.}

(Cope, Nat. Hist. Review, V, I865, p. I14; Boulexger, Ann. Mag. Nat. Hist., (9) I, I9I8, p. 372).

Pupil horizontal. Tongue deeply notched and free behind. Vomerine teeth absent or feebly developed. Tympanum more or less distinct. Fingers free, toes extensively webbed (the web involving the base of the disks); fingers and toes with large disks, which are broader than long and have a transverse groove across the lower surface, continuous with the groove between the upper and lower surfaces. Outer metatarsals entirely separated by web.

Omosternum and sternum with a bony style. No intercalary ossicle between the penultimate and terminal phalanges; the latter T-shaped.

Tadpoles. - A large sucking disk behind the mouth. Distribution: Malay Peninsula; Philippines; Borneo.

$$
\text { Synopsis of the Species. }
$$

$A$. Tongue without papilla. Vomerine teeth present.

I. Head as long as broad, much depressed ... I. S. larutcnsis p. 234.

II. Head longer than broad, moderately depressed. 2. S. guttatus p. 235 . B. Tongue with papilla. No vomerine teeth.

I. Heel reaching tip of snout or beyond.... 3. S. nubilus p. 236 .

II. Heel reaching between eye and nostril ... 4. S. tuberilinguis p. 237.

Synopsis of the Tadpoles.

A. Both jaws undivided ............... S. larutensis p. 234 . $B$. Upper jaw divided in two pieces ........... S. guttatus p. 235.

\section{Staurois larutensis (Blgr.).}

Rana larutensis Boulenger, Ann. Mag. Nat. Hist., (7) III, I899, p. 273, pl. XI, fig. I. Rana larutensis Laidlaw, Proc. Zool. Soc. London, I900, p. 886, pl. LVII, figs. 3,4 (tadpole).

Rana larutensis Boulenger, Vert. Fauna Malay Penins., Rept. and Batr., London, 1912, p. 245 .

Staurois larutchsis Boulenger, Ann. Mng. Nat. Hist., (9) I, I918, p. 374.

Tongue without papilla; vomerine teeth in two very small groups just behind the level of the choanae. Head as long as broad, much depressed; snout rounded or subacuminate, shorter than the orbit; canthus rostralis sharp; loreal region concave; 
nostril equally distant from eye and end of snout; interorbital space narrower than the upper eyelid; tympanum distinct, $1 / 3$ the diameter of the very large eye. Fingers with large disks, which are larger than the tympanum; disks of toes smaller than those of fingers; first finger shorter than second; toes very broadly webbed; subarticular tubercles feeble; a small, feebly prominent inner, no outer metatarsal tubercle; the heel reaches the tip of the snout or beyond; tibia $3 / 5$ to $2 / 3$ length of head and body.

Skin smooth or faintly granular; a feeble, interrupted dorsolateral fold sometimes present.

Pale yellowish green above, head and body more or less blotched with black; limbs with black transverse bars; white below, the limbs pale green and grey, throat and under surfaces of thighs sometimes marked with black, hands and feet very dark, web between the toes black. From snout to vent $\sigma^{7} 45$, $975 \mathrm{~mm}$.

Male with external vocal sacs.

The eggs are unpigmented.

Tadpole. - A ventral sucking disk extending from the lip to beyond the middle of the abdomen. Jaws minutely serrated, undivided. Series of teeth $5^{4} 5 /{ }^{1} 4^{1}$. Length $65 \mathrm{~mm}$.

Greenish white, mottled with dark green, above; white below. Habitat: Borneo. - Malay Peninsula, up to $\mathrm{I} 500 \mathrm{~m}$.

\section{Staurois guttatus (Gthr.).}

Ixalus guttatus Günther, Cat. Batr. Sal. Brit. Mus., I 858, p. 76 , pl. IV, fig. D. Rana natatrix (part.), Boulenger, Cat. Batr. Sal. Brit. Mus., 1882, p. 7 I.

Ixalues sp. Mocquard, Nouv. Arch. Mus. d'Hist. nat., (3) II, 1890, p. 154, pl. XI, figs. $4-46$ (tadpole).

Rana guttata Boulenger, Ann. Mag. Nat. Hist., (6) XIV, I894, p. 87. Staurois guttatus Boulenger, Ann. Mag. Nat. Hist., (9) I, I918, p. 374.

Tongue without papilla; vomerine teeth in two small oblique groups between the choanae. Head longer than broad, moderately depressed; snout rounded, prominent, long; canthus rostralis angular; loreal region deeply concave; nostril near to the tip of the snout; interorbital space narrower than the upper eyelid; tympanum distinct, about $1 / 3$ to $1 / 2$ the width of the eye. Disks of fingers very large, of toes moderate; first finger shorter than second, which is shorter than fourth; fifth toe longer than third; toes very broadly webbed; subarticular 
tubercles rather small; two small metatarsal tubercles; the heel reaches beyond the tip of the snout.

Skin coarsely granulate above; sometimes a distinct glandular dorsolateral fold; belly finely granular, otherwise smooth below.

Above brown, with large, rounded, sometimes confluent dark-brown spots; legs with dark cross-bars; hinder side of thighs blackish-brown, with a few small lighter spots; web between the toes black. Length $47 \mathrm{~mm}$.

Male with two internal vocal sacs.

Tadpole. - A large sucking disk behind the mouth. Jaws with denticulated borders, the upper one consisting of two pieces.

This tadpole has been referred to Staurois guttatus by Boulenger (Ann. Mag. Nat. Hist., (6) XIV, I894, p. 87). It may belong as well to $S$. mubilus or tuberilingais or to some species of Rana, allied with $R$. whiteheadi.

Habitat: Borneo (Mt. Kina Balu, 900 and I 300 m.; Baram riv.; Mt. Dulit; Seberuang riv.; Matang).

\section{Staurois nubilus Mocq.}

Ixalus nubilus Mocquard, Nouv. Arch. Mus. d'Hist. nat., (3) II, I89o, p. I53; pl. XI, fig. 3 .

Ixalus natutor var. nubilus Mocquard, Mém. Soc. Zool. France, V, 1892, p. 195. Staurois mubilus Boulenger, Ann. Mag. Nat. Hist., (9) I, I9I8, p. 374.

A rounded papilla in the middle of the anterior part of the tongue; vomerine teeth absent. Snout obtuse, projecting, as long as the eye; canthus rostralis angular; loreal region vertical; nostril twice nearer to tip of snout than to eye; interorbital space a little broader than the upper eyelid; tympanum distinct, somewhat more than $1 / 3$ the width of the eye. Fingers and toes with large disks, those of fingers larger than the tympanum; first finger as long as second; toes fully webbed; subarticular tubercles well developed; inner metatarsal tubercle narrow, rather prominent, no outer one; the heel reaches the tip of the snout or beyond.

Upper surfaces coarsely granulate; no fold above the tympanum; smooth beneath.

Dark brown above, uniform or with a few light veins; more or less distinct cross-bars may be present on the hind limbs; lower parts yellowish grey. From snout to vent $45 \mathrm{~mm}$.

Habitat: Borneo (Seberuang riv.). - Pelawan. 


\section{Staurois tuberilinguis Blgr.}

Staurois tuberilinguis Boulenger, Ann. Mag. Nat. Hist., (9) I, I91 S, p. 374.

A large conical papilla in the middle of the anterior third of the tongue; vomerine teeth absent. Head longer than broad, moderately depressed; snout obtusely pointed, strongly projecting, as long as the eye; canthus rostralis sharp; loreal region feebly oblique, deeply concave; nostril a little nearer to the tip of the snout than to the eye; interorbital space as broad as or a little broader than the upper eyelid; tympanum moderately distinct, not quite $1 / 3$ the diameter of the eye. Fingers with very large, toes with smaller disks; first finger longer than second; fourth toe not much longer than fifth; toes fully webbed, the web feebly notched; subarticular tubercles small, feebly prominent; inner metatarsal tubercle oval, flat, $1 / 3$ the length of the inner toe, no outer tubercle; no tarsal fold; heel reaching between eye and nostril; tibia $1 / 2$ length of head and body (from snout to vent), or slightly longer.

Feebly granulate above, with flat glandules on the sides; belly smooth or feebly granulate.

Dark brown above and on the sides, including the upper lip, with a few very indistinct lighter vermicular markings on head and back; limbs with or without rather ill-defined dark cross-bands; hinder side of thighs dark brown, with small yellow spots or vermicular markings; web between toes blackish; lower parts white, throat brown or spotted with brown. From snout to vent $42 \mathrm{~mm}$.

Habitat: Borneo (Mt. Kina Balu, I 300 m.; Mt. Batu Song, Serawak, $300 \mathrm{~m}$.$) .$

\section{Simomantis Blgr.}

(Boulenger, Ann. Mag. Nat. Hist., (9) I, 1918, p. 373).

Pupil horizontal. Tongue deeply notched and free behind. Vomerine teeth absent. Tympanum not very distinct, small. Fingers and toes webbed (web of toes involving part of the disks), with very large disks, which are broader than long and have a transverse groove across the lower surface, continuous with the groove between the upper and lower surfaces. Outer metatarsals entirely separated by web.

Omosternum and sternum with a bony style. No intercalary 
ossicle between the penultimate and terminal phalanges; the latter. T-shaped.

Distribution: Borneo.

\section{Simomantis latopalmata (Blgr.).}

Txalus latopalmatus Boulenger, Ann. Mag. Nat. Hist., (5) XX, 1887, p. 97.

Ixalus latopalmatus Mocquard, Nouv. Arch. Mus. d'Hist. nat., (3) II, I890, p. 152, pl. XI, fig. 2.

Simomantis latopalmata Boulenger, Ann. Mag. Nat. Hist., (9) I, I918, p. 373.

Snout broadly rounded, obliquely truncate, very short; loreal region nearly vertical, concave; interorbital space as broad as the upper eyelid; tympanum not very distinct, very small. Fingers dilated into enormous disks, the width of which equals $3 / 4$ the width of the eye; disks of toes about half the size of those of fingers; a broad web, extending nearly to the disks, between the outer fingers, and a short one between the second and third; toes very broadly webbed, the web enclosing $1 / 2$ of the disks; subarticular tubercles oval, flat; no distinct metatarsal tubercles. Hind limb very long and strong; the knee reaches the shoulder; tibia as long as the distance between tympanum and vent.

Skin finely granulate above, smooth beneath.

Blackish above, with pale brown variegations on the back and whitish dots on the sides; limbs with lighter cross bands; hinder side of thighs blackish, speckled with whitish; lower surfaces whitish. From snout to vent $67 \mathrm{~mm}$.

Habitat: Borneo (Mt. Kina Balu; Lawas).

\section{Cornufer Tsch.}

(Tschudi; Mém. Soc. Sc. nat. Neuchâtel, II, i 839, p. 28 ; Boulenger, Ann. Mag. Nat. Hist., (9) I, I918, p. 372).

Pupil horizontal. Tongue notched and free behind. Vomerine teeth present. Tympanum distinct. Fingers free, toes slightly webbed; tips of fingers, and usually of toes also, with large disks, which have a transverse groove across the lower surface, continuous with the groove between the upper and lower surfaces. Outer metatarsals united.

Omosternum and sternum with a bony style, which in the omosternum is forked at the base. No intercalary ossicle between the penultimate and terminal phalanges; the latter $\mathrm{T}$-shaped. 
Distribution: Burma; Philippines; Borneo; Solomon Islands; Fiji islands.

$$
\text { Synopsis of the Species. }
$$

A. Two metatarsal tubercles.

I. Disks of toes small. .............. C. vitiensis p. 239.

II. Disks of toes large............... . guppyi p. 240 .

$B$. One metatarsal tubercle.

I. Heel reaching beyond tip of snout....... 3. C. unicolor p. 240.

II: Heel reaching the nostril ............ C. baluensis p. 24 I.

\section{Cornufer vitiensis (Girard).}

Halophila viticnsis Girard, Proc. Acad. Nat. Sc. Philadelphia (1852/53), I854, p. 423 .

Cornufer dorsalis Boulenger (nec Duméril), Cat. Batr. Sal. Brit. Mus., I882, p. Io8, with figs.

Cormufer dorsalis Boulenger, Proc. Zool. Soc. London, I887, p. 337.

Vomerine teeth in two oblique groups behind the level of the choanae. Snout $I^{1 / 3}$ the length of the orbit; canthus rostralis angular; interorbital space as broad as the upper eyelid; tympanum very distinct, half the width of the eye. Disks of fingers large, of toes small; first finger shorter than second; third toe longer than fifth; toes webbed at the base; subarticular tubercles well developed, two metatarsal tubercles; the heel reaches beyond the eye.

Skin smooth, belly and lower surface of thighs granular; a small tubercle on the upper eyelid.

Greyish or reddish brown above, with more or less distinct blackish markings on the back; sometimes a light line along the middle of the head and along the hind limbs; hind limbs with black cross-bars; lower surfaces more or less marbled with brown.

Boulenger identifies Halophila vitiensis. Girard with Cormufer dorsalis, described by A. Duméril (Ann. Sc. Nat., (3) XIX, I853, p. I74) from Java. The type specimen of the latter, however, preserved in the Paris museum, and examined by me, does not agree with the species of the Fiji islands, after the description of Boulenger, having small digital disks, first finger longer than second, the heel reaching beyond the tip of the snout and longitudinal folds on the back; the tongue bears a papilla. It is a species of Rana (Platymantis), the nearest 
ally of which seems to be Rana (Platymantis) meyeri Gthr. from the Philippines. The locality Java certainly is incorrect; probably it is a Philippine species (see Peters, Monatsber. Akad. Berlin, 1873 , p. 61 I).

Barbour (Proc. New England Zoöl. Club, VII, I921, p. 97) suggests that the specimens, mentioned from the Solomon islands by Boulenger, belong to $C$. guppyi; $C$. vitiensis then should be an inhabitant of the Fiji islands only.

Habitat: Solomon islands. - Fiji islands.

\section{Cornufer guppyi Blgr.}

Cornufer guppyi Boulenger, Proc. Zool. Soc. London, I884, p. 211.

Cornufer Guppyi Boulenger, Transact. Zool. Soc. London, XII, I886, p. 53, pl. XI, fig. I.

Tongue without papilla; vomerine teeth in two short transverse or slightly oblique series behind the level of the choanae. Head large, much depressed, a little broader than long, its length a little more than $1 / 3$ the length of head and body; snout rounded, not projecting, a little longer than the upper eyelid; canthus rostralis distinct, slightly curved; loreal region very oblique, concave; nostril much nearer to tip of snout than to eye; interorbital space plane, as broad as the upper eyelid; tympanum very distinct, $3 / 5$ the diameter of the eye. Disks of fingers very large, of outer fingers nearly as large as the tympanum; disks of toes large, but a little smaller than those of fingers; first finger shorter than second, which is as long as fourth; toes $1 / 3$ webbed; subarticular tubercles moderate; two rather indistinct, much flattened metatarsal tubercles; the heel reaches the anterior corner of the eye.

Smooth, belly and lower surface of thighs granular; a fold above the tympanum.

Greyish brown or pinkish above, spotted or dotted with brown; limbs cross-barred; lower surface whitish. Length more than $100 \mathrm{~mm}$.

Male with internal vocal sacs.

Habitat: Solomon islands.

3. Cornufer unicolor Tschudi.

Cornufer unicolor (part.) Tschudi, Mém. Soc. Sc. nat. Neuchâtel, II, 1839, p. 28. Cormufer unicolor Boulenger, Cat. Batr. Sal. Brit. Mus., 1882, p. 107.

Tongue feebly notched; vomerine teeth behind the level of 
the choanae. Head much depressed, as long as broad; occiput longitudinally concave, with a median crest; canthus rostralis angular; loreal region high, oblique; eye large, prominent; tympanum $2 / 3$ the width of the eye. Fingers and toes slender, with rather large disks; first and second finger equal; third toe a little shorter than fifth; toes webbed at the base; a feeble inner metatarsal tubercle; the heel reaches beyond the tip of the snout.

Upper eyelid with a conical tubercle; a fold above the tympanum; breast and belly granular.

Dark brown above, lighter beneath.

I suggest that this species is based on specimens of Rana rugata. Habitat: New Guinea.

\section{Cornufer baluensis Blgr.}

Cornufer baluensis Boulenger, Ann. Mag. Nat. Hist., (6) XVII, I8g6, p. 449. Rana sariba Shelford, Ann. Mag. Nat. Hist., (7) XV, 1905, p. 209.

Cormufer baluensis Boulenger, Ann. Mag. Nat. Hist., (9) I, 1918, p. 373.

Vomerine teeth in two oblique groups behind the level of the choanae. Snout rounded, as long as the upper eyelid; canthus rostralis obtuse; loreal region concave; interorbital space nearly as broad as the upper eyelid; crown flat; tympanum $2 / 3$ the width of the eye. Fingers and toes with welldeveloped disks, which are much smaller than the tympanum; first finger a little shorter than second; toes $1 / 3$ webbed; subarticular tubercles moderate, feebly prominent; a feebly prominent oval inner metatarsal tubercle, as long as the inner toe without the disk; no outer metatarsal tubercle; the heel reaches the nostril.

Upper parts and throat granulate, some of the granules confluent into wavy, longitudinal, short ridges; belly and lower surface of limbs smooth.

Greyish brown above, marbled with darker; limbs with rather irregular dark cross-bars; whitish beneath, throat and lower surface of limbs marbled with brown. From snout to vent $35 \mathrm{~mm}$.

Habitat: Borneo (Mt. Kina Balu; Mt. Saribau, Serawak).

\section{Batrachylodes Blgr.}

(Boulenger, Proc. Zool. Soc. London, 1887, p. 337).

Pupil horizontal. Tongue oval, feebly nicked and free behind. INDO-AUSTRALIAN AMPHIBIA. 
No vomerine teeth. Tympanum distinct. Fingers and toes free, the tips dilated into large disks. Outer metatarsals united ${ }^{1}$ ).

Omosternum and sternum with a bony style. No intercalary ossicle between the penultimate and terminal phalanges ${ }^{1}$ ); the latter T-shaped.

Distribution: Solomon islands.

\section{Batrachylodes vertebralis Blgr.}

Batrachylodes vertebralis Boulenger, Proc. Zool. Soc. London, 1887, p. 337, pl. XXVIII, fig. 3 .

Batrachylodes vertebralis Barbour, Proc. New England Zoöl. Club, VII, I 92 I, p. 95.

Snout obtuse, short; loreal region nearly vertical; nostril nearer to the tip of the snout than to the eye; interorbital space broader than the upper eyelid; tympanum $3 / 5$ the width of the eye. Disk of third finger as large as the tympanum, disks of toes smaller than those of fingers; first finger shorter than second; subarticular tubercles fecble; a rather indistinct oval inner metatarsal tubercle; the heel reaches the posterior border of the eye.

Skin smooth.

Brown or yellowish above; a fine whitish vertebral line, continued along the upper surface of the thigh and the outer side of tibia and tarsus, and a whitish line on the canthus rostralis and continued behind the eye to the groin, may be present; side of head and anterior half of body sometimes dark brown; indistinct brown bands across the limbs; lower parts white or yellow. From snout to vent $30 \mathrm{~mm}$.

Habitat: Solomon islands.

9. Rhacophorus Kuhl \& v. Hass.

(KuHL en v. HaSselt, Alg. Konst- en Letter-bode, 1822, p. 104).

Polypedates Tschudi, Mém. Soc. Sc. Neuchâtel, II, 1839, p. 75.

Pupil horizontal. Tongue deeply notched and free behind. Vomerine teeth present ${ }^{2}$ ). Tympanum usually distinct. Fingers free or webbed, toes webbed; tips of fingers and toes with disks. Outer metatarsals separated by web.

Omosternum and sternum with a bony style. An intercalary ossicle between the penultimate and terminal phalanges; the latter generally bifurcate.

I) After a communication by Dr. Boulenger.

2) Except sometimes in $R /$ 。 edentulus. 
Tadpoles. - Eyes lateral or superior. Spiraculum sinistral. Vent dextral, at some distance above the lower edge of the subcaudal crest. Upper crest of tail not extending beyond base of tail. Mouth normal; papillae absent along the upper border of the upper lip; series of teeth 4 to $7 / 3$.

Distribution: Madagascar; E.- and S.E.-Asia; western part of the Indo-Australian Archipelago, including Celebes.

\section{Synopsis of the Species.}

A. Fingers free. Back with rough warts. .... 1. Rh. leprosus p, 244 .

$B$. Fingers webbed at the base.

I. Tympanum more than half the width of the eye.

I. A bony crest above the tympanum... 2. Rh. otilophus p. 245 .

2. Head without crests.

a. Tympanum smaller than the eye.

$\alpha$. Skin of the head coossified with the skull .............. 3. Rh. leucomystux p. 246, 249 .

B. Skin of the head not ossified ... 4. Rh. colletti p. 250.

b. Tympanum as large as the eye.... 5. Rh. macrotis p. $25 \mathrm{I}$.

II. Tympanum not more than half the width of the eye.

I. The heel reaches a little beyond the tip of the snout, with a tubercle ....6.6. Rh, everetti p. $25 \mathrm{I}$.

2. The heel reaches far beyond the tip of the snout, with a tubersle...... 7. Rh. macroscelis p. 252.

3. The heel reaches far beyond the tip of the snout, without tubercle ..... 8. Rh. hosii p. 253 .

$C$. Fingers (at least the outer ones) $1 / 3$ webbed, or more, the web not reaching disk of third finger.

I. Head with four spine-like processes.... 9. Kh. georgii p. 253 .

II. Head smooth.

I. Heel with dermal appendage.

a. The heel reaches beyond the tip of the snout ............... Io. Rh. javanus p. 254 .

$b$. The heel does not reach beyond the tip of the snout.

a. Outer fingers $1 / 3$ webbed...... II. Rh. appendiculatus p. 255 .

$\beta$. Outer fingers $1 / 2$ webbed...... I2. Rh. poecilonotus p. 256 .

$\gamma$. Outer fingers about $2 / 3$ webbed ... 13. Rh. bifasciatus p. 257 .

$\delta$. Fingers nearly entirely webbed ... 14. Rh. dulitensis p. 258 .

2. Heel without dermal appendage. 
a. Outer fingers $1 / 3$ webbed. Vomerine teeth normally developed ........ 15. R\%. modestus p. 259.

b. Outer fingers half webbed. Vomerine teeth very reduced or absent..... 16. Rh. cdentulus p. 259.

c. Outer fingers $2 / 3$ webbed. Vomerine teeth normally developed.

$\alpha$. Interorbital space broader than the upper eyelid.......... 17. Rh. acutirostris p. 260.

$\beta$. Interorbital space as broad as the upper eyelid........... 18. Rh. monticola p. $26 \mathrm{r}$.

$D$. The web between the fingers reaches at least the disks of the three outer ones.

I. Hind limbs with dark cross-bars.

1. Snout pointed.

a. Disks of fingers much smaller than tympanum ........... 19. Rh, shelfordi p. 262 .

b. Disks of fingers nearly as large as tympanum ............20. Rh. fasciatus p. 262.

2. Snout rounded ..........2 I. Rh. pardalis p. 263 .

II. Hind limbs without dark cross-bars.

I. The web does not reach the disk of the first finger. . . . . . . . 22, Rh. reinzvardti p. 264 .

2. The web reaches the disk of the first finger. 23. Rh. nigropalmatus p. 266.

\section{Synopsis of the Tadpoles.}

A. Eyes lateral. Series of teeth 4 to $5 / 3$.

I. Spiraculum in the middle between end of snout and vent............... 2. Rh. otilophus p. 245 .

II. Spiraculum nearer to the vent than to the tip of the snout............... 3. Rh. leucomystax p. 246. $B$. Eyes superior. Series of teeth 6 to $7 / 3$.

I. Tail pointed ............ $\left\{\begin{array}{l}\text { Io, Rh, javanus? p. } 254 . \\ \text { I8. Rh. monticola? p. } 26 \text { I. }\end{array}\right.$ II. Tail rounded.............. 22. Rh, reinwardti p. 264 .

\section{Rhacophorus leprosus (S. Müll.).}

Theloderma leporosa (S. Müller), Tschudi, Mém. Soc. Sc. Neuchâtel, II, 1839, p. 73. Hyla leprosa Schlegel, Abbild. neuer oder unvollst. bek. Amph., Düsseldorf, $1837-44$, p. 105.

Hyla leprosa Schlegel, Handl.'Dierk., Breda, I858, II, p. 55, pl. IV, fig. 68. Theloderma leprosa Horst, Notes Leyden Mus., V, I883, p. 237.

Polypedates leprosus Günther, Ann. Mag. Nat. Hist., (5) XX, 1887, p. 315, pl. XVI, figs. A, $a, a^{1}$. 
Rhacophoras leprosus Boulenger, Vert. Fauna Malay Penins;, Rept. and Batr,

London, I912, p. 247 .

Vomerine teeth in two short, nearly transverse series close to the inner front edges of the choanae. Head broader than long; snout rounded, vertically truncate, as long as the upper eyelid, longer than deep; canthus rostralis rounded; loreal region very oblique, feebly concave; nostril close to the end of the snout; interorbital space as broad as or a little broader than the upper eyelid; tympanum very distinct, $3 / 4$ diameter of eye. Diameter of disks of outer fingers half to nearly as large as the width of the tympanum, those of first finger and toes smaller; first finger shorter than second, which is shorter than fourth; fingers free; third toe as long as fifth; toes nearly entirely webbed, the web reaching the disks of third and fifth, third phalanx of fourth toe included by a narrow fringe; subarticular tubercles well developed; a small inner metatarsal tubercle; the heel reaches between eye and tip of snout; tibia half length of head and body.

Upper parts entirely covered with very prominent, rough warts of different sizes; lower parts of head and body, arms and thighs granular.

Colour in life chocolate-brown above, the top of the warts paler, some of those on the back yellow; jet-black beneath, marbled with pale bluish grey; lower surface of fingers and toes, interdigital web, and disks bright rose-red. From snout to vent $65 \mathrm{~mm}$.

Male without vocal sac.

Type specimen examined in the Leiden Museum ${ }^{1}$ ).

Habitat: Sumatra (near Padang!). - Malay Peninsula, $800-\mathrm{I} 370 \mathrm{~m}$.

\section{Rhacophorus otilophus Blgr.}

Rhacophorus otilophus Boulenger, Proc. Zool. Soc. London, 1893, p. 527, pl. XLIV (with tadpole).

Rhacopliorus otilophus v. Kampen, Zool. Jahrb., Syst., XXII, 1905, p. 705.

Vomerine teeth in two small oblique series close to the inner anterior edge of the large choanae. Head much depressed,

I) The type specimen has the longue pointed and not notched behind, as already stated by Tschudi and Horst. It is however clearly visible, that this condition has been caused by lesion. 
large, a little broader than long; snout pointed, a little longer than the orbit; canthus rostralis sharp; loreal region deeply concave; nostril close to the tip of the snout; interorbital space a little broader than the upper eyelid; tympanum nearly as large as the eye. Disks of fingers rather large, of toes smaller; fingers with a rudimentary web; toes $2 / 3$ webbed; the heel reaches between the eye and the nostril.

Skin adherent to the rugose frontoparietals; a strong spinose bony crest above the tympanum; a spine at the angles of the jaws; back finely, belly and lower surface of thighs coarsely granulate; heel, and sometimes the elbow, with a small triangular dermal appendage.

Pale olive above, with dark grey spots and longitudinal streaks; hind limbs with dark cross-bars. Length $80 \mathrm{~mm}$.

Male with internal vocal sacs.

Tadpole. - Length of body $\mathrm{I}^{1} / 2$ to $\mathrm{I}^{2} / 3$ times its width, $3 / 5$ to $4 / 5$ the length of the tail, which is $21 / 3$ to 3 times as long as deep, the depth of the muscular portion being about $3 / 5$ of the total depth. Nostril nearer to the end of the snout than to the eye; eyes lateral, equally distant from the spiraculum and the end of the snout or a little nearer to the former, the distance between them $2 \frac{1}{2}$ to 3 times that between the nostrils, and $21 / 4$ to $2 \frac{1}{3}$ times the width of the mouth; spiraculum sinistral, directed upwards and backwards, equidistant from the end of the snout and the vent; vent dextral, above the lower edge of the tail. Tail acutely pointed.

Lower border of lips with papillae; jaws black; series of teeth $3^{1} 3 / 3$. Length $80 \mathrm{~mm}$.

$\mathrm{Hab}$ it at: Sumatra (district Palembang!); Borneo (Bongon, N.-Borneo; Baram; Serawak).

\section{Rhacophorus leucomystax (Kuhl).}

Hyla leucomystax (Kuhl), Gravenhorst, Deliciae Mus. Zool. Vratislav., Fasc. I, Lipsiae, 1829, p. 26.

Hyla leucomystax Schlegel, Abbild. neuer oder unvollst. bek. Amph., Düsseldorf, 1837-44, p. 140, pl. L, figs. I, 2, 4.

Rhacophorus maculatus (part.), Boulenger, Cat. Batr. Sal. Brit. Mus., 1882, p. 83 . Hylorana longipes Fischer, Arch. f. Naturgesch., LI, I, I885, p. 47.

Rhacophorus leucomystax Boulenger, Proc. Zool. Soc. London, I889, p. 29, with fig. of skull.

Rhacophorus leucomystax Flower, Proc. Zool. Soc. London, 1896, p. 474, pl. XLIV, fig. 2 (with tadpole). 
Rhacophorus leucomystax Flower, Proc. Zool. Soc. London, I899, p. 898, pl.

LIX, figs. $3,3 a$ (with tadpole).

Rhacophorus leucomystax v. Kampen, Weber's Zool. Ergebn., Leiden, IV, I907, p. 399 (with tadpole).

Rhacophorus leucomystax Boulenger, Vert. Fauna Malay Penins., Rept. and

Batr., London, 19r2, p. 248.

Rhacophorus maculatus leucomystax Annandale, Rec. Ind. Mus., VIII, I912, p. I4.

Vomerine teeth in two more or less oblique series between the choanae, beginning close to the inner front edge of the latter. Head as long as broad; snout obtusely pointed, projecting, about as long as the upper eyelid; canthus rostralis angular, straight; loreal region nearly vertical, concave; nostril much nearer to end of snout than to eye; interorbital space in adult specimens $1 \frac{1}{2}$ to 2 times the width of the upper eyelid, narrower in the young; tympanum very distinct, $2 / 3$ to $3 / 4$ the diameter of the eye. Disks of fingers rather large, smaller than the tympanum; disks of toes smaller than those of fingers; first finger shorter than second, which is much shorter than fourth; fingers with a slight rudiment of web, toes $2 / 3$ webbed, the web reaching the disks of $3^{\mathrm{d}}$ and $5^{\text {th }}$ toe or nearly so far; last two phalanges of $4^{\text {th }}$ toe only included by a narrow fringe; subarticular tubercles well developed; a small inner metatarsal tubercle; a rudimentary outer metatarsal tubercle rarely present '); the heel reaches at least the eye, sometimes beyond the tip of the snout; tibia $1 / 2$ to $3 / 5$ the length of head and body.

Skin co-ossified with the frontoparietalia, and, in older spe. cimens, usually with the nasalia and paraquadrata (squamosa) too (in very young specimens, up to about $35 \mathrm{~mm}$. in length, the skin is free from the skull); finely granulate above; a fold above the tympanum; belly and lower surface of thighs coarsely granulate.

Coloration very variable, even in the same individual. Upper parts grey, yellow, bronze, brown, reddish, or greenish, usually spotted or mottled with brown or black; sometimes a black streak from the temporal region backwards and a few dark spots on the sides; edges of jaws white; limbs with dark cross-bars; hinder side of thighs uniform or light-spotted; lower parts white or buff, throat and breast sometimes with dark vermiculation. From snout to vent $8 \mathrm{I} \mathrm{mm}$.

Male with internal vocal sacs.

I) In specimens from Saleyer and Timor. 
Tadpole. - Length of the body $1 \frac{1 / 2}{2}$ to 2 times its width; tail $I \frac{1}{2}$ to 2 times the length of the body, or more, $2 \frac{1}{2}$ to rather more than 3 times as long as deep; the depth of the muscular portion at its base rather more than half the largest total depth. Nostril nearer to the end of the snout than to the eye; eyes lateral, nearer to the spiraculum than to the tip of the snout, the distance between them more than twice that between the nostrils, and much larger than the width of the mouth; spiraculum sinistral, visible from above and from below, directed upwards and backwards, nearer to the vent than to the tip of the snout; vent dextral. Tail acutely pointed, the upper crest of about the same depth as the lower one or shallower, not extending on the back.

Lips with papillae along the sides and the lower border, except along a small notch in the centre of the lower lip; jaws edged with black; series of teeth $3^{1} 3 / 3$ or $4^{1} 4 / 3$, the inner one of lower lip sometimes narrowly interrupted.

Brown or dirty buff above, irregularly mottled with darker; beneath white or buff; sides and tail buff, mottled with brown; crests colourless. Length $46 \mathrm{~mm}$.

From the sea-level to high up in the mountains.

The eggs are $\mathrm{I}^{1} / 2 \mathrm{~mm}$. in diam., unpigmented (Siedlecki). The spawn is deposited on the edge of small pools or on leaves or other objects above them; the tadpoles fall into the water, where the further development takes place.

Habitat: Simalur isl.!; Babi isl.!; Ulau Lekon!; Nias!; Sumatra (Atjeh; Langkat!; Medan!; Brastagi, Karo highland, I 400 m.!; Laut tador; Toba lake; Andalas!; Kalung!; Fort de Kock; Panjinggahan!; Sidjundjung; Muaralabu; Sandaran Agung, 7 I 5 m., Kurintji valley; Indragiri); Natuna islands (Bunguran); Borneo (Tuaran riv., N.-Borneo; Mt. Kina Ba!u; Singkawang; Pagat, distr. Batangalai; Barabai); Java (Serang; Lebak; Batavia!; Buitenzorg!; Mt. Salak; Gadok; Tjibodas!; Perbawati!; Sukabumi!; Tjiandjur; Djampang Tengah !; Gunung Sesuru!; Tjitalahab!; Babakan!; Tjandi, 60 m.!; Ambarawa; Wonosobo!; Djokjakarta, II 3 m.!; Tengger mts., I 200 m.); Lombok, II 85 m.; Sumba; Timor; Saleyer!; Kabaëna; Celebes (Makasser; Bantimurung!; Loka, I Ioo m.; Tjamba; Boni; Kandari; Tinondo; Kantewu!; between Lake Towuti and Lake Matana; Lake Poso; Mongondon!; Bolaang!; Toli Toli; Koro valley, 500-700 m.; Bwool; Tuwa; Tomohon; Rurukan; 
Menado; Kema). - E.-Himalayas and S.-China to Malay Peninsula (up to $1500 \mathrm{~m}$. ); Singapore; Philippines; Pelawan.

\section{3a. Rhacophorus leucomystax var. sexvirgata (Reinw.).}

Hyla scxvirgata (Reinw.), Gravenhorst, Deliciae Mus. Zool. Vratislav., Fasc. I, Lipsiae, 1829, p. 28.

Hyla quadrilineata (Boie), Wiegmann, N. Acta Acad. Leop.-Carol., XVII, I, 1835, p. 260 , pl. XXII, fig. I.

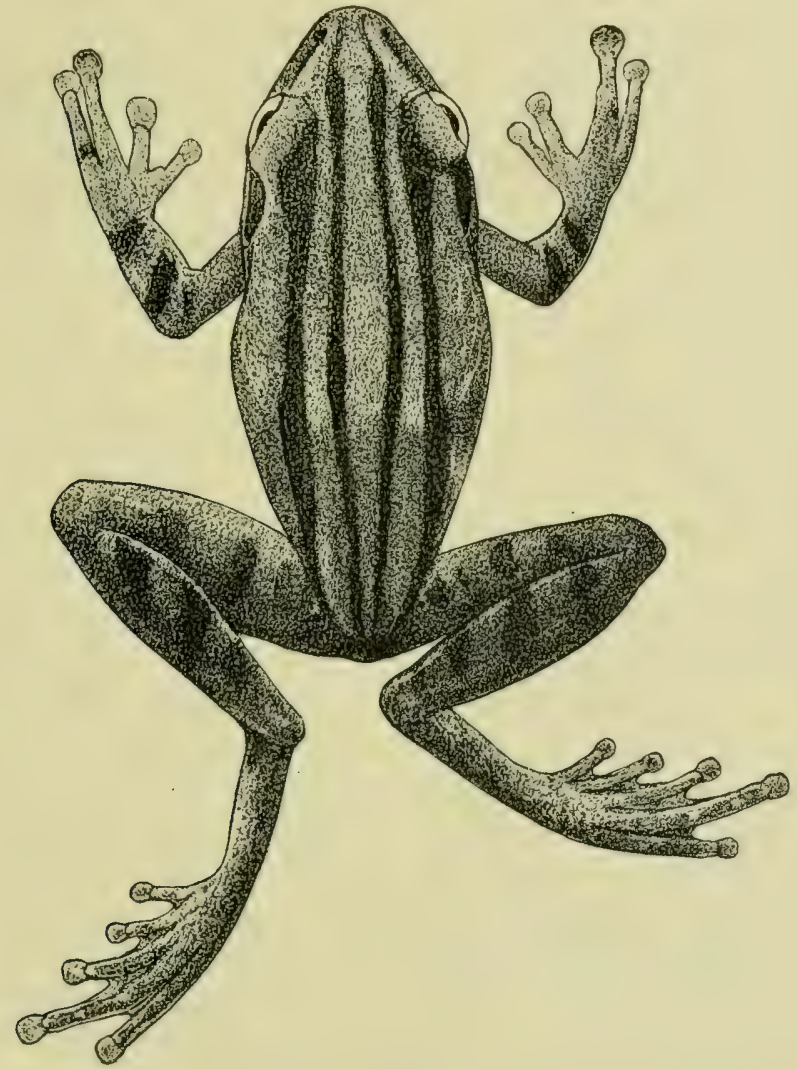

Fig. 27. Rhacophorus leucomystax (Kuh1) var. sexvirgata (Reinw.), X r.

Polypedates quadrilineatus Steindachner, Verh. zool.-bot. Ges. Wien, XIV, I864, p. 253, pl. X, figs. 2-2c.

Rhacophorus maculatus, var. quadrilineata Boulenger, Cat. Batr. Sal. Brit. Mus., I882, p. 84 .

Rhacophorus leucomystax (part.) Boulenger, Vert. Fauna Malay Penins, Rept. and Batr., London, 1912, p. 248. 
Distinguished from the type by the presence of four more or less distinct dark longitudinal bands on the upper surface of head and body, which, however, may appear conspicuously and disappear in the same individual; the black lateral streaks always present.

Perhaps a distinct species.

Habitat: Sumatra (Takengan, Gajo countries!; Upper and Lower Langkat; Medan!; Brastagi, Karo highland, I400 m.!; Bandarbaru, Batak mts., \pm 900 m.!; Lauttador; Toba lake; Matur!; Matua!; Padangtarab!; Fort de Kock!; Lembok; Bunga Mas; Hari leko riv.!); Banka; Borneo (Mt. Kina Balu; Serawak; Barabai); Java (Krawang!; Batavia!; Buitenzorg!; Gadok; Perbawati, Mt. Gedeh!; Sukabumi!; Wonosobo!; Nongkodjadjar, I 200 m.!); Madura; Timor!; Celebes; Ternate? '). From India to the Malay Peninsula; Singapore; Formosa; Philippines; Pelawan.

\section{Rhacophorus colletti Blgr.}

Rhacophorus Colletti Boulenger, Proc. Zool. Soc. London, I89̊o, p. 36.

? Rhacophorus cruciger Mocquard (nec Blyth), Nouv. Arch. Mus. d'Hist. nat., (3) II, 189o, p. I50.

Rhacophoras colletti Werner, Zool. Jahrb., Syst., XIII, 1900, p. 494, pl.XXXII, fig. 4 .

Vomerine teeth in two oblique series between the very large choanae and beginning at their inner front edges. Head as long as broad; snout triangular, a little longer than the diameter of the orbit; canthus rostralis angular; loreal region oblique, slightly concave; nostril nearer to the tip of the snout than to the eye; interorbital space a little broader than the upper eyelid; tympanum very distinct, $3 / 4$ or $3 / 5$ the width of the eye. Disks of fingers about half the size of the tympanum, of toes smaller; fingers with a slight rudiment of web, toes nearly entirely webbed; subarticular tubercles moderate; a very small inner metatarsal tubercle; the knee reaches the fore limb, the heel far beyond the tip of the snout; tibia $2 / 3$ length of head and body.

Skin of head free; upper parts smooth, belly and lower surface of thighs granular; a fold above the tympanum.

I) Locality mentioned by Meyer (Abh. Zool. Mus. Dresden, I887, p. I5), but probably incorrect. 
Grey or greyish brown above, loreal region and sides of body lighter; back usually with an hourglass-shaped dark figure; lips with a fine blackish edge; sides dark marbled; limbs with dark cross-bands; anal region blackish, with a white edge above; lower parts whitish, the throat sometimes with brown vermiculations. From snout to vent $75 \mathrm{~mm}$.

Habitat: Sumatra (Langkat); Natuna islands (Bunguran); Borneo (Baram).

\section{Rhacophorus macrotis Blgr.}

Rhacophorus macrotis Boulenger, Ann. Mag. Nat. Hist., (6) VII, I89I, p. 282.

Vomerine teeth in two oblique groups on a level with the front borders of the very large choanae. Head nearly as long as broad; snout triangular, a little longer than the orbit; canthus rostralis angular; loreal region concave; nostril near to the tip of the snout; interorbital space not broader than the upper eyelid; tympanum distinct, as large as the eye. Disks of fingers about half the diameter of the eye, of toes smaller; fingers with a distinct rudiment of web, toes nearly entirely webbed; subarticular tubercles moderate; a very small inner metatatarsal tubercle; the heel reaches the tip of the snout; tibia half the length of head and body.

Skin of head co-ossified with the rugose frontoparietals, of back smooth or finely granulate; belly and lower side of thighs granular.

Grey-brown above, with a few small dark brown spots or two indistinct black longitudinal bands; loreal region greyish white; a dark brown band from the end of the snout through the nostril, the eye and the tympanum to the side of the body, expanding on the tympanum to a large temporal blotch; limbs with ill-defined dark cross bands; hinder side of thighs brown, dotted with white; lower parts whitish, speckled with brown. From snout to vent $78 \mathrm{~mm}$.

Habitat: Sumatra (Siolak Daras, 900 m., Kurintji valley); Natuna islands (Bunguran); Borneo (Baram; Baran riv.). Pelawan; Balabak.

\section{Rhacophorus everetti Blgr.}

Rhacophorus Everetti Boulenger, Ann. Mag. Nat. Hist., (6) XIV, 1894, p. 87.

Vomerine teeth in two oblique groups between the choanae, 
which are moderately large. Head slightly broader than long; snout rounded, shorter than the orbit; canthus rostralis obtuse, curved; loreal region very oblique, concave; nostril near to the end of the snout; interorbital space as broad as the upper cyelid; tympanum distinct, $2 / 5$ the width of the eye; disks of fingers nearly as large as the tympanum; fingers with a slight rudiment of web, toes $3 / 4$ webbed; a very small inner metatarsal tubercle; no tarsal fold; the heel reaches a little beyond the tip of the snout.

Skin not adherent to the skull. Finely granulate above, coarsely beneath; small conical tubercles below the vent, at the heel, and along the outer edge of fore-arm and tarsus.

Pale yellowish or reddish brown above, with dark brown markings, among which a cross-band between the eyes; limbs with dark cross-bands; lower parts uniform white. From snout to vent $32 \mathrm{~mm}$.

$\mathrm{Hab}$ it at: Pelawan.

\section{Rhacophorus macroscelis Blgr.}

Rhacophorus macroscelis Boulenger, Ann. Mag. Nat. Hist., (6) XVII, 1896, p. 403.

Vomerine teeth in two small oblique groups close to the inner borders of the choanae. Head large, as long as broad; snout rounded, shorter than the orbit; canthus rostralis strong; loreal region deeply concave; nostril near to the end of the snout; interorbital space as broad as the upper eyelid; tympanum distinct, half the diameter of the eye. Fingers webbed at the base; toes webbed to the disks of the third and fifth, penultimate phalanx of fourth free; a very small inner metatarsal tubercle; the knee reaches the shoulder, the heel far beyond the tip of the snout.

Above with small scattered warts; heel with a conical tubercle; throat and belly granulate.

Olive above, marbled with darker; a yellow cross-line between the eyes and a large W-shaped yellow marking on the occiput; upper lip white, with vertical blackish blotches; flanks white, with large black spots; limbs with dark cross-bars; dirty white beneath, belly and hind limbs dotted with brown. From snout to vent $3 \mathrm{I} \mathrm{mm}$.

Habitat: Borneo (Mt. Kina Balu). 


\section{Rhacophorus hosii Blgr.}

Rhacophorus Hosii Bọlenger, Ann. Mag. Nat. Hist., (6) XVI, 1895, p. I69.

Vomerine teeth in two oblique series between the rather large choanae, beginning from their inner front edges. Snout truncate, as long as the orbit; canthus rostralis angular; loreal region concave; nostril close to the tip of the snout; interorbital space as broad as the upper eyelid; tympanum distinct, half the diameter of the eye. Disks smaller than tympanum; fingers with a slight rudiment of web; toes nearly entirely webbed, the penultimate phalanx of fourth toe free; subarticular tubercles moderate; a small inner metatarsal tubercle; the knee reaches the shoulder, the heel far beyond the tip of the snout.

Finely granulate above, coarsely granulate on the belly.

Dark grey-brown above; lips with darker vertical bars; one or two small black spots above the axil; limbs with dark cross-bands; anal region black; posterior surface of thighs dark-brown; whitish beneath, throat marbled with brown, belly dotted with brown. From snout to vent $48 \mathrm{~mm}$.

Habitat: Borneo (Pata riv., Serawak).

\section{Rhacophorus georgii Roux.}

Rhacophorus Georgii Roux, Verh. naturf. Ges. Basel, XV, r904, p. 430, pl, VIII.

Vomerine teeth in two oblique series beginning from the inner front edges of the choanae. Head as long as broad; snout rounded; canthus rostralis distinct; loreal region feebly concave; nostril nearer to the tip of the snout than to the eye; interorbital space twice the width of the upper eyelid; tympanum very distinct, oval, its diameter equal to the distance between the nostril and the tip of the snout. Disks of fingers large, of third finger almost as broad as the smaller diameter of the tympanum; first finger shorter than second; fingers $2 / 3$ webbed; toes, with exception of the fourth, webbed to the disks; subarticular and inner metatarsal tubercles feebly prominent; no outer metatarsal tubercle; the heel reaches beyond tip of snout.

Occiput with four stiff spine-like processes: a laterally compressed one above each tympanum, and two between the tympana; skin of upper surfaces with small warts or tubercles; a narrow fold along the outer edge of the fourth finger, and 
another one along the outer edge of the fifth toe, extending a little along fore-arm and tarsus; heel with a small, bilobate dermal flap; belly, throat and posterior surface of thighs granulate; some large tubercles near the vent.

Colour in life: back light green (greyish blue in spirit), speckled with lighter; sides of body and limbs marbled with dark green and yellow (in spirit violet and white); throat and belly with red vermiculation. Length $70 \mathrm{~mm}$.

Habitat: Celebes (Tuwa, Palu valley).

\section{IO. Rhacophorus javanus Bttgr.}

?Rhacophorus moschata (nomen nudum), Kuhl en v. Hasselt, Alg. Konst- en Letter-bode, 1822, p. 104.

: Hyla margaritifera Schlegel, Abbild. neuer oder unvollst. bek. Amph., Düsseldorf, $1837-44$, p. 107 .

Rhacophorus javanus Boettger, Zool. Anz., XVI, 1893, p. 338.

Rhacophorus javanus v. Kampen, Weber's Zool. Ergebn., Leiden, IV, 1907, p. 402. Polypedates javanus Barbour, Mem. Mus. Comp. Zoöl. Harvard Coll., XLIV, I, I 912 , p. 68, pl. VIII, fig. $3 \mathrm{I}$.

Rhacophorus javanus v. Kampen, Nat. Tijdschr. Ned.-Indië, LXIX, ․․, p. 42, pl. II, figs. 7,8 (tadpole).

Vomerine teeth in two oblique series beginning from the inner front edges of the choanae. Head broader than long; snout feebly projecting, as long as the upper eyelid, longer than deep; canthus rostralis rather distinct; loreal region oblique, concave; nostril nearer to the tip of the snout than to the eye; interorbital space a little broader than the upper eyelid; tympanum $2 / 5$ to $1 / 2$ the diameter of the eye. Disks of three outer fingers about half the diameter of the eye, of inner finger and of toes smaller; first finger shorter than second, which is shorter than fourth; the three outer fingers $1 / 2$ to $2 / 3$ webbed, the first one only at the base; fifth toe a little longer than third; the web between the toes reaches all the disks, except that of fourth toe, the penultimate phalanx of which is only included by a narrow fringe; subarticular tubercles small, single; a small inner, no outer metatarsal tubercle; no tarsal fold; the heel reaches a little beyond the tip of the snout; tibia a little more than half the length of head and body.

Smooth above; a transverse ridge above the vent, a triangular dermal flap at the heel and ridges along the outer edges of fore-arm, outer finger, tarsus and fifth toe; a fold above 
the tympanum; belly and proximal part of lower surface of thighs granulate.

Upper parts greyish white, finely dotted with blackish; a narrow dark cross-bar between the eyes and another, indistinct one behind it; limbs without cross-bars; the dermal ridges and the flap of the heel whitish; yellowish red beneath, throat and belly whitish. Length $59 \mathrm{~mm}$.

Tadpole. - The following tadpoles from Pasir Datar, W.-Java, probably belong to this species.

Length of body $\mathrm{I}^{1} / 2$ to nearly 2 times its width; tail $\mathrm{I} 1 / 2$ (in young specimens) to $2 \frac{1}{4}$ (in older ones) times as long as body and $3 \frac{1}{2}$ (in the young ones) to $4 \frac{1}{2}$ (in older ones) times as long as deep. Nostril about as far from eye as from tip of snout; eyes superior, in the middle between spiraculum and tip of snout; distance between them $\mathrm{I}^{1} / 2$ to 2 times that between the nostrils; spiraculum sinistral, directed upwards and backwards; visible from above and from below, equally distant from tip of snout and vent; vent dextral. Tail pointed; the upper crest a little deeper than the lower one and reaching the base of the tail.

Mouth ventral; sides and lower border of lips with a continuous series of papillae, which along the sides are placed in 2 to 3 , along the lower border in 3 to 4 rows; jaws edged with black; series of teeth $5^{1} 5 / 3$, second and third series of upper lip very narrowly interrupted (the second one sometimes continuous); the series of lower lip nearly equal in length, the inner one sometimes hardly interrupted.

Body grey above, white below; tail yellowish with light grey, transparant crests; posterior part of tail with large blackish-grey spots. Length $58 \mathrm{~mm}$.

Ha bit a t: Java (Buitenzorg; Tjibodas!; Mt. Malabar, I 500 m.!; Tjisurupan).

\section{Rhacophorus appendiculatus (Gthr.).}

Polypedates appendiculatus Günther, Cat. Batr. Sal. Brit. Mus., 1858, p. 79.

Rhacophorus appendiculatus Boulenger, Cat. Batr. Sal. Brit. Mus., I882, p. 86, pl. VIII, fig. 4 .

Rhacophorus appendiculatus Mocquard, Nouv. Arch. Mus. d'Hist. nat., (3) II, 1890, p. 150.

Rhacophorus phyllopy'gus Werner, Zool. Jahrb., Syst., XIII, 1900, p. 494, pl. XXXII, fig. 5 .

Rhacophorus appendiculatus Roux, Revue Suisse Zool., XXVI, r918, F. 414. 
Vomerine teeth in two oblique series between the choanae. Head as long as broad; snout rather pointed, nearly as long as the upper eyelid, longer than deep; canthus rostralis more or less rounded, curved; loreal region oblique, slightly concave; nostril a little nearer to the tip of the snout than to the eye; interorbital space as broad to $I^{1} / 3$ times as broad as the upper eyelid; tympanum distinct, half the diameter of the eye. Disks of fingers and toes well developed, that of third finger about as large as the tympanum, those of toes somewhat smaller; first finger shorter than second, which is shorter than fourth; outer fingers $1 / 3$, toes nearly entirely webbed; subarticular tubercles very prominent, those of third and fourth fingers, or that of fourth finger only, sometimes double; a small inner, no outer metatarsal tubercle; the heel reaches the eye or the tip of the snout; tibia half the length of head and body.

Smooth above, or with small warts; small dermal prominences near the vent and on the heel; a more or less developed cutaneous fringe along the outer edge of tarsus and fore-arm; sometimes a feeble dermal fold along the edge of the lower jaw; belly granular or smooth, lower surface of thighs granular.

Greyish above; a rufous or blackish cross-bar between the eyelids, another one on the snout and a third one on the nape, and some large spots of the same colour on the back may be present; limbs more or less distinctly cross-barred. Length $46 \mathrm{~mm}$.

Habitat: Mentawei islands (Sipora); Sumatra (Sungai Kumbang, $1600 \mathrm{~m} . !$, Kurintji peak; Indragiri); Borneo (Baram; Mt. Dulit). - Philippines.

\section{I2. Rhacophorus poecilonotus Blgr.}

Rhacophorns poecilonotus Boulenger, Jrn. Fed. Malay St. Mus., VIII, 1920, p. 294.

Vomerine teeth in two long transverse or slightly oblique series between the choanae. Head very strongly depressed; snout rounded or more or less pointed; canthus rostralis curved; loreal region very oblique, concave; nostril equally distant from end of snout and eye; interorbital space a little broader than the upper eyelid; tympanum distinct, $2 / 3$ diameter of eye. Disks of fingers as large as the tympanum, of toes smaller; fingers half webbed, toes webbed to the disks; subarticular and inner metatarsal tubercles feeble; the heel reaches the eye or between eye and tip of snout. 
Smooth above; heel with a more or less distinct conical tubercle; belly and lower surface of thighs granular.

Coloration very variable. Grey or pale brown above, with brown or blackish marblings or symmetrical markings, or blackish brown with pale grey or whitish markings forming two cross-bands on the snout and two bands along the back; limbs orange, with dark brown transverse lines, which may be very numerous; lower parts white. From snout to vent $48 \mathrm{~mm}$.

Male with a subgular vocal sac.

Habitat: Sumatra (Sungai Kumbang, i 400 m., Kurintji peak).

\section{I3. Rhacophorus bifasciatus nova spec.}

Vomerine teeth in two slightly oblique series between the choanae. Head as long or nearly as long as broad; snout more or less pointed, as long as the upper eyelid, longer than deep; canthus rostralis angular, curved; loreal region oblique, concave; nostril usually a little nearer to the tip of snout than to the eye; interorbital space as broad as the upper eyelid; tympanum distinct, $1 / 2$ to $2 / 3$ the width of the eye. Disks of three outer fingers about as large as the tympanum, of first finger and of toes smaller; first finger shorter than second, which is shorter than fourth; outer fingers about $2 / 3$ webbed, the web not reaching the disks; first finger only webbed at the base; fifth toe a little longer than third; toes nearly entirely webbed, the web reaching all the disks, except that of fourth toe; subarticular tubercles well developed, single; a feeble inner, no outer metatarsal tubercle; the heel reaches the tip of the snout or between eye and tip of snout; tibia half length of head and body, or hardly longer.

Smooth above; feeble dermal ridges above the vent and along outer edges of fore-arm and outer finger, and of tarsus and outer toe; heel with a triangular dermal appendage; a feeble fold above the tympanum; belly and lower surface of thighs granulate.

Purplish above, with two irregular, white dorsolateral bands, which are confluent in the coccygeal region; in young specimens they are broken up into blotches. Fore head, including the anterior part of the upper eyelids, white, with purplish streaks; web between fingers and toes partly dark; usually INDO-AUSTRALIAN AMPHIBIA. 
a few narrow dark cross-streaks on the limbs; white beneath. Length $60 \mathrm{~mm}$.

Closely allied with $R /$. jaranus, from which it is distinguished by the shorter hind limbs and the coloration; from $R / \iota$. poecilonotus it can be distinguished by the more extensively webbed fingers.

Habitat: Sumatra (Sungai Kring!, Sungai Kumbang, I600 m.!, and Sinlak Deras! in Kurintji, E. Jacobson leg.).

\section{I4. Rhacophorus dulitensis Blgr.}

Rhacophorus dulitensis Boulenger, Proc. Zool. Soc. London, 1892, p. 507, pl. $\mathrm{XXX}$, fig. 1.

Rhacophorus chiropterus Werner, Verh. zool.-bot. Ges. Wien, XLVI, I896, p. 22, pl. I, fig. 2.

Vomerine teeth in two slightly oblique series between the choanae. Head broader than long; snout rounded, as long as the upper eyelid; canthus rostralis distinct; loreal region nearly vertical, concave; nostril in the middle between eye and tip of snout or a little nearer to the latter; interorbital space much broader than the upper eyelid; tympanum distinct, $2 / 3$ to $3 / 4$ the width of the eye. Disks of toes smaller than those of fingers, which are smaller than the tympanum; first finger shorter than second, which is shorter than fourth; fingers nearly entirely webbed, the web reaching the disk of the fourth one; toes nearly entirely webbed; subarticular tubercles and inner metatarsal tubercle feeble; no outer metatarsal tubercle; the heel reaches the tip of the snout; tibia about half length of head and body.

Smooth above; a slight dermal ridge along the outer edge of fore-arm and tarsus, and a dermal flap above the vent and at the heel; belly and lower surface of thighs granulate.

Yellowish (in life grass-green or greyish green) above; head and back with purplish dots; a purplish line round the snout, from eye to eye, passing through the nostrils and sometimes extending above the tympanum to the sides of the body; ridges of fore-arm and tarsus and border of the dermal flap above the vent yellowish; web between the outer toes red; yellow beneath, belly in the living animal with green spots; chin yellowish green in life, the lower lip with a yellow border. From snout to vent $43 \mathrm{~mm}$.

Habitat: Sumatra (Sungai Kring! and Sungai Kumbang, 1600. m.!, in Kurintji); Borneo (Baram; Mt. Dulit). 


\section{I5. Rhacophorus modestus Blgr.}

Rhacophorus modestus Boulenger, Jrn. Fed. Malay St. Mus., VIII, 1920, p. 293.

Vomerine teeth in two oblique series between the choanae. Head as long as broad; snout rounded, as long as the upper eyelid; canthus rostralis distinct, straight or slightly curved; loreal region oblique, slightly concave; nostril a little nearer to the end of the snout than to the eye; interorbital space as broad as or a little broader than the upper eyelid; tympanum distinct, $1 / 2$ or $2 / 3$ the width of the eye. Fingrers and toes with large disks, those of outer fingers as large as the tympanum, those of first finger and of toes smaller; first finger shorter than second, which is shorter than fourth; outer fingers $1 / 3$, toes $2 / 3$ webbed; subarticular and inner metatarsal tubercles feeble, no outer metatarsal tuhercle; the heel reaches the eye or between eye and tip of snout; tibia about half the length of head and body.

Smooth above, belly and lower surface of thighs granular.

Grey or brown above, sometimes darker on the sides, usually with a white streak or a series of white spots along the flanks; a dark canthal and temporal streak; limbs with dark cross-bands; lower parts white, uniform or spotted with brown. From snout to vent $4 \mathrm{I} \mathrm{mm}$.

Male with a subgular vocal sac.

Habitat: Sumatra (Sungai Kumbang, I400 m., Kurintji; Kurintji peak, 2200 m.!).

\section{I6. Rhacophorus edentulus F. Müll.}

Rhacophornes edentulus F. Müller, Verh. naturf. Ges. Basel, X, I895, p. 840, 869. Rhacophorus edcntulus Boulenger, Proc. Zool. Soc. London, I897, p. 234, pl. XVI, fig. 2.

Vomerine teeth absent, or reduced to two very small, indistinct groups near the inner edges of the rather large choanae. Snout rounded, a little shorter than the orbit; canthus rostralis distinct; loreal region slightly concave; nostril nearer to the tip of the snout than to the eye; interorbital space as broad as the upper eyelid; tympanum moderately distinct, $2 / 5$ to $1 / 2$ the diameter of the eye. Disks of fingers as large as or a little larger than the tympanum; outer fingers haif webbed; toes webbed to the disks of the third and fifth, penultimate phalanx of fourth free; subarticular tubercles feeble; a very small inner metatarsal tubercle; no tarsal fold; the heel reaches the tip of the snout or beyond. 
Smooth or finely shagreened above; a fold from the eye to the shoulder; belly and lower side of thighs granulate.

Green above (bluish grey or lilac in spirit), uniform or with dark dots; a large rust-red blotch on the head and another on the body may be present; upper arm yellowish white; thigh yellowish white with a narrow green stripe; white beneath. From snout to vent $40 \mathrm{~mm}$.

Male without vocal sacs.

Habitat: Celebes (Loka; Bone mts., $\pm 500 \mathrm{~m}$; B Bulawa mts., $\pm 1200 \mathrm{~m}$.; Totoyia valley, $\pm 500 \mathrm{~m}$.; Tomohon; Rurukan; Bua Praeng).

\section{I7. Rhacophorus acutirostris Mocq.}

Rhacophorus acutirostris Mocquard, Nouv. Arch. Mus. d' Hist. nat., (3) II, I890, p. I5 I, pl. XI, fig. I.

Rhacophorus acutirostris Mocquard, Le Naturaliste, (2) XII, 1890, p. I63.

Vomerine teeth in two widely separated small groups between the choanae. Snout angular, hardly longer than the eye; canthus rostralis distinct; nostril equidistant from eye and tip of snout; interorbital space broader than the upper eyelid; tympanum a little more than $1 / 3$ the width of the eye. Disks of toes as large as the tympanuin, of fingers larger; outer fingers $2 / 3$ webbed, the inner one nearly free; toes $3 / 4$ webbed; subarticular tubercles well developed; a small inner, no outer metatarsal tubercle; the heel reaches the eye or a little beyond.

Smooth above; a series of 6 or 7 small, rounded tubercles along the outer edge of the fore-arm; a strong fold above the tympanum; belly and lower side of thighs strongly granulate.

Slate brown above; a narrow dark cross-bar between the eyes often present; sides of body and thighs with large, nearly black spots; tubercles along fore-arm white; sometimes a small white spot below the eye; lower surfaces yellowish white, mottled with brown. In young specimens the upper surfaces are rufous, with a few brown spots or cross-bars; the hind limbs also may have such cross-bars and the lower surfaces are uniform grey or yellowish white. From snout to vent $47 \mathrm{~mm}$.

Habitat: Borneo (Mt. Kina Balu, 200 m.). 


\section{I8. Rhacophorus monticola Blgr.}

Rhacophorus monticola Boulenger, Ann. Mag. Nat. Hist., (6) XVIII, I \&96, p. 395. Rhacophorus monticola Boulenger, Proc. Zool. Soc. London, I897, p. 234, pl.

XVI, fig. 3 .

Rhacophorus monticola v. Kampen, Weber's Zool. Ergebn, Leiden, IV, I907, p. 403 (tadpole).

Vomerine teeth in two oblique series between the choanae. Snout more or less pointed, as long as the orbit; canthus rostralis distinct; loreal region slightly concave; nostril equally distant from the eye and the tip of the snout; interorbital space as broad as the upper eyelid; tympanum moderately distinct, half the diameter of the eye. Disks of fingers as large as or a little larger than the tympanum; outer fingers $2 / 3$ webbed; toes webbed to the disks of the third and fifth, penultimate phalanx of fourth free; subarticular tubercles feeble; a very small inner metatarsal tubercle; no tarsal fold; the heel reaches the eye or the anterior border of the orbit.

Finely shagreened above, granulate on the belly and under the thighs; a fold above the tympanum.

Coloration very variable. Greyish or green (bluish or purplish in spirit) above, uniform or with scattered small yellow spots, or dotted, spotted or vermiculate with darker, or with large symmetrical markings, viz. a cross-band between the eyes, an hourglass- or X-shaped blotch on the anterior part of the back, and a cross-band on the sacrum; limbs with dark crossbands; flanks white, or purple with large white spots; lower parts white. From snout to vent $48 \mathrm{~mm}$.

Male without vocal sacs.

Description of tadpoles from Loka, probably belonging to this species:

Length of body nearly $\mathrm{I}^{1} / 2$ times its width; tail $\mathrm{I}^{1} / 2$ to 2 times the length of the body. Nostril equally distant from the tip of the snout and the eye; eyes superior, about as far from the end of the snout as from the spiraculum, the distance between them much larger than that between the nostrils, about equal to the width of the mouth, and about half the width of the body; spiraculum sinistral, lateral, directed upwards and backwards, in the middle between end of snout and vent; vent dextral, above the lower border of the crest of the tail. Tail pointed, the upper crest reaches the base of the tail.

The whole lower and lateral borders of lips with papillae; 
series of teeth $5^{1} 5 / 1^{1} 2^{1}$ or $6^{1} 6 / /^{1} 2^{1}$, the second row of upper, and the third one of lower lip very narrowly interrupted, the three series of lower lip about equal in length.

Body brown above, yellowish white below; tail yellowish white; in old specimens a bright cross-bar between the eyes. Length $44 \mathrm{~mm}$.

Habitat: Celebes (Loka, ro7o m.; Bonthain peak, $790 \mathrm{~m}$; Indrulaman, S.-Celebes, $600 \mathrm{~m}$.).

\section{I9. Rhacophorus shelfordi Blgr.}

Rhacophorns Shelfordi Boulenger, Proc. Zool. Soc. London, 1900, p. 185, pl. XVII, fig. 2 .

Vomerine teeth in two long, nearly straight, transverse series in the middle between the choanae. Snout pointed, as long as the orbit; canthus rostralis strong; loreal region slightly concave; nostril equally distant from the orbit and the end of the snout; interorbital space broader than the upper eyelid; tympanum distinct, $3 / 5$ the diameter of the eye. Disks of fingers much smaller than the tympanum, of toes smaller than those of fingers; fingers and toes webbed to the disks; subarticular and inner metatarsal tubercles very small; no tarsal fold; the heel reaches between the eye and the nostril.

Smooth above, belly granulate.

Purplish brown above; a dark band across the snout, another one between the eyes, and three across the back; an X-shaped dark marking in the scapular region; loreal and temporal regions blackish; a fine yellow line on each side of the head from the tip of the snout along canthus rostralis and superciliary edge to above the tympanum; sides of body yellowish, with a blackish network; limbs with dark crossbands; sides of thighs blackish, closely speckled with white; web between toes marbled with blackish; lower parts colourless. From snout to vent $45 \mathrm{~mm}$.

Male with internal vocal sacs.

Habitat: Borneo (Mt. Penrissen, Serawak).

\section{Rhacophorus fasciatus Blgr.}

Rhacophorus fasciatus Boulenger, Ann. Mag. nat. Hist., (6) XVI, I\$95, p. I69.

Vomerine teeth in two long oblique series between the choanae, beginning from their inner front edges. Snout pointed, 
as long as the orbit; canthus rostralis angular; loreal region slightly concave; nostril equally distant from the orbit and the end of the snout; interorbital space broader than the upper eyelid; tympanum distinct, $1 / 2$ or $3 / 5$ the diameter of the eye. Disks of fingers nearly as large as the tympanum, of toes smaller; fingers and toes entirely webbed; subarticular and inner metatarsal tubercles very small; no tarsal fold; the heel reaches the tip of the snout.

Smooth above, belly granulate.

Pale reddish brown above, minutely speckled with brown and with six brown cross-bands, the first across the snout, the second between the eyes, the third, broadest, between the tympana; a fine yellow, brown-edged line borders the head above, from the tip of the snout along the canthus rostralis and supraciliary border to above the tympanum; limbs with dark cross-bands; lower parts and hinder side of thighs colourless. From snout to vent $54 \mathrm{~mm}$.

Male with an internal vocal sac.

Habitat: Borneo (mountains of the Akar riv., Serawak).

\section{I. Rhacophorus pardalis Gthr.}

Rhacophorus Reinwardtii Eydoux et Souleyet, Voyage Bonite, Zool., I, r84 I, p. I50, pl. X, figs. I, I A-B.

Rhacophorus pardalis Günther, Cat. Batr. Sal. Brit. Mus, I858, p. 83, pl. VI, fig. D. Rhacophorus pardalis Boulenger, Cat. Batr. Sal. Brit. Mus, I882, p. 91.

Rhacophorus pulchellus Werner, Zool. Jahrb., Syst., XIII, 1900, p. 495, pl. XXXIII, fig. 7 .

Rhacophorus pardalis Roux, Revue Suisse Zool., XXVI, I9I8, p. 415.

Vomerine teeth in two slightly oblique series beginning at the inner front edges of the choanae. Head nearly as long as broad; snout rounded, as long as the upper eyelid; canthus rostralis distinct; loreal region oblique, slightly concave; nostril nearer to the tip of the snout than to the eye; interorbital space as broad as, or broader than the upper eyelid; tympanum distinct, $1 / 2$ to $2 / 3$ the width of the eye. Fingers and toes with large disks, those of outer fingers as large as or a little smaller than the tympanum, those of first finger and of toes a little smaller; first finger shorter than second, which is shorter than fourth; fingers webbed to the disks, except the first, which is free; third and fifth toe equal in length; toes webbed to the disks; subarticular tubercles 
moderate; a small inner, no outer metatarsal tubercle; the heel reaches the tip of the snout; tibia about half the length of head and body.

Smooth above; a dermal fold along outer border of forearm and hand, tarsus and foot, and a cutaneous flap on the heel; a fold above the tympanum; belly and lower surface of thighs granular.

Coloration very variable. Brown, grey or purplish above, usually darker marbled or spotted; hird limbs with dark crossbars; dark spots on the sides of the body and a round white spot above the heel may be present; webs between fingers and toes without black spots. Length $55 \mathrm{~mm}$.

Male with an internal vocal sac.

Habitat: Mentawei islands (Sipora); Sumatra (Djapura, Indragiri); Borneo (Pagat, S. E.-Borneo; Samarinda!; Semberrah riv.!). - Philippines; Pelawan.

\section{Rhacophorus reinwardti (Boie).}

Rhacophorus Reinvardti (nomen nudum), Kuhl en v. Hasselt, Alg. Konst- en Letterbode, I822, p. I04.

Hypsiboas Reinwardtii (Boie), Wagler, Natïrl. Syst. Amph., München, I830, p. 200. Hyla Reinwardtii (part.) Schlegel, Abbild. neuer oder unvollst. bek. Amph., Diisseldorf, 1837-44, p. I05, pl. XXX, figs. I, 2, 4 (not 3).

Rhacophorus Reinzerdtii Duméril et Bibron, Erpét. gén., VIII, I841, p. 532; IX, I854, p. 403, pl. LXXXIX, figs. I, I $a$.

Rhacophorus reinwardtii Boulenger, Cat. Batr. Sal. Brit. Mus., 1882, p. 88 (excl. the tadpole).

Rhacophorus Reinzordti var. lateralis Werner, Zool. Jahrb., Syst., XIII, I900, p. 495 , pl. XXXIII, fig. 6 .

Polypedates reinwardtii Siedlecki, Biol. Centr., XXIX, I909, p. 704, pls. VIJ-X. Rhacophorus reinwardti v. Kampen, Nat. Tijdschr. Ned.-Indië, LXIX, I909, p. 43 (tadpole).

Vomerine teeth in two hardly oblique series between the choanae. Head broader than long; snout rounded, as long as the upper eyelid; canthus rostralis obtuse; loreal region oblique, slightly concave; nostril equally distant from the eye and the tip of the snout; interorbital space broader than the upper eyelid; tympanum distinct, $2 / 3$ to $3 / 4$ the width of the eye. Fingers and toes with large disks, those of outer fingers as large as or larger than the tympanum; first finger shorter than second, which is shorter than fourth; fingers webbed to the dishis, except the first, which is nearly entirely free; third 
and fifth toe equal in length; the web between the toes reaches all the disks; subarticular tubercles moderate; a small inner, no outer metatarsal tubercle; the heel reaches between the eye and the tip of the snout; tibia half the length of head and body.

Smooth above; belly; sides of body and lower surface of thighs coarsely granulate; a fold above the tympanum; a cutancous fringe along the outer edge of fore-arm and fourth

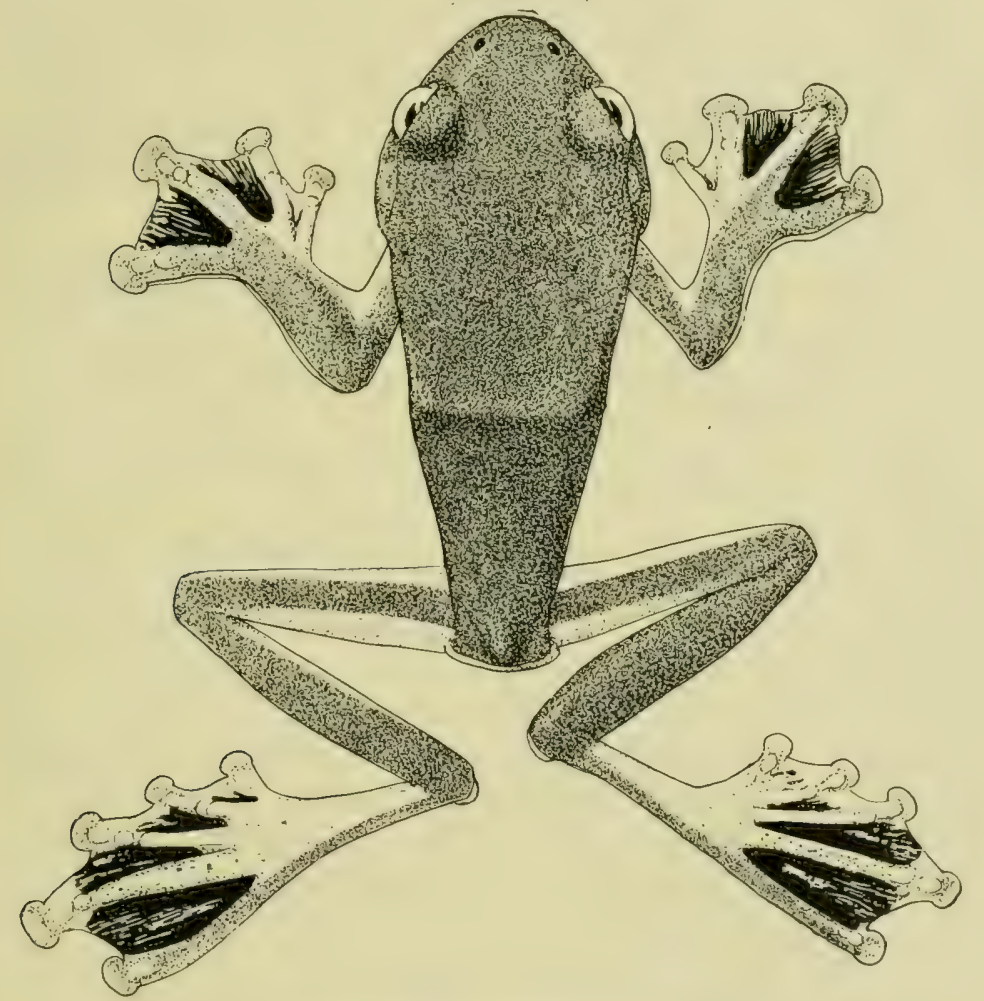

Fig. 28. Rhacophorzes reinwardti (Boie), $X \mathbf{I}$.

finger, and along that of tarsus and fifth toe; a transverse flap of skin above the vent and another on the heel.

Coloration very variable, even in the same individual. Olive or lilac above (green to olive in life); a black spot on the axilla usually present; web between the two or three outer fingers and the three or four outer toes with a large black spot; sides, belly and lower surface of thighs may be reticu- 
lated with black. In the var. lateralis Wern. this dark colour is more extensive. From snout to vent $\sigma^{7} 52$, o $76 \mathrm{~mm}$.

Male with an internal vocal sac.

Tadpole., - Length of body $\mathrm{I}^{2} / 3$ its width; tail more than $I^{1} / 2$ times as long as the body, more than 3 times as long as deep. Nostril equally distant from the eye and the end of the snout; eyes superior, hardly nearer to the spiraculum than to the tip of the snout, the distance between them greater than that between the nostrils; spiraculum sinistral, lateral, directed backwards and upwards, equally distant from tip of snout and vent; vent dextral, in the middle between the muscular portion and the lower border of the tail. Tail rounded, the upper crest a little deeper than the lower one, reaching the base of the tail.

Sides of lips with one or two, lower border with two uninterrupted series of papillae; jaws denticulated, narrowly edged with black; series of teeth $5{ }^{1} 5 / 3$, the second and third series of upper lip narrowly interrupted, the three rows of lower lip about equal in length.

Grey above, yellowish white beneath, immaculate; crests and tip of tail colourless. Length $26 \mathrm{~mm}$.

The embracement in copulation in axillary. The eggs are rather large $( \pm 3 \mathrm{~mm}$. in diam.), unpigmented. The spawn is usually deposited between leaves of bushes in a mass of mucilage, above or not far from water, the young tadpoles being washed away by the rain (Siedlecki).

Habitat: Sumatra (Lauttador); Banka!; Borneo? (Serawak $\left.{ }^{1}\right)$ ); Java (Batavia; Buitenzorg!; Gadok; Mt. Pangeranggo; Tjibodas!; Pasirdatar, 900 m.!; Sukabumi!; Tjiseureuh, near Sindanglaja!; Tjiandjur; Ambarawa; Wonosobo; Nongkodjadjar, Tengger mts., r $200 \mathrm{~m}$. !).

\section{Rhacophorus nigropalmatus Blgr.}

? Flying frog" Wallace, The Malay Archipelago, London, $1869, \mathrm{I}, \mathrm{p} .3 \mathrm{j}$, with fig. Rhacophorus Reinwardti Hubrecht, Midden-Sumatra, IV, I, I887, p. $9^{2}$ ).

Rhacophorus nigropalmatus Boulenger, Ann. Mag. Nat. Hist., (6) XVI, I895, p. I 70. Rhacophorus nioropalmatus Werner, Zool. Jahrb., Syst., XIII, I900, p. 496, pl. XXXIV, fig. 8.

I) According to Peters, Ann. Mus. Genova, III, 1872, p. 44.

2) Specimen in the Leyden Museum examined by me. 
Rhacophorus nigropalmatus Boulenger, Fasciculi Malayenses, Zool., pt. I, I903, p. 137 , pl. VI, fig. I.

Khacophorus nigropalmatus Isenschmid, Mitth. naturf. Ges. Bern, I903, p. 73, 85, pl. II (skeleton), VI (embryons).

Rhacophorus nigropalmatus Boulenger, Vert. Fauna Malay Penins., Rept. and Batr., London, 1912, p. 25I, fig. $7 \mathbf{I}$.

Vomerine teeth in two long, straight or slightly curved transverse series between the front edges of the choanae. Head a little broader than long; snout rounded, as long as the upper eyelid, longer than deep; canthus rostralis obtuse, curved; loreal region oblique, concave; nostril nearer to the tip of the snout than to the eye; interorbital space broader than the upper eyelid; tympanum distinct, $1 / 2$ to $2 / 3$ the diameter of the eye. Fingers and toes with large disks, those of the three outer fingers as large as or smaller than the tympanum, disks of toes and first finger a little smaller than those of outer fingers; first finger shorter than second, which is shorter than fourth; all the fingers webbed to the disks; third and fifth toe equal in length; toes webbed to the disks; subarticular tubercles distinct; a small, pointed inner, no outer metatarsal tubercle; the heel reaches the nostril, the tip of the snout, or beyond; tibia about half length of head and body.

Smooth or finely granulate above; belly, sides of body and lower surface of thighs coarsely granulate; a strong dermal fold along the outer edge of the fore-arm and another at the heel; less developed folds along outer edges of fourth finger, tarsus and fifth toe; a triangular fold along the inner side of the arm and a small flap above the vent.

In life green above, usually powdered with white, or with lichen-like white markings; one or two conspicuous white spots on the upper surface of the thigh; flanks yellow or orange, veined with black; interdigital membranes black at the base, towards the border yellow or orange, veined with black; throat and chest cream-colour, belly and lower surface of limbs salmon-pink, sometimes dotted with yellow. Length $105 \mathrm{~mm}$.

The spawn is deposited on the earth in masses of mucilage, each containing about 20 to 30 eggs, which are rich of yolk.

Habitat: Sumatra (Laut Tador; Tandjungkasau; Muarolabu!; Benakat, Palembang!); Borneo (Akar riv.; Bidi). Siam; Malay Peninsula. 


\section{IO. Philautus Gistel.}

(Gistel, Naturg. Thierr., I848, p. X; Stejneger, Proc. U.S. Nat. Mus., XXVIII, I905, p. 346).

Ixalus (nom. preocc.), Duméril et Bibron, Erpét. gén., Paris, VIII, 1841, p. 523. Leplomantis Peters, Monatsber. Akad. Berlin, I867, p. 32; Poche, Zool. Anz., XXVI, 1903, p. 700.

Pupil horizontal. Tongue deeply notched and free behind. Vomerine teeth none. Tympanum distinct or hidden. Fingers free or webbed, toes webbed; tips of fingers and toes with disks. Outer metatarsals separated by a groove or narrow web.

Omosternum and sternum with a bony style. An intercalary ossicle between the penultimate and terminal phalanges; the latter obtuse or bifurcate.

This genus is hardly distinguishable from Rhacophorus, as in $R /$. edentulus the vomerine teeth may be absent; perhaps both genera should be united, as Hylella with Hyla.

Distribution: S.E.-Asia, including the western part of the Indo-Australian Archipelago.

$$
\text { Synopsis of the Species. }
$$

$A$. Toes nearly entirely, two outer fingers half webbed.................. I. Ph. bimaculatus p. 269 .

$B$. Toes not more than $2 / 3$, fingers not or feebly webbed.

I. Tympanum at least $2 / 3$ the width of the eye. Fingers free.

1. Toes half webbed. .......... 2. Ph. pictus p. 269 .

2. Toes webbed at the base.

a. Skin of upper parts tubercular..... 3. Ph. favosignatus p. 270.

b. Skin smooth ............ 4. Ph. anodon p. $27 \mathrm{I}$.

II. Tympanum not more than half the width of the eye.

1. Heel reaching beyond the tip of the snout. a. Toes half webbed. Tympanum $1 / 3$ or $2 / 5$ the width of the eye.

«. Interorbital space broader than upper eyelid. Disks of fingers smaller than tympanum. . . . . . . . . . 5. Ph. longicrus p. 272.

$\beta$. Interorbital space broader than upper eyelid. Disks of outer fingers larger than tympanum......... 6. Ph. jacobsoni p. 272. 
$\gamma$. Interorbital space as broad as the upper eyelid. Disks of outer fingers larger than tympanum....... 7. Ph. similis p. 273 .

b. Toes not quite half webbed. Tympanum $1 / 5$ the width of the eye .......

c. Toes with a rudiment of web. Tympanum $2 / 5$ the width of the eye ...... 9. Ph. cornutus p. 274 .

2. Heel not reaching beyond the tip of the 8. Ph. pallidipes p. 273 . snout.

a. Toes $2 / 3$ webbed......... I0. Ph. vittiger p. 275 .

b. Toes $1 / 3$ to $1 / 2$ webbed.

$\alpha$. Nostril a little nearer to end of snout than to eye........... II. Ph, petersi p. 275 .

$\beta$. Nostril equally distant from end of snout and eye ........ 12. Ph. aurifasciatus p. 276 .

\section{Philautus bimaculatus (Ptrs.).}

Leptomantis bimaculata Peters, Monatsber. Akad. Berlin, 1867, p. 32. Ixalus? bimaculatus Boulenger, Cat. Batr. Sal. Brit. Mus., 1882, p. 106. Ixalus bimaculatus Boulenger, Proc. Zool. Soc. London, I898, p. 475.

Snout truncate, hardly longer than the eye; canthus rostralis distinct; nostrils lateral, close to tip of snout, the distance between them equal to their distance from the eye; tympanum hidden, $1 / 3$ the width of the eye. Disks of fingers larger than those of toes; fingers between second and third $1 / 3$, between third and fourth $1 / 2$ webbed; toes nearly entirely webbed, the distal and part of the penultimate phalanx of fourth toe free; a small inner metatarsal tubercle.

Skin smooth; a few tubercles on the chin; belly granulate.

Violet-brown above, with irregular spots and cross-bands, one of which connects the eyes; some yellowish white dots on the lips; limbs with dark cross-bars; yellowish white beneath. Length $34 \mathrm{~mm}$.

Male with an internal vocal sac.

Habitat: Borneo. - Philippines.

\section{Philautus pictus (Ptrs.).}

Ixalus pictus Peters, Monatsber. Akad. Berlin, 1871, p. 580.

Ixalus pictues Peters, Ann. Mus. Genova, III, 1872, p. 44, pl. VI, fig. 2.

Ixalus pictus Boulenger, Cat. Batr. Sal. Brit. Mus., I882, p. 99.

Ixalus pictus Boulenger, Vert. Fauna Malay Penins., Rept. and Batr., London,

I 912, p. 255. 
Snout pointed, longer than the orbit; canthus rostralis strong; loreal region nearly vertical, slightly concave; nostril nearer to tip of snout than to eyc; interorbital space broader than the upper eyelid; tympanum very distinct, $2 / 3$ to $3 / 4$ the diameter of the eye. Disks of fingers and toes large, but smaller than tympanum; fingers free, toes half webbed; subarticular tubercles moderate; a small, very feebly prominent inner metatarsal tubercle; the heel reaches the end of the snout or a little beyond.

Upper parts rough with small granular tubercles; throat smooth, belly coarsely granulate.

Light brown or bright reddish orange above; head, body and limbs with cream-coloured, dark-edged spots; belly white, with or without greenish black blotches. From snout to vent $35 \mathrm{~mm}$.

Habitat: Borneo (Serawak; Barabai). - Malay Peninsula (up to I200 m.); Singapore; Philippines ${ }^{1}$ ).

\section{Philautus flavosignatus (Bttg.).}

Ixalus favosignatus Boettger, Zool. Anz., XVI, I893, p. 339.

Tongue without papilla. Head broader than long; snout pointed, a little longer than the diameter of the orbit; canthus rostralis distinct; loreal region somewhat concave; nostril much nearer to the tip of the snout than to the eye; interorbital space twice the width of the upper eyelid; tympanum $3 / 4$ the diameter of the eye. Disks of fingers large, of toes somewhat smaller; first finger much shorter than second; fingers free, toes webbed at the base; subarticular tubercles strong, a very feeble inner metatarsal tubercle; the heel reaches the tip of the snout.

Skin of upper parts covered with granules and pointed tubercles, which are more crowded in the parotoid region; throat finely, belly and lower side of thighs more coarsely granulate.

Ashy grey above; a line along the border of the upper eyelid and along the canthus rostralis sulphur-yellow, a sulphur-yellow spot in the parotoid region and smaller spots of the same colour on the fore-arm and the hind limbs; the two inner

1) According to De Elera, Catálogo Sist. de toda la Fauna de Filipinas, I, I 895 , p. 450. 
fingers and the three inner toes colourless; beneath ivory white. From snout to vent $45 \mathrm{~mm}$.

Habitat: Java (Tjisurupan).

\section{Philautus anodon (v. Kamp.).}

Rhacophorus anodon v. Kampen, Weber's Zool. Ergebn., Leiden, IV, I907, p. 400, pl. XVI, fig. 4 .

Tongue without papilla. Width of head equal to its length, and $1 / 3$ the length of head and body; snout strongly projecting, transversely truncate; canthus rostralis angular, straight, as long as the upper eyelid; loreal region almost vertical, concave; nostril quite near the tip of the snout; interorbital space twice the width of the upper eyelid; tympanum distinct, nearly as large as and close to the eye. Fingers with large disks, diameter of disk of third finger more than half that of

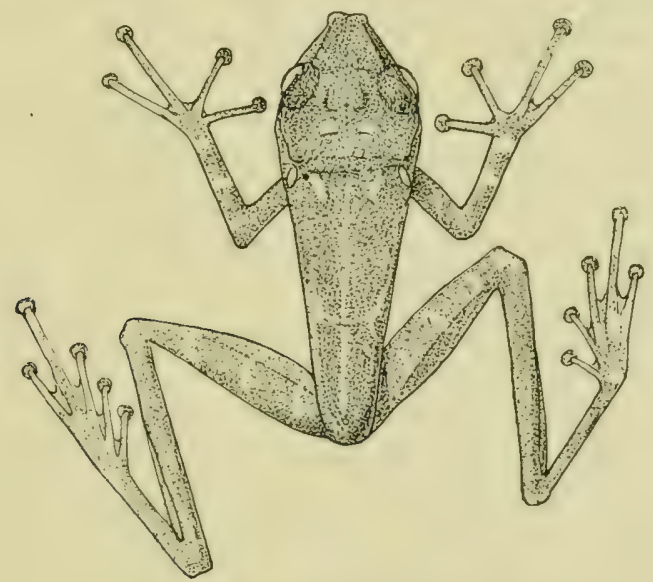

Fig. 29. Philautus anodon (v. Kamp.)., $\pm \times 2$.

tympanum; disks of toes a little smaller than those of fingers; first finger shorter than second, which is shorter than fourth; fingers free, toes with a rudiment of web, which between the three outer toes only includes about one-half of the first phalanx; subarticular tubercles distinct, no metatarsal tubercles; no tarsal fold; terminal phalanges $T$-shaped; the heel reaches beyond the tip of the snout; tibia nearly $2 / 3$ the length of head and body.

Skin adherent to the skull, entirely smooth.

Brownish violet, lighter beneath; several small white dots, 
viz. several ones scattered on back and belly, a series along the canthus rostralis and the outer border of the upper eyelid, other ones along the lips, on fingers and toes, and in transverse series on the limbs, a larger one, bordered with dark, behind each tympanum. Length $24 \mathrm{~mm}$.

Type specimen examined.

Habitat: Sumatra (near Ajer mantjur, Kaju tanam!).

\section{Philautus longicrus (Blgr.).}

Ixalus longicrus Boulenger, Ann. Mag. Nat. Hist., (6) XIV, I894, p. 88.

Snout pointed, as long as the orbit; canthus rostralis angular; loreal region concave; nostril nearer to the end of the snout than to the eye; interorbital space broader than the upper eyelid; tympanum distinct, about $2 / 5$ the diameter of the eye. Disks of fingers a little smaller than the tympanum; fingers free; toes half webbed; the heel reaches far beyond the tip of the snout, the knee reaches the shoulder.

Above rough with small warts; two oblique glandular ridges, converging behind, between the shoulders; throat smooth, belly and lower surface of thighs granulate.

Grey above, with a large X-shaped dark marking or a pair of ) (-shaped bands on the back; a dark cross band or triangular blotch between the eyes, and regular cross bands on the limbs; a black, light edged spot on the knee; a streak below the canthus rostralis, a bar below the eye, and the whole temporal region blackish; dirty white beneath, throat finely speckled with brown, a series of small round spots on the lower lip. From snout to vent $2 \mathrm{I} \mathrm{mm}$.

Male with internal vocal sacs.

Habitat : Pelawan.

\section{Philautus jacobsoni (v. Kamp.).}

Ixalus jacobsoni v. Kampen, Notes Leyden Mus., XXXIV, I9II-12, p. 78.

Tongue without papilla. Head as long as broad; snout pointed, projecting, a little shorter than the upper eyelid, longer than deep; canthus rostralis distinct; loreal region oblique, concave; nostril in the middle between tip of snout and eye; interorbital space broader than the upper eyelid; tympanum rather distinct, $1 / 3$ the diameter of the eye. Disks of fingers large, those of the two outer fingers a little larger 
than the tympanum; disks of toes a little smaller; first finger shorter than second, which is much shorter than fourth; fingers with a feeble rudiment of web; third and fifth toe of equal length; toes half webbed; subarticular tubercles well developed; an oblong inner metatarsal tubercle, no outer one; no tarsal fold; terminal phalanges club-shaped; the heel reaches beyond the tip of the snout; tibia a little more than half length of head and body.

Skin of upper parts smooth, with a few small tubercles on the occiput; throat, belly and lower surface of thighs granular.

Upper parts dark violet-brown, lower surfaces shaded with dark; groin and anterior and posterior surfaces of thighs light-coloured. Length $24 \mathrm{~mm}$.

Type specimen examined.

Habitat: Java (Mt. Ungaran!).

\section{Philautus similis nova spec.}

Tongue without papilla. Head slightly broader than long; snout pointed, projecting, hardly shorter than the upper eyelid, longer than deep; canthus rostralis distinct; loreal region oblique, concave; nostril nearer to the tip of the snout than to the eye; interorbital space as broad as the upper eyelid; tympanum nearly invisible, about $1 / 3$ the width of the eye. Disks of fingers large, those of the two outer fingers a little larger than the tympanum; disks of toes a little smaller; first finger shorter than second, which is much shorter than fourth; fingers with a fecble rudiment of web; third and fifth toe of equal length; toes half webbed; subarticular tubercles well-developed; an oblong inner, no outer metatarsal tubercle; no tarsal fold; the heel reaches hardly beyond the tip of the snout; tibia a little more than half length of head and body.

Upper surfaces smooth; throat, belly and lower surface of thighs granular.

Blackish, variegated with light brown above; limbs with dark cross-bars; lower parts yellowish brown. Length $29 \mathrm{~mm}$. H a bit at: Sumatra (Mt. Talamau, I 200 m.!, E. Jacobson leg.).

\section{Philautus pallidipes (Barb.).}

Ixalus pallidipes Barbour, Proc. Biol. Soc. Washington, XXI, 1908, p. 190. Philautus pallidipes Barbour, Mem. Mus. Comp. Zoöl. Harvard Coll., XLIV, I, I912, p. 69.

INDO-AUSTRALIAN AMPHIBIA. 
Snout rounded, as long as the diameter of the orbit; canthus rostralis moderately distinct; loreal region slightly concave; nostril slightly nearer to tip of snout than to eye; interorbital space broader than the upper eyelid; tympanum rather indistinct, round, $1 / 5$ the width of the eye. Disks of fingers and toes distinct, larger than tympanum; fingers free, toes not quite half webbed; subarticular tubercles small; a small, elongate, inner metatarsal tubercle; the heel reaches beyond the tip of the snout.

Skin minutely granular above; throat and belly more coarsely granular.

Upper surfaces uniform brown, varying from dark reddish to greyish; palms of hands and ends of toes yellow; beneath yellow, speckled with dark brown, most intensely on the throat; thighs barred with dark brown. Length $25 \mathrm{~mm}$.

Habitat: Java (near the summit of Mt. Pangeranggo).

\section{Philautus cornutus (Blgr.).}

Ixalus cormutus Boulenger, Jrn. Fed. Malay St. Mus., VIII, 1920, p. 295, pl. VIII, figs. $2,2 a-c$.

Head as long as broad; snout pointed, projecting, as long as the orbit; canthus rostralis sharp; loreal region concave; nostril nearer to end of snout than to eye; interorbital space a little broader than the upper eyelid; tympanum distinct, $2 / 5$ diameter of eye. Disks larger than the tympanum; fingers free, toes with a mere rudiment of web; subarticular tubercles feeble; a small inner metatarsal tubercle; heel reaching beyond tip of snout; tibia $3 / 5$ to $2 / 3$ length of head and body.

Upper parts with small granular asperities and symmetrical glandular ridges, the most constant of which extends from the eye to the sacral region, converging towards its fellow; another ridge may extend across the interocular region; a strong fold from the eye to the shoulder; a more or less developed conical tubercle on the upper eyelid; lower parts granulate, the granules larger in the males, especially on the throat.

Brown, grey or yellowish-green above, with very variable darker markings; the larger tubercles sometimes whitish; a black streak from the tip of the snout to the shoulder, passing through the eye, and another between the eyes; a yellowish 
spot sometimes present on the upper surface of the snout, followed or not by a yellowish cross-band between the eyes; limbs with more or less distinct dark cross-bands; lower parts yellowish brown, spotted with dark brown; throat of male sometimes blackish. From snout to vent $28 \mathrm{~mm}$.

Male with an internal vocal sac.

Habitat: Sumatra (Sungai Kring, 2200 m., Kurintji peak).

\section{IO. Philautus vittiger (Blgr.).}

Ixalus vittiger Boulenger, Ann. Mag. Nat. Hist., (6) XIX, I897, p. I06.

Snout truncate, not projecting, as long as the orbit; canthus rostralis distinct; loreal region concave; nostril nearer to the tip of the snout than to the eye; interorbital space broader than the upper eyelid; tympanum distinct, haif the diameter of the eye. Disks of fingers and toes smaller than the tympanum; fingers with a rudiment of web, toes $2 / 3$ webbed; a small inner metatarsal tubercle; the heel reaches the tip of the snout.

Skin smooth above; throat smooth, belly granulate.

Pale grey above, spotted all over with black; a white, blackedged streak on each side from eye to groin, another on the arm, and a third one on the thigh; fore-arm and tibia spotted with black; lower parts white. From snout to vent $22 \mathrm{~mm}$.

Habitat: Java (Pengalengan, I $200 \mathrm{~m}$.).

\section{I. Philautus petersi (Blgr.).}

Ixalus aurifusciatus Peters, Ann. Mus. Genova, III, 1872, p. 44.

Ixalus Petersi Boulenger, Proc. Zool. Soc. London, 1900, p. 185, pl. XVII, fig. 3 .

Snout rounded or obtusely pointed, as long as the orbit; canthus rostralis distinct; loreal region concave; nostril a little nearer to the end of the snout than to the eye; interorbital space as broad as the upper eyelid; tympanum distinct, $2 / 5$ or $1 / 2$ the diameter of the eye. Disks of fingers a little smaller than the tympanum; fingers free; toes half webbed; subarticular tubercles moderate; a small inner metatarsal tubercle; the heel reaches the tip of the snout.

Upper parts smooth or with small flat warts; belly and lower surface of thighs granulate.

Grey-brown above, with dark brown symmetrical markings, a cross-band between the eyes being constant; usually a )( or )-(-shaped marking on the anterior part of the body; a 
dark streak on the canthus rostralis; limbs with dark crossbars; lower parts white, with or without brown spots on the throat. From snout to vent $40 \mathrm{~mm}$.

$P h$. petersi is distinguished from $P h$. aurifasciatus, after Boulenger, by a larger, more distinct tympanum, longer digits and a duller colouration. The size of the tympanum and the colouration, however, are very variable in Ph. aurifasciatus, and therefore the differences between the two species are very slight, if at all present. Perhaps the shape of the snout and the position of the nostrils are more valuable characters in distinguishing both species.

Habitat: Natuna islands (Bunguran); Borneo (Mt. Kina Balu; Mt. Penrissen; Mt. Dulit).

\section{I2. Philautus aurifasciatus (Schlg.).}

Hyla aurifasciata (nomen nudum), Kuhl en v. Hasselt, Alg. Konst- en Letterbode, 1822, p. 104.

Hyla aurifasciata Schlegel, Abbild, neuer oder unvollst. bek. Amph., Düsseldorf, $1837-44$, p. 27, pl. IX, fig. 4 .

Ixalus aurifasciatus Boulenger, Cat. Batr. Sal. Brit. Mus, 1882, p. 100.

Ixalus aurifasciatus Boettger, Ber. Offenb. Ver. f. Naturk. (1887-91), 1892, p. 142. Ixalus aurifasciatus v. Kampen, Weber's Zool. Ergebn., Leiden, IV, 1907, p. 404.

Tongue without papilla. Head as long as broad; snout pointed, projecting, about as long as the upper eyelid, longer than deep; canthus rostralis distinct, curved; loreal region oblique, slightly concave; nostril as far from the tip of the snout as from the eye; interorbital space broader than the upper eyelid; tympanum feebly distinct, $1 / 3$ to nearly $1 / 2$ the diameter of the eye. Disks of fingers and toes rather large, those of third finger and fourth toe about as large as the tympanum; first finger shorter than second, which is shorter than fourth; fingers free or very slightly webbed, toes $1 / 3$ to $1 / 2$ webbed; subarticular tubercles moderate; a small, rounded, inner, no outer metatarsal tubercle; no tarsal fold; the heel reaches the nostril or the tip of the snout; tibia half the length of head and body or a little longer.

Skin with a few small tubercles above, granular on throat, belly and lower side of thighs.

Coloration very variable. Brown, black, or green above, darker marbled or with irregular yellow streaks; sometimes a narrow light vertebral line; upper parts of snout often light, 
usually bordered behind by a dark cross-band between the eyes; the light colour of the snout is sometimes extending along the middle of the back; sometimes one to three large yellow or white spots in the loin; limbs with dark cross-bars; lower parts yellowish, greyish or brownish, sometimes with a narrow white median line. From snout to vent $3 \mathrm{I} \mathrm{m}$.

Habitat: Sumatra (Karo countries, $\pm 400 \mathrm{~m}$. ; Petani, Deli, I000 m.!); Java (Buitenzorg?; Mt. Pangeranggo; Mt. Gedeh, \pm 1200 and $1600 \mathrm{~m}$. !; near Tjibodas, $1400-2000 \mathrm{~m}$.; Mt. Ungaran?!; Tengger mts., I $200 \mathrm{~m}$.).

\section{Ir. Nyctixalus Blgr.}

(Boulenger, Ann. Mag. Nat. Hist., (5) X, I882, p. 35).

Pupil vertical. Tongue deeply notched and free behind. Vomerine teeth none. Tympanum distinct or indistinct. Fingers free, toes more or less webbed; tips of fingers and toes with disks. Outer metatarsals united.

Omosternum and sternum with a bony style. No intercalary ossicle between the two distal phalanges ${ }^{1}$ ); terminal phalanges obtuse.

But for the shape of the pupil $N$. robinsoni closely resembles Philautus aurifasciatus, as Annandale remarks, and the same seems to be true for $N$. marcaritifer and $P /$. anodon or favosignatus. It is therefore not impossible, that Nyctixalus is based on species of Philautus, in which the shape of the pupil is variable; it should be desirable to examine this character in living specimens.

Distribution: Java.

Synopsis of the Species.

A. Tympanum distinct, nearly as large as the eye. I. $N$. margaritifer p. 277. B. Tympanum indistinct, very small. .......... N. robinsoni p. 278 .

\section{Nyctixalus margaritifer Blgr.}

Nyctixalus margaritifer Boulenger, Ann. Mag. Nat. Hist., (5) X, r882, p. 35.

Head rather large, broader than the body; snout prominent, obliquely truncate; canthus rostralis angular; loreal region

I) After a communication of Mr. Malc. Smith, who kindly examined a specimen of $N$. margaritifer for me. 
concave; nostril close to tip of snout; interorbital space concave, broader than the upper eyelid; eye large; tympanum very distinct, nearly as large as the eye. Fingers rather long, first shorter than second; toes short, with a slight web at the base, extending as a narrow fringe along the sides; subarticular tubercles moderately developed; a very indistinct inner metatarsal tubercle; the heel reaches the tip of the snout.

Upper surface with very small pearl-like scattered tubercles; upper eyelid strongly tubercular; belly and lower surface of thighs granulate.

Dark brown; a yellow spot on each shoulder; other, smaller, yellow spots on the limbs, fingers and toes; belly marbled with yellow. From snout to vent $35 \mathrm{~mm}$.

Male without vocal sacs.

Habitat: Java (Mt. Wilis).

\section{Nyctixalus robinsoni Annand.}

Nyctixalus margaritifer Barbour, Mem. Mus. Comp. Zoöl. Harvard Coll., XLIV, I, I912, p. 70, pl. VIII, fig. 32.

Nyctixalus robinsoni Annandale, Jrn. Feder. Malay States Mus., VII, 1917, p. I10.

Head large, triangular; snout pointed, a little longer than the orbit; nostril about in the middle between eye and tip of snout; interorbital space flat, broader than the upper eyelid; tympanum indistinct, very small. Disks of fingers and toes at least as large as the tympanum; fingers short, first not extending as far as second; toes about $1 / 3$ webbed; subarticular tubercles feebly developed; an indistinct inner metatarsal tubercle; the heel reaches the anterior border of the eye or the tip of the snout.

Upper surface with scattered rounded tubercles; upper eyelid tubercular; throat and belly coarsely tubercular; a strong fold above the tympanum.

Upper surface dark grey or brown, obscurely mottled; sometimes a silvery cross-bar between the eyes; sides mottled with black and white; hind limbs with irregular brown crossbars; lower surface speckled with grey or entirely infuscated. Length $20 \mathrm{~mm}$.

Male without vocal sacs.

Habitat: Java (near Tjibodas, I400-2000 m.). 


\section{DISTRIBUTION}

\section{OF SPECIES ON THE ISLANDS OF THE INDO-AUSTRALIAN ARCHIPELAGO,}

WITH REMARKS ON THEIR GEOGRAPHICAI, DISTRIBUTION.

\section{Pulo Weh.}

Bufo valhallae Meade-Waldo.

" melanostictus Schneid.

Rana limnocharis Boie.

\section{Simalur.}

Microhyla achatina Boie.

Rana macrodon Kuhl.

" hosii Blgr.

$"$ erythraea (Schlg.).

"nicobariensis (Stol.).

Oxyglossus laevis Gthr.

Rhacophorus leucomystax (Kuhl).

\section{Pulo Babi.}

Rana macrodon Kuhl.

$"$ nicobariensis (Stol.).

Rhacophorus leucomystax (Kuhl).

\section{Nias.}

Ichthyophis glutinosus (L.).

Bufo melanostictus Schneid.

" claviger Ptrs.

Kaloula baleata (S. Müll.).

Microhyla achatina Boie. annectens Blgr.

Rana macrodon Kuhl.

" labialis Blgr.

" erythraea (Schlg.).
Rana nicobariensis (Stol.).

Rhacophorus leucomystax (Kuhl).

Mentawei islands.

Ichthyophis glutinosus (I..).

Nectophryne guentheri Blgr.

Calophrynus punctatus Ptrs.

Phrynella pulchra Blgr.

Rana macrodon Kuhl.

" kuhli Schlg.

$"$ microdisca Bttgr.

" labialis Blgr.

$"$ nicobariensis (Stol.).

Oxyglossus laevis Gthr.

Rhacophorusappendiculatus(Gthr.)

$"$ pardalis Gthr.

\section{Engano.}

Rana macrodon Kuhl.

"nicobariensis (Stol.).

\section{Sumatra.}

\begin{tabular}{|c|c|c|}
\hline Caeciliidae & 2 & species. \\
\hline Pelobatidae & 3 & $n$ \\
\hline Bufonidae & 12 & $\pi$ \\
\hline Dyscophinae & I & $"$ \\
\hline Brevicipitinae & 9 & $n$ \\
\hline Ranidae & 34 & $n$ \\
\hline
\end{tabular}

Ichthyophis glutinosus (L。).

", monochrous (Blkr.). 
Megalophrys montana K. \&v. H. nasuta (Schlg.). hasselti (S. Müll.).

Nectophryne guentheri Blgr.

Bufo jerboa Blgr. borbonica (Boie).

" sumatranus Ptrs.

" melanostictus Schneid.

" asper Gravh.

" claviger Ptrs.

" quadriporcatus Blgr.

" parvus Blgr.

" biporcatus Gravh.

Pseudobufo subasper Tschudi. " werneri (v. Kamp.).

Dyscophina volzi v. Kamp.

Calophrynus pleurostigma(S.Müll.). Phrynella pulchra Blgr.

" pollicaris Blgr.

Kaloula baleata (S. Müll.). pulchra Gray.

Microhyla inornata Blgr.

" achatina Boie.

" annectens Blgr.

" berdmorii (Blyth).

Rana limnocharis Boie.

" cancrivora Gravh.

" macrodon Kuhl.

" kuhli Schlg.

" microdisca Bttgr.

" glandulosa Blgr.

" debussyi v. Kamp.

" jerboa (Gthr.).

" kampeni Blgr.

" crassiovis Blgr.

" hosii Blgr.

" chalconota (Schlg.).

" labialis Blgr.

" erythraea (Schlg.).

" persimilis v. Kamp.

, nicobariensis (Stol.).

" signata (Gthr.).

Oxyglossus laevis Gthr.

Rhacophorus leprosus (S. Müll.). otilophus Blgr.

Rhacophorus leucomystax (Kuhl).

$"$ virgata (Reinw.). colletti Blgr.

" appendiculatus(Gthr.).

" poecilonotus Blgr.

" bifasciatus v. Kamp.

" dulitensis Blgr.

" modestus Blgr.

" pardalis Gthr.

" reinwardti (Boie).

" nigropalmatus Blgr.

Philautus anodon (v. Kamp.).

$$
\begin{array}{ll}
" & \text { similis v. Kamp. } \\
" \quad \text { cornutus (Blgr.). } \\
" \quad \text { aurifasciatus (Schlg.). }
\end{array}
$$

\section{Riou arch.}

? Bufo melanostictus Schneid.

" gymnauchen Blkr.

Rana cancrivora Gravh.

\section{Banka.}

Bufo melanostictus Schneid.

Rana limnocharis Boie.

” cancrivora Gravh.

" baramica Bttgr.

" erythraea (Schlg.).

Rhacophorus leucomystax (Kuhl)

var. sexvirgata (Reinw.).

" reinwardti (Boie).

\section{Natuna islands.}

Nesobia natunae (Gthr.).

Megalophrys nasuta (Schlg.).

Nectophryne guentheri Blgr.

Bufo melanostictus Schneid.

" quadriporcatus Blgr.

" divergens Ptrs.

Calophrynus pleurostigma(S.Müll.).

Microhyla bungurana (Gthr.).

Rana limnocharis Boie. 
Rana macrodon Kuhl.

» hascheana (Stol.).

„. erythraea (Schlg.).

Rhacophorus leucomystax (Kuhl). Philautus petersi (Blgr.).

\section{Borneo.}

\begin{tabular}{|c|c|c|}
\hline Caeciliidae & 2 & species. \\
\hline Pelobatidae & 5 & $n$ \\
\hline Bufonidae & 20 & $n$ \\
\hline Dyscophinae & 2 & $\eta$ \\
\hline Brevicipitinae & I I & \\
\hline Kanidae & 45 & $"$ \\
\hline
\end{tabular}

Ichthyophis glutinosus (L.). monochrous (Blkr.).

Megalophrys montana K. \& v. H.

" nasuta (Schlg.).

$" \quad$ hasselti (S. Müll.).

" gracilis (Gthr.).

" baluensis (Blgr.).

Nectophryne misera Mocq.

$\begin{array}{ll}" & \text { hosii Blgr. } \\ " & \text { everetti Blgr. } \\ " & \text { guentheri Blgr. } \\ " & \text { macrotis Blgr. } \\ " & \text { signata Blgr. } \\ " & \text { maculata Mocq. } \\ " & \text { picturata Smith. }\end{array}$

Bufo leptopus Gthr.

" penangensis (Stol.).

" jerboa Blgr.

" fuligineus Mocq.

" spinulifer Mocq.

" melanostictus Schneid.

" gymnauchen Blkr.

" asper Gravh.

" quadriporcatus Blgr.

„ divergens Ptrs.

" biporcatus Gravh.

Pseudobufo subasper Tschudi.

Colpoglossus brooksi Blgr.

Calliglutus smithi Barb. \& Noble.

Calophrynus pleurostigma(S.Müll.). $"$ heterochirus Blgr.
Calophrynus punctatus Ptrs.

Sphenophryne fusca (Mocq.).

Gastrophryne borneënsis (Blgr.).

Phrynella pollicaris Blgr.

Kaloula baleata (S. Müll.).

" pulchra Gray.

" (?) sundana Ptrs.

Microhyla leucostigma Blgr. annectens Blgr.

Rana limnocharis Boie.

" cancrivora Gravh.

" macrodon Kuhl.

" kuhli Schlg.

" microdisca Bttgr.

" palavanensis Blgr.

" glandulosa Blgr.

" baramica Bttgr.

" luctuosa (Ptrs.).

" laterimaculata Barb.\& Noble.

" jerboa (Gthr.).

" whiteheadi Blgr.

" cavitympanum Blgr.

" everetti Blgr.

" hosii Blgr.

" chalconota (Schlg.).

? " labialis Blgr.

\# erythraea (Schlg.).

" nicobariensis (Stol.).

" signata (Gthr.).

Oreobatrachus baluensis Blgr.

Oxyglossus laevis Gthr.

Staurois larutensis (Blgr.).

$$
\begin{array}{ll}
" \quad \text { guttatus (Gthr.). } \\
" \quad \text { nubilus Mocq. } \\
" \quad \text { tuberilinguis Blgr. }
\end{array}
$$

Simomantis latopalmata (Blgr.).

Cornufer baluensis Blgr.

Rhacophorus otilophus Blgr.

$\begin{array}{ll}" & \text { leucomystax (Kuhl). } \\ " & \quad \text { var. sex- } \\ & \text { virgata (Reinw.) } \\ " & \text { colletti Blgr. } \\ " & \text { macrotis Blgr. } \\ " & \text { macroscelis Blgr. } \\ & \text { hosii Blgr. }\end{array}$


Rhacophorusappendiculatus(Gthr.) dulitensis Blgr. acutirostris Mocq. shelfordi Blgr. fasciatus Blgr. pardalis Gthr.

? " reinwardti (Boie). ” nigropalmatus Blgr.

Philautus bimaculatus (Ptrs.). $" \quad$ pictus (Ptrs.).

$" \quad$ petersi (Blgr.).

\section{Pelawan.}

? Ichthyophis monochrous (Blkr.). Megalophrys ligayae Taylor.

Bufo philippinicus Blgr. hasselti (S. Müll.). ?" divergens Ptrs.

Sphenophryne beyeri (Taylor). Rana palavanensis Blgr. " glandulosa Blgr.

" papua Less.

Staurois nubilus Mocq.

Rhacophorus leucomystax (Kuhl).

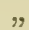
" virgata (Rein

" everetti Blgr.

" pardalis Gthr.

Philautus longicrus (Blgr.).

\section{Pulo Laut.}

Rana cancrivora Gravh.

\section{Java.}

\begin{tabular}{|c|c|c|}
\hline Caeciliidae & 2 & species. \\
\hline Pelobatidae & 2 & $"$ \\
\hline Bufonidae & 7 & $m$ \\
\hline Brevicipitinae & 4 & $\pi$ \\
\hline Ranidae & 23 & $n$ \\
\hline & & \\
\hline
\end{tabular}

Ichthyophis glutinosus (L.). monochrous (Blkr.).
Megalophrys montana K. \& v. H. hasselti (S. Müll.).

Nectophryne borbonica (Boie).

Bufo cruentatus Tschudi.

„ melanostictus Schneid.

" asper Gravh.

" parvus Blor.

" biporcatus Gravh.

" chlorogaster Daud.

Kaloula baleata (S. Müll.).

Microhyla achatina Boie.

" annectens Blgr.

" palmipes Blgr.

Rana limnocharis Boie.

„ cancrivora Gravh.

" macrodon Kuhl.

" kuhli Schlg.

" microdisca Bttgr.

?" hascheana (Stol.).

" jerboa (Gthr.).

" whiteheadi Blgr.

" hosii Blgr.

" chalconota (Schlg.).

" erythraea (Schlg.).

"nicobariensis (Stol.).

Oxyglossus lima (Kuhl).

Rhacophorus leucomystax (Kuhl).

var. sexvirgata (Reinw.). javanus Bttgr. reinwardti (Boie).

Philautus flavosignatus (Bttgr.).

" jacobsoni (v. Kamp.).

" pallidipes (Barb.)

" vittiger (Blgr.).

" aurifasciatus (Schlg.).

Nyctixalus margaritifer Blgr.

» robinsoni Annand.

\section{Madura:}

Bufo melanostictus Schneid.

" biporcatus Gravh.

Microhyla palmipes Blgr.

Rana cancrivora Gravh. 


\section{Bali.}

Bufo biporcatus Gravh. Rana limnocharis Boie. " cancrivora Gravh.

\section{Lombok.}

Bufo cavator Barb. „ biporcatus Gravh. Oreophryne monticola (Blgr.). Rana limnocharis Boie. " cancrivora Gravh. " modesta Blgr.

Rhacophorus leucomystax (Kuhl).

\section{Sumbawa.}

Rana limnocharis Boie. " cancrivora Gravh.

\section{Flores.}

Kaloula pulchra Gray. Rana cancrivora Gravh.

" modesta Blgr.

" microdisca Bttgr.

" papua Less.

Oxyglossus laevis Gthr.

\section{Ombai.}

Hyla everetti Blgr.

Rana cancrivora Gravh.

\section{Wetar.}

Rana verruculosa Roux. " elberti Roux.

\section{Sumba.}

Hyla everetti Blgr.

Kaloula baleata (S. Müll.).

Rana cancrivora Gravh.

Rhacophorus leucomystax (Kuhl).

\section{Savu.}

Hyla everetti Blgr.

\section{Roti.}

Rana cancrivora Gravh.

\section{Timor.}

Hyla everetti Blgr.

„ infrafrenata Gthr.

Rana cancrivora Gravh.

" verruculosa Roux.

Rhacophorus leucomystax (Kuhl). , var. sexvirgata (Reinw.).

\section{Saleyer.}

Rana cancrivora Gravh.

" modesta Blgr.

Rhacophorus leucomystax (Kuhl).

\section{Kabaëna.}

Rhacophorus leucomystax (Kuhl).

\section{Buton.}

Rana cancrivora Gravh.

\section{Celebes.}

$\begin{array}{lrc}\text { Bufonidae } & 2 & \text { species. } \\ \text { Brevicipitinae } & 4 & \pi \\ \text { Ranidae } & \text { I } 6 & \\ & 22 & \text { species. }\end{array}$

Bufo celebensis Schlg.

" biporcatus Gravh.

Oreophryne variabilis (Blgr.). $" \quad$ celebensis (F. Müll.).

Kaloula baleata (S. Müll.).

" pulchra Gray.

Rana cancrivora Gravh.

” grunniens Daud.

" modesta Blgr.

", kuhli Schlg.

" microdisca Bttgr.

„ palavanensis Blgr.

" macrops Blgr.

" papua Less.

" celebensis (Schlg.).

" chalconota (Schlg.) 
Rana erythraea (Schlg.).

Oxyglossus laevis Gthr.

Rhacophorus leucomystax (Kuhl).

var. sexvirgata (Reinw.).

" georgii Roux.

" edentulus F. Müll.

$" \quad$ monticola Blgr.

\section{Talaut islands.}

Hyla infrafrenata Gthr. Rana modesta Blgr.

\section{Morotai.}

?Oreophryne senckenbergiana

Rana papua Less. Bttgr.

\section{Halmahera.}

Hyla rueppelli Bttgr.

" infrafrenata Gthr.

Oreophryne senckenbergiana Bttgr. Hylophorbus montanus (Bttgr.).

Rana modesta Blgr. boettgeri (v. Méh.).

" rugata v. Kamp.

" papua Less.

\section{Ternate.}

Hyla infrafrenata Gthr.

?Oreophryne senckenbergiana

Rana papua Less. Bttgr.

? Rhacophorus leucomystax (Kuhl) var. sexvirgata (Reinw.).

\section{Batjan.}

Hyla infrafrenata Gthr.

? Oreophryne senckenbergiana

Rana modesta Blgr. Bttgr.
Gebe.

Hyla bernsteini Horst.

? " genimaculata Horst.

\section{Gag.}

? Hyla genimaculata Horst.

\section{Misool.}

Hyla amboinensis Horst.

" infrafrenata Gthr.

" aruensis Horst.

\section{Buru.}

Hyla infrafrenata Gthr.

Rana modesta Blgr.

" papua Less.

\section{Ceram.}

Hyla amboinensis Horst.

" infrafrenata Gthr.

„ vagabunda Ptrs. \& Dor.

Rana modesta Blgr.

" papua Less.

" grisea v. Kamp.

\section{Ambon.}

Hyla amboinensis Horst.

, infrafrenata Gthr.

? Oreophryne celebensis (F. Müll.).

Rana grunniens Daud.

" modesta Blgr.

Uliaser islands.

Rana modesta Blgr.

Nusa Laut.

Hyla infrafrenata Gthr.

Rana grunniens Daud.

\section{Goram island.}

Rana rugata v. Kamp. 


\section{Timorlaut islands.}

Hyla infrafrenata Gthr. " rubella Gray.

Rana papua Less.

\section{Kei islands.}

Hyla infrafrenata Gthr. Rana rugata v. Kamp.

” papua Less.

\section{Aru islands.}

Batrachopsis melanopyga (Doria). Hyla bicolor (Gray).

" infrafrenata Gthr.

” aruensis Horst.

" congenita Ptrs \& Dor.

Oreophryne mertoni (Roux).

Microbatrachus pusillus Roux.

Rana arfaki Meyer.

" papua Less.

\section{Waigeu.}

Hyla infrafrenata Gthr.

Ràna beauforti (v. Kamp.).

" arfaki Meyer.

” papua Less.

\section{Batanta.}

? Oreophryne celebensis (F. Müll.). Rana rugata v. Kamp.

„ papua Less.

\section{Salawati.}

Hyla bernsteini Horst.

, infrafrenata Gthr.

? Oreophryne senckenbergiana

Bttgr.

\section{New Guinea.}

Pelobatidae I species.

Cystignathidae 3 n

Hylidae 33 "

Brevicipitinae 38,

Ranidae

Io $n$

$\overline{85}$ species.
Batrachopsis melanopyga (Doria). Phanerotis fletcheri Blgr.

Ranaster convexiusculus Macl.

Crinia signifera Girard.

Nyctimantis papua Blgr. " granti Blgr.

Hyla rhacophorus v. Kamp.

" papuensis Wern.

" graminea Blgr.

" bernsteini Horst.

" eucnemis Lönnb.

" obsoleta Lönnb.

" montana Ptrs \& Dor.

" fallax Blgr.

" brachypus (Wern.).

" atropunctata v. Kamp.

$"$ longicrus (Blgr.).

" albolabris Wand.

" arfakiana Ptrs. \& Dor.

" wolterstorffi (Wern.).

" pratti Blgr.

" wollastoni Blgr.

" chloronota (Blgr.).

" jeudei Wern.

", bicolor (Gray).

" impura Ptrs. \& Dor.

" macgregori Dgl.-Og.

" infrafrenata Gthr.

" spengeli Blgr.

" humeralis Blgr.

" sanguinolenta v. Kamp.

" caerulea (White).

" angiana Blgr.

" congenita Ptrs. \& Dor.

" vagabunda Ptrs. \& Dor.

$"$ nasuta (Gray).

$"$ (?) dorsalis (Macl.).

Liophryne rhododactyla Blgr.

$" \quad$ brevipes Blgr.

" kampeni Blgr.

Sphenophryne cornuta Pts. \& Dor.

klossi Blgr.

macrorhyncha

(v. Kamp.).

polysticta (v. Méh.). 
Sphenophryne fusca (Mocq.). Oreophryne verrucosa (Blgr.).

$\begin{array}{ll}" & \text { ateles (Blgr.). } \\ & \text { crucifera (v. Kamp.). } \\ & \text { anthonyi (Blgr.). } \\ & \text { loriae (Blgr.). } \\ & \text { biroi (v. Méh.). } \\ & \text { albopunctata } \\ & \quad \text { (v. Kamp.). }\end{array}$

Oxydactyla brevicrus v. Kamp.

Callulops doriae Blgr.

Xenobatrachus rostratus (v. Méh.). " ocellatus(v.Kamp.). " macrops (v. Kamp.). " bidens (v. Kamp.). " giganteus(v.Kamp.). " ophiodon Ptrs.\&Dor. Xenorhina oxycephala (Schlg.). Asterophrys turpicula (S. Müll.). Copiula oxyrhina (Blgr.).

" (?) rostellifera Wand.

Choerophryne proboscidea v.Kamp. Hylophorbus biroi (v. Méh.).

$\begin{array}{ll}" & \text { variegatus v. Kamp. } \\ " & \text { rufescens Macl. } \\ " & \text { ocellatus (v. Méh.). } \\ " & \text { robustus (Blgr.). } \\ " & \text { microtis (Wern.). } \\ " & \text { (?) neuhaussi (Vogt). }\end{array}$

Aphantophryne pansa Fry. Cophixalus geislerorum Bttgr. Pomatops valvifera Barb.

Rana grunniens Daud.

" moszkowskii (Vogt).

” rugata v. Kamp.

” punctata (Ptrs. \& Dor.).

” arfaki Meyer.

". papua Less.

" daemeli (Steind.).

? " kreffti Blgr.

" grisea v. Kamp.

Cornufer unicolor Tschudi.

Frederik Hendrik island.

Ranaster convexiusculus Macl.
Hyla infrafrenata Gthr.

Rana papua Less.

\section{Jobi.}

? Hyla fallax Blgr.

" ouwensi Barb.

" atropunctata v. Kamp.

" infrafrenata Gthr.

" obtusirostris (Meyer).

Rana rugata v. Kamp.

" papua Less.

\section{Meisor.}

Hyla infrafrenata Gthr.

Rana rugata v. Kamp.

\section{Roön island.}

Rana rugata v. Kamp. var. rubristriata (Barb.).

\section{Schouten islands.}

Rana rugata v. Kamp.

\section{Yule island.}

Hyla impura Ptrs. \& Dor.

" congenita Ptrs \& Dor.

\section{Ferguson island.}

? Hyla macgregori Dgl.-Og.

, infrafrenata Gthr.

Rana rugata v. Kamp.

$"$ papua Less.

d'Entrecastaux islands.

-Hyla infrafrenata Gthr.

Murray island.

Rana papua Less.

Trobriand island.

Hyla infrafrenata Gthr.

St. Aignan island.

Copiula oxyrhina (Blgr.). 
Hylophorbus robustus (Blgr.). Rana rugata v. Kamp.

\section{Sudest island.}

Genyophryne thomsoni Blgr.

\section{Duke of York island.}

Hyla infrafrenata Gthr.

Rana rugata v. Kamp.

\section{Faor.}

Rana rugata v. Kamp.

\section{Bertrand island.}

Rana rugata v. Kamp.

\section{Bismarck arch.}

Hyla brachypus (Wern.).

" militaria (Ramsay).

Rana ventricosa Vogt.

" boulengeri (Bttgr.).
Rana rugata v. Kamp.

" solomonis (Blgr.).

" punctata (Ptrs. \& Dor.).

" kreffti Blgr.

Solomon islands.

?. Hyla atropunctata v. Kamp.

" macrops Blgr.

„ thesaurensis Ptrs.

" lutea Blgr.

, solomonis Vogt.

Rana guppyi Blgr.

" bufoniformis Blgr.

" opisthodon Blgr.

„ rugata v. Kamp.

$"$ solomonis (Blgr.).

" kreffti Blgr.

Ceratobatrachus guentheri Blgr.

Cornufer vitiensis (Girard).

" guppyi Blgr.

Batrachylodes vertebralis Blgr.

Among the seven families of Amphibia, which inhabit the Indo-Australian Archipelago two (Caeciliidae, Pelobatidae) are indian, two (Cystignatlidae, Hylidae) australian. The three other ones (Bufonidae, Brevicipitidae, Ranidae) contain both indian and australian species; they are, however, essentially indian, only a few species of them inhabiting Australia; moreover, in the case of the Bufonidae, the australian species belong to genera entirely different from those of the Archipelago. Hence we may assume that 5 families (Caeciliidae, P'elobatidae, Bufonidae, Brevicipitidae, Ranidae) have reached the Archipelago from the west, the 2 other ones (Cystignathidae, Hylidae) from the east.

As to the distribution in the. Archipelago itself the subfamily Dyscophinae of the Brevicipitidae is only known in a few species from Sumatra and Borneo, the Caeciliidae in only two species from Sumatra, Borneo, Java and a few smaller surrounding islands, the Bufonidae reach eastward to Celebes and Lombok. The Pelobatidae have a discontinuous distribution, inhabiting Sumatra, Borneo and Java in the west, New Guinea and the Aru islands in the east; the only eastern species, however, belongs to an endemic genus, which perhaps 
is more nearly related to the australian Cystignathidae than to the Pelobatidae.

The Ranidae are distributed in the entire Archipelage, though generally decreasing in number of species eastward. So they are less numerous in New Guinea than in the much smaller island Celebes, and in this island, again, their number of species is smaller than in Java. It is, however, remarkable that a comparatively large number of endemic species and even two endemic genera inhabit the Bismarck and Solomon islands in the extreme eastern part of the area of distribution of this family.

A similar phenomenon is shown by the Breviçipitidae in still higher degree. This indian family has its largest number of genera and species in New Guinea, and the small Sudest island, east of New Guinea, possesses even an endemic subfamily, the Genyophryninae.

The distribution of the Amphibia does not show a sharp boundary between the Indian and the Australian regions. Whereas the western part of the Indo-Australian Archipelago, including Celebes and the Lesser Sunda islands, has a purely indian character concerning its fauna of Amphibians, the eastern part, including the Moluccos and the Timor archipelago, is a region of transition, in which the indian and the australian fauna are mixed. Noreover, this region shows an own character by the high development of the Brevicipitidae among the indian, and the Hylidae among the australian families.

The characteristics of the distribution of the Amphibia in the Archipelago may be explained in the most simple manner by assuming the former existence of narrow and inconstant land connections (Sarasin) between the Sunda islands and New Guinea, as has been explained by me ${ }^{1}$ ). Such narrow bridges must be an obstacle for the distribution of Amphibians, which generally are rare on small islands. This fact may be shown by comparing the numbers of species of Amphibia inhabiting various islands of the Indo-Australian Archipelago with those of the Lacertilia of the same islands ${ }^{2}$ ), f. i.:

1) Nova Guinea, 1X, I, 1909, p. 47.

2) Taken from: N. de Rooy, The Reptiles of the Indo-Australian Archipelago, I, Leiden, I9I5. 
289

\begin{tabular}{|c|c|c|c|}
\hline & Amphibia. & Lacertilia. & $\begin{array}{l}\text { Proportion } \\
\text { of Amphibia. }\end{array}$ \\
\hline Nias ...... & I I & 23 & 0,48 \\
\hline Engano .... & 2 & 9 & 0,22 \\
\hline Sumatra.... & $6 \mathrm{I}$ & 62 & 0,98 \\
\hline Borneo..... & 85 & 9 I & 0,93 \\
\hline Java ....... & 38 & 43 & 0,88 \\
\hline Lombok . . . . & 7 & I I & 0,64 \\
\hline Timor ..... & 5 & 15 & 0,33 \\
\hline Celebes ..... & 22 & $4 I$ & 0,54 \\
\hline Halmahera ... & 9 & 29 & $0,3 \mathrm{I}$ \\
\hline Ternate .... & 4 & 24 & 0,17 \\
\hline Ceram ..... & 6 & 20 & 0,30 \\
\hline Ambon..... & 5 & 22 & 0,23 \\
\hline Kei islands ... & 3 & 26 & O, I I \\
\hline Aru islands ... & 9 & 29 & 0,3 I \\
\hline New Guinea. . . & 85 & I I 3 & 0,75 \\
\hline
\end{tabular}

It results from this table, that the number of species of Amphibia is relatively the largest in the larger islands, the smallest in smaller islands and especially in the islands between Celebes and New Guinea, agreeing with the supposition that these islands have had only narrow land connections, which were hardly to transgress by Amphibians. 


\section{ALPHABETICAL INDEX}

$\mathrm{OF}$

\section{GENERA AND SPECIES.}

achatina, Hylaplesia I54.

achatina, Microhyla I 53, I 54.

achatina var. moluccensis, Micro-

hyla I I5.

acutirostris, Rhacophorus 244, 260. affinis, Méhelyia I 8.

albolabris, Hyla 25, 39 .

albopunctata, Oreophryne II I,

I 19.

albopunctata, Sphenophryne I 9.

amboinensis, Hyla 24, 29.

angiana, Hyla 25,59 .

angustopalmata, var. of Rana tigrina

I 70 .

annectens, Microhyla $\mathbf{5} 53, \mathbf{1}_{5} 6$.

anodon, Philautus 268, $27 \mathrm{r}, 277$.

anodon, Rhacophorus $27 \mathrm{I}$.

Ansonia penangensis 75 .

anthonyi, Oreophryne III, I I 7.

anthonyi, Sphenophryne Ir 7 .

Anura I, 4.

Aphantophryne Ioo, I45.

Aphantophryne pansa $\mathbf{I} 45$.

Apoda r.

appendiculatus, Polypedates 255.

appendiculatus, Rhacophorus 243 .

255.

Arcifera 4, 5 .

arfaki, Limnodytes I99, 20 I.

arfaki, Rana I63, I65, I 99.

arfakiana, Hyla 25, 27, 39, 41, 42. aruensis, Hyla 27, 56 . asper, Bufo 71, 74, 82

Asterophrys 99, I33.

Asterophrys melanopyga 17 .

Asterophrys turpicula $\mathbf{3} 33$.

ateles, Oreophrýne I I I, I I5.

ateles, Sphenophryne II5.

atra, Xenorhina $\mathbf{1} 32$.

atropunctata, Hyla 25, 37, 39.

aurifasciata, Hyla 276.

aurifasciatus, Ixalus 275,276 .

aurifasciatus, Philautus 269,276 ,

277.

Austrochaperina 104.

baleata, Callula 148.

baleata, Kaloula 148 .

baleatus, Bombinator 148 .

baluense, Leptobrachium I6.

baluensis, Cornufer 239, 24 I .

baluensis, Megalophrys 7, г6.

baluensis, Oreobatrachus 229 .

baramica, Rana I64, I95.

basipalmata, Chaperina 107.

Batrachia .

Batrachopsis 6, I6.

Batrachopsis melanopyga 17 .

Batrachylodes I60, $24 \mathrm{I}$.

Batrachylodes vertebralis 242 .

beauforti, Cornufer r 89 .

beauforti, Platymantis $\mathbf{I} 9$.

beauforti, Rana $162, \mathbf{1} 89$.

Berdmorei, Engystoma $15^{8}$. 
berdmorii, Microhyla $153,{ }_{5} 8$. bernsteini, Hyla 24, 26, 3 I. beyeri, Chaperina I ro. beyeri, Sphenophryne 105, I Iо. bicolor, Eucnemis 44. bicolor, Hyla 26, 27,44 . bicolor, Hylella 44. bidens, Xenobatrachus 127, I29. bidens, Xenórhina r 29. bifasciatus, Rhacophorus 243,257 . bilineata, Hyla 224. bimaculata, Leptomantis 269 . bimaculatus, Ixalus 269 . bimaculatus, Philautus 268, 269. biporcatus, Bufo 74, 86, 87, 90. birói, Hylophorbus 137 , 138 . biroi, Oreophryne I I I, I 8 . Birói, Phrynixalus I 38 . biroi, Sphenophryne II7, II8. blythii, var. of Rana macrodon $\mathbf{1 7 5}$. Boettgeri, Gnathophryne I40. boettgeri, Hylophorbus I37, I40. Bombinator baleatus 148 .

Bombinator oxycephalus I32. borbonica, Hylaplesia 70. borbonica, Nectophryne 66, 70 . borbonicus, Bufo 70,78 . borneense, Engystoma I 24. borneënsis, Gastrophryne I24. boulengeri, Cornufer 187 . boulengeri, Hyla $3^{6 .}$ boulengeri, Hylella 35 . boulengeri, Platymantis 187 . boulengeri, Rana э62, 187, 188 . boulengeri, Scytopis 35 . brachypus, Hyla 25, 37 . brachypus, Hylella 37. Brevicipitidae 5, 95 . Brevicipitinae 5, 98, 123, I34. brevicrus, Oxydactyla 122. brevipes, Liophryne ıо०, гог. brooksi, Colpoglossus 97. bürgeri, Rhacophorus I6r. Bufo $5,66,72$, 123. Bufo asper 7I, 74, 82 .
Bufo biporcatus $74,86,87,90$.

Bufo borbonicus 70,78 .

Bufo cavator 74,89 .

Bufo celebensis 74,84 .

Bufo chlorogaster 74,92 .

Bufo claviger $74,86,88$.

Bufo cruentatus 73,78 .

Bufo divergens 74, 88.

Bufo fuligineus 73,77 .

Bufo gymnauchen $74,8 \mathrm{I}$.

Bufo jerboa 73,76 .

Bufo leptopus 73, 75 .

Bufo longecristatus 82 .

Bufo melanostictus $73,74,80,82$, 87,9 .

Bufo minimus 98 .

Bufo montanus 78 .

Bufo obscurus 83 .

Bufo parvus 74, 88.

Bufo penangensis $73,74,75$.

Bufo philippinicus 74,86 .

Bufo quadriporcatus 74,87 .

Bufo scaber 80.

Bufo spinipes 82 .

Bufo spinulifer 73,79 .

Bufo studeri 102.

Bufo sumatranus 73,78 .

Bufo valhallae 73,79 .

Bufonidae 4,65 .

bufoniformis, Rana 162, I84, 186 . bungurana, Microhyla 152, 154 . bunguranum, Diplopelma ${ }_{54}$.

Caecilia glutinosa 2.

Caecilia hypocyanea 2.

Caeciliidae I. caerulea, Hyla 27, 56, 58, 60 . caerulea, Rana 58 . caeruleus, Pelodryas 58. Calamita dolichopsis 52 .

Calliglutus 95, 98.

Calliglutus smithi 98 .

Callula I 47 .

Callula baleata 148 .

Callula frontifasciata II5. 
Callula pulchra ${ }_{5} 5^{\circ}$.

Callula sundana I $_{5}$.

Callulops 99, 123.

Callulops doriae 123 .

Calohyla celebensis I 48 .

Calohyla sundana $\mathbf{I} 5$ I.

Calophrynus 99, rо2.

Calophrynus heterochirus 102, 104.

Calophrynus pleurostigma 102 .

Calophrynus punctatus 102, 104.

Calophrynus stellatus ro4.

cancrivora, Rana I 62, I 66, 1 70, 172. cancrivora, var. of Rana tigrina 170. cavator, Bufo .74, 89.

cavitympanum, Rana I63, I67, 2 I r.

celebensis, Bufo 74, 84 .

celebensis, Calohyla 148.

celebensis, Limnodytes 204 .

celebensis, Oreophryne III, II2.

celebensis, Rana 165, 204.

celebensis, Sphenophryne iI2.

ceramensis, var. of Rana grisea 207.

Ceratobatrachus I60, 228 .

Ceratobatrachus guentheri 228 .

Ceratophryne nasuta г.

Ceratophrys montana 9.

Ceratophrys turpicola 133.

ceratophthalmus, Chaperina 105. chalconota, Rana I66, I67, $217,220$.

chalconotus, Hyla 215, 217.

Chaperina I04.

Chaperina basipalmata 107.

Chaperina beyeri i ro.

Chaperina ceratophthalmus 105.

Chaperina friedericii ro5.

Chaperina fusca rog.

Chaperina macrorhyncha $10 \%$

Chaperina polysticta ro8.

Chaperina punctata 107.

Chaperina quatuorlobata 107.

chiropterus, Rhacophorus 258.

chlorogaster, Bufo 74, 92.

chloronota, Hyla 25, 42:

chloronota, Hylella 42 .

Choanacantha 126.
Choanacantha mehelyi 127 .

Choanacantha rostrata 127 .

Choerophryne $100,136$.

Choerophryne proboscidea 136 .

chysii, Megalophrys ro.

claviger, Bufo $74,86,88$.

colletti, Rhacophorus $243,250$.

Colpoglossus 95, 97.

Colpoglossus brooksi 97 .

congenita, Hyla $27,28,60$.

congenita, Litoria 60.

conspicillata, Rana 178 .

convexiusculus, Ranaster 19 .

Cophixalus roo, 146.

Cophixalus crucifer I 16 .

Cophixalus geislerorum 95, $\mathbf{1 4 6 .}$

Copiula 99, 134.

Copiula oxyrhina $134,135$.

Copiula rostellifer $\mathbf{1} 35$.

Copiula rostellifera $\mathrm{r}_{34}, \mathbf{1} 35$.

Cornufer $160,238$.

Cornufer baluensis 239, 24I .

Cornufer beauforti 189 .

Cornufer boulengeri 187 .

Cornufer corrugatus 190 .

Cornufer corrugatus rubristriatus I9I.

Cornufer dorsalis 239.

Cornufer guppyi 239, 240.

Cornufer moszkowskii i 88 .

Cornufer punctatus I92.

Cornufer solomonis I9I.

Cornufer unicolor 105, 239, 240.

Cornufer vitiensis 239.

cornuta, Sphenophryne 105.

cornutus, Ixalus 274 .

cornutus, Philautus 269, 274 .

corrugata, Platymantis 190.

corrugata, Rana I90, 192.

corrugata var. papuensis, Platy-

mantis 190.

corrugatus, Cornufer 190.

corrugatus, Hylodes 190.

corrugatus rubristriatus, Cornufer

I9I. 
crassiovis, Rana 163, 2 I3.

Crinia I8, 2 I.

Crinia signifera 2 I.

crucifer, Cophixalus I I6. crucifera, Oreophryne II I, Ir6. cruciger, Rhacophorus 250. cruentata, Hylaplesia 78 . cruentatus, Bufo 73,78 . cyanea, Hyla $5 \mathrm{I}$.

Cystignathidae 4, I 7, I8.

Daemeli, Hylorana 205. daemeli, Rana 165, 204, 205. debussyi, Rana 164, I67, I 97, I 99. decorata, Rana i96.

Diplopelma I $_{52}$.

Diplopelma bunguranum I 54 .

Discodeles I6 1, I 83 . divergens, Bufo 74, 88 .

Docidophryne spinipes $8 \mathrm{I}$. dolichopsis, Calamita 52 .

dolichopsis, Hyla 52 .

dolichopsis var. pollicaris, Hyla 55 .

dolichopsis var. tenuigranulata, Hyla $5^{2}$. doriae, Callulops 123. dorsalis, Cornufer 239. dorsalis, Hyla 27, 65, dorsalis, Litoria 65 . dubia, Gnathophryne 143. dubia, Xenorhina I 43. dubius, Hylophorbus I38, I43. dulitensis, Rhacophorus 243,258 . durheimi, Rana 2 I5. Dyscophina volzi 96 . Dyscophinae 5, 95 .

Ecaudata 4.

edentulus, Rhacophorus 242, 244 , 259, 268.

elberti, Rana 165, 200, 204.

Eleutherognathinae 99.

elongata,var. of Rana erythraea 224.

Engystoma I 24.

Engystoma Berdmorei I $5^{8}$.
Engystoma borneense 124 . Engystomatidae 95, 98. Epicrium 2. Epicrium monochrous 3 . erythraea, Hyla 222. erythraea, Rana 165, 166, 222. erythraea var. elongata, Rana 224. erythraeus, Limnodytes 222.

Eucnemis bicolor 44 . eucnemis, Hyla 24, 32 . everetti, Hyla 26, 5 I. everetti, Nectophryne 66, 68. everetti, Rana I63, 2 I4, 2 I 7 . everetti, Rhacophorus 243, 25 . exigua, Nectophryne 68.

fallax, Hyla 25, 26, 35 . fallax, Hylomantis 44 . fallax, Rana $20 \mathrm{r}$.

fasciatus, Rhacophorus 244,262 . Fejérvárya limnocharis I 67.

Firmisternia 4, 95.

flavosignatus, Ixalus 270.

flavosignatus, Philautus 268, 270 , 277.

fletcheri, Phanerotis I 8 . florensis, Rana 20 r.

friedericii, Chaperina 105. frontifasciata, Callula $\times 5$. fuligineus, Bufo 73, 77 . fusca, Chaperina rog. fusca, Phrynomantis I 2 . fusca, Sphenophryne ro5, rog.

Gastrophryne 99, x24.

Gastrophryne borneënsis 124 . geislerorum, Cophixalus 95, г 46 . genimaculata, Hyla $26,47$. Genyophryne I59. Genyophryne thomsoni 159. Genyophryninae 5, I 59. georgii, Rhacophorus 243, 253. gigantea, Xenorhina 130. giganteus, Xenobatrachus I 27, I30. glandulosa, Rana 164, I94, I96. 
glutinosa, Caecilia 2.

glutinosus, Ichthyophis 2.

Gnathophryne 99, I37.

Gnathophryne Boettgeri I 40.

Gnathophryne dubia 143.

Gnathophryne robusta 143 . gracile, Leptobrachium 15. gracilis, Megalophrys 7, 15 . gracilis, Rana 167.

graminea, Hyla 24, 30.

granti, Nyctimantis 22, 23.

grisea, Rana 165, 204, 207.

grisea var. ceramensis, Rana 207. grunniens, Rana $163,172,176$,

I7 8,182 .

guentheri, Ceratobatrachus 228 . guentheri, Nectophryne 66, 68. guentheri, Pedostibes 68. guppyi, Cornufer 239, 240. guppyi, Rana 162, 183. guttata, Litoria 52. guttata, Rana 235 .

guttatus, Ixalus 235.

guttatus, Staurois 234, 235 . gymnauchen, Bufo 74, 8I. Gymnophiona I.

Halophila vitiensis 239.

hascheana, Rana r64, I8r.

Hascheanus, Polypedates I8I.

hasselti, Megalophrys 5, 7, I3.

Hasseltii, Leptobrachium I3.

Hasseltii, Rana I3.

heterochirus, Calophrynus ro2, I04.

hosii, Nectophryne 66,67 .

hosii, Rana 166, 167, 215, 2 18.

hosii, Rhacophorus 243, 253.

humeralis, Hyla 25,56 .

Hyla 5, 22, 24, 268.

Hyla spec. 28, 34 .

Hyla albolabris 25,39 .

Hyla amboinensis $24,29$.

Hyla angiana 25,59 .

Hyla arfakiana 25, 27, 39, 4r, 42. Hyla aruensis 27, 56 .
Hyla atropunctata $25,37,39$.

Hyla aurifasciata 276 .

Hyla bernsteini 24, 26, 3 I.

Hyla bicolor, 26, 27, 44 .

Hyla bilineata 224 .

Hyla boulengeri 36 .

Hyla brachypus 25, 37 .

Hyla caerulea 27, 56, 58, 60 .

Hyla chalconotus 215, 217 .

Hyla chloronota 25, 42.

Hyla congenita 27, 28, 60 .

Hyla cyanea $5 \mathbf{r}$.

Hyla dolichopsis 52.

Hyla dolichopsis var. pollicaris 55 .

Hyla dolichopsis var, tenuigranulata 52 .

Hyla dorsalis 27,65 .

Hyla erythraea 222.

Hyla eucnemis 24, 32 .

Hyla everetti 26, 5 I.

Hyla fallax 25, 26, 35 .

Hyla genimaculata 26,47 .

Hyla graminea 24, 30 .

Hyla humeralis 25,56 .

Hyla impura $26,45,47,48$.

Hyla infrafrenata $24,26,27,38$,

$51,54,56,57$.

Hyla jeudei 26, 43 .

Hyla Kampeni 29.

Hyla leprosa 244.

Hyla leucomystax 246.

Hyla longicrus 25, 38 .

Hyla lutea $26,50,5$ I.

Hyla macgregori 26, 46, 49 .

Hyla macrops 26, 48, 50 .

Hyla margaritifera 254 .

Hyla militaria 24, 26, 28, 38, 55 .

Hyla montana 25, 28, 33, 34 .

Hyla mystax $3 \mathrm{I}$.

Hyla nasuta 27,64 .

Hyla nigropunctata 37 .

Hyla obsoleta 24, 32 .

Hyla obtusirostris 27,63.

Hyla ouwensi 25,37 .

Hyla papua 33. 
Hyla papuensis 24, 30 .

Hyla pratti 25, 4I.

Hyla pulchra 33.

Hyla quadrilineata 249 .

Hyla Reinwardtii 264.

Hyla rhacophorus 24,28 .

Hyla rubella 27, 28, 62 .

Hyla rueppelli $25,35,36$.

Hyla sanguinolenta 27,57 .

Hyla Semoni 64.

Hyla sexvirgata 249 .

Hyla solomonis 26,50 .

Hyla spengeli 26, 54.

Hyla thesaurensis $26,46,47,49,50$.

Hyla vagabunda 27,63 .

Hyla wollastoni 25,42 .

Hyla wolterstorffi 27,40 .

Hyladactylus 147.

Hylaedactylus lividus I48.

Hylaplesia ${ } 52$.

Hylaplesia achatina $\mathbf{I} 54$.

Hylaplesia borbonica 70.

Hylaplesia cruentata 78 .

Hylarana r6 I, 193.

Hylella 268.

Hylella bicolor 44 .

Hylella boulengeri 35 .

Hylella brachypus 37 .

Hylella chloronota 42 .

Hylella longicrus 38 :

Hylella nigropunctata 37 .

HEylella solomonis 37 .

Hylella wolterstorffi 40.

Hylidae 4, 22.

Hylodes corrugatus 190.

Hylomantis fallax 44 .

Hylophorbus 99, I00, I37, I 47 .

Hylophorbus birói $1_{37}, \mathrm{I}_{3} 8$.

Hylophorbus boettgeri 137, r 40.

Hylophorbus dubius i 38,143 .

Hylophorbus microtis ${ }_{3} 38$, 144 .

Hylophorbus montanus I37, I39.

Hylophorbus neuhaussi 100, I37, I38, 144.

Hylophorbus ocellatus $\mathrm{I} 37$, I4 I.
Hylophorbus robustus $138,143$.

Hylophorbus rufescens I 37 , I 40.

Hylophorbus variegatus 137,138 .

Hylorana 193.

Hylorana Daemeli 205.

Hylorana jerboa 208.

Hylorana longipes 246 .

Hylorana Nicobariensis 224.

Hyperolius nigropunctatus' 37 .

Hyperolius pygmaeus 35 .

hypocyanea, Caecilia 2.

Hypsiboas Reinwardtii 264 .

Ichthyophis 2.

Ichthyophis glutinosus 2 .

Ichthyophis. monochrous 2,3 .

Ichthyophis weberi 3,4 .

impura, Hyla 26, 45, 47, 48 .

infrafrenata, Hyla 24, 26, 27, 38 ,

$5 \mathrm{I}, 54,56,57$.

inornata, Microhyla I 52, I 53 .

Ixalus 268.

Ixalus aurifasciatus 275,276 .

Ixalus bimaculatus 269 .

Ixalus cornutus 274 .

Ixalus flavosignatus 270 .

Ixalus guttatus 235 .

Ixalus jacobsoni 272 .

Ixalus latopalmatus 238 .

Ixalus longicrus 272 .

Ixalus natator var. nubilus 236 .

Ixalus nubilus 236 .

Ixalus pallidipes 273 .

Ixalus Petersi 275.

Ixalus pictus 269 .

Ixalus vittiger 275 .

jacobsoni, Ixalus 272.

jacobsoni, Philautus 268, 272.

javanica, Rana 224.

javanica,var. of Rana macularia 224.

javanus, Polypedates 254.

javanus, Rhacophorus 243, 244 , 254,258 .

jerboa, Bufo 73,76 . 
jerboa, Hylorana 208.

jerboa, Rana I66, 167, 208, 2 I 6.

jeudei, Hyla 26, 43 .

Junghuhnii, Polypedates 217.

Kalophrynus pleurostigma 102.

Kaloula 5, 100, 147.

Kaloula baleata 148 .

Kaloula pulchra 148 , 15 .

Kaloula sundana I48, I 5 r.

Kampeni, Hyla 29.

kampeni, Liophryne roo, ror.

kampeni, Rana 163, 2 I 2.

klossi, Sphenophryne 105, 107.

kreffti, Rana 165, 204, 206.

kuhli, Rana 163, г66, I 78 .

labialis, Rana $163, \mathbf{1 6 4}, \mathbf{6} 65, \mathrm{I} 66$, I $67,218,220$.

laevis, Oxyglossus 230.

larutensis, Rana 234.

larutensis, Staurois 234 .

lateralis, Mantophryne I 40.

lateralis, Rana 223.

lateralis, var. of Rhacophorus reinwardti 264.

laterimaculata, Rana r64, 198 .

latopalmata, Simomantis 238 .

latopalmatus, Ixalus 238 .

Lechriodus 16.

Lechriodus melanopyga i 7 .

lemniscata, Rana 224.

leporosa, Theloderma 244.

leprosa, Hyla 244.

leprosa, Theloderma 244.

leprosus, Polypedates 244.

leprosus, Rhacophorus 243, 244.

Leptobrachium 7 .

Leptobrachium baluense 16 .

Leptobrachium gracile 15 .

Leptobrachium Hasseltii I3.

Leptobrachium montanum I 3 .

Leptobrachium natunae 6 .

Leptomantis 268 .
Leptomantis bimaculata 269 .

leptopus, Bufo 73, 75 .

leucomystax, Hyla 246.

leucomystax, Rhacophorus 243,

$244,246$.

leucomystax var. sexvirgata, Rha-

cophorus 249.

leucostigma, Microhyla I 53, 156 .

leytensis, Rana I80.

ligayae, Megalophrys 7,8 .

lima, Oxyglossus 230, 232.

lima, Rana 232.

linìnocharis, Fejérvárya 167 .

limnocharis, Rana I62, I66, I67.

Limnodynastes $\mathrm{I} 7$.

Limnodytes arfaki 199, 20 I.

Limnodytes celebensis 204 .

Limnodytes erythraeus 222 .

Limnodytes luctuosus 196 .

lineata, Méhelyia I I8.

Liophryne 99, 100.

Liophryne brevipes I00, I0I.

Liophryne kampeni ıоo, Іог.

Liophryne rhododactyla 100.

Litoria congenita 60.

Litoria dorsalis 65 .

Litoria guttata $5^{2}$.

Litoria montana 33 .

Litoria obtusirostris 63 .

lividus, Hylaedactylus 148 .

longecristatus, Bufo 82 .

longicrus, Hyla 25, 38 .

longicrus, Hylella 38 .

longicrus, Ixalus 272.

longicrus, Philautus 268, 272.

longipes, Hylorana 246.

loriae, Oreophryne III, Ir 7 .

loriae, Sphenophryne II 7 .

luctuosa, Rana 164, I67, 196.

luctuosus, Limnodytes 196 .

lutea, Hyla 26, 50, 5 I.

macgregori, Hyla 26, 46, 49.

mackloti, Rana 16 r.

macra, Metopostira I4I. 
macrodon, Rana $163, \quad 165$, I66,

I 73, I 74.

macrodon var. blythii, Rana 175 . macrops, Hyla 26, 48, 50 .

macrops, Rana I64, r93.

macrops, Xenobatrachus I27, 28 . macrops, Xenorhina 128 .

macrorhyncha, Chaperina 107.

macrorhyncha, Sphenophryne ro5,

107.

macroscelis, Rana 199.

macroscelis, Rhacophorus 243,252. macrotis, Nectophryne 66, 69.

macrotis, Rhacophorus $243,25 \mathrm{I}$.

macularia var. javanica, Rana 224.

maculata, Nectophryne 66, 7 I.

maculatus, Rhacophorus 246 .

maculatus var. quadrilineata, Rhacophorus 249.

magna, Rana 176.

Mantophryne 99, 137 .

Mantophryne lateralis $\mathbf{1} 40$.

Mantophryne microtis I44.

Mantophryne neuhaussi 144.

Mantophryne robusta 143.

margaritifer, Nyctixalus 277, 278.

margaritifera, Hyla 254.

Masonii, Rana 208, 2 I0.

Megalophrys 6, 7 .

Megalophrys baluensis 7, I6.

Megalophrys chysii ro.

Megalophrys gracilis 7, I5.

Megalophrys hasselti 5, 7, I3.

Megalophrys ligayae 7,8 .

Megalophrys montana 5, 7, 8, I3.

Megalophrys nasuta 7, I0.

Megophrys 7 .

Megophrys monticola 8 .

mehelyi, Choanacantha I27.

Méhelyia Iro.

Méhelyia affinis I 8 .

Méhelyia lineata I 8 .

melanopyga, Asterophrys I7.

melanopyga, Batrachopsis 17 .

melanopyga, Lechriodus I 7 . melanostictus, Bufo $73,74,80,82$,

87,9 r.

mertoni, Oreophryne III, I 20.

mertoni, Sphenophryne 120.

Metopostira 99, I37.

Metopostira macra I4I.

Metopostira ocellata I $4 \mathrm{I}$.

meyeri, Platymantis 240.

meyeri, Rana 240.

Microbatrachus 99, I 2 I.

Microbatrachus pusillus I $2 \mathrm{I}$.

microdisca, Rana I64, I80.

Microdiscopus sumatranus 230.

Microhyla 5, 100, I 52 .

Microhyla achatina I 53, I 54 .

Microhyla, achatina var. moluc-

censis II 5 .

Microhyla annectens 153, I56.

Microhyla berdmorii 153 , I 58 .

Microhyla bungurana $\mathbf{I}_{52}, \mathrm{I}_{54}$.

Microhyla inornata $152,153$.

Microhyla leucostigma I53, 156 .

Microhyla niasensis $15^{6}$.

Microhyla palmipes 153, I 57 .

microtis, Hylophorbus I38, 144.

microtis, Mantophryne $\mathbf{I} 44$.

microtympanum, Rana 176 .

militaria, Hyla 24, 26, 28, 38, 55 .

militarius, Pelodryas 55 .

minimus, Bufo 98.

misera, Nectophryne 66.

Mocquardi, Rana 217.

modesta, Rana I63, 166, I73, 176.

modestus, Rhacophorus 244, 259 .

moellendorffii, Rana 226.

Mogophrys 7 .

Mogophrys montana 8 .

moluccana, Rana 20 r.

moluccensis, var. of Microhyla

achatina 115 .

monochrous, Epicrium 3 .

monochrous, Ichthyophis 2, 3 .

montana, Ceratophrys 9.

montana, Hyla 25, 28, 33, 34 .

montana, Litoria 33 . 
montana, Megalophrys 5, 7, 8, I3. montana, Mogophrys 8.

montanum, Leptobrachium 13.

montanus, Bufo 78 .

montanus, Hylophorbus I37, I39.

montanus, Phrynixalus I39, I40.

monticola, Megophrys 8.

monticola, Oreophryne III, II3. monticola, Rhacophorus 244, 26 r. monticola, Sphenophryne I 3 . moschata, Rhacophorus 254. moszkowskii, Cornufer I 88 . moszkowskii, Rana 162, 188 . mystax, Hyla $3 \mathbf{I}$.

nasuta, Ceratophryne Io. nasuta, Hyla 27, 64 . nasuta, Megalophrys 7, Io. nasutus, Pelobatrachus I I. nasutus, Pelodytes 64 . natator var. nubilus, Ixalus 236 . natatrix, Rana 235. natunae, Leptobrachium 6. natunae, Nesobia 6.

Nectes 92 .

Nectes obscurus 82 .

Nectes pleurotaenia 92 .

Nectes subasper 92, 94 .

Nectes sumatranus 93 .

Nectes werneri 94.

Nectophryne 66.

Nectophryne borbonica 66,70 .

Nectophryne everetti 66,68 .

Nectophryne exigua 68.

Nectophryne guentheri 66,68 .

Nectophryne hosii 66,67 .

Nectophryne macrotis $66,69$.

Nectophryne maculata 66, $7 \mathbf{r}$.

Nectophryne misera 66.

Nectophryne picturata 66, 72, I I0.

Nectophryne signata 66,70 .

Nectophryne sumatrana 70.

Nectophryne sundana I5r.

Nesobia 6.

Nesobia natunae 6 . neuhaussi, Hylojhorbus гоo. I37, I $3 \delta$, I 44 .

neuhaussi, Mantophryne $\mathbf{4 4}$. niasensis, Microhyla ${ }^{5} 5^{6}$.

Nicobariensis, Hylorana 224. nicobariensis, Rana I65, I66, 2 I 9 , 224.

nigropalmatus, Rhacophorus 244 , 266.

nigropunctata, Hyla 37 .

nigropunctata, Hylella 37 .

nigropunctatus, Hyperolius 37 .

novae-britanniae, Rana 206, 207 , 223.

novae-guineae, Phanerotis 20.

novae-guineae, Rana 205.

nubilus, Ixalus 236 .

nubilus, Staurois $234,236$.

nubilus, var. of Ixalus natator 236 .

Nyctimantis 22.

Nyctimantis granti 22, 23.

Nyctimantis papua 22.

Nyctimystes 22.

Nyctixalus 161, 277 .

Nyctixalus margaritifer 277,278 . Nyctixalus robinsoni 277,278 .

obscurus, Bufo 83 .

obscurus, Nectes 82 .

obsoleta, Hyla 24, 32.

obsoleta, Rana 226.

obtusirostris, Hyla 27, 63 .

obtusirostris, Litoria 63 .

ocellata, Metopostira I4I.

ocellata, Xenorhina 28.

ocellatus, Hylophorbus I37, I4I.

ocellatus, Xenobatrachus г 26, I2S.

ophiodon, Xenobatrachus I27, I3 I. opisthodon, Rana $16_{3}, \mathbf{I} 85$, I 87 .

Oreobatrachus $160,229$.

Oreobatrachus baluensis 229.

Oreophryne 99, I I0, I22, 146.

Oreophryne albopunctata III, I 19.

Oreophryne anthonyi III, II 7 .

Oreophryne ateles III, II 5 . 
Oreophryne biroi III, II 8 . Oreophryne celebensis III, II 2 . Oreophryne crucifera III, I 6 . Oreophryne loriae III, II 7 . Oreophryne mertoni III, I 20. Oreophryne monticola III, II 3 . Oreophryne senckenbergiana III, I I 5 .

Oreophryne variabilis III, II 2 .

Oreophryne verrucosa I I I , I I 3 , I I 5 . otilophus, Rhacophorus 243,244 , 245.

ouwensi, Hyla 25,37 .

oxycephala, Xenorhina $\mathbf{I}_{3} 2$. oxycephalus, Bombinator 132 .

Oxydactyla 99, I22.

Oxydactyla brevicrus I22.

Oxyglossus 5, 160, 230.

Oxyglossus laevis 230 .

Oxyglossus lima 230, 232. oxyrhina, Copiula I34, I35. oxyrhinus, Phrynixalus I 35 .

palavanensis, Rana 165 , I 82 .

pallidipes, Ixalus 273 .

pallidipes, Philautus 269, 273 .

palmipes, Microhyla I 53, I 57 .

pansa, Aphantophryne $\mathbf{1 4 5}$.

pantherina, Rana 2 I 2.

papua, Hyla 33.

papua, Nyctimantis 22 .

papua, Rana I65, I66, 201, 205, 207.

papuensis, Hyla 24, 30 .

papuensis, var. of Platymantis

corrugata $\mathbf{9} 90$.

paradoxa, Rana 178 .

pardalis, Rhacophorus 244,263 .

parvus, Bufo 74,88 .

Pedostibes guentheri 68 .

Pelewensis, var. of Platymantis plicifera $\mathbf{9} 9$ o.

Pelobatidae $4,5, \mathbf{I} 7$.

Pelobatrachus nasutus II .

Pelodryas caeruleus 58 .

Pelodryas militarius 55 .
Pelodytes nasutus 64 .

penangensis, Ansonia 75 .

penangensis, Bufo $73,74,75$.

persimilis, Rana $165,223$.

Petersi, Ixalus 275.

petersi, Philautus 269,275 .

Phanerotis I 7, I8.

Phanerotis fletcheri $\mathrm{I} 8$.

Phanerotis novae-guineae 20.

Philautus I6 I, 268, 277.

Philautus anodon 268, 27 I, 277.

Philautus aurifasciatus 269,276 ,

277.

Philautus bimaculatus 268, 269 .

Philautus cornutus 269, 274 .

Philautus flavosignatus 268, 270 ,

277.

Philautus jacobsoni 268, 272.

Philautus longicrus 268, 272.

Philautus pallidipes 269,273 .

Philautus petersi $269,275$.

Philautus pictus 268, 269 .

Philautus similis 269, 273.

Philautus vittiger 269,275 .

philippinicus, Bufo 74, 86.

Phrynella 99, I24.

Phrynella pollicaris 125 .

Phrynella pulchra 125.

Phrynixalus 99, I37.

Phrynixalus Birói 138 .

Phrynixalus montanus I39, 140.

Phrynixalus oxyrhinus $\mathrm{x} 35$.

Phrynomantis fusca I 2 .

phyllopygus, Rhacophorus 255 .

picturata, Nectophryne 66, 72, I 10.

picturata, Rana 227.

pictus, Ixalus 269.

pictus, Philautus 268, 269.

Platymantis I6r, I 87 .

Platymantis beauforti 189 .

Platymantis boulengeri 187 .

Platymantis corrugata $\mathbf{I} 90$.

Platymantis corrugata var. papu-

ensis 190.

Platymantis meyeri 240. 
Platymantis plicifera 190 .

Platymantis plicifera var. Pelewensis 190.

Platymantis punctata 192.

Platymantis solomonis 192.

pleurostigma, Calophrynus ro2.

pleurostigma, Kalophrynus го2.

pleurotaenia, Nectes 92.

pleurotaenia, Pseudobufo 93.

plicifera, Platymantis I90.

plicifera var. Pelewensis, Platy-

mantis I9o.

plicifera, Rana I9o.

poecilonotus, Rhacophorus 243 , 256, 258.

pollicaris, Phrynella 125 .

pollicaris, var. of Hyla dolichopsis

$55^{\circ}$

Polypedates 242.

Polypedates appendiculatus 255 .

Polypedates Hascheanus $\mathrm{I} 8 \mathrm{I}$.

Polypedates javanus 254 .

Polypedates Junghuhnii 2 I 7 .

Polypedates leprosus 244.

Polypedates quadrilineatus 249 .

Polypedates raniceps 220 .

Polypedates reinwardtii 264 .

Polypedates signatus 226 .

polysticta, Chaperina ro8.

polysticta, Sphenophryne ro5, ro8.

Pomatops 100, 147.

Pomatops valvifera 147 .

pratti, Hyla 25, 4I.

proboscidea, Choerophryne 136.

Pseudobufo 66, 92.

Pseudobufo pleurotaenia 93.

Pseudobufo subasper 92.

Pseudobufo werneri 92, 94.

Pseudophryne I23.

pulchellus, Rhacophorus 263.

pulchra, Callula 150.

pulchra, Hyla 33.

pulchra, Kaloula r48, I50.

pulchra, Phrynella I25.

punctata, Chaperina ro7. punctata, Platymantis 192.

punctata, Rana I62, 192.

punctatus, Calophrynus 102, 104.

pusillus, Microbatrachus $12 \mathrm{I}$.

pygmaeus, Hyperolius 35 .

quadrilineata, Hyla 249.

quadrilineata, var. of Rhacophorus

maculatus 249 .

quadrilineatus, Polypedates 249.

quadriporcatus, Bufo 74,87 .

quatuorlobata, Chaperina 107.

Rana, 5, г6о, I6г, I67.

Rana arfaki 163, 165, I99.

Rana baramica $164, \mathrm{I} 95$.

Rana beauforti 162,189 .

Rana boulengeri $162,187,188$.

Rana bufoniformis $162, \mathbf{1 8 4}, 186$.

Rana caerulea 58.

Rana cancrivora $162,166,170,172$.

Rana cavitympanum $163,167,211$.

Rana celebensis $165,204$.

Rana chalconota $166,167,2$ I 7, 220.

Rana conspicillata 178 .

Rana corrugata $190,192$.

Rana crassiovis $163,213$.

Rana daemeli 165, 204, 205 .

Rana debussyi $164,167,197$, I99.

Rana decorata 196.

Rana durbeimi 215.

Rana elberti 165, 200, 204.

Rana erythraea 165, 166, 222.

Rana erythraea var. elongata 224 .

Rana everetti I63，214，217.

Rana fallax 201.

Rana florensis $20 \mathrm{r}$.

Rana glandulosa r64, I94, r96.

Rana gracilis 167 .

Rana grisea 165, 204, 207.

Rana grisea var. cernmensis 207 .

Rana grunniens 163,172, I76, I 78, I 82 .

Rana guppyi 162, 183 .

Rana guttata 235 . 
Rana hascheana $i 64, \mathbf{I} 8 \mathrm{I}$.

Rana Hasseltii I 3.

Rana hosii $166,167,215,218$.

Rana javanica 224.

Rana jerboa I66, I67, 208, 216.

Rana kampeni $163,212$.

Rana kreffti $165,204,206$.

Rana kuhli $163,166,178$.

Rana labialis $163,164,165, \mathbf{1 6 6}$, I67, $218,220$.

Rana larutensis 234.

Rana lateralis 223.

Rana laterimaculata $164,198$.

Rana lemniscata 224.

Rana leytensis I8o.

Rana lima 232.

Rana limnocharis $162, x 66, x 67$.

Rana luctuosa r64, I67, I96.

Rana mackloti $\mathbf{x} 6 \mathbf{I}$.

Rana macrodon $163, \mathrm{I} 65, \mathbf{1 6 6}$, I 73, I 74 .

Rana macrodon var. blythii $\mathbf{1} 75$.

Rana macrops i64, 193.

Rana macroscelis 199 .

Rana macularia var. javanica 224.

Rana magna i 76 .

Rana Masonii 208, 2 ro.

Rana meyeri 240.

Rana microdisca I64, 180.

Rana microtympanum 176 .

Rana Mocquardi 217.

Rana modesta I63, I66, I 73, I 76 .

Rana moellendorffii 226 .

Rana moluccana $20 \mathrm{r}$.

Rana moszkowskii i62, I88.

Rana natatrix 235 .

Rana nicobariensis 165, r66, 219 , 224.

Rana novae-britanniae 206,207 , 223.

Rana novae-guineae 205 .

Rana obsoleta 226.

Rana opisthodon $163,185,187$.

Rana palavanensis $165, \mathbf{1} 82$.

Rana pantherina 212.
Rana papua I65, I66, 201, 205, 207.

Rana paradoxa 178 .

Rana persimilis $165,223$.

Rana picturata 227.

Rana plicifera $\mathbf{1} 90$.

Rana punctata 162, 192.

Rana rugata $162,188,190,241$.

Rana rugata var. rubristriata $\tau 62$, I9I.

Rana sanchezi 2 I 7 .

Rana sariba 24I.

Rana Schlüteri I 70 .

Rana signata $164,165,226$.

Rana solomonis 162, I91.

Rana temporalis 224.

Rana tigrina $\mathbf{I} 70$.

Rana tigrina var. angustopalmata I 70.

Rana tigrina var. cancrivora I 70.

Rana tigrina var. verruculosa 172 .

Rana tytleri $217,224$.

Rana varians $20 \mathrm{I}$.

Rana ventricosa $16_{3}, \mathbf{1} 86$.

Rana verruculosa 162, I 72 .

Rana waigeënsis $199,204$.

Rana wasl 167.

Rana whiteheadi $163,167,210,236$.

Ranaster 17, I8, I9.

Ranaster convexiusculus i9.

raniceps, Polypedates 220.

Ranidae 5, r6o.

Ranidella signifera $2 \mathbf{I}$.

reinwardti, Rhacophorus 2 I 6,244 , $263,264,266$.

Reinwardti, var. lateralis, Rhacophorus 264.

Reinwardtii, Hyla 264.

Reinwardtii, Hypsiboas 264.

reinwardtii, Polypedates 264 .

Rhacophorus 5, I6I, 242, 268.

Rhacophorus acutirostris 244,260 。

Rhacophorus anodon $27 \mathrm{I}$.

Rhacophorus appendiculatus 243 , 255.

Rhacophorus bifasciatus 243,257 . 
Rhacophorus bürgeri r $6 \mathrm{r}$.

Rhacophorus chiropterus 258.

Rhacophorus colletti $243,25^{\circ}$.

Rhacophorus cruciger $25^{\circ}$.

Rhacophorus dulitensis $243,258$.

Rhacophorus edentulus 242,244 , 259, 268.

Rhacophorus everetti 243, $25 \mathrm{I}$.

Rhacophorus fasciatus 244, 262.

Rhacophorus georgii 243, 253.

Rhacophorus hosii $243,253$.

rhacophorus, Hyla 24, 28.

Rhacophorus javanus 243, 244 , $254,258$.

Rhacophorus leprosus $243,244$.

Rhacophorus leucomystax 243 , $244,246$.

Rhacophorus leucomystax, var. sexvirgata 249.

Rhacophorus macroscelis 243,252 . Rhacophorus macrotis 243, 25 I.

Rhacophorus maculatus 246 .

Rhacophorus maculatus var. quadrilineata 249.

Rhacophorus modestus 244, 259.

Rhacophorus monticola 244, $26 \mathrm{I}$.

Rhacophorus moschata 254 .

Rhacophorus nigropalmatus 244, 266.

Rhacophorus otilophus 243, 244, 245 .

Rhacophorus pardalis $244,263$.

Rhacophorus phyllopygus 255 .

Rhacophorus poecilonotus 2.43, $256,258$.

Rhacophorus pulchellus 263 .

Rhacophorus reinwardti 216,244 , $263,264,266$.

Rhacophorus Reinwardti var. lateralis 264 .

Rhacophorus shelfordi $244,262$. rhododactyla, Liophryne 100.

robinsoni, Nyctixalus 277,278 .

robusta, Gnathophryne 143. robusta, Mantophryne 143 . robustus, Hylophorbus ${ }_{13} 8,{ }_{43}$. rostellifer, Copiula 135 . rostellifera, Copiula $134, \mathbf{1 3 5}$. rostrata, Choanacantha 127. rostrata, Xenorhina $127, \mathbf{I} 28$. rostratus, Xenobatrachus 126, I 27. rubella, Hyla 27, 28, 62 . rubristriata, var. of Rana rugata I62, I9I.

rueppelli, Hyla $25,35,36$.

rufescens, Hylophorbus $137,140$. rugata, Rana 162, I88, 190, 241 . rugata var. rubristriata, Rana 162 , I9I.

Salientia 4. sanchezi, Rana 2i 7. sanguinolenta, Hyla 27, 57 . sariba, Rana 24 r. scaber, Bufo 80. schlaginhaufeni, Sphenophryne ro 7. Schlüteri, Rana i 70.

Scytopis boulengeri 35 . Semoni, Hyla 64. senckenbergiana, Oreophryne I I I,

II 5 .

sexvirgata, Hyla 249. sexvirgata, var. of Rhacophorus

leucomystax 249 . shelfordi, Rhacophorus 244, 262 . signata, Nectophryne 66, 70. signata, Rana $164, \mathrm{r65}, 226$. signatus, Polypedates 226. signifera, Crinia $2 \mathrm{I}$. signifera, Ranidella 2 r. similis, Philautus 269,273 . Simomantis $160,237$. Simomantis latopalmata 238 . smithi, Calliglutus 98. solomonis, Cornufer I9I. solomonis, Hyla 26, 50 . solomonis, Hylella 37. solomonis, Platymantis $\mathbf{1 9 2 .}$ solomonis, Rana 162, I9I. spengeli, Hyla 26, 54 . 
Sphenophryne 99, 104, 110, 122, 146.

Sphenophryne albopunctata II9.

Sphenophryne anthonyi II 7.

Sphenophryne ateles II 5.

Sphenophryne beyeri ro5, r Io.

Sphenophryne biroi II7, II8.

Sphenophryne celebensis II 2 .

Sphenophryne cornuta I05.

Sphenophryne fusca 105, rog.

Sphenophryne klossi-105, 107.

Sphenophryne loriae Ir 7 .

Sphenophryne macrorhyncha 105, I07.

Sphenophryne mertoni 120.

Sphenophryne monticola i 3 .

Sphenophryne polysticta 105, ro8.

Sphenophryne schlaginhaufeni r $\%$.

Sphenophryne variabilis II 2.

Sphenophryne verrucosa II 3 .

Sphenophryne wolfi II 3 .

spinipes, Bufo 82.

spinipes, Docidophryne 8r.

spinulifer, Bufo 73, 79.

Staurois 5, I60, 234.

Staurois guttatus 234, 235 .

Staurois larutensis 234.

Staurois nubilus 234. 236 .

Staurois tuberilinguis 234,236 , 237.

stellatus, Calophrynus 104.

studeri, Bufo Ioz.

subasper, Nectes 92, 94.

subasper, Pseudobufo 92.

sumatrana, Nectophryne 70.

sumatranus, Bufo 73,78 .

sumatranus, Microdiscopus 230.

sumatranus, Nectes 93.

sundana, Callula $15 \mathrm{r}$.

sundana, Calohyla 15 r.

sundana, Kaloula 148, I 5 I.

sundana, Nectophryne I5 r.

Symphygnathinae 98 .

temporalis, Rana 224. tenuigranulata; var. of Hyla dolichopsis 52 .

Theloderma leporosa 244.

Theloderma leprosa 244 .

thesaurensis, Hyla 26, 46, 47, 49,

50.

thomsoni, Genyophryne $\mathbf{1} 59$.

tigrina, Rana 170.

tigrina var. angustopalmata, Rana

I 70.

tigrina var. cancrivora, Rana i 7o. tigrina var. verruculosa, Rana I72. tuberilinguis, Staurois 234, 236,

237.

turpicola, Ceratophrys I 33 .

turpicula, Asterophrys I33.

tytleri, Rana 2 I 7, 224.

unicolor, Cormufer 105, 239, 240.

vagabunda, Hyla 27,63 .

valhallae, Bufo 73, 79 .

valvifera, Pomatops 147.

variabilis, Oreophryne I I I, I I 2.

variabilis, Sphenophryne II 2 .

varians, Rana $20 r$.

variegatus, Hylophorbus $137, \mathbf{1}^{8}$.

ventricosa, Rana I63, I86.

verrucosa, Oreophryne III, I I3,

I I 5 .

verrucosa, Sphenophryne II3.

verruculosa, Rana I62, I72.

verruculosa, var. of Rana tigrina I 72.

vertebralis, Batrachylodes 242 .

vitiensis, Cornufer 239.

vitiensis, Halophila 239.

vittiger, Ixalus 275.

vittiger, Philautus 269, 275 .

volzi, Dyscophina 96 .

waigeënsis, Rana I99, 204.

wasl, Rana 167.

weberi, Ichthyophis 3, 4 .

werneri, Nectes 94.

werneri, Pseudobufo 92, 94. 
whiteheadi, Rana 163, 167, 210, 236.

wolfi, Sphenophryne 113 .

wollastoni, Hyla $25,42$.

wolterstorffi, Hyla $27,40$.

wolterstorffi, Hylella 40.

Xenobatrachus 99, 126.

Xenobatrachus bidens 127, 129.

Xenobatrachus giganteus 127,130 .

Xenobatrachus macrops 127, I 28.

Xenobatrachus ocellatus I26, I 28.
Xenobatrachus ophiodon $127, \mathbf{1} 31$.

Xenobatrachus rostratus $126,127$.

Xenophrys 7.

Xenorhina 99, I26, I31, I34.

Xenorhina atra 132.

Xenorhina bidens 129.

Xenorhina dubia 143 .

Xenorhina gigantea 130 .

Xenorhina macrops 128 .

Xenorhina ocellata 128.

Xenorhina oxycephala 132.

Xenorhina rostrata $127, \mathbf{1} 28$. 




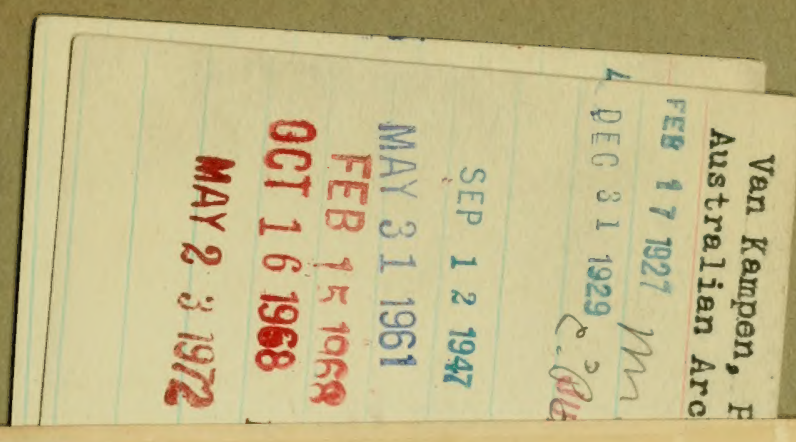

จ3 
